(110) 


\section{Akten zur Auswärtigen Politik der Bundesrepublik Deutschland}

Herausgegeben im Auftrag des Auswärtigen Amts vom Institut für Zeitgeschichte

Hauptherausgeber

Hans-Peter Schwarz

Mitherausgeber

Helga Haftendorn, Klaus Hildebrand, Werner Link, Horst Möller und Rudolf Morsey

R. Oldenbourg Verlag München 1998 


\section{Akten zur Auswärtigen Politik der Bundesrepublik Deutschland 1967}

Band I: 1. Januar bis 31. März 1967

Wissenschaftlicher Leiter

Rainer A. Blasius

Bearbeiter

Ilse Dorothee Pautsch, Jürgen Klöckler, Matthias Peter und Harald Rosenbach

R. Oldenbourg Verlag München 1998 
Die Deutsche Bibliothek - CIP-Einheitsaufnahme

Akten zur auswärtigen Politik der Bundesrepublik Deutschland

/ hrsg. im Auftr. des Auswärtigen Amts vom Institut für

Zeitgeschichte. - München : Oldenbourg.

1967.

Bd. 1. 1. Januar bis 31. März 1967. - 1998

ISBN 3-486-56322-X

(C) 1998 R. Oldenbourg Verlag GmbH, München

Rosenheimer Straße 145, D-81671 München

Internet: http://www.oldenbourg.de

Das Werk einschließlich aller Abbildungen ist urheberrechtlich geschützt. Jede Verwertung außerhalb der Grenzen des Urheberrechtsgesetzes ist ohne Zustimmung des Verlages unzulässig und strafbar. Dies gilt insbesondere für Vervielfältigungen, Übersetzungen, Mikroverfilmungen und die Einspeicherung und Bearbeitung in elektronischen Systemen.

Umschlaggestaltung: Dieter Vollendorf

Gedruckt auf säure- und chlorfreiem, alterungsbeständigem Papier

Gesamtherstellung: R. Oldenbourg Graphische Betriebe GmbH, München

ISBN 3-486-56322-X 


\section{Inhalt}

Vorwort .............................................................................. VII

Vorbemerkungen zur Edition .................................................... VIII

Verzeichnisse

Dokumentenverzeichnis ................................................................ XVII

Literaturverzeichnis .................................................................. CLXXXV

Abkürzungsverzeichnis …………………………………............... CXCI

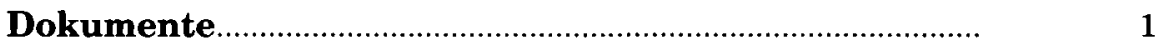

Band I (Dokumente 1-114) .......................................................

Band II (Dokumente 115-313) ........................................................

Band III (Dokumente 314-449) ....................................................... 1239

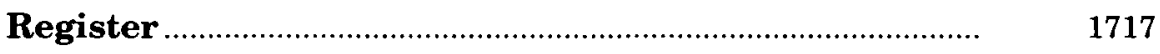

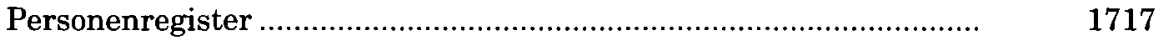

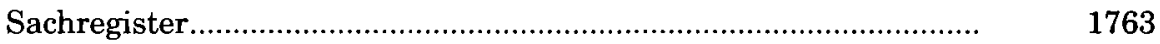

Organisationsplan des Auswärtigen Amts vom April 1967................ 1827 



\section{Vorwort}

Mit den Jahresbänden 1967 wird zum fünften Mal eine ausführlich kommentierte Sammlung von Dokumenten aus den Beständen des Politischen Archivs des Auswärtigen Amts unmittelbar nach Ablauf der dreißigjährigen Aktensperrfrist veröffentlicht. Das bewährte Editionskonzept der seit Herbst 1993 bereits publizierten „Akten zur Auswärtigen Politik der Bundesrepublik Deutschland“"über die Jahre 1949/50 (ein Band), 1963 (drei Bände), 1964 (zwei Bände), 1965 (drei Bände) und 1966 (zwei Bände) ist beibehalten worden.

Das Erscheinen der vorliegenden Bände gibt Anlaß, allen an dem Werk Beteiligten zu danken. So gilt mein verbindlichster Dank dem Auswärtigen Amt, insbesondere dem Politischen Archiv sowie den Damen und Herren in den Referaten, die beim Deklassifizierungsverfahren zur Offenlegung der Dokumente beigetragen haben. In gleicher Weise zu danken ist dem Bundeskanzleramt für die Erlaubnis, unverzichtbare Dolmetscheraufzeichnungen einbeziehen zu können. Desgleichen danke ich dem Archiv für Christlich-Demokratische Politik in St. Augustin für die Genehmigung, einige Schriftstücke aus dem Nachlaß des ehemaligen Bundeskanzlers Kurt Georg Kiesinger publizieren zu können, und dem Willy-Brandt-Archiv im Archiv der sozialen Demokratie der FriedrichEbert-Stiftung in Bonn für die Erlaubnis, einige Schriftstücke aus dem Nachlaß des Bundesministers des Auswärtigen der Jahre 1966 bis 1969, Willy Brandt, abdrucken zu dürfen.

Besonderer Dank gebührt ferner den Kollegen im Herausgebergremium, die sich ihrer viel Zeit in Anspruch nehmenden Aufgabe in bewährter Kollegialität gewidmet haben. Ferner sei die tadellose Zusammenarbeit mit den zuständigen Persönlichkeiten und Gremien des Instituts für Zeitgeschichte dankbar hervorgehoben. Gedankt sei auch dem präzise arbeitenden Verlag R. Oldenbourg.

Unter den in der Titelei genannten Bearbeitern ist der Anteil von Frau Dr. Ilse Dorothee Pautsch am Gelingen der Bände besonders groß. Die Vorarbeiten und die Dokumentensammlung lagen weitgehend in ihrer Hand. Sie war außerdem mit der Kommentierung der Monate März, Juli und August 1967 befaßt. Die Monate Februar, Juni und November 1967 wurden von Herrn Dr. Jürgen Klöckler, die Monate Januar, Mai und Dezember 1967 von Herrn Dr. Matthias Peter und die Monate April, September und Oktober 1967 von Herrn Dr. Harald Rosenbach, der auch das Sachregister anfertigte, kommentiert. Ihnen allen, insbesondere aber auch Herrn Dr. Rainer A. Blasius, der wie bei den vorhergehenden Jahresbänden für die wissenschaftliche Leitung verantwortlich war, sei für die erbrachte Leistung nachdrücklichst gedankt.

Ebenso haben wesentlich zur pünktlichen Fertigstellung der Edition Frau Dr. Ute Jancke und Herr Dr. Sven Olaf Berggötz durch die Erstellung des Personenregisters und Herr Dr. Wolfgang Hölscher durch die kompetente Beratung bei der Herstellung des Umbruchs beigetragen.

Die Editionen für 1968 und 1969 sowie für 1951 befinden sich in Arbeit. Sie sollen im vorgesehenen Rhythmus erscheinen.

Bonn, den 1. Oktober 1997

Hans-Peter Schwarz 


\title{
Vorbemerkungen zur Edition
}

\begin{abstract}
Die „Akten zur Auswärtigen Politik der Bundesrepublik Deutschland 1967“ (Kurztitel: AAPD 1967) umfassen drei Bände, die durchgängig paginiert sind. Den abgedruckten Dokumenten gehen im Band I neben Vorwort und Vorbemerkungen ein Dokumentenverzeichnis, ein Literaturverzeichnis sowie ein Abkürzungsverzeichnis voran. Am Ende von Band III finden sich ein Personenund ein Sachregister sowie ein Organisationsplan des Auswärtigen Amts vom April 1967.
\end{abstract}

\section{Dokumentenauswahl}

Grundlage für die Fondsedition der Akten zur Auswärtigen Politik der Bundesrepublik Deutschland im Jahre 1967 waren die Bestände des Politischen Archivs des Auswärtigen Amts (PA/AA). Besonderes Gewicht wurde auf die zentralen Bestände „Ministerbüro“ und „Büro Staatssekretär“ gelegt. Angemessene Berücksichtigung fanden aber auch die einzelnen Abteilungen und Referate des Auswärtigen Amts. Schriftstücke aus anderen Bundesministerien, die in die Akten des Auswärtigen Amts Eingang gefunden haben, wurden nur zur Kommentierung herangezogen und lediglich in Fällen von besonderer außenpolitischer Bedeutung als Dokumente aufgenommen. Fast ausnahmslos haben dagegen die im Auswärtigen Amt vorhandenen Aufzeichnungen über Gespräche des Bundeskanzlers mit ausländischen Staatsmännern und Diplomaten Aufnahme gefunden. Als notwendige Ergänzung dienten die im Bundeskanzleramt überlieferten Gesprächsaufzeichnungen.

Entsprechend ihrer Herkunft belegen die edierten Dokumente in erster Linie die außenpolitischen Aktivitäten des Bundesministers des Auswärtigen. Sie veranschaulichen aber auch die Außenpolitik des jeweiligen Bundeskanzlers. Die Rolle anderer Akteure, insbesondere im parlamentarischen und parteipolitischen Bereich, wird beispielhaft dokumentiert, sofern eine Wechselbeziehung zum Auswärtigen Amt gegeben war.

Die ausgewählten Dokumente sind nicht zuletzt deshalb für ein historisches Verständnis der Außenpolitik der Bundesrepublik Deutschland von Bedeutung, weil ausschließlich Schriftstücke veröffentlicht werden, die bisher der Forschung unzugänglich und größtenteils als Verschlußsachen der Geheimhaltung unterworfen waren. Dank einer entsprechenden Ermächtigung wurden den Bearbeitern die VS-Bestände des PA/AA ohne Einschränkung zugänglich gemacht und Anträge auf Herabstufung und Offenlegung von Schriftstücken beim Auswärtigen Amt ermöglicht. Das Bundeskanzleramt war zuständig für die Deklassifizierung von Verschlußsachen aus den eigenen Beständen. Kopien der offengelegten Schriftstücke, deren Zahl diejenige der in den AAPD 1967 weit übersteigt, werden im PA/AA zugänglich gemacht (Bestand B 150).

Nur eine äußerst geringe Zahl der für die Edition vorgesehenen Aktenstücke wurde nicht zur Veröffentlichung freigegeben. Hierbei handelt es sich vor allem um Dokumente, in denen personenbezogene Vorgänge im Vordergrund stehen oder die auch heute noch sicherheitsrelevante Angaben enthalten. Von 
einer Deklassifizierung ausgenommen war Schriftgut ausländischer Herkunft bzw. aus dem Bereich mulilateraler oder internationaler Organisationen wie etwa der NATO. Unberücksichtigt blieb ebenfalls nachrichtendienstliches $\mathrm{Ma}$ terial.

\section{Dokumentenfolge}

Die 449 edierten Dokumente sind in chronologischer Folge geordnet und mit laufenden Nummern versehen. Bei differierenden Datumsangaben auf einem Schriftstück, z.B. im Falle abweichender maschinenschriftlicher und handschriftlicher Datierung, ist in der Regel das früheste Datum maßgebend. Mehrere Dokumente mit demselben Datum sind, soweit möglich, nach der Uhrzeit eingeordnet. Erfolgt eine Datierung lediglich aufgrund sekundärer Hinweise (z.B. aus Begleitschreiben, beigefügten Vermerken usw.), wird dies in einer Fußnote ausgewiesen. Ein Dokument, bei dem nur der Entstehungsmonat bekannt ist, wird am Ende des betreffenden Monats eingereiht. Bei Aufzeichnungen über Gespräche oder Besprechungen ist das Datum des dokumentierten Vorgangs ausschlaggebend, nicht der Zeitpunkt der Niederschrift.

\section{Dokumentenkopf}

Jedes Dokument beginnt mit einem halbfett gedruckten, stets gleichgestalteten Dokumentenkopf, in dem wesentliche formale Angaben zusammengefaßt werden. Auf Dokumentennummer und -überschrift folgen in kleinerer Drucktype ergänzende Angaben, so rechts außen die Datumsangabe. Links außen wird, sofern vorhanden, das Geschäftszeichen des edierten Schriftstücks einschließlich des Geheimhaltungsgrads (zum Zeitpunkt der Entstehung) wiedergegeben. Das Geschäftszeichen, das aus der Kurzbezeichnung der ausfertigenden Arbeitseinheit besteht sowie aus weiteren Elementen wie dem gemäß Aktenplan inhaltlich definierten Aktenzeichen, der Tagebuchnummer einschließlich verkürzter Jahresangabe und gegebenenfalls dem Geheimhaltungsgrad, läßt Rückschlüsse auf den Geschäftsgang zu und eröffnet die Möglichkeit, zugehöriges Aktenmaterial zu ermitteln. Dokumentennummer, verkürzte Überschrift und Datum finden sich auch im Kolumnentitel uber dem Dokument.

Aus den Angaben im Dokumentenkopf, vor allem aus der Überschrift, läßt sich die Art des jeweiligen Dokuments erschließen. Aufzeichnungen und Vermerke des internen Schriftverkehrs im Auswärtigen Amt sind eine in der Edition besonders häufig vertretende Dokumentengruppe. Der Verfasser wird jeweils in der Überschrift benannt. Läßt sich ein solcher weder unmittelbar noch mittelbar nachweisen, wird die ausfertigende Arbeitseinheit (Abteilung oder Referat) angegeben.

Eine weitere Gruppe von Dokumenten bildet der Schriftverkehr zwischen der Zentrale in Bonn und den Auslandsvertretungen. Diese erhielten ihre Informationen und Weisungen in der Regel mittels Drahterlaß, der fernschriftlich oder per Funk übermittelt wurde. Auch bei dieser Dokumentengruppe wird in der Überschrift der Verfasser genannt, ein Empfänger dagegen nur, wenn der Drahterlaß an eine einzelne Auslandsvertretung bzw. deren Leiter gerichtet 
war. Anderenfalls werden die Adressaten in einer Fußnote aufgeführt. Bei Runderlassen an sehr viele oder an alle diplomatischen Vertretungen wird der Empfängerkreis nicht näher spezifiziert, um die Anmerkungen nicht zu überfrachten. Ebenso sind diejenigen Auslandsvertretungen nicht eigens aufgeführt, die nur nachrichtlich von einem Erlaß in Kenntnis gesetzt wurden. Ergänzend zum Geschäftszeichen wird im unteren Teil des Dokumentenkopfes links die Nummer des Drahterlasses sowie der Grad der Dringlichkeit angegeben. Rechts davon befindet sich das Aufgabedatum und - sofern zu ermitteln die Uhrzeit der Aufgabe. Ein Ausstellungsdatum wird nur dann angegeben, wenn es vom Datum der Aufgabe abweicht.

Der Dokumentenkopf bei einem im Auswärtigen Amt eingehenden Drahtbericht ist in Analogie zum Drahterlaß gestaltet. Zusätzlich zu Datum und Uhrzeit der Aufgabe wird hier auch der Zeitpunkt der Ankunft festgehalten, jeweils in Ortszeit.

In weniger dringlichen Fällen verzichteten die Botschaften auf eine fernschriftliche Übermittlung und zogen die Form des mit Kurier übermittelten Schriftberichts vor. Beim Abdruck solcher Stücke wird im Dokumentenkopf neben der Überschrift mit Absender und Empfänger das Geschäftszeichen und das Datum genannt. Eine Sonderform des Schriftberichts stellt das sogenannte Privatdienstschreiben dar, mit dem außerhalb des offiziellen Geschäftsgangs zu einem Sachverhalt Stellung bezogen werden kann; darauf wird in einer Anmerkung aufmerksam gemacht.

Neben dem Schriftwechsel zwischen der Zentrale und den Auslandsvertretungen gibt es andere Schreiben, erkennbar jeweils an der Nennung von Absender und Empfänger. Zu dieser Gruppe zählen etwa Schreiben der Bundesregierung, vertreten durch den Bundeskanzler oder den Bundesminister des Auswärtigen, an ausländische Regierungen, desgleichen auch Korrespondenz des Auswärtigen Amts mit anderen Ressorts oder mit Bundestagsabgeordneten.

Breiten Raum nehmen Niederschriften über Gespräche bzw. Besprechungen ein. Sie werden als solche in der Überschrift gekennzeichnet. Hervorzuheben sind innerhalb dieser Dokumentengruppe Gesprächsaufzeichnungen der Dolmetscher. Für deren chronologische Einordnung ist das Gesprächs- oder Besprechungsdatum ausschlaggebend, während Verfasser und Datum der Niederschrift - sofern ermittelbar - in einer Anmerkung ausgewiesen werden.

Die wenigen Dokumente, die sich keiner der beschriebenen Gruppen zuordnen lassen, sind aufgrund individueller Überschriften zu identifizieren.

Die Überschrift bei allen Dokumenten enthält die notwendigen Angaben zum Ausstellungs-, Absende- oder Empfangsort bzw. zum Ort des Gesprächs oder der Besprechung. Erfolgt keine besondere Ortsangabe, ist Bonn stillschweigend zu ergänzen. Hält sich der Verfasser oder Absender eines Dokumentes nicht an seinem eigentlichen Dienstort auf, wird der Ortsangabe ein „z.Z." vorangesetzt.

Bei den edierten Schriftstücken handelt es sich in der Regel jeweils um die erste Ausfertigung oder - wie etwa bei den aufgrund festgelegter Verteiler vervielfältigten Drahtberichten - um eines von mehreren gleichrangig nebeneinander zirkulierenden Exemplaren. Statt einer Erstausfertigung mußten hin 
und wieder ein „Durchschlag als Konzept“, ein Durchdruck, eine Abschrift oder eine Ablichtung herangezogen werden. Ein entsprechender Hinweis findet sich in einer Fußnote. In wenigen Fällen sind Entwürfe abgedruckt und entsprechend in den Überschriften kenntlich gemacht.

\section{Dokumententext}

Unterhalb des Dokumentenkopfes folgt - in normaler Drucktype - der Text des jeweiligen Dokuments, einschließlich des Betreffs, der Anrede und der Unterschrift. Falls die Textvorlage eine inhaltlich substantielle Überschrift aufweist, wird diese mitabgedruckt. Die Dokumente werden in der Regel ungekürzt veröffentlicht. In wenigen Ausnahmefällen sind geringfügige Auslassungen vorgenommen worden; sie werden durch [...] gekennzeichnet und in einer Fußnote erläutert. Textergänzungen der Bearbeiter stehen ebenfalls in eckigen Klammern.

Offensichtliche Schreib- und Interpunktionsfehler werden stillschweigend korrigiert. Eigentümliche Schreibweisen bleiben nach Möglichkeit erhalten: manchmal erwies sich jedoch eine Vereinheitlichung bzw. Modernisierung als sinnvoll. Dies trifft teilweise auch auf fremdsprachige Orts- und Personennamen zu, deren Schreibweise nach den im Auswärtigen Amt gebräuchlichen Regeln wiedergegeben wird.

Selten vorkommende und ungebräuchliche Abkürzungen in der Textvorlage werden aufgelöst. Typische Abkürzungen von Institutionen, Parteien etc. werden allerdings übernommen. Hervorhebungen in der Textvorlage, also etwa maschinenschriftliche Unterstreichungen oder Sperrrungen werden - sofern sie nicht formaler Natur sind - kursiv wiedergegeben. Darüber hinaus dient der Kursivdruck dazu, bei Gesprächsaufzeichnungen die Sprecher voneinander abzuheben. Im äußeren Aufbau (Absätze, Zentrierungen usw.) folgt das Druckbild der Textvorlage, soweit dies unter Berücksichtigung der satztechnisch bedingten Gegebenheiten möglich ist.

Mit Ausnahme der dem Namen hinzugefügten Dienstbezeichnung, die der Überschrift eines Dokuments zu entnehmen ist, wird eine Unterschriftsformel vollständig wiedergegeben. Ein handschriftlicher Namenszug ist nicht besonders gekennzeichnet, eine Paraphe mit Unterschriftscharakter aufgelöst (mit Nachweis in einer Fußnote). Findet sich auf einem Schriftstück der Name zusätzlich maschinenschriftlich vermerkt, bleibt dies unerwähnt. Ein maschinenschriftlicher Name, dem ein "gez." vorangestellt ist, wird entsprechend übernommen; fehlt in der Textvorlage der Zusatz „gez.“, wird er in eckigen Klammern ergänzt.

Unter dem Dokumententext wird die jeweilige Fundstelle des Schriftstückes in halbfetter Schrifttype nachgewiesen. Bei Dokumenten aus dem PA/AA wird auf die Angabe des Archivs verzichtet und nur der jeweilige Bestand mit Bandnummer genannt. Dabei ist, soweit möglich, der aktuelle Stand der Verzeichnungsarbeiten im Politischen Archiv berücksichtigt. Dokumente aus VSBeständen sind mit der Angabe „VS-Bd.“ versehen. Bei Dokumenten anderer Herkunft werden Archiv und Bestandsbezeichnung angegeben. Da alle edierten Dokumente für die wissenschaftliche Benutzung bisher nicht oder nur in 
eingeschränktem Maße zur Verfügung standen, erübrigte sich eine systematische Suche nach Vor- und Teilveröffentlichungen.

\section{Kommentierung}

In Ergänzung zum Dokumentenkopf enthalten die Anmerkungen formale Hinweise und geben Auskunft über wesentliche Stationen im Geschäftsgang. Angaben technischer Art, wie Registraturvermerke oder standardisierte Verteiler, werden nur bei besonderer Bedeutung erfaßt. Wesentlich ist dagegen die Frage, welche Beachtung das jeweils edierte Dokument auf den verschiedenen Ebenen des Auswärtigen Amts bzw. außerhalb dieser Behörde gefunden hat. Dies läßt sich an den Paraphen maßgeblicher Akteure sowie an den - überwiegend handschriftlichen - Weisungen, Bemerkungen oder auch Reaktionen in Form von Frage- oder Ausrufungszeichen ablesen, die auf dem Schriftstück selbst oder auf zugehörigen Begleitschreiben und -vermerken zu finden sind. Die diesbezüglichen Merkmale sowie damit in Verbindung stehende Hervorhebungen (Unterstreichungen oder Anstreichungen am Rand) werden in Anmerkungen nachgewiesen. Auf den Nachweis sonstiger An- oder Unterstreichungen wird verzichtet. Abkürzungen in handschriftlichen Passagen werden unter Kennzeichnung durch eckige Klammern aufgelöst.

In den im engeren Sinn textkritischen Anmerkungen werden nachträgliche Korrekturen oder textliche Änderungen des Verfassers und einzelner Adressaten festgehalten. Unwesentliche Textverbesserungen sind hiervon ausgenommen. Ferner wird auf einen systematischen Vergleich der Dokumente mit Entwürfen ebenso verzichtet wie auf den Nachweis der in der Praxis üblichen Einarbeitung von Textpassagen in eine spätere Aufzeichnung oder einen Drahterlaß.

Die Kommentierung soll den historischen Zusammenhang der edierten Dokumente in ihrer zeitlichen und inhaltlichen Abfolge sichtbar machen, weitere Aktenstücke und anderweitiges Schriftgut nachweisen, die unmittelbar oder mittelbar angesprochen werden, sowie Ereignisse oder Sachverhalte näher erläutern, die dem heutigen Wissens- und Erfahrungshorizont ferner liegen und aus dem Textzusammenhang heraus nicht oder nicht hinlänglich zu verstehen sind. Dem erstgenannten Gesichtspunkt tragen jene rück- oder weiterverweisenden Anmerkungen Rechnung, die Bezüge zwischen einzelnen Dokumenten in den vorliegenden drei Bänden offenlegen und auf die AAPD 1963 bis 1966 bzw. auf die in Vorbereitung befindlichen AAPD 1968 verweisen. Das Auffinden von Dokumenten zu einem bestimmten thematischen Schwerpunkt ist mit Hilfe des Sachregisters möglich.

Besonderer Wert wird bei der Kommentierung darauf gelegt, die Dokumente durch Bezugsstücke aus den Akten der verschiedenen Arbeitseinheiten des Auswärtigen Amts bis hin zur Leitungsebene zu erläutern. Zitate oder inhaltliche Wiedergaben sollen die damaligen Entscheidungsprozesse erhellen. Dadurch wird zugleich Vorarbeit geleistet für eine vertiefende Erschließung der Bestände des PA/AA. Um die Identifizierung von Drahtberichten bzw. Drahterlassen zu erleichtern, werden außer dem Verfasser und dem Datum die Drahtberichtsnummer und, wo immer möglich, die Drahterlaßnummer angegeben. 
Findet in einem Dokument veröffentlichtes Schriftgut Erwähnung - etwa Abkommen, Gesetze, Reden oder Presseberichte -, so wird die Fundstelle in einer Anmerkung nach Möglichkeit genauer spezifiziert. Auszüge aus den Bezugsstücken oder inhaltliche Zusammenfassungen sollen zum Verständnis der Dokumente beitragen. Bei Anmerkungen oder Anmerkungsteilen, deren Zweck die knappe Erläuterung eines Sachverhalts oder Ereignisses ist, erfolgen keine systematischen Hinweise auf archivalische oder veröffentlichte Quellen. Sekundärliteratur wird generell nicht in die Kommentierung aufgenommen.

Angaben wie Dienstbezeichnung, Dienststellung, Funktion, Dienstbehörde und Nationalität dienen der eindeutigen Identifizierung der in der Kommentierung vorkommenden Personen. Die genannten Merkmale werden dabei erforderlichenfalls in Kombination oder auch im Wechsel dem Namen hinzugefügt. Bei Bundesministern erfolgt ein Hinweis zum jeweiligen Ressort nur im Personenregister. Eine im Dokumententext lediglich mit ihrer Funktion genannte Person wird nach Möglichkeit in einer Anmerkung namentlich nachgewiesen. Davon ausgenommen sind der jeweilige Bundespräsident, der Bundeskanzler bzw. der Bundesminister des Auswärtigen.

Die Bezeichnung einzelner Staaten wird so gewählt, daß Verwechslungen ausgeschlossen sind. Als Kurzform für die Deutsche Demokratische Republik kommen in den Dokumenten die Begriffe SBZ oder DDR vor und werden so wiedergegeben. Der in der Forschung üblichen Praxis folgend, wird jedoch in der Kommentierung und in den Regesten der Begriff DDR verwendet. Das Adjektiv „deutsch“ findet nur bei gesamtdeutschen Belangen oder dann Verwendung, wenn eine eindeutige Zuordnung gegeben ist. Der westliche Teil von Berlin wird als Berlin (West), der östliche Teil der Stadt als Ost-Berlin bezeichnet. Im übrigen orientiert sich die Edition bei der Benutzung geographisch-politischer Begriffe an der Sprache der Quellen.

Der Vertrag vom 8. April 1965 über die Einsetzung eines gemeinsamen Rates und einer vereinigten Kommission der Europäischen Gemeinschaften trat am 1. Juli 1967 in Kraft. Zur Kennzeichnung der Zusammenlegung von EWG, EURATOM und EGKS wird in der Kommentierung ab diesem Datum von „Europäische Gemeinschaften“ bzw. „EG“ gesprochen.

Für häufig benutzte Publikationen wie Editionen, Geschichtskalender und Memoiren werden Kurztitel oder Kurzformen eingeführt, die sich über ein entsprechendes Verzeichnis auflösen lassen. Der Platzersparnis dienen ebenfalls die Rückverweise auf bereits an anderer Stelle ausgeführte Anmerkungen.

Wie bei der Wiedergabe der Dokumente finden auch in den Anmerkungen die im Auswärtigen Amt gebräuchlichen Regeln für die Transkription fremdsprachlicher Namen und Begriffe Anwendung. Bei Literaturangaben in russischer Sprache wird die im wissenschaftlichen Bereich übliche Transliterierung durchgeführt.

\section{Verzeichnisse}

Das Dokumentenverzeichnis ist chronologisch angelegt. Es bietet zu jedem Dokument folgende Angaben: Die halbfett gedruckte Dokumentennummer, Datum und Überschrift, die Fundseite sowie eine inhaltliche Übersicht in Form 
eines Regests. Um die Einheitlichkeit der Regesten in ihrem notwendigerweise verkürzenden Charakter zu wahren, steht bei der Zusammenfassung des Dokumenteninhalts nicht die Aufzählung aller angesprochenen Themen im Vordergrund, sondern die Aufmerksamkeit gilt wesentlichen Schwerpunkten oder neuartigen Gedanken. Die Regesten können und sollen lediglich einer ersten Orientierung dienen. Hinsichtlich ihrer formalen Gestaltung wird auf die vorangehenden Ausführungen zur Kommentierung verwiesen.

Das Literaturverzeichnis enthält nur solche Publikationen, die häufig zur Kommentierung herangezogen und mit Kurztiteln oder Kurzformen versehen wurden. Diese sind alphabetisch geordnet und werden unter Angabe der notwendigen bibliographischen Daten aufgelöst.

Das Abkürzungsverzeichnis führt - mit Ausnahme der erwähnten Kurzformen - die im Dokumententeil vorkommenden Abkürzungen auf, es sei denn, sie sind so gebräuchlich, daß sich eine Auflösung erübrigt. Nicht aufgenommen werden Abkürzungen, die in einer Fußnote erläutert sind.

\section{Register}

Im Personenregister werden in der Edition vorkommende Personen unter Nennung derjenigen politischen, dienstlichen oder beruflichen Funktionen aufgeführt, die im inhaltlichen Zusammenhang der Dokumente wesentlich sind. In der Regel wird nur die maßgebliche Funktion im Jahr 1967 angegeben. Zu den im Auswärtigen Amt gebräuchlichen deutschen Funktionsbezeichnungen für ausländische Diplomaten werden in Einzelfällen die entsprechenden Termini in der jeweiligen Landessprache in Klammern hinzugefügt. Steht ein Dokument in seiner Gesamtheit in Beziehung zu einer Person, so wird im Register statt der betreffenden Seitenzahlen die halbfett gedruckte Dokumentennummer ausgeworfen.

Das Sachregister ermöglicht einen thematisch differenzierten Zugriff auf die Dokumente. Auch hier wird in den Fällen, in denen sich ein Schlagwort auf ein Dokument in seiner Gesamtheit bezieht, die halbfett gedruckte Dokumentennummer anstelle von Seitenzahlen aufgeführt.

Der Organisationsplan vom April 1967 zeigt die Struktur des Auswärtigen Amts und orientiert über die Leiter der jeweiligen Arbeitseinheiten. 
Verzeichnisse 



\section{Dokumentenverzeichnis}

Meyer-Lindenberg führt aus, daß der EWG-Ministerrat am 6. Dezember 1966 der Kommission ein Mandat für Sondierungsgespräche mit Israel über dessen Assoziierungsantrag vom 4. Oktober 1966 erteilt habe. Die Bundesregierung halte eine Neuverhandlung des Handelsabkommens vom 4. Juni 1964 zwischen der EWG und Israel für den schnellsten Weg zur Verbesserung der gegenseitigen Handelsbeziehungen, während eine Assoziierung "schwerwiegende Probleme" aufwerfe. Die präjudizielle Wirkung einer solchen Entscheidung im Hinblick auf die Assoziierung weiterer afrikanischer Staaten und damit auf den europäischen Charakter der EWG wäre beträchtlich. Ferner sei die Regelung der Beziehungen zu den EFTA-Staaten vordringlich. Schließlich werde die Frage aufgeworfen, ob eine Befürwortung des israelischen Antrags durch die Bundesregierung nicht deren Bemühungen um die Wiederaufnahme diplomatischer Beziehungen mit den arabischen Staaten erschwere. Meyer-Lindenberg regt an, der israelischen Regierung mitzuteilen, daß ihr Wunsch von der EWG geprüft und die Haltung der Bundesregierung zu gegebener Zeit vom Kabinett festgelegt werde.

Ruete berichtet, daß dem ehemaligen Vertreter des Leiters der Handelsvertretung in Warschau, Blumenfeld, von polnischer Seite der Vorschlag zu politischen Sondierungsgesprächen in Bonn unterbreitet worden sei. Die Entsendung einer polnischen Delegation unter Beteiligung eines verantwortlichen Beamten des polnischen Außenministeriums stelle ein Novum dar und gehe weit über die gegenüber Abgeordneten des Bundestages im Sommer des Vorjahres geäußerte Möglichkeit der Aufnahme parlamentarischer Kontakte hinaus. Ruete schlägt vor, die Bereitschaft zu vertraulichen Gesprächen zu signalisieren und unverbindlich anzuregen, daß ein konkreter Terminvorschlag in Form eines vertraulichen Schreibens des Vertreters des polnischen Außenministeriums in der zu bildenden Delegation erfolgen möge.

Sahm nimmt den Entwurf einer Instruktion für die Delegation der Bundesrepublik bei den Verhandlungen mit der Tschechoslowakei zum Anlaß festzustellen, daß seitens der Bundesregierung erstmals die Gesprächsbereitschaft über eine Aufnahme diplomatischer Beziehungen erklärt werde. Voraussetzung hierfür sei jedoch, daß eine künftige Botschaft in Prag auch die Interessen von Berlin (West) de facto wahrnehmen und dem Alleinvertretungsanspruch Ausdruck verliehen werden könne. Er 
weist darauf hin, daß eine offizielle Interpretation der beiden häufig und unterschiedlich benutzten Begriffe "Heimatrecht" und „Obhutspflicht" durch das Bundeskabinett erforderlich sei. Sahm äußert ferner die Meinung, daß sich die Bundesrepublik die Normalisierung des Verhältnisses zu Osteuropa etwas kosten lassen müsse. Staaten, die der Politik der Bundesregierung besonders aufgeschlossen gegenüberständen, sollte wirtschaftlich und finanziell entgegengekommen werden, um denjenigen osteuropäischen Staaten, die sich zurückhaltend zeigten, einen Anreiz zur Änderung ihrer Haltung zu geben.

Amt

Brandt macht darauf aufmerksam, daß sich die Bundesrepublik der Unterzeichnung eines zwischen den USA und der UdSSR auszuhandelnden Nichtverbreitungsabkommens kaum werde entziehen können. Sie müsse jedoch, gemeinsam mit anderen nicht-nuklearen Staaten „kraftvoll und beharrlich“ ihre Interessen vertreten, insbesondere hinsichtlich der uneingeschränkten Beteiligung an der zivilen Atomforschung. Ferner vertritt Brandt die Ansicht, daß durch das angestrebte Abkommen der Weg nach Europa weder versperrt noch unnötig erschwert werden dürfe. Auch sollten bestehende Regelungen innerhalb der NATO zur nuklearen Planung nicht berührt werden; die Bundesrepublik erhebe hier Anspruch auf volle Beteiligung. Demgegenüber seien Projekte in Anlehnung an die MLF nicht mehr realistisch, da die Gefahr bestehe, „hinter einem Wurstzipfel herzuhopsen", der nicht zu erwischen sei. Vielmehr müsse überlegt werden, ob der Bundesrepublik nicht mehr Luft verschafft werden könne, wenn der 1954 ausgesprochene Verzicht auf die Herstellung von Kernwaffen durch einen Verzicht auf Erwerb, Mitbesitz und Verfügungsgewalt ergänzt würde.

Lahr legt die Grundsätze der Bundesregierung für die Gewährung von Ausrüstungshilfe dar. Diese habe sich als wertvolles Instrument der Außenpolitik erwiesen, stoße nun aber auf Bedenken im Bundestag und sei darüber hinaus von Kürzungen im Haushalt 1967 betroffen. Dabei könnte hier mit relativ geringen Mitteln große politische Wirkung erzielt werden, denn die Ausrüstungshilfe entspreche dem Wunsch der Entwicklungsländer nach politischer Konsolidierung und trage ihrem Prestigebedürfnis Rechnung. Als Gegenleistung dürfe die Bundesregierung Unterstützung in ihrer Deutschlandpolitik erwarten. Es müsse auch bedacht werden, daß der Kreis der Empfänger auf wenige Staaten in den ruhigeren Teilen Afrikas begrenzt sei. Lahr stellt ferner fest, daß keine Angriffswaffen geliefert würden und beabsichtigt sei, von der Lieferung sogenannter Verteidigungswaffen gänzlich abzukommen. Um den im Haushalt für 1967 vorgesehenen Betrag durchzusetzen, regt 
er an, daß begrifflich unterschieden werden solle zwischen Verteidigungshilfe einschließlich Waffen einerseits, die den NATOStaaten vorbehalten bleibe, sowie andererseits Ausrüstungshilfe an Entwicklungsstaaten "praktisch ohne Waffen".

Schnippenkötter resümiert den Stand der Dreier-Verhandlungen nach der Gesprächsrunde vom 28. bis 30. November 1966. Während die Untersuchung über die sowjetische Bedrohung fertiggestellt wurde, konnte in Einzelfragen wie etwa der anzusetzenden Dauer der militärischen Vorwarnzeit im Falle eines Angriffs des Warschauer Pakts gegen die NATO keine Einigung erzielt werden. Gleichfalls nicht abgeschlossen sei eine Untersuchung des militärischen Potentials der NATO im Abschnitt Europa-Mitte sowie eine vergleichende Studie über die Kampfkraft der deutschen, britischen und amerikanischen Streitkräfte. Unterschiedliche Ansichten beständen auch in der Frage, ob das Vorhandensein starker konventioneller Streitkräfte in Europa zweckmäßig sei; im Gegensatz zur deutschen und amerikanischen Auffassung vertrete die britische Regierung die Auffassung, „daß eine konventionelle Verteidigung in Europa aussichtslos" sei. Noch nicht erörtert wurde, ob und unter welchen Voraussetzungen eine Rückverlegung von amerikanischen und britischen Truppen aus der Bundesrepublik militärisch vertretbar sei. Höhe

Grewe bezeichnet den am 16. Dezember 1966 vom amerikanischen Außenminister Rusk übergebenen Formulierungsvorschlag für den Artikel I eines Nichtverbreitungsabkommens als unakzeptabel, da er eine befriedigende Lösung des Problems der nuklearen Teilhabe innerhalb der NATO im Sinne einer weitergehenden Einbeziehung der Nicht-Kernwaffenstaaten unmöglich mache. Bei einer amerikanisch-sowjetischen Einigung auf der Grundlage des vorgelegten Textes würde die integrierte Militärstruktur der NATO auf dem jetzt erreichten und die Bundesregierung nicht befriedigenden Niveau verbleiben. Außerdem müßten sich die europäischen Partner auf die zunehmend fraglich gewordene amerikanische Nukleargarantie verlassen. Die NATO würde somit zu einem Instrument amerikanischer Kontrolle des militärischen Gleichgewichts in Europa auf der Basis des Status quo. Ziel der Bundesregierung müsse folglich die Sicherstellung eines tragbaren Textentwurfes sein. Dies bedeute auch, daß ein Beitritt zum Abkommen nicht allen Staaten offenstehen dürfe. Deutlicher als bisher sei herauszustellen, daß das amerikanische Vorgehen mit der „Idee der atlantischen Partnerschaft" unvereinbar sei. 

italienischen Außenminister Fanfani in Rom

Brandt erläutert, daß die Bundesregierung bei dem geplanten Gipfeltreffen der Staats- und Regierungschefs der EWG-Staaten in Rom nicht nur die Ost-West-Beziehungen erörtern wolle. Auch die bei Staatspräsident de Gaulle bestehenden Zweifel in Europa-Fragen sollten zerstreut werden. Hinsichtlich eines Beitritts Großbritanniens zur EWG führt er aus, daß vorurteilslos neue Ansatzpunkte erarbeitet werden müßten, um so vielleicht zu qualifizierten Konsultationen zu gelangen. Fanfani weist darauf hin, daß die Gipfelkonferenz „der Vorbereitung der Geister auf konstruktive und gelassene Englandverhandlungen “ dienen solle. Die Minister stimmen darin überein, daß es hinsichtlich der für den 1. Juli 1968 vorgesehenen Liberalisierung des EWG-Binnenmarktes für Großbritannien keine zu langen Übergangszeiten geben dürfe. Brandt unterbreitet Vorschläge für eine gemeinsame europäische Forschungspolitik und Verhandlungen mit den USA über ein Kooperationsabkommen im Rahmen der OECD. Hinsichtlich eines Nichtverbreitungsabkommens dürfe weder das Interesse der Nichtnuklearstaaten an einer friedlichen Entwicklung der Kernenergie noch deren Beteiligung an der gemeinsamen Strategie der NATO und an deren Krisenmanagement beeinträchtigt werden.

Diehl stellt fest, daß Frankreich die Entwicklung und Herstellung von Atomwaffen ,im wesentlichen gemeistert" habe. Dabei habe es 1956/57 gewisse Ansatzpunkte für eine deutsch-französische Zusammenarbeit im Nuklearbereich gegeben. Jedoch bestehe Staatspräsident de Gaulle nun darauf, daß die Bundesrepublik keine nationale Verfügungsgewalt und keinen $\mathrm{Be}$ sitz oder Mitbesitz von Atomwaffen anstrebe. Demgegenüber müsse deutlich gemacht werden, daß die Bundesrepublik gerade nach dem Scheitern des MLF-Projektes und der noch völlig ungewissen Option einer europäischen Atomstreitmacht schutzwürdige nationale Interessen auf nuklearem Gebiet besitze, die eine begrenzte, aber ausbaufähige Kooperation mit Frankreich wünschenswert machten. Dabei könne die Bundesrepublik auch als Bindeglied zwischen dem "Außenseiter Frankreich“ und den übrigen NATO-Staaten fungieren. Möglichkeiten der Zusammenarbeit ergäben sich u. a. auf dem Gebiet der Raketenabwehr, hinsichtlich der friedlichen Nutzung der Kernenergie, bei der Entwicklung von Reaktoren sowie in der Nukleartechnologie. an Staatssekretär Schütz

Wickert berichtet von den Verhandlungen mit der Tschechoslowakei über den Abschluß eines Handelsabkommens und die Aufnahme diplomatischer Beziehungen. Der Abteilungsleiter im tschechoslowakischen Außenministerium, Rezek, habe die Auffassung bekräftigt, daß das Münchener Abkommen von 
1938 von Anfang an null und nichtig gewesen sei. Bei einer Anerkennung dieser "objektiven Tatsache“ würde die tschechoslowakische Regierung weder neue Forderungen erheben noch die Bundesrepublik ,zur Kasse" bitten. Er, Wickert, habe verdeutlicht, daß sich die Bundesregierung von einer Diskussion über Gültigkeit oder Ungültigkeit "ungleicher Verträge" auch nichts verspreche, jedoch dem tschechoslowakischen Standpunkt hinsichtlich des Münchener Abkommens nicht leicht folgen könne. Allerdings bestehe die Bereitschaft, anläßlich eines Botschafteraustauschs die „Verurteilung der Hitlerschen Gewaltpolitik, die zum Münchener Abkommen geführt habe", zu wiederholen.

Der Staatssekretär resümiert ein Gespräch mit den Botschaftern der Drei Mächte. Schütz berichtete McGhee, Roberts und François Seydoux, daß die Aussichten für eine Weiterarbeit der Passierscheinstelle für dringende Familienangelegenheiten nach Auslaufen der bestehenden Regelung Ende Januar 1967 nicht sehr günstig seien. Auch wolle die DDR mit der Ankündigung, die Mitarbeit im Alliierten Abrechnungsbüro für den Post- und Fernmeldeverkehr zu beenden, ihre Forderung nach Internationalisierung des innerdeutschen Postverkehrs untermauern. Schütz schlug daher vor, daß die ,Allied Working Party on International Accounting of Post and Telecommunications" weiterhin Postgebühren abrechnen und die Postverwaltungen der beteiligten Staaten in einem Zirkular davon in Kenntnis setzen sollten. Er teilte weiter mit, daß die DDR einen Ausgleich in Höhe von mehreren hundert Millionen DM für die seit 1948 geleisteten Dienstleistungen im innerdeutschen Postverkehr fordere, jedoch nur ein Ausgleich für zukünftige Leistungen erwogen werden und hierüber eine $\mathrm{Ab}$ sprache auf technischer Ebene erfolgen könne. Es müsse überlegt werden, ob auf die im November 1966 durch die DDR einseitig festgelegte neue Gebührenordnung für die Benutzung der Wasserstraßen von Berlin (West) nicht mit einer entsprechenden Anordnung des Berliner Senats geantwortet werden müsse. Auswärtige Amt

Ruete berichtet über sein Gespräch mit dem rumänischen Außenminister. Manescu erklärte, daß hinsichtlich der Aufnahme diplomatischer Beziehungen weder Bedingungen gestellt, noch Schwierigkeiten gemacht würden. Auf der anderen Seite könnten die von der Bundesrepublik vertretenen Positionen keinesfalls durch Rumänien ,attestiert“ werden. Der Botschafteraustausch solle in Form eines Kommuniqués beschlossen werden, das nicht mit gewagten politischen Erklärungen zu belasten sei. Ferner könnten hinsichtlich der Vertretung der Interessen von Berlin (West) durch eine in Bukarest zu errichtende Botschaft keine schriftlichen Zusicherungen gemacht werden; je- 
doch werde die rumänische Regierung zu mündlichen Abmachungen stehen. Was die Zusammenführung „rumänischer Staatsangehöriger" mit ihren in der Bundesrepublik lebenden Familien angehe, so sei Rumänien bereit, aus humanitären Gründen Ausreiseanträgen mehr Aufmerksamkeit zu schenken. an Staatssekretär Schütz

Wickert faßt seine Gespräche mit dem Abteilungsleiter im tschechoslowakischen Außenministerium zusammen. Rezek bekräftigte, daß die tschechoslowakische Auffassung, die Bundesrepublik müsse die Ungültigkeit des Münchener Abkommens von 1938 ex tunc anerkennen, zwar eine Erwartung, aber keine Forderung darstelle. $\mathrm{Zu}$ dem seitens der Bundesregierung erwogenen Austausch bilateraler Gewaltverzichtserklärungen meinte er, daß die Tschechoslowakei „Mitglied der sozialistischen Familie" sei und daher eine Friedenssicherung in europäischem Rahmen vorziehe. Hinsichtlich der Einbeziehung von Berlin (West) in ein Handelsabkommen werde überlegt, ob diese Frage nicht durch die vorhergehende Aufnahme diplomatischer Beziehungen und eine damit verknüpfte Vereinbarung über die Wahrnehmung der Interessen von Berlin (West) durch die Botschaft der Bundesrepublik in Prag gelöst werden könne. Rezek betonte, daß nach wie vor Interesse an der Aufnahme diplomatischer Beziehungen zur Bundesrepublik bestehe.

Der Bundeskanzler erklärt, daß er nicht als „Demandeur“ komme, sondern als jemand, der mit der Umsetzung des deutschfranzösischen Vertrages von 1963 nicht zufrieden sei und alles tun wolle, um nach Maßgabe der heutigen Umstände das Versäumte nachzuholen. Daneben wünsche die Bundesregierung, die Beziehungen zu den osteuropäischen Staaten zu normalisieren und auch das Verhältnis zur UdSSR zu verbessern. Vielleicht könne auch eine Entkrampfung gegenüber der DDR dazu beitragen, den „hermetischen Abschluß der Bevölkerung in der DDR $^{\text {" }} \mathrm{zu}$ beenden. Mit dieser Politik wolle die Bundesrepublik „als Europäer mit Europäern“ die Ost-West-Konfrontation überwinden helfen. De Gaulle führt aus, daß die UdSSR mit der eigenen Entwicklung ringe, bei ihren Verbündeten die nationale Idee obsiege und das Verhältnis zur Volksrepublik China gespannt sei. Deshalb sei es notwendig, eine echte politische Entspannung zu betreiben. Kiesinger erwidert, daß im Gegenzug zu dieser an die Bundesregierung gerichteten Erwartung die Verbündeten der Wiedervereinigung Deutschlands nicht nur einen "Lippendienst" erweisen dürften. Was die Haltung gegenüber den USA betreffe, so lasse sich die Bundesregierung von der Erkenntnis leiten, daß jeder Staat eigene Interessen verfolge. Deswegen gebe es gute Gründe für einen Verbleib in der NATO-Integration, eben weil die Bundesrepublik nicht die- 
selbe Bewegungsfreiheit wie Frankreich besitze. Allerdings denke er nicht daran, Politik „in Hörigkeit von Amerika“ zu betreiben. zösischen Außenminister Couve de Murville in Paris

Der Bundesminister berichtet, daß die Verhandlungen zwischen der Bundesrepublik und Rumänien über die Aufnahme diplomatischer Beziehungen gut zu verlaufen schienen. Auch die Gespräche, die derzeit in Prag geführt würden, ließen darauf hoffen, daß im Verhältnis zur Tschechoslowakei eine Normalisierung bald möglich sei. Die UdSSR habe dagegen lediglich in der Frage des Austauschs von Gewaltverzichtserklärungen Interesse an einem informellen Meinungsaustausch signalisiert. Der französische Außenminister führt aus, daß der Wandel in den Ost-West-Beziehungen nsehr wichtig, vielleicht das Wichtigste" sei. Polen biete die größten Schwierigkeiten, da es noch stark "traumatisiert" sei, während die sowjetische Regierung mit Rücksicht auf die unterschiedlichen Interessen ihrer Bündnispartner eine abwartende Haltung einnehme. Brandt bittet mit Blick auf eine mögliche Wiederaufnahme diplomatischer Beziehungen zu Jugoslawien um die Mithilfe der französischen Regierung, damit den Staaten der blockfreien Welt verdeutlicht werde, daß die Politik der Bundesregierung gegenüber den osteuropäischen Staaten keine Änderung ihrer Haltung zur DDR bedeute. Dies betreffe auch die arabischen Staaten, mit denen eine „Parallelaktion“ zur Wiederaufnahme diplomatischer Beziehungen laufe. Staatspräsident de Gaulle in Paris

Kiesinger führt aus, daß Vertreter der Industrie in der Bundesrepublik auf einen britischen Beitritt zur EWG und den Abbau der Zollgrenzen zur EFTA drängten, da der Exportüberschuß der Wirtschaft fast ausschließlich im Handel mit den EFTA-Staaten erzielt werde. Die Position der Bundesregierung gegenüber Großbritannien sei in erster Linie wirtschaftlicher und nicht so sehr politischer Natur. Der Staatspräsident erwidert, daß mit der Gemeinschaft der Sechs eine wirtschaftliche Solidarität, ja eine „echte Gemeinschaft“ habe geschaffen werden sollen. Daraus würde mit dem Beitritt Großbritanniens aber nur noch eine Freihandelszone, da die britische Regierung sich nicht den gleichen Regeln unterwerfen wolle. Dies gelte beispielsweise für die Währungspolitik, denn Großbritannien „habe keine Währung, sondern nur die Fiktion einer Währung“. Sollten die übrigen EWG-Staaten auf einem britischen Beitritt bestehen, werde Frankreich gegebenenfalls die Gemeinschaft verlassen. Die Beitrittsfrage bleibe „zur Zeit am besten suspendiert". 
Bundesminister Brandt erklärt, daß die Bundesregierung bei der Erörterung der europäischen politischen Zusammenarbeit auf der geplanten Konferenz der Staats- und Regierungschefs der EWG-Staaten in Rom jedem Weg, der Fortschritte verspreche, zustimmen könne. Ministerpräsident Pompidou betont, ein solches Treffen müsse zeigen, daß es von Nutzen gewesen sei; deshalb sollten insbesondere Themen des Gemeinsamen Marktes und der internationalen Währungspolitik erörtert werden. Außenminister Couve de Murville ergänzt, daß die Zeit noch nicht reif sei, Formen der politischen Zusammenarbeit unter den Sechs zu diskutieren. Brandt regt an, in Rom über die wissenschaftlich-technologische Zusammenarbeit zu sprechen und „unter der Hand“ einen Kompromiß hinsichtlich der Zusammensetzung einer vereinigten Kommission der europäischen Gemeinschaften $\mathrm{zu}$ finden, um dann während der Konferenz den Abschluß der Fusion bekanntzugeben. Staatspräsident de Gaulle greift einen Vorschlag des Bundeskanzlers Kiesinger auf und erklärt sich bereit, der Fusion zuzustimmen, wenn der Präsident der EWG-Kommission, Hallstein, zum Jahresende abgelöst werde. Er stellt ferner die Mitwirkung Frankreichs in einer Kommission der Sechs über Technologie-Probleme in Aussicht. Abschließend weist Kiesinger darauf hin, daß eine Erörterung der Ost-West-Beziehungen zwangsläufig auch die Deutschland-Frage aufwerfen werde, was er für gefährlich halte.

Schütz bittet die Auslandsvertretungen in 70 blockfreien Staaten, der jeweiligen Gastregierung die Absicht der Bundesregierung zu erläutern, diplomatische Beziehungen mit osteuropäischen Staaten aufzunehmen. Die damit angestrebte „Entspannungswirkung" werde aber beeinträchtigt, wenn dritte Staaten den Botschafteraustausch zum Anlaß nähmen, ihrerseits engere Kontakte zur DDR zu knüpfen. Demgegenüber müsse darauf hingewiesen werden, daß jede Herstellung politischer $\mathrm{Be}$ ziehungen zur DDR nach wie vor "eine einseitige Option für den Osten" darstelle. Deshalb werde die Bundesregierung weiterhin ,jede Anerkennung des Ulbricht-Regimes als unfreundlichen Akt ansehen" und darauf so reagieren, daß die Interessen des deutschen Volkes gewahrt blieben.

Staatspräsident de Gaulle stellt als Bilanz der Gespräche fest, daß der deutsch-französische Vertrag von 1963 ,lebe“ und ,jetzt wieder ins Licht getreten" sei. Sowohl hinsichtlich der Einschätzung der Ost-West-Beziehungen als auch in der Haltung gegenüber den USA und in der Frage eines britischen Beitritts zur EWG gebe es keine fundamentalen Gegensätze. Bundeskanzler Kiesinger hebt hervor, daß das beiderseitige Interesse, "mehr und qualitativ anders als mit anderen" zusammenzuarbeiten, eine Konstante im politischen Wandel bleibe. Und obwohl es für Frankreich einfacher sei, der Formel "détente, en- 
tente, coopération“ zu folgen, wisse die Bundesregierung, daß die Entspannung nach menschlichem Ermessen der einzige Weg zur Wiedervereinigung sei. Darüber hinaus sei Europa in erster Linie das Anliegen der Europäer. Bundesminister Brandt und Ministerpräsident Pompidou informieren über die getroffenen Vereinbarungen für eine engere deutsch-französische wirtschaftliche und wissenschaftlich-technologische Zusammenarbeit. Ferner solle auf dem Gebiet der Verteidigung eine gemeinsame sicherheitspolitische Studie erarbeitet und die Kooperation in der Rüstungsproduktion gefördert werden. Schließlich werde nicht zuletzt mit Blick auf die Entwicklung der EWG eine engere bilaterale Abstimmung vor allem in der Steuer- und Währungspolitik angestrebt. Auswärtige Amt

Ruete teilt mit, daß der Beschluß zur Aufnahme diplomatischer Beziehungen mit Rumänien anläßlich des Besuchs des rumänischen Außenministers Manescu Ende des Monats in Form eines Kommuniqués in Bonn bekanntgegeben werden solle. In der Frage der Vertretung von Berlin (West) durch die künftige Botschaft in Bukarest sei die rumänische Delegation nicht zu einer schriftlichen Fixierung bereit gewesen. Es sei jedoch versichert worden, daß rumänische Behörden Unterstützungsgesuche, die von Bürgern aus Berlin (West) an die Botschaft herangetragen würden, aus humanitären Gründen berücksichtigen würden. Die bisher von der Handelsvertretung in Bukarest wahrgenommenen Befugnisse zur Vertretung der Wirtschaftsinteressen von Berlin (West) sollten auf die Wirtschaftsabteilung der Botschaft übergehen. Ruete stellt fest, daß dieses Verhandlungsergebnis zwar keine „vollauf befriedigende Lösung" darstelle, die rumänische Regierung jedoch ihren Rechtsstandpunkt in der Berlin-Frage nicht aufgeben könne. amerikanischen Botschafter McGhee

Kiesinger berichtet, er habe in den deutsch-französischen Regierungsbesprechungen vom 13./14. Januar 1967 die unterschiedliche Einschätzung der Beziehungen zu den USA durch die Bundesrepublik und Frankreich damit begründet, daß es nicht darum gehe, „den Vereinigten Staaten gegenüber gehorsam zu sein", sondern mit den USA eine den eigenen Interessen entsprechende Politik zu betreiben. Staatspräsident de Gaulle habe dies anerkannt, insbesondere aber daran festgehalten, daß die amerikanische Vietnam-Politik auf dem falschen Weg sei. In dieser Frage könne die Bundesrepublik nicht dasselbe sagen wie Frankreich, und sei es nur, weil „Deutschland ein geteiltes Land" sei. Ferner habe er de Gaulle erklärt, daß eine auch von der Bundesregierung verfolgte Politik der europäischen Entspannung nicht mit der Erwartung betrieben werden dürfe, daß sich auf diese Weise die Wiedervereinigung automatisch einstellen werde. Vielmehr müsse das Wiederver- 
einigungsproblem aktiv angegangen werden. McGhee erwidert, daß die USA von der Bundesregierung erwarteten, in allen Fragen eigene Interesse zu verfolgen; es gebe keine Sonderbeziehungen zwischen Staaten, „die so weit gingen, daß man den Eigeninteressen zuwiderlaufende Dinge tue ${ }^{\iota}$. Er versichert, daß der Abschluß eines Nichtverbreitungsabkommens eine europäische Lösung nicht ausschließe. Die Bundesrepublik könne dann wie bisher auch Trägersysteme besitzen, allerdings keine atomaren Sprengköpfe, über deren Einsatz de Gaulle das letzte Wort haben müsse.

Truckenbrodt faßt ein Gespräch zwischen Bundesminister Brandt und dem Apostolischen Nuntius in Bonn zusammen. Bafile zeigte sich besorgt, daß eine Verabschiedung des geplanten Schulgesetzes in Baden-Württemberg den Fortbestand der katholischen Konfessionsschulen im Regierungsbezirk Südwürttemberg-Hohenzollern gefährden und damit eine „schwerwiegende und offenkundige Verletzung" des Konkordats von 1933 zwischen dem Deutschen Reich und dem Heiligen Stuhl darstellen würde. Ein solcher Verstoß würde den Vatikan der Rechtfertigung berauben für die bislang praktizierte peinlich genaue Einhaltung des Konkordats hinsichtlich der Diözesangrenzen und -organisation in den seit 1945 unter polnischer Verwaltung stehenden ehemaligen Ostgebieten des Deutschen Reiches - mit möglichen Auswirkungen auf die geplante Ernennung eines polnischen Geistlichen zum residierenden $\mathrm{Bi}$ schof im vakanten Bistum Ermland. Brandt betonte, daß kein Zusammenhang hergestellt werden sollte zwischen dem Schulgesetz in Baden-Württemberg und dem unveränderten Fortbestand der Diözesen in den ehemaligen Ostgebieten. Er sicherte jedoch zu, sich um eine Lösung innerhalb des verfassungsrechtlichen Rahmens bemühen zu wollen.

Harkort stellt fest, daß für den Devisenteil der Dreiergespräche zwischen der Bundesrepublik, Großbritannien und den USA die Stunde der Wahrheit gekommen zu sein scheine. Die Haushaltslage in der Bundesrepublik zwinge zu einer pessimistischen Beurteilung der Möglichkeiten für eine Fortsetzung des Devisenausgleichs für die Stationierungskosten britischer und amerikanischer Truppen in der Bundesrepublik. So seien für 1967 und das folgende Jahr praktisch keine Zahlungen mehr möglich. Harkort macht darauf aufmerksam, daß mit einer sehr ernst zu nehmenden Verschlechterung der Beziehungen zu den beiden Verbündeten gerechnet werden müsse, nicht zuletzt auch mit dem Abzug eines erheblichen Teils der britischen Truppen, wenn diese „finanziellen Karten auf den Tisch" gelegt würden. Dennoch müßten die Partner über diese Situation informiert werden. Er schlägt daher vor, daß Mitte Februar 1967 die Leiter der deutschen, amerikanischen und britischen Delegationen. Duckwitz, McCloy und Thomson, zu Gesprächen zusammenkommen. Falls ein Devisenhilfeabkommen 
gegenstandslos werden sollte, so könne ein allgemein gehaltenes Abkommen über rüstungswirtschaftliche Zusammenarbeit vorgeschlagen werden. Auswärtige Amt

Knappstein berichtet von einer Unterredung über den Entwurf für ein Nichtverbreitungsabkommen. Der Leiter der amerikanischen Abrüstungsbehörde, Foster, teilte mit, daß der Vertrag lediglich die Weitergabe von nuklearen Sprengsätzen und die physische Kontrolle über Sprengsätze untersage, wobei der Begriff "control“ verstanden werde als "decision to fire“. Alle Vorstufen dieser Entscheidung, wie z.B. Konsultationen zu Zielund Einsatzplanung und alle bestehenden bilateralen oder multilateralen Arrangements innerhalb der NATO, ja sogar das Montieren von nuklearen Sprengköpfen auf Trägersysteme, würden davon nicht berührt und somit von der UdSSR geduldet. Es dürfe allerdings nicht erwartet werden, „daß die Sowjets dies öffentlich sagten“. Weiterhin habe Foster zugesichert, daß eine europäische politische Union auch unter dem geplanten Abkommen rechtmäßig über Kernwaffen verfügen könne. Es sei allerdings umso besser, je weniger darüber öffentlich gesagt werde. Ebenso werde die Beteiligung der Bundesrepublik an der friedlichen Kernforschung und der Atomwirtschaft nicht eingeschränkt. Knappstein kommt zu dem Schluß, daß die amerikanisch-sowjetischen Gespräche zu einem großen Teil auf stillschweigenden Übereinkünften beruhten.

Grewe berichtet von einem Gespräch mit dem Generalsekretär der NATO. Brosio drückte seine Hoffnung aus, daß die USA bei der Diskussion des Entwurfs eines Nichtverbreitungsabkommens am 1. Februar 1967 im NATO-Rat keine verbindliche Festlegung der Bündnispartner erwarteten. Sollten einige NATOMitgliedstaaten die amerikanischen Bestrebungen bremsen wollen, so könne über Verfahrensfragen Einfluß zur Geltung gebracht werden. Er denke hierbei vor allem an die Bundesrepublik und Italien, da diese beiden „zivilen Atommächte" durch das Abkommen zum erstenmal grundsätzlich in eine andere Kategorie eingereiht würden als die traditionellen Kernwaffenstaaten - vielleicht eine Konsequenz des verlorenen Zweiten Weltkrieges. Grewe resümiert, daß der NATO-Generalsekretär die amerikanische Politik hinsichtlich der Nichtverbreitung nach wie vor für verhängnisvoll hält und eine Erosion der Allianz befürchtet. Moskau

Lahr teilt mit, daß der sowjetische Botschafter in Bonn am 18. Januar 1967 wegen der Wiederaufnahme der bilateralen Wirtschaftsverhandlungen vorgesprochen habe. Die UdSSR erwarte 
allerdings eine präzise Antwort auf ihre Forderungen nach vollständigem Wegfall der Einfuhr-Kontingentierung und nach Gewährung der gleichen Zollvorteile wie die der EWG-Mitgliedstaaten. Lahr antwortete daraufhin dem Botschafter, daß trotz der für die Bundesrepublik unzumutbar gewordenen passiven Bilanz des Handels mit der UdSSR Bereitschaft zu einer verstärkten Einfuhr sowjetischer Güter vorhanden sei; das Ziel müsse allerdings eine gegenseitige Ausweitung des Warenaustauschs sein. Der Abschluß eines neuen Abkommens sei zwar erwünscht, jedoch nur im Rahmen der am 6. Mai 1966 bekanntgegebenen Liberalisierung des Osthandels. Den sowjetischen Wünschen hinsichtlich Kontingentierung und Zöllen könne nicht entsprochen werden. Da Zarapkin während des $\mathrm{Ge}$ sprächs bei seinen „hart vorgetragenen, offensichtlich völlig unrealistischen" Forderungen geblieben sei, äußert Lahr abschließend Zweifel, ob die sowjetische Regierung überhaupt zu einem neuen Abkommen zu gelangen wünsche. ungarischen Stellvertretenden Außenminister Szilágyi in Budapest

Lahr bezeichnet seine Gespräche mit der ungarischen Regierung als Sondierungen, die durchaus zu konkreten Verhandlungen führen könnten. Zunächst ausgeklammert bleiben sollten diejenigen Fragen, bei denen es beträchtliche Meinungsverschiedenheiten gebe. So werde nicht verlangt, daß Ungarn mit einer Aufnahme diplomatischer Beziehungen die Deutschlandpolitik der Bundesregierung anerkenne. Auch hinsichtlich einer Einbeziehung von Berlin (West) sei keine gesonderte Klausel notwendig. Intern müsse jedoch in dieser Frage Klarheit bestehen. Szilágyi bezeichnet die offizielle Einbeziehung von Berlin (West) in die Aufgaben einer Botschaft der Bundesrepublik in Budapest als heikles Problem. Darüber hinaus äuBert er sich enttäuscht über die unbefriedigende Entwicklung des Handels und über die „feindliche" Einstellung der Bundesrepublik, die sich in der Unterstützung von ungarischen Emigrantenorganisationen und Radiosendern wie der Deutschen Welle und Radio Free Europe zeige. ungarischen Außenhandelsminister Bíró in Budapest

Lahr und Bíró vertreten unterschiedliche Auffassungen zur Entwicklung der Handelsbeziehungen zwischen der Bundesrepublik und Ungarn. Während Lahr die Aufwärtsentwicklung im Gesamtvolumen sowie die Ausgeglichenheit von Import und Export betont, weist Bíró darauf hin, daß sich der Handel mit der Bundesrepublik langsamer als erwartet entwickelt habe. Zudem habe Ungarn von den Beschlüssen der Bundesregierung vom 6. Mai 1966 über eine Liberalisierung des Osthandels weniger profitiert als andere Ostblock-Staaten. Besonders bedauert er die Beeinträchtigungen der ungarischen Ausfuhren durch die EWG-Marktordnungen, vor allem diejenige für 
Rindfleisch. Lahr macht darauf aufmerksam, daß Zollvergünstigungen, die die Bundesrepublik westlichen Handelspartnern gewähre, Resultat eines langen Prozesses seien. Er drückt die Hoffnung aus, daß sich eine Aufnahme diplomatischer Beziehungen mit Ungarn positiv auf den Handel auswirken werde.

Ruete legt dar, daß die französische Regierung beabsichtige, ihre in der Bundesrepublik stationierten Luftstreitkräfte nach Frankreich zurückzuverlegen. Davon seien u. a. die Flugplätze in Lahr und Bremgarten betroffen. Bereits am 12. Oktober 1966 habe die Bundesregierung die Übernahme dieser Einrichtungen der kanadischen Luftwaffe angeboten, die sich ihrerseits von ihren in Frankreich gelegenen Stützpunkten zurückziehen müsse. Die kanadische Seite habe nun Informationen zum Stand der Gespräche mit Frankreich über die Übernahme der Flugplätze weitergegeben. Danach werde Bremgarten bis zum 1. Juni 1967 geräumt sein, Lahr jedoch erst bis zum 1. Januar 1968. Bis dahin sollen die Anlagen in Lahr gemeinsam genutzt werden, da die französische Regierung Wert darauf lege, daß alle kanadischen Einheiten bis zum 1. April 1967 Frankreich verlassen haben. britischen Botschafter Roberts

Roberts teilt mit, daß die Erläuterungen des Staatssekretärs Schütz am 23./24. Januar 1967 in London zu den finanziellen Schwierigkeiten der Bundesregierung, einen Ausgleich für die Kosten der Stationierung britischer Truppen in der Bundesrepublik zu leisten, große Bestürzung ausgelöst hätten. Er habe Weisung, die Bundesregierung unmißverständlich auf den Ernst der Lage hinzuweisen. Brandt macht seinerseits darauf aufmerksam, daß das Bundeskabinett noch keinen Beschlu $\beta$ zum Devisenausgleich gefaßt habe. Roberts verweist darauf, daß bei einem ungünstigen Entscheid die britische Regierung keine Wahl habe, als eine beträchtliche Verminderung ihrer Streitkräfte in Deutschland vorzunehmen. Er bittet daher darum, die Entscheidung des Bundeskabinetts solange zu verschieben, bis die Leiter der deutschen, amerikanischen und britischen Delegationen bei den Devisenausgleichsverhandlungen, Duckwitz, McCloy und Thomson, zu einem Gespräch zusammengekommen seien. Washington

Ruete bittet um Mitteilung an das amerikanische Außenministerium, daß die Bundesregierung größtes Verständnis habe für die inoffiziellen Bemühungen, die Freilassung von vier in der DDR inhaftierten amerikanischen Staatsbürgern zu erreichen. Gleichwohl halte sie es für bedenklich, zu diesem Zweck Konzessionen an die „Aufwertungspolitik Pankows" zu ma- 
chen, weil es sich um eine "unverhüllte politische Erpressung“ handele. So bedeuteten beispielsweise Erleichterungen bei der Gewährung von TTDs (Temporary Travel Documents) einen schwer zu revidierenden Fehler, da die DDR bei nächster Gelegenheit erhöhte Forderungen präsentieren werde. Die USA sollten deshalb gebeten werden zu prüfen, ob die Freilassung der Häftlinge auf der Basis finanzieller und wirtschaftlicher Angebote zu erreichen sei.

Bahr notiert aus einem Gespräch mit dem Attaché an der amerikanischen Botschaft in Bonn, Cline, daß sich die amerikanische Regierung beim bevorstehenden Besuch des Bundesministers Brandt in Washington damit zufrieden geben werde, wenn ihr die Erfüllung des laufenden Abkommens über den Devisenausgleich zugesichert werde. Es werde nicht erwartet, daß Brandt sich hinsichtlich zukünftiger Zahlungen festlege oder daß die Bundesrepublik "Waffen oder Material" kauft, das „sie nicht braucht oder will“. Cline habe ohnehin die Probleme der Zahlungsbilanz als zweitrangig gegenüber den Fragen der Sicherheit und der fehlenden „Definition der deutschen Interessen" bezeichnet. Darüber hinaus habe er zugesichert, daß die amerikanische Regierung noch keine Beschlüsse über einen Abzug oder eine Verringerung amerikanischer Streitkräfte in der Bundesrepublik gefaßt habe. Bahr äußert die Ansicht, daß die USA mit der Politik der Nichtverbreitung die Hoffnung verbänden, nukleare Sicherheit durch eine bilaterale Garantie zu erreichen. Dies sei leichter als die „Abrüstung von Blöcken“. Lindenberg

Angesichts der unterschiedlichen deutschen und französischen Ansichten über den Zeitpunkt der Verabschiedung des Vertrags über die Fusion der europäischen Exekutiven und damit über die Dauer der verbleibenden Amtszeit des Präsidenten Hallstein macht Meyer-Lindenberg darauf aufmerksam, daß die Zeit gekommen sei, zu einigen personalpolitischen Fragen Stellung zu beziehen. So sollte sich die Bundesregierung darüber klarwerden, ob sie den möglicherweise von Frankreich und Italien als Nachfolger von Hallstein favorisierten italienischen Vertreter in der EWG-Kommission, Colonna, akzeptieren wolle. Darüber hinaus müsse ein Entschluß gefaßt werden, wer die drei Kandidaten der Bundesregierung für die neue EWGKommission sein sollen und wer ab 1. Januar 1968 als Vizepräsident der Kommission der Europäischen Gemeinschaften in Frage komme, falls Hallstein auf dieses ihm zustehende Amt verzichten werde. Schließlich sei zu überlegen, ob es überhaupt für Hallstein ratsam sei, ein mögliches Angebot zur Leitung der Verhandlungen für die Fusion der Europäischen Gemeinschaften zu übernehmen. 
Ruete legt dar, daß das von der amerikanischen Regierung vorgeschlagene Nichtverbreitungsabkommen seitens der Bundesrepublik Zugeständnisse verlange, ohne Gegenleistungen zu bieten. Es sei daher zu überlegen, ob diese Konzessionen nicht zum Gegenstand eines direkten Gesprächs mit der UdSSR gemacht werden könnten. In einem solchen Gedankenaustausch könnte die Bundesregierung den sowjetischen Gesprächspartnern zudem anbieten, in gewissem Umfang einem Abzug von Truppen der westlichen Verbündeten zuzustimmen. Auch das Thema Gewaltverzicht könnte einbezogen werden. Darüber hinaus bestünde die Gelegenheit, hinsichtlich der Einbeziehung von Berlin (West) in Abkommen mit Ostblock-Staaten die sich bislang bei der Verfolgung einer aktiven Ostpolitik als hinderlich erwiesen habe - zu einer Absprache zu kommen. Hier sei zu prüfen, ob nicht die Idee einer international garantierten „Freistadt Berlin“, die in einem besonderen Verhältnis zur Bundesrepublik stehe und durch diese außenpolitisch vertreten werde, zur Diskussion gestellt werden könne. Es sei dabei allerdings unerläßlich, sehr geheim und taktisch sehr vorsichtig vorzugehen, um nicht in der Berlin-Frage wichtige Positionen aufzugeben. Amt

Groll berichtet von einem Gespräch mit dem bulgarischen Stellvertretenden Außenhandelsminister. Penkov teilte mit, Außenhandelsminister Budinov werde die Bundesrepublik besuchen, wenn die Bundesregierung Bulgarien durch eine große Geste helfe, die für 1967 zu erwartende Zahlungsbilanzschwierigkeiten zu überwinden. Penkov verwies auf die Deckungslükke von 180 Mio. DM im Handel mit der Bundesrepublik, die durch Maßnahmen der EWG verursacht worden seien. Bulgarien sehe als geeignete Hilfen ein Moratorium in Höhe der Deckungslücke für 1967 und eine befristete Aussetzung der Abschöpfungen für bestimmte Agrarprodukte an. Groll vertritt die Ansicht, daß einer Entscheidung der Bundesregierung für diese Hilfeleistung als logische Konsequenz die Aufnahme diplomatischer Beziehungen folgen würde. Ein Scheitern des Besuchs von Budinov würde dagegen einen Erfolg für die DDR darstellen, die mit propagandistischen Mitteln versuche, eine Annäherung zwischen der Bundesrepublik und Bulgarien zu verhindern. tunesischen Wirtschaftsminister Ben Salah

Ben Salah teilt mit, die tunesische Regierung wäre sehr glücklich, wenn die Bundesrepublik möglichst bald wieder die diplomatischen Beziehungen aufnehmen würde, die im Mai 1965 von einer Reihe arabischer Staaten abgebrochen wurden. Sie habe jedoch kein Verständnis dafür, daß dabei eventuell der Arabischen Liga eine vermittelnde Rolle zugedacht werde, ei- 
ner Organisation, die sich nach tunesischer Ansicht als „Element der Störung“ erwiesen habe. Auf wirtschaftlichem Gebiet sollte die Bundesregierung den tunesischen Antrag auf Assoziierung mit der EWG unterstützen, denn hier fühle sich Tunesien im Vergleich zu den Mitkandidaten Algerien und Marokko diskriminiert. Mit Blick auf die tunesische Position in der Nahost-Krise von 1965 sichert Brandt Ben Salah zu, daß die Bundesregierung diejenigen Staaten nicht vergessen werde, „die Deutschland treu geblieben seien". Hinsichtlich wirtschaftlicher Hilfe verweist er auf die schlechte Lage des Bundeshaushalts für 1967; dies bedeute aber nicht, daß bestehende Verpflichtungen nicht eingehalten würden. Lindenberg

Meyer-Lindenberg macht darauf aufmerksam, daß das Abkommen vom 19. Dezember 1966 über die friedliche Erforschung und Nutzung des Weltraums, das eine offene Beitrittsklausel enthält und nun bei den drei Depositarmächten zur Unterschrift aufliegt, mit hoher Wahrscheinlichkeit von der DDR in Moskau unterzeichnet werde. Er rät davon ab, so vorzugehen wie im Falle des Teststopp-Abkommens von 1963, das ebenfalls von der DDR unterzeichnet wurde, und alle in Betracht kommenden Staaten aufzufordern, die Notifizierung über den Beitritt der DDR zurückzuweisen oder unbeantwortet zu lassen. Mittlerweile gebe es nämlich keine Sicherheit mehr, daß eine vergleichbare Anzahl von Staaten wie 1963 dem Wunsch der Bundesregierung entspräche; jede Abweichung aber würde vom Ostblock propagandistisch ausgenutzt werden. Daher sollten „ausdrückliche Zurückweisungserklärungen unter Hinweis auf die fehlende Staatlichkeit der SBZ" nur von der Bundesregierung selbst und den drei Westmächten abgegeben werden; alle anderen Staaten würden lediglich darum ersucht werden, die Unterrichtung über die Zeichnung durch die DDR nicht zu bestätigen.

Schnippenkötter analysiert, inwieweit der von amerikanischer Seite vorgelegte Entwurf eines Nichtverbreitungsabkommens den Vorstellungen der Bundesregierung entspricht. Er kommt zu dem Schluß, daß einigen Wünschen bereits dadurch nachgekommen werden könnte, indem eine großzügige Textinterpretation von amerikanischer bzw. von amerikanischer und sowjetischer Seite verbindlich zugesichert werde. Dies betreffe vor allem den Fortbestand der NATO-internen Konsultationen im Kernwaffenbereich, die Zusammenarbeit der Bundesrepublik mit den USA - aber auch mit anderen Staaten - bei der zivilen Nutzung der Kernenergie sowie eine künftige Einigung Europas auf dem Gebiet der atomaren Bewaffnung. Darüber hinaus strebe die Bundesregierung aber auch Textänderungen an. Dabei handele es sich vor allem um eine Berücksichtigung 
der besonderen Lage „ziviler Atommächte“, die durch die vorgesehene Einbeziehung nuklearer Sprengvorrichtungen für friedliche Zwecke in die Verbotsliste erschwert werde.

Haas faßt die Gespräche des Bundesministers Brandt mit dem rumänischen Außenminister am 30./31. Januar 1967 über die Aufnahme von diplomatischen Beziehungen zusammen. Es sei Einverständnis darüber erzielt worden, daß die wirtschaftlichen Befugnisse der Handelsvertretungen im bisherigen Umfang auf die künftigen Botschaften übertragen werden sollten. Zudem werde die rumänische Regierung die Wahrung der Interessen von Berlin (West) aus humanitären Gründen durch die Botschaft der Bundesrepublik in Bukarest dulden. Auch in der Frage der Familienzusammenführung sei eine wohlwollende Prüfung zugesagt worden. Angesichts der passiven rumänischen Handelsbilanz mit der Bundesrepublik habe Manescu seiner Hoffnung auf weitere Steigerung und auf Ausgleich des Warenverkehrs Ausdruck gegeben. Ein Kulturabkommen zwischen der Bundesrepublik und Rumänien sei nun ebenfalls anzustreben.

Diehl resümiert Eindrücke aus Gesprächen mit führenden amerikanischen Persönlichkeiten anläßlich von Besprechungen der Planungsstäbe in Washington. Er habe betont, daß ein Nichtverbreitungsabkommen die wesentlichen Interessen der nichtnuklearen Staaten zu berücksichtigen habe. Der Vertragstext weise eine Reihe von Mängeln auf. $\mathrm{Zu}$ seiner Überraschung hätten die Gesprächspartner der Auffassung zugestimmt, daß der Aufbau eines Raketenabwehrsystems durch die UdSSR und die USA Europa "nackt in der Kälte" lasse und einen Rücktrittsgrund im Sinne des Vertragstextes darstelle. In den USA habe die Ostpolitik der Bundesregierung einen starken Eindruck hinterlassen, aber es bestehe nach wie vor Erklärungsbedarf. Zur weiteren Behandlung des Vietnam-Krieges habe Vizepräsident Humphrey erklärt, daß zuviel geredet werde und nun die Arbeit auf "germanische Weise“ zu erledigen sei. Der amerikanische Wunsch, die Bundesrepublik stärker in Vietnam zu engagieren, sei noch immer vorhanden.

Klaiber berichtet über die Gespräche des polnischen Außenministers in Frankreich. Rapacki sehe aufgrund der Ostpolitik der Bundesrepublik Polen in einer fortschreitenden Isolierung. Seine französischen Gesprächspartner hätten demgegenüber den Standpunkt vertreten, daß die Bundesregierung den Grundsatz der Entspannung akzeptiert habe und allmählich aus der Reserve herauskomme. Zwar stimme die französische Regierung der polnischen Auffassung nach einem Verzicht der Bundesrepublik auf Zugang zu Atomwaffen und nach Anerkennung der Oder-Neiße-Linie zu. Auf kein Verständnis stoße jedoch die 
polnische Position gegenüber der DDR. Wenn Polen die Entspannung wolle, werde es die Wiedervereinigung eines Tages hinnehmen müssen.

Amt

Grewe informiert über die Sitzung des Ständigen NATO-Rats, auf welcher der amerikanische Botschafter den aus Gesprächen mit der UdSSR resultierenden Entwurf für ein Nichtverbreitungsabkommen vorlegte. Cleveland führte dazu aus, daß es sich nicht um einen abschließend formulierten Text handele. Während sich der belgische, britische, dänische und norwegische Vertreter für eine vorbehaltlose Zustimmung aussprachen, wurden die gravierendsten Bedenken von italienischer, griechischer und türkischer Seite geäußert. Der griechische Botschafter Palamas stellte das westliche Interesse an einem solchen Abkommen grundsätzlich in Frage. Der französische Botschafter de Leusse erklärte, seine Regierung beabsichtige nicht, das Abkommen zu unterzeichnen. Grewe teilt abschließend mit, daß die Diskussion keineswegs als Zustimmung des NATO-Rats zu dem vorgelegten Entwurf oder als ein ausdrückliches Mandat zur Vorlage dieses Textes bei der Konferenz der 18-Mächte-Abrüstungskommission in Genf gewertet werden könne.

Brandt bittet darum, im amerikanischen Außenministerium darauf aufmerksam zu machen, daß ein Nichtverbreitungsabkommen ohne gleichwertige Anerkennung der EURATOMKontrollen der europäischen Zusammenarbeit auf dem Gebiet der friedlichen Nutzung der Kernenergie wesentliche Grundlagen entziehen würde. Da Frankreich eine gemeinschaftsfremde Kontrolle durch die IAEO ablehne, würde EURATOM in eine lose Forschungsorganisation verwandelt. Zwar erkenne die Bundesrepublik die Notwendigkeit einer Zusammenarbeit zwischen EURATOM und IAEO an. Es dürfe jedoch nicht ein anerkannt wirksames regionales Kontrollsystem durch ein möglicherweise diskriminierendes ersetzt werden. Ferner würden auch bilaterale Abmachungen zwischen EURATOM und den USA gefährdet.

Walther informiert über ein Gespräch mit dem sowjetischen Stellvertretenden Außenminister. Semjonow sprach in $\mathrm{Zu}-$ sammenhang mit dem Alleinvertretungsanspruch, der von der Bundesrepublik bei der Aufnahme diplomatischer Beziehungen mit Rumänien abermals unterstrichen worden sei, von Revanchismus. Bezüglich des Ostteils von Berlin erklärte er, daß dort die „volle Souveränität" der DDR gegeben sei, und vertrat die These des selbständigen Territoriums von Berlin (West) und der beiden deutschen Staaten. Daraufhin betonte Walther die moralischen Ansprüche auf „die alte Hauptstadt des Reiches“. 
Semjonow erwiderte, daß es einen Unterschied zwischen historisch begründeten Ansprüchen und den Realitäten gebe. Im folgenden erklärte er, daß die Politik der Bundesregierung darauf abgestimmt sei, in der Bevölkerung Revanchegefühle zu erzeugen, und führte das Erstarken der NPD dafür als Symptom an.

Amt

Hoffmann informiert über den Versuch der amerikanischen Botschaft, den von Phnom Penh vorübergehend nach Saigon abgeordneten Legationsrat Joetze für Vermittlungstätigkeiten im Vietnam-Krieg zu gewinnen. Auf den amerikanischen Wunsch, einen Kontakt zu Vertretern der „Front National de Libération du Viêt-nam Sud“ in Phnom Penh herzustellen, sei Joetze nicht eingegangen; er werde auch zukünftig ausweichend reagieren.

Schütz berichtet über ein Gespräch mit dem sowjetischen Botschafter. Zarapkin forderte eine realistische Politik in Form der Anerkennung der DDR als Voraussetzung für gute Beziehungen zur UdSSR. Demgegenüber schlug der Staatssekretär vor, Fragen zu behandeln, die den beiderseitigen Rechtsstandpunkt unberührt ließen, und übergab in diesem Zusammenhang den Entwurf für Gewaltverzichtserklärungen. Darin hieß es, daß die Bundesregierung bei der Verfolgung ihrer deutschlandpolitischen Ziele auf die Anwendung von Gewalt oder die Drohung mit Gewalt verzichte. Zarapkin erklärte, daß die mögliche Annahme dieser Formulierung nicht bedeute, daß die sowjetische Regierung damit die Deutschlandpolitik der Bundesregierung akzeptiere. Über den Entwurfstext zeigte sich Schütz verhandlungsbereit, falls die UdSSR in verbindliche Gespräche eintrete. sowjetischen Botschafter Zarapkin

Kiesinger erklärt, daß er die von den früheren Bundesregierungen vertretene Formel „keine Entspannung ohne Wiedervereinigung" nicht länger aufrechterhalte. Angesichts der politischen, gesellschaftlichen und wirtschaftlichen Unterschiede in beiden Teilen Deutschlands erläutert der sowjetische Botschafter, daß nicht „Feuer mit Wasser“ vereint werden könne. Der Bundeskanzler weist dies mit dem Hinweis zurück, daß er nicht an ein anderes gesellschaftliches Bewußtsein der Bevölkerung „drüben“ glaube. Zudem bestehe bei einer zukünftigen Wiedervereinigung nicht die Absicht, das vorhandene Sozialund Wirtschaftssystem einfach auf die DDR zu übertragen, da Fakten geschaffen worden seien, die nicht einfach beseitigt werden könnten. Zarapkin beurteilt den Alleinvertretungsanspruch der Bundesrepublik als wesentliches Hindernis einer Annäherung und regt die Aufnahme normaler Beziehungen an. Daraufhin formuliert Kiesinger ein Gedankenspiel, wonach die 
Bundesrepublik unter Wahrung ihres Rechtsstandpunktes Beziehungen mit der im anderen Teil Deutschlands vorhandenen „politischen Organisation“ unterhalten könne, ohne diese im Rechtssinn als souveränen Staat anzuerkennen. Demgegenüber hebt Zarapkin hervor, daß die DDR alle Attribute eines souveränen Staates besitze. Staatssekretär Schütz

Brandt faßt seine Gespräche im amerikanischen Außenministerium zusammen. Er wies darauf hin, daß das Nichtverbreitungsabkommen mit Fortschritten in allgemeinen Abrüstungsfragen zu verknüpfen sei und kein Hindernis für die europäische Einigung darstellen dürfe. Der Leiter der amerikanischen Abrüstungsbehörde, Foster, erklärte die Bereitschaft der USA, in einer Note gegenüber der Bundesrepublik zur Auslegung des Abkommens Stellung zu nehmen. Der amerikanische Außenminister Rusk bezeichnete die Kontrollfrage als ernstes Problem und machte deutlich, daß EURATOM-Kontrollen nicht abgeschafft, sondern durch IAEO-Kontrollen ergänzt werden sollten. Der Bundesminister betonte die Konsequenzen einer diskriminierenden Kontrollklausel für Forschung und Industrie in der Bundesrepublik. Zur Lage innerhalb der NATO und deren integrierten Struktur kritisierte Rusk gewisse Erosionserscheinungen in Großbritannien, Belgien und Luxemburg, die Rückwirkungen in den USA haben könnten. Brandt bat darum, nicht aus emotionalen Gründen oder ausschließlich aus Zahlungsbilanzgründen zu handeln. Auswärtige Amt

Brandt informiert über ein Gespräch mit dem amerikanischen Verteidigungsminister McNamara. Der Bundesminister betonte die grundsätzliche Bereitschaft zur Mitarbeit an einem Nichtverbreitungsabkommen mit dem Ziel, einen Schutz vor nuklearer Bedrohung und Erpressung sowie eine Garantie gegen eine erneute Eskalation der Nuklearrüstung zu erhalten. Die nichtnuklearen Staaten sollten dadurch jedoch keinen Einschränkungen in der zivilen nuklearen Forschung unterliegen. McNamara wies die Ansicht zurück, daß den nuklearen Mächten aus der Entwicklung und Produktion von Atomwaffen groBe industrielle Vorteile erwüchsen. Die USA seien zudem weiterhin bereit, Erkenntnisse der militärischen Forschung, die im zivilen Bereich anwendbar seien, allen Staaten zur Verfügung zu stellen. Auswärtige Amt

Groll berichtet über ein Gespräch mit dem Abteilungsleiter im bulgarischen Außenhandelsministerium. Stefanow habe das Verhalten der Bundesregierung bei der offiziellen Bekanntgabe 
der Aufnahme der diplomatischen Beziehungen mit Rumänien unter anderem wegen des Theaterdonners in der Presse kritisiert. Seit der Außenministerkonferenz des Warschauer Pakts vom 8. bis 10. Februar 1967 sei nunmehr der bulgarische Bewegungsspielraum bedauerlicherweise eingeengt worden. Im Falle Bulgariens wünsche er sich die Übergabe von Noten in aller Stille. Wegen des bulgarischen Handelsbilanzdefizits sei das Verhältnis beider Staaten zudem weniger durch politische als durch wirtschaftliche Schwierigkeiten belastet. Daher habe Stefanow um die Gewährung eines zinslosen Kredits gebeten.

Schütz stellt Erwägungen zur Wiederaufnahme diplomatischer Beziehungen mit Jugoslawien an. Der Staatssekretär kennzeichnet das weitere Vorgehen der Bundesrepublik als nicht ohne Risiko. Zum einen bestehe keine Möglichkeit, Jugoslawien wirtschaftliche oder finanzielle Leistungen als Ersatz für diplomatische Beziehungen anzubieten, und zum anderen könnten einige Staaten der Dritten Welt zu „falschen Schlußfolgerungen in ihrem Verhalten gegenüber Ostberlin“ kommen. Zunächst müsse die Aufnahme von Beziehungen mit mindestens zwei weiteren osteuropäischen Staaten ohne Schaden in der Dritten Welt erfolgen.

Duckwitz legt den Stand der Dreier-Verhandlungen mit den USA und Großbritannien bezüglich des Devisenausgleichs dar. Die USA seien an einer Fortsetzung der Verhandlungen mit dem Ziel interessiert, die künftige Stärke der amerikanischen und britischen Streitkräfte in der Bundesrepublik festzulegen. Sollte es jedoch zu einer Reduzierung der britischen Streitkräfte kommen, werde der dann zu erwartende innenpolitische Druck in den USA möglicherweise auch zur Verminderung der amerikanischen Streitkräfte in Europa führen. Duckwitz erläutert, daß der Devisenausgleich mit Großbritannien angesichts der britischen Zahlungsbilanz der Schlüssel zur Lösung des Problems sei. Falls die Bundesrepublik nicht zum Ausgleich der Devisenkosten bereit sei, werde der britischen Regierung keine andere Wahl bleiben, als die Streitkräfte zu vermindern oder vollständig abzuziehen.

Lahr nimmt zu der von Israel geforderten Gewährung von Rentenleistungen an gesundheitsgeschädigte NS-Opfer Stellung. Bereits in der Sitzung des Bundeskabinetts vom 4. Mai 1966 habe er deutlich gemacht, daß die israelischen Anliegen völlig unbegründet seien. Das Bundeskabinett sei jedoch nicht bereit gewesen, sich dem Begehren grundsätzlich zu verschließen. Dies habe er dem israelischen Botschafter Ben Natan mitgeteilt. In der nächsten Sitzung des Bundeskabinetts vom 11. Mai 1966 habe Bundeskanzler Erhard überraschend erklärt, daß er immer für die Ablehnung der israelischen Forderung gewesen 
sei. Der Staatssekretär bekräftigt den damals eingenommenen Standpunkt und regt an, in zukünftigen Gesprächen mit israelischen Vertretern auf die Haushaltslage zu verweisen.

Ruete erörtert die Möglichkeiten einer Fühlungnahme mit Frankreich über den Beitritt der Bundesrepublik zu einem Nichtverbreitungsabkommen. Da Frankreich ein solches Abkommen nicht unterschreiben werde, gelte es, auf diese Weise nachteilige Auswirkungen im Hinblick auf die deutsch-französische Zusammenarbeit in der Europa- und Ostpolitik zu vermeiden. Dazu solle der Botschafter in Paris mit Sondierungen beim französischen Außenminister Couve de Murville beauftragt werden. Klaiber habe festzustellen, wie sich unterschiedliche Optionen der Bundesrepublik hinsichtlich eines Nichtverbreitungsabkommens auf die deutsch-französischen Beziehungen auswirken könnten. Premierminister Wilson

Wilson bekräftigt den Wunsch nach Aufnahme Großbritanniens in die EWG. Eine Erweiterung der Gemeinschaft sei wirtschaftlich und politisch eine „Quelle großer Stärke“. Kiesinger antwortet, daß er den Beitritt ebenfalls wünsche, und verweist auf die Absicht, die EWG zu einer vollen Wirtschaftsgemeinschaft auszubauen. Er betont, daß Staatspräsident de Gaulle in dieser Frage nicht durch Druck, sondern nur durch Argumente zu überzeugen sei. Wilson erwidert, daß Großbritannien nichts verlangen werde, was die Weiterentwicklung des deutschfranzösischen Vertrags von 1963 belasten könnte. Im folgenden regt er an, möglichst bald mit den Beitrittsverhandlungen zu beginnen, da ansonsten die in Großbritannien vorhandene positive Strömung nicht andauern werde.

Lahr spricht sich gegen die Wiederaufnahme von diplomatischen Beziehungen mit Jugoslawien aus. In der Dritten Welt werde verstanden, daß sich die Ostblock-Staaten hinsichtlich der Aufnahme diplomatischer Beziehungen mit der Bundesrepublik in einer "grundsätzlich anderen Lage gegenüber Pankow" befänden als sie selbst. Der Staatssekretär erklärt, daß jede abschreckende Wirkung der Hallstein-Doktrin verlorenginge, wenn die Bundesrepublik ausgerechnet mit Jugoslawien diplomatische Beziehungen aufnehme, das 1957 den „Sündenfall" begangen hat. Lahr empfiehlt, sich bei einem Botschafteraustausch zunächst auf Bulgarien, Ungarn, die Tschechoslowakei und Polen zu konzentrieren und den Zusammenbruch des Alleinvertretungsanspruchs nicht zu beschleunigen. 

Premierminister Wilson

Wilson betont, daß der Abschluß eines Nichtverbreitungsabkommens für Großbritannien von besonderer Bedeutung sei. Der Bundeskanzler führt daraufhin aus, daß sich das Gefühl in der Bundesrepublik, „degradiert und endgültig zu einer Nation zehnter Klasse gestempelt" worden zu sein, nicht ausschließlich auf ein Nichtvereitungsabkommen an sich beziehe, sondern auch auf die Art und Weise, wie dieses vorbereitet und wie das Problem an die Bundesregierung herangetragen worden sei. Der britische Premierminister bezeichnet es als unglücklich, wenn den nichtnuklearen Staaten Nachteile im Bereich der zivilen Atomforschungen entstünden. Im folgenden erklärt Kiesinger, daß er sich als ehrlicher Makler für einen Beitritt Großbritanniens zur EWG bei der französischen Regierung einsetzen werde. Diese Zusicherung bezeichnet Wilson als das wichtigste Ergebnis der Gespräche. Er erklärt, daß die allgemeine Stimmung in Großbritannien zugunsten eines Beitritts auszunutzen sei. Falls keine Lösung in der Frage des Devisenausgleichs für die in der Bundesrepublik stationierten britischen Streitkräfte gefunden werde, kündigt Wilson ernsthafte Schritte an, die mit der ${ }_{n}$ Gelassenheit eines chirurgischen Eingriffs“ vorgenommen würden. London und Paris

Thierfelder erläutert die angestrebte Änderung des Verfahrens der Einbeziehung von Berlin (West) in die völkerrechtlichen Verträge der Bundesrepublik. Das von den Drei Mächten vorgeschlagene Ausnahmeverfahren in bezug auf die osteuropäischen Staaten, das eine Äußerung der Bundesrepublik hinsichtlich der stillschweigenden Verständigung über die Einbeziehung von Berlin (West) vorsehe, sei wenig befriedigend. Eine unterschiedliche Behandlung der Staaten Osteuropas gegenüber den restlichen Staaten sei nicht praktikabel. Der Ministerialdirektor regt daher eine automatische Einbeziehung von Berlin (West) in alle völkerrechtlichen Verträge der Bundesrepublik an, ohne das Recht auf Zustimmung der Alliierten Kommandatura einschränken zu wollen. Auswärtige Amt

Kempff berichtet über den vielbeachteten Besuch des Bundesministers für gesamtdeutsche Fragen in Finnland. Wehner habe in einem Gespräch mit Präsident Kekkonen auf die Frage, ob die Bundesregierung mit der neuen Ostpolitik einen Keil zwischen die Ostblock-Staaten treiben wolle, erklärt, daß dies angesichts der Größenordnung „selbstmörderisch“ wäre. Ziel der Politik der Bundesregierung sei vielmehr, die Beziehungen zu allen Staaten Osteuropas zu verbessern. Kekkonen habe daraufhin bezweifelt, daß die Bundesregierung bei Fortsetzung ihrer Ostpolitik die Hallstein-Doktrin aufrechterhalten könne. 
In anschließenden Interviews sei Wehner den Mutmaßungen entgegengetreten, als Feuerwehr gekommen zu sein, um der finnischen Regierung eine Anerkennung der DDR auszureden.

Sahm resümiert den Stand der Arbeiten der Studiengruppe zur Untersuchung der zukünftigen Aufgaben der Allianz (HarmelStudie). Die USA und Großbritannien hätten am 15. Februar 1967 eine Verbesserung der Konsultationen innerhalb des Bündnisses sowie eine beiderseitige Truppenreduzierung in NATO und Warschauer Pakt vorgeschlagen. NATO-Generalsekretär Brosio und der belgische Außenminister Harmel hätten eine umfassende Bestandsaufnahme der Allianz angeregt. Der Entwurf einer von den Teilnehmern gebilligten Resolution lasse Raum für die Behandlung fast aller vorgeschlagenen Themen. Sahm regt an, daß Bundesminister Brandt gegenüber Harmel das besondere Interesse der Bundesrepublik an der künftigen Arbeit der Studiengruppe bekunden solle.

Schnippenkötter berichtet über die Beratungen des interministeriellen Arbeitsstabes zur Frage eines Nichtverbreitungsabkommens. Zusammenfassend empfiehlt er, auf einen Wegfall des Kontrollartikels hinzuwirken. Ansonsten solle dieser mit Blick auf die Exportfähigkeit der Bundesrepublik zumindest weltweit akzeptabel gemacht werden. Ein „perfektionistisch. dogmatisches" Kontrollverfahren in Form einer Überwachung durch Inspektoren sei zu vermeiden. Vielmehr müsse ein "evolutionär-pragmatisches" Vorgehen durch technische Überwachungsmaßnahmen gefunden werden. Von den USA sei ferner eine vertragliche Zusicherung über die ausreichende Lieferung von Kernbrennstoffen zu erwirken. Außerdem sei die Bundesrepublik an den für friedliche Zwecke zu nutzenden Erkenntnissen militärischer Forschung zu beteiligen. belgischen Außenminister Harmel

Kiesinger und Harmel erörtern den Ablauf der beabsichtigten Gipfelkonferenz der Staats- und Regierungschefs der EWGMitgliedstaaten anläßlich des zehnten Jahrestages der Unterzeichnung der Römischen Verträge. Harmel unterbreitet den Vorschlag, die Außenminister zu beauftragen, mit den Kollegen der NATO-Mitgliedstaaten, die - etwa wie Großbritannien nicht der EWG angehörten, in Rom bestimmte Fragen gemeinsam zu beraten. Ziel dieser Aussprache müsse es sein, daß alle Teilnehmer sich verpflichten, keine Entscheidungen ohne vorherige Konsultationen zu treffen. Die Fortentwicklung der Koordination der Außenpolitik könne im Mittelpunkt stehen. Der belgische Außenminister betont, daß er derartige Aussprachen für den Beginn einer weitergehenden politischen Zusammenarbeit in Europa erachte. Der Bundeskanzler erklärt die Bereitschaft der Bundesregierung, diesen Vorschlag mit der fran- 
zösischen Regierung zu erörtern. Eine Art „europäisches Honoratiorentreffen" lehnt Kiesinger ab, und er äußert sich zurückhaltend über eine Beteiligung von Staaten, die der EWG nicht angehören. Harmel entgegnet darauf, daß das zukünftige Europa nicht ohne Großbritannien geschaffen werden könne, sondern auf einem "dreifüßigen Stativ“ aus Frankreich, Großbritannien und der Bundesrepublik stehen müsse.

21.02. Aufzeichnung des Ministerialdirektors MeyerLindenberg

Meyer-Lindenberg nimmt Stellung zur geplanten Wiederaufnahme der diplomatischen Beziehungen mit Jordanien. Die jordanische Regierung habe ihre sofortige Bereitschaft erklärt und gebeten, den genauen Zeitpunkt festzulegen. Von der Bundesregierung sei als Termin der 24. oder 27. Februar 1967 vorgeschlagen worden. Der Ministerialdirektor regt an, Jordanien über eine in Aussicht genommene Hilfe für Palästina-Flüchtlinge zu informieren. Die Bekanntgabe dieser Maßnahme solle dazu beitragen, daß andere arabische Staaten eher geneigt sein werden, dem Beispiel Jordaniens zu folgen.

\subsection{Botschafter Klaiber, Paris, an das Auswärtige Amt}

Klaiber berichtet über den Besuch des ehemaligen Bundeskanzlers Adenauer beim französischen Staatspräsidenten am Vortag. Adenauer habe erklärt, daß die UdSSR mittels eines Nichtverbreitungsabkommens die europäische und insbesondere die Industrie in der Bundesrepublik entmachten wolle. Arbeitslosigkeit und soziale Unruhen seien die möglichen Folgen, die schließlich zur „Unterwerfung Deutschlands unter den sowjetischen Willen" genutzt würden. De Gaulle habe erwidert, daß ein Nichtverbreitungsabkommen in der aktuellen Form eine „Zementierung der Vormachtstellung der beiden Atomgiganten in der Welt“ bedeute.

\section{22.02. Vermerk des Referenten Bahr}

Bahr erörtert die Deutschlandpolitik der Bundesregierung. Die DDR sei versucht, die Gefahr der Isolierung, die durch die veränderte Haltung der Bundesregierung gegenüber den osteuropäischen Staaten ausgelöst worden sei, durch eine „übersteigerte Form des Separatismus" zu überspielen. Die DDR habe daher einen Wettlauf mit der Bundesrepublik angetreten, bei dem es um die gegenseitige Blockierung gehe. Folglich sei es entscheidend, mit der UdSSR in ein Gespräch zu kommen, um so die Position der Bundesrepublik in Osteuropa zu erweitern. Um gleichzeitig Einfluß auf die Politik der DDR zu nehmen, regt er intensive diplomatische Aktionen an.

Sahm wendet sich dagegen, auf das Zeigen von Emblemen und Flaggen der DDR bei internationalen Sportveranstaltungen lediglich mit einer Generalerklärung zu antworten. Solange ei- 
ne offensive Deutschlandpolitik nur verkündet, aber noch nicht ausgeführt werde, sei eine solche Erklärung geeignet, Fachverbände und Regierungen zu veranlassen, die darin „neu formulierte Minimal-Position“ zu beziehen. Außerdem weist er darauf hin, daß sich eine derartige Erklärung nicht auf das Gebiet des Sports eingrenzen lasse, sondern auch Auswirkungen auf Messen, Ausstellungen und nichtstaatliche Organisationen haben werde. Damit würde einer „Status-Verbesserung der Zone Tür und Tor" geöffnet und der Eindruck erweckt, als ob das Steuer der Deutschlandpolitik abrupt herumgeworfen werde. Er regt daher an, von der Abgabe einer Generalerklärung zunächst abzusehen. Auswärtige Amt

Mirbach gibt ein Gespräch mit dem Staatssekretär im indischen Außenministerium wieder. Jha wies darauf hin, daß sich nach Informationen der indischen Botschaft in Teheran die von der Bundesrepublik an den Iran gelieferten 88 Kampfflugzeuge zur „immerwährenden Überholung“ in Pakistan befänden. Dies widerspreche den seit Beginn des indisch-pakistanischen Konflikts abgegebenen Erklärungen der Bundesregierung, keine Waffen an die beteiligten Staaten zu liefern. Der Botschafter bestätigte diese Position.

Bundesminister Brandt regt an, die Interpretation des Alleinvertretungsanspruchs zu überdenken. Inzwischen habe sich bei der Bevölkerung im anderen Teil Deutschlands ein höherer Grad von Identifizierung mit dem Regime entwickelt, die sich nicht auf die Führung der SED, sondern auf die quasistaatliche Ordnung beziehe. Staatssekretär Schütz befürwortet die Abgabe einer Generalerklärung, daß durch die Verwendung von Symbolen und Emblemen der DDR bei internationalen Sportveranstaltungen die Rechtsauffassung der Bundesregierung nicht beeinträchtigt werde. Dagegen betont Ministerialdirektor Ruete, daß damit der „Raum vor der völkerrechtlichen Anerkennung der Zone" freigegeben würde. Ministerialdirektor Meyer-Lindenberg teilt diese Auffassung und führt aus, daß im Falle der Duldung der „Zonenflagge im Bundesgebiet“ der Gesetzgeber tätig werden müsse. Ministerialdirigent Sahm spricht sich für eine Generalerklärung ohne Sportteil aus. Brandt erklärt, daß darüber hinausgegangen werden müsse. $\mathrm{Ab}$ schließend bittet er um die Vorlage des Entwurfs einer Erklärung. Diese solle Ausführungen zum Staatsbürgerschaftsgesetz der DDR vom 20. Februar 1967 sowie zum Wunsch der Bundesregierung nach menschlichen Begegnungen unbeschadet der bestehenden Herrschaftssysteme enthaiten. 

Auswärtige Amt

Sattler informiert über ein Gespräch mit dem Abteilungsleiter im Päpstlichen Staatssekretariat hinsichtlich der Kirchenverwaltung der ehemaligen Ostgebiete des Deutschen Reichs sowie des Schulgesetzes in Baden-Württemberg. Auf den Vorschlag der Einsetzung eines Apostolischen Administrators auf Zeit für das Bistum Ermland erwiderte Samorè, daß dies „leider nicht genügend" sei. Der Botschafter teilte daraufhin mit, daß die Bundesregierung keinen Protest gegen die Ernennung weiterer Apostolischer Administratoren erwäge. Bezüglich des am 8. Februar 1967 im Landtag von Baden-Württemberg verabschiedeten Schulgesetzes erklärte Samorè, durch zusätzliche Verhandlungen, an denen der Botschafter beteiligt sein müsse, sowohl eine Erhöhung der Anzahl katholischer Privatschulen als auch eine weitere Verstärkung des christlichen Charakters der vorgesehenen Gemeinschaftsschulen erreichen zu wollen. Auswärtige Amt

Harder berichtet über Äußerungen des ägyptischen Rüstungsbeauftragten. Khalil habe betont, daß noch immer der gute Wille der VAR hinsichtlich der Wiederaufnahme von diplomatischen Beziehungen mit der Bundesrepublik vorhanden sei. Jedoch sei der psychologische Zeitpunkt vor dem Botschafteraustausch mit Rumänien günstiger gewesen. Zudem lasse die neue Ostpolitik der Bundesregierung das deutsch-arabische Verhältnis komplizierter erscheinen. Außerdem habe Khalil deutlich gemacht, daß sich die Bundesregierung in Zusammenhang mit der Normalisierung des Verhältnisses nicht zu sehr auf die Arabische Liga verlassen solle. Vielmehr seien rechtzeitige und sorgfältige Vorarbeiten der Bundesregierung in den "Schwerpunktländern“ der Liga zu leisten.

Brückner informiert über eine Unterredung mit dem Abteilungsleiter im ungarischen Außenministerium. Vadász habe erklärt, daß die am 4. Februar 1967 übergebenen schriftlichen Ausführungen der Bundesregierung bezüglich der Modalitäten der Aufnahme diplomatischer Beziehungen nicht exakt mit den von Staatssekretär Lahr im Januar 1967 in Budapest mündlich gegebenen Erläuterungen übereinstimmten. Ferner seien die Bemühungen hinsichtlich eines Botschafteraustausches mit Ungarn in der Bundesrepublik von einer Propagandakampagne begleitet worden. Anschließend habe Vadász eine Aufzeichnung vom selben Tag übergeben, nach welcher der zukünftigen Botschaft der Bundesrepublik in Budapest das Recht auf Vertretung der Interessen von Berlin (West) nicht zuerkannt werden solle. Des weiteren werde festgestellt, daß die 
Aufnahme diplomatischer Beziehungen mit Ungarn der Verbesserung des Verhältnisses der beiden „souveränen deutschen Staaten" dienen solle.

72

27.02. Gespräch des Bundesministers Brandt mit dem amerikanischen Botschafter McGhee

Brandt und McGhee erörtern den Ablauf eines Besuchs des Leiters der amerikanischen Abrüstungsbehörde, Foster, in der Bundesrepublik, um Probleme bezüglich eines Nichtverbreitungsabkommens zu behandeln. Der amerikanische Botschafter spricht im folgenden verschiedene Kontrollverfahren im Rahmen eines Nichtverbreitungsabkommens an. Der Bundesminister führt aus, daß die Frage der Überwachung und der Kontrolle durch Inspektoren überschätzt werde und innerhalb weniger Jahre aufgrund des technischen Fortschritts neue Überwachungsmethoden mittels "black boxes“ gefunden werden müssen. McGhee ist der Meinung, daß die Möglichkeiten für Industriespionage begrenzt seien. Brandt erklärt abschließend, daß ein Nichtverbreitungsabkommen innerhalb der Regierungskoalition kein ernstes Problem darstelle, jedoch habe Bundeskanzler Kiesinger innerhalb seiner Partei gewisse Schwierigkeiten.

Schütz unterbreitet Bundesminister Brandt Themenvorschläge für die nächste Sitzung des Kabinettsausschusses für innerdeutsche Angelegenheiten. Er regt eine Überprüfung der "durchlöcherten“ TTD-Regelung mit dem Ziel einer Aufhebung an. Dabei betont er, daß die Einführung der Temporary Travel Documents ursprünglich kein Bestandteil der Deutschlandpolitik, sondern 1961 eine Reaktion auf den Bau der Berliner Mauer gewesen sei. Er räumt aber ein, daß ein Einreiseverbot aus der DDR für Personen mit Spionage- und Agentenaufträgen und für Teilnehmer an Veranstaltungen, die dem KPD-Verbot zuwiderlaufen, aufrechterhalten bleiben solle. Hinsichtlich der Teilnahme von DDR-Bürgern an internationalen Veranstaltungen legt Schütz den Entwurf einer Generalerklärung vor. Damit solle die Bundesrepublik ihre Handlungsfreiheit zurückgewinnen und „aufhören, hinter der Entwicklung herzurennen". Er empfiehlt, das Zeigen von Flaggen, Symbolen und Hymnen der DDR bei innerdeutschen Veranstaltungen zwar weiterhin abzulehnen, bei internationalen Begegnungen dagegen zukünftig hinzunehmen.

Duckwitz berichtet über die Dreier-Verhandlungen zwischen der Bundesrepublik, den USA und Großbritannien am 27. Februar 1967 in London. Der Kanzler des Herzogtums Lancaster, Thomson, erklärte, daß die britische Regierung in großem Umfang Truppen aus der Bundesrepublik abziehen werde, falls die Bundesregierung keinen Versuch unternehmen sollte, die Devisenlücke zu schließen. Grundsätzlich sei die britische Regie- 
rung bereit, zivile öffentliche Beschaffungen der Bundesrepublik in Großbritannien anzurechnen, jedoch müsse ein hoher militärischer Anteil in Form eines zugesagten oder vereinbarten, langfristigen Beschaffungsprogramms angestrebt werden. Duckwitz erklärte, daß neue Berechnungen des Bundesministeriums der Finanzen anstelle der bisher vorgesehenen 150 Mio. DM einen Betrag von 250 Mio. DM für zivile Beschaffungen in Großbritannien ergeben hätten. Amt

Grewe berichtet über die Diskussion im Politischen Ausschu $\beta$ des Ständigen NATO-Rats hinsichtlich einer Abänderung des Vergabeverfahrens von bisher vom Allied Travel Office (ATO) in Berlin (West) für Einwohner der DDR ausgestellten Temporary Travel Documents (TTD). Der dänische Vertreter regte an, statt der ATO nun der dänischen Regierung die letzte Entscheidung bei der Vergabe von Einreisegenehmigungen zu erteilen. Er hob hervor, daß Dänemark eine „höchst liberale VisaPolitik" betreibe. Die Entscheidung über die Vergabe solle jedem einzelnen NATO-Mitgliedstaat obliegen, auch für die Einreiseerlaubnis von DDR-Bewohnern. Der niederländische Vertreter gab zu bedenken, ob strittige Fälle zukünftig nicht primär in der Bonner Vierer-Gruppe behandelt werden sollten. Abschließend erklärte Grewe, daß es für die NATO und die Bundesrepublik ermutigend sei, da $\beta$ das TTD-System trotz des dänischen Vorstoßes als solches nicht in Frage gestellt werde.

Frank faßt ein Gespräch des Staatssekretärs Lahr mit dem österreichischen Außenminister zusammen. Tončić-Sorinj bot an, die Bestrebungen der Bundesrepublik nach Beitritt zur Donau-Konvention diplomatisch zu unterstützen, jedoch müsse der Eindruck eines zu engen Zusammenwirkens zwischen der Bundesrepublik und Österreich vermieden werden. Mit Blick auf die noch offenen österreichischen Wünsche zum Kreuznacher Abkommen von 1961 machte er darauf aufmerksam, daß es sich weniger um rechtliche als um politische Fragen handele und er unter dem Druck der Vertriebenenorganisationen stehe. Eine Anrufung des im Abkommen vorgesehenen Schiedsgerichts könnte für beide Seiten vielleicht unangenehm sein, weil dann "sehr weit zurückreichende Dinge“ behandelt werden müßten. Mit Blick auf die Verhandlungen Österreichs mit der EWG betonte der Außenminister, daß die Schaffung eines "Gemeinschaftsorgans" nicht mit der österreichischen Souveränität vereinbar wäre. Gleichfalls müsse sich Österreich das Recht zu selbständigen Maßnahmen in bezug auf den Osthandel vorbehalten. 

Budapest, an das Auswärtige Amt

Brückner berichtet von einem Gespräch mit einem „Vertrauensmann" des ungarischen Außenministeriums. So habe er erfahren, daß die ungarische Regierung an eine Aufnahme diplomatischer Beziehungen zur Bundesrepublik weiterhin keine Bedingungen knüpfe. Strittigster Punkt von Verhandlungen werde die Einbeziehung von Berlin (West) sein. Jede Zuständigkeit durch eine Botschaft der Bundesrepublik werde voraussichtlich strikt abgelehnt werden, weil Berlin (West) nach ungarischer Auffassung kein Bestandteil der Bundesrepublik sei. Zwar sollte eine Fortsetzung der Gespräche nicht unnötig hinausgezögert werden, doch sei vor der vom 24. bis 26. April 1967 in Karlsbad stattfindenden Konferenz der europäischen kommunistischen und Arbeiterparteien der Ostblock-Staaten keine Entscheidung zu erwarten. Abschließend weist Brückner auf das große ungarische Interesse an der Geheimhaltung von Verhandlungen hin. Generalsekretär Brosio, NATO

Kiesinger äußert die Befürchtung, daß die NATO - nachdem der Höhepunkt des Kalten Krieges überschritten sei - zu einem bloßen Gehäuse zu erstarren drohe, weil ihr der gemeinsame politische Inhalt fehle. Angesichts der Beziehungen besonderer Art zwischen den Atommächten USA und UdSSR stelle sich die Frage, ob die amerikanischen Interessen noch identisch seien mit denen der europäischen NATO-Staaten. Daher sei die Gründung der Harmel-Studiengruppe, in der die zukünftigen Aufgaben der Allianz erörtert werden sollen, positiv zu bewerten. Brosio hebt hervor, daß es das Hauptziel der Harmel-Studie sei, das gemeinsame politische Ziel der Verbündeten klarzustellen. Allerdings bestehe die Gefahr, daß sich durch die Diskussionen die Spaltung in der NATO noch vertiefe. Das geplante Nichtverbreitungsabkommen bezeichnet er als überflüssig angesichts der bestehenden atlantischen Allianz und als ein Element der Schwächung. Da allerdings die USA die Initiative ergriffen hätten, könnten die NATO-Mitgliedstaaten jetzt nur noch solche Bestimmungen des Vertrages zu verhindern suchen, die sich gegen die vitalen Interessen Europas und des Bündnisses richteten. Kiesinger stimmt zu und weist auf die Zumutungen hin, die dieser Vertrag für die Nichtnuklearstaaten bedeute.

Lahr faßt das Ergebnis einer Sitzung des Bundesverteidigungsrats zusammen. Es wurde die Auffassung vertreten, da 3 Großbritannien unter allen Umständen einen Teil der Rheinarmee abziehen werde. So könne das Verhalten der Bundesregierung in der Frage eines Devisenausgleichs nur noch auf Umfang, Rhythmus und Modalitäten dieser Rückverlegung Einflu $\beta$ haben. Bundeskanzler Kiesinger bezeichnete es als 
„verbrecherisch", für das Problem des Devisenausgleichs keine Lösung zu finden, wenn die Bundesregierung zu dem Schluß kommen sollte, daß ein Verbleiben britischer Einheiten für die Sicherheit notwendig sei. Davon müsse er sich aber noch überzeugen. Lahr stellt fest, daß es zwei Konzepte gebe, wie die Leistungen an Großbritannien erhöht werden könnten: Während das Auswärtige Amt eine Aufstockung des Verteidigungshaushaltes um 200 Mio. DM für Bestellungen in Großbritannien oder als Vorauszahlung befürworte, verweise das Bundesministerium der Verteidigung auf ein Munitionsgeschäft im Umfang von 100 Mio. DM.

Hardenberg legt dar, daß in den seit August 1966 geführten Verhandlungen zwischen dem Ostausschuß der Deutschen Wirtschaft und der albanischen Handelskammer lediglich über die Laufzeit einer Handelsvereinbarung und die Warenlisten eine Einigung habe erzielt werden können. Schwierigkeiten bereite die albanische Weigerung, Berlin (West) in ein Abkommen oder einen begleitenden Briefwechsel einzubeziehen. Das primär politische Interesse der Bundesregierung an einem ersten Schritt in Richtung einer Aufnahme amtlicher Beziehungen rechtfertige jedoch keinen Verzicht auf eine Berlin-Klausel. Daher solle den albanischen Verhandlungspartnern mitgeteilt werden, daß die Position des Ostausschusses zu einer Einbeziehung von Berlin (West) nicht modifiziert werden könne. Hardenberg fügt hinzu, daß dies für die Zukunft die Möglichkeit einer stärker privatrechtlichen Vereinbarung offenlasse, in der kein räumlicher Geltungsbereich genannt werden müsse. Eine solche Übereinkunft, die nicht als Vorstufe für ein zwischenstaatliches Handelsabkommen zu werten sei, bringe allerdings keinen nennenswerten außenpolitischen Vorteil.

Gehlhoff faßt die Ergebnisse seiner Gespräche in Algier zusammen. Die algerische Regierung betrachte die Bundesrepublik als einen ihrer wichtigsten Handelspartner und wolle daher aus politischen Gründen ein gutes Verhältnis unterhalten. Sie sei auch an einer Wiederaufnahme diplomatischer Beziehungen in absehbarer Zeit interessiert. Allerdings könne nicht ausgeschlossen werden, daß Algerien dem erheblichen Druck seitens der UdSSR und anderer Ostblock-Staaten nachgeben und ein Generalkonsulat der DDR zulassen werde. Der Staatssekretär im algerischen Außenministerium, Rahal, habe Gehlhoff versichert, kein arabischer Staat könne erwarten, daß die Bundesrepublik die diplomatischen Beziehungen zu Israel wieder abbreche. Innenminister Medeghiri habe betont, daß Algerien im Gegensatz zu 1965 nicht mehr gewillt sei, seine Interessen zugunsten der „viel beredeten arabischen Solidarität ${ }^{\text {“ }}$ zurückzustellen. 

französischen Botschafter François Seydoux

Kiesinger unterrichtet den französischen Botschafter vom Inhalt eines belgischen Aide-mémoire, bei der geplanten Konferenz der Staats- und Regierungschefs der sechs EWG-Mitgliedstaaten anläßlich des zehnten Jahrestages der Unterzeichnung der Römischen Verträge zu vereinbaren, vor Entscheidungen zu bestimmten politischen Themen die Partnerstaaten zu konsultieren. Dazu könne auch Großbritannien eingeladen werden, während über die europäischen Gemeinschaften weiterhin nur unter den Sechs gesprochen werden solle. Der Bundeskanzler meint, daß eine solche Erweiterung des Kreises zur Erörterung außenpolitischer Themen ein „trojanisches Pferd“ sei. In dem Aide-mémoire werde außerdem die Erwartung ausgedrückt, daß die Bundesregierung hierzu bei der französischen und der italienischen Regierung die Initiative ergreife. Dadurch sei der belgische Vorschlag bei ihm sozusagen „deponiert" worden. Seydoux bemerkt, daß auch über politische Themen nur unter den Sechs gesprochen werden könne und anderen Staaten erst eine Mitgliedschaft in der EWG die Möglichkeit zur Teilnahme eröffne. Kiesinger kündigt an, daß die Bundesregierung von sich aus nicht initiativ werde, da sie davon ausgehe, daß gewisse Bedenken in Paris bestünden. In Rom sollten nur die Sechs vertreten sein. Seydoux bemerkt abschließend, vielleicht meine die belgische Regierung, gegenüber Großbritannien Reverenz erweisen zu müssen. Abschließend betont Kiesinger, daß eine Wiedervereinigung nur möglich sein werde, wenn dies der Wille der Bevölkerung in beiden Teilen Deutschlands sei. Alleinvertretung bedeute nicht, daß die Bundesregierung „den Vormund für die Bevölkerung der Zone spielen“" wolle. Auswärtige Amt

Knappstein teilt mit, daß Präsident Johnson auf einer Pressekonferenz am Vortag angekündigt habe, die USA wollten mit der sowjetischen Regierung Möglichkeiten einer Begrenzung des Wettrüstens bei offensiven und defensiven nuklearen Raketenwaffen erörtern. Dieser Meinungsaustausch werde unabhängig von der in Genf tagenden Konferenz der 18-MächteAbrüstungskommission durch den amerikanischen Botschafter in Moskau, Thompson, geführt. Die positive Antwort von Kossygin komme Johnson gelegen, da sie den Druck verringere, bald eine Entscheidung über die Errichtung eines Anti-Raketensystems in den USA fällen zu müssen. Bemerkenswert im Vergleich zu amerikanischen Rüstungskontrollvorschlägen aus dem Jahr 1964 seien die Einbeziehung von Offensivwaffen und die Wahl von Moskau als Verhandlungsort. Die USA sollten möglichst bald um vollständige Unterrichtung und Konsultation gebeten werden, damit sich die Gespräche nicht, wie beim Nichtverbreitungsabkommen, auf Bereiche ausdehnen würden, die die Bundesrepublik unmittelbar beträfen. 

Auswärtige Amt

Duckwitz informiert über die Dreier-Verhandlungen in London. Der Sonderbeauftragte des amerikanischen Präsidenten, McCloy, verwies auf die Notwendigkeit, die atlantische Allianz mit neuem Leben zu erfüllen. Mittlerweile greife eine Atmosphäre des Mißtrauens und der nationalen Eigensucht um sich, und einzelne NATO-Staaten schienen sich mehr vom Westen als vom Osten bedroht zu fühlen. Wichtig sei vor allem, daß nicht aus allein finanziellen Gründen Maßnahmen getroffen würden, die die Sicherheit der Allianz gefährdeten. Der Kanzler des Herzogums Lancaster, Thomson, wies demgegenüber darauf hin, daß die britischen Zahlungsbilanzprobleme so dringlich seien, daß eine Klärung strategischer Fragen nicht abgewartet werden könne. Duckwitz betonte, daß es gefährlich sei, langfristig wirksame Entscheidungen von großer Tragweite für die NATO unter dem Eindruck vorübergehender finanzieller Schwierigkeiten zu treffen. Wie McCloy vertrat er die Ansicht, daß vorrangig das strategische Konzept der NATO geklärt werden müsse. Der einzig angemessene Weg zur Verringerung der Verteidigungsausgaben sei eine ausgewogene Verminderung von Streitkräften „auf beiden Seiten des Eisernen Vorhangs".

Frank schildert die Auswirkungen, die eine Aufnahme des von den USA vorgeschlagenen Kontrollartikels (Artikel III) in ein Nichtverbreitungsabkommen auf die Europäische Atomgemeinschaft haben würde. Diejenigen Mitgliedstaaten, die dem Abkommen beiträten, müßten eine zusätzliche Überwachung ihrer zivil genutzten atomaren Anlagen durch die IAEO und somit doppelte Kontrollen akzeptieren. Sollten nicht alle EURATOMStaaten unterzeichnen, so hätte dies eine Zersplitterung des europäischen Kernenergiemarktes zur Folge und würde sowohl die Zusammenarbeit zwischen Vertragspartnern und Nichtvertragspartnern als auch die gemeinschaftseigene Forschungstätigkeit von EURATOM behindern. Letztlich könnte dies zu einer Abwertung von EURATOM und damit zu einer Schwächung der europäischen Gemeinschaft führen. Ferner weist Frank auf Bestimmungen im EURATOM-Vertrag hin, die einer Unterzeichnung des Nichtverbreitungsabkommens durch die Mitgliedstaaten - zumindest ohne vorherige Prüfung des Vertragstextes durch die EURATOM-Kommission - entgegenstünden. Anzustreben sei folglich ein Wegfall oder eine Abschwächung des Artikels III sowie eine Anerkennung der EURATOMKontrollen durch die IAEO.

Jung faßt den Verlauf einer deutschlandpolitischen Diskussion am 27. Februar 1967 unter Beteiligung des Referenten Bahr, des Ministerialdirektors Thierfelder und des Ministerialdiri- 
genten Frank zusammen. Ausgangspunkt der Erörterung war der Gedanke, die DDR im nichtpolitischen multilateralen Bereich als Völkerrechtssubjekt zu behandeln, ohne ihr gleichzeitig die Eigenschaften eines souveränen Staats zuzugestehen. Bahr schlug vor, die DDR als Staat durchgehen zu lassen wenn auch als einen ohne Legitimität. Die Anerkennung der DDR als Verhandlungspartner sei unumgänglich. Frank stellte die Frage, ob die Wiedervereinigungspolitik der Bundesregierung dadurch gefährdet werden könne, daß der DDR eine beschränkte Geschäftsfähigkeit zugebilligt werde. Bahr führte dazu aus, daß der früheren Vorstellung einer "Wiedervereinigung durch Anschluß“ das neue Prinzip der "Wiedervereinigung durch Umarmung “ entgegengestellt werden müsse. In der Gesprächsrunde herrschte die Ansicht vor, daß die bisherige Deutschlandpolitik nicht mehr in die Landschaft passe. Ein neues deutschlandpolitisches Konzept solle vom Planungsstab für Bundesminister Brandt zur Vorbereitung eines Gesprächs mit Bundeskanzler Kiesinger erarbeitet werden. amerikanischen Sonderbeauftragten McCloy in Stuttgart

McCloy spricht Kiesinger auf dessen Äußerung vom 27. Februar 1967 über eine „atomare Komplizenschaft“ zwischen den beiden großen Kernwaffenstaaten an, die Präsident Johnson verärgert habe. In der Frage eines Devisenausgleichs für die USA und Großbritannien seien die Dreier-Verhandlungen an einem kritischen Punkt angelangt. Die finanziellen Lasten der Stationierung müßten so verteilt werden, daß möglichst keine oder nur geringfügige Truppenverlegungen notwendig würden. Die USA stellten schon nicht mehr dieselben exakten Forderungen wie noch im Herbst 1966. Auch Großbritannien wolle nicht mehr als 5000 Soldaten abziehen. Kiesinger äußert dagegen die Ansicht, daß die britische Regierung ihre in der Bundesrepublik stationierten Einheiten auf jeden Fall massiv zu verringern beabsichtige. Angesichts möglicher amerikanischer Truppenreduzierungen erläutert McCloy den Plan einer Rotation. Danach solle die 24. Division bis auf eine Brigade und bis auf das Divisionshauptquartier in die USA zurückverlegt werden. Dieser Verband solle dann so ausgewechselt werden, daß sich jede der drei Brigaden einmal im Jahr in der Bundesrepublik aufhalten würde.

Brandt teilt Kiesinger Überlegungen zur künftigen Politik gegenüber Jugoslawien mit. Er kommt zu dem Schluß, daß zwar eine Wiederaufnahme der Beziehungen im Interesse der Europa- und Entspannungspolitik liege, jedoch vor einem solchen Schritt einige Voraussetzungen zu erfüllen seien. So müsse ausgeschlossen werden, daß diese Maßnahme nach den 1957 hergestellten Beziehungen zwischen Jugoslawien und „OstBerlin" nun durch Staaten der Dritten Welt fehlinterpretiert 
werde und $\mathrm{zu}$ einer verstärkten internationalen Aufwertung der DDR führe. Brandt weist darauf hin, daß es auch nach dem Botschafteraustausch mit Rumänien nicht $z u$ einem solchen Dammbruch gekommen sei. Eine mit den Verbündeten abgestimmte neue diplomatische Aktion könne dazu dienen, die Grundzüge der Entspannungspolitik darzulegen. Dabei müsse deutlich werden, daß eine „Friedenssicherung plus Organisierung Europas" der entscheidende Orientierungspunkt sei. Die Nichtanerkennung der DDR dürfe nur Mittel zum Zweck, nicht Selbstzweck sein. Zunächst aber solle in Belgrad geklärt werden, welche Maßnahmen vor einer Aufnahme diplomatischer Beziehungen ergriffen werden könnten, um das Verhältnis zu Jugoslawien zu verbessern. London

Thierfelder legt dar, daß die Ostpolitik der Bundesrepublik durch das bisherige Verfahren der Einbeziehung von Berlin (West) in internationale Verträge in Schwierigkeiten gerate. Die Bundesregierung schlage nun eine öffentliche Erklärung der Drei Mächte vor, daß alle Abkommen der Bundesrepublik automatisch, also auch ohne eine entsprechende Klausel, in Berlin (West) Gültigkeit erlangten. Dies solle nicht den Status der Stadt und die dortigen Rechte der Alliierten berühren, sondern lediglich dazu dienen, Vertragsverhandlungen und -abschlüsse zu entpolitisieren. Der britische Vorschlag vom 19. Oktober 1966, der ein Ausnahmeverfahren für Verhandlungen mit kommunistischen Staaten vorsehe, sei wegen der vorgesehenen unterschiedlichen Behandlung von kommunistischen und nichtkommunistischen Staaten unzweckmäßig. Die britischen Gesprächspartner erhoben weiterhin Bedenken dagegen, da 3 die alliierten Vorbehaltsrechte in Berlin (West) durch die von der Bundesrepublik vorgeschlagene Regelung beeinträchtigt werden könnten.

Semjonow spricht Bedenken an, die in der Bundesrepublik durch Politiker und Wissenschaftler gegen den von amerikanischer Seite vorgeschlagenen Kontrollartikel in einem Nichtverbreitungsabkommen geäußert worden seien. Dabei handele es sich lediglich um eine neue Variante der alten Bestrebungen der Bundesrepublik, Zugang zu Kernwaffen zu erhalten. Walther verweist demgegenüber auf die Bedeutung der zivilen Kernforschung für Export und Energieversorgung. Daher gebe es Vorbehalte gegen ein Kontrollsystem, das wie Industriespionage erscheine. Es gehe allein um das "Wie ${ }^{4}$ einer Überwachung, die sich auf das nukleare Sprengmaterial beschränken sollte. Semjonow wendet sich gegen eine Überwachung durch EURATOM, da dies eine Eigenkontrolle darstelle. Er betont die politische Bedeutung eines Nichtverbreitungsabkommens 
als ersten Schritt zu einer Abschaffung der Gefahren eines Atomkrieges und erhebt den Vorwurf, daß die Bundesregierung hinter den Kulissen erhebliche Anstrengungen unternehme, um den Abschluß des Abkommens zu verhindern.

Ruete stellt Überlegungen an, wie der erweiterte Nuklearverzicht, den die Bundesrepublik durch die Unterzeichnung eines Nichtverbreitungsabkommens leisten würde, für eine Entspannungspolitik gegenüber der UdSSR nutzbar gemacht werden könnte. Er kommt zu dem Schluß, daß dazu das direkte Gespräch gesucht werden müsse. So könnte den sowjetischen Bestrebungen entgegengewirkt werden, sich Zugeständnisse der Bundesregierung über die USA einräumen zu lassen, ohne selbst Gegenleistungen zu erbringen. Das Ziel müßten verbindliche Festlegungen sein, daß die UdSSR einen Beitritt der Bundesrepublik zum Abkommen als Beitrag zur Entspannung und als eine Voraussetzung für eine Normalisierung der bilateralen Beziehungen ansähen. Zudem solle die sowjetische Regierung zusichern, daß sie die Bundesrepublik künftig nicht mit Atomwaffen bedrohen oder erpressen werde und daß sie keinen Einfluß nehmen werde auf die zivile Kernforschung in der Bundesrepublik. Ferner müsse der UdSSR die Möglichkeit genommen werden, unter Berufung auf das Abkommen Einspruch gegen die angestrebte europäische Einigung zu erheben. Leiter der amerikanischen Abrüstungsbehörde, Foster

Kiesinger betont, daß aus Sicht der Bundesregierung noch umfassende Konsultationen über das Nichtverbreitungsabkommen notwendig seien, so beispielsweise zu den Folgen für die bilateralen Beziehungen zu den USA innerhalb der NATO sowie für die deutsche Frage. Zwar werde nicht mehr daran festgehalten, daß die Wiedervereinigung einer Entspannung vorausgehen müsse. Jedoch sei es auch nicht hinnehmbar, eine Lösung der deutschen Frage in die ferne Zukunft zu vertagen. Zudem müsse erörtert werden, wie die Bundesrepublik zu schützen sei, falls sie nach einer Unterzeichnung des Abkommens von der UdSSR bedroht oder nuklear erpreßt werde. Foster weist darauf hin, daß es noch keinen fertig ausgehandelten Vertragstext gebe und daß die Konsultationen keinem festen Zeitplan unterlägen. Allerdings arbeite die Zeit nicht für den Westen. Der Vertragsentwurf solle möglichst bald der Konferenz der 18-Mächte-Abrüstungskommission vorgelegt werden, denn die blockfreien Staaten befürchteten bereits jetzt eine Konspiration der westlichen Alliierten. Kiesinger äußert die Befürchtung, daß nach der Vorlage des Entwurfs wesentliche Entscheidungen nicht mehr rückgängig gemacht werden könnten, und somit eine schlimme Lage für die Bundesrepublik entstünde. 
Anläßlich der Weisung des Bundesministers Brandt, die Ständige Vertretung bei der NATO in Paris solle sich für eine Abschaffung der TTD-Regelung einsetzen, macht Ruete darauf aufmerksam, daß die Bestimmungen über die Vergabe von Temporary Travel Documents nur durch die Alliierten aufgehoben werden können und die Bundesregierung zudem verpflichtet wäre, sich vor einem solchen politischen Vorstoß mit den Drei Mächten abzusprechen. Darüber hinaus gibt er zu bedenken, daß die TTD-Bestimmungen eines der wenigen Gebiete seien, auf dem die Drei Mächte noch die Verantwortung für Deutschland als Ganzes wahrnähmen. Der Wegfall der TTDs könnte zu einer internationalen Aufwertung der DDR führen, nicht zuletzt deshalb, weil dann dort ausgegebene Reisedokumente in den NATO-Staaten akzeptiert werden müßten. Während für die Bevölkerung in der DDR keine Erleichterungen zu erwarten seien, erhalte die Propagandatätigkeit „Ostberlins im westlichen Ausland freie Bahn". Werde dennoch eine Aufhebung der TTD-Regelung befürwortet, so sollte diese nur im Rahmen eines neuen deutschlandpolitischen Konzepts - verbunden mit Forderungen nach "Gegenleistungen der Zone" - vorgeschlagen werden. Leiter der amerikanischen Abrüstungsbehörde, Foster

Foster sichert zu, daß die amerikanische Regierung erst nach Abschluß der Konsultationen mit den Alliierten über ein Nichtverbreitungsabkommen zu einer Vereinbarung mit der UdSSR kommen wolle. Allerdings empfehle er aus taktischen Gründen, möglichst bald andere Staaten an der Diskussion zu beteiligen. Manche Argumente ließen sich leichter durchsetzen, wenn sie nicht von der Bundesregierung, sondern von dritter Seite vorgebracht würden. Foster warnt davor, in die materiell wirksamen Abschnitte des Abkommens auch Absichtserklärungen aufzunehmen; dies würde den Vertrag nur für weitere Wünsche und Anträge öffnen. Die Gestaltungsmöglichkeiten seien zudem bei der Präambel größer als bei den übrigen Vertragsbestimmungen. Zur Frage der Sicherheitskontrollen bezeichnet er den deutschen Vorschlag einer automatischen Überwachung als weiterer Sondierung wert. Botschafter Schnippenkötter erläutert, daß sich die Kontrolle auf Flußdiagramme und den Verbleib spaltbaren Materials beschränken solle, was bisher nicht hinlänglich berücksichtigt worden sei.

Zur Frage einer Unterstützung osteuropäischer EmigrantenOrganisationen in der Bundesrepublik erläutert Ruete, daß dafür sowohl im Bundeshaushalt als auch in den Haushalten der Länder Mittel vorgesehen seien. Er führt aus, daß nach dem Zweiten Weltkrieg solche Gruppierungen allein aufgrund ihrer antikommunistischen Gesinnung gefördert worden seien. Diese Einstellung wirke noch nach, so daß z. B. im Jahr 1964 Bemü- 
hungen des Auswärtigen Amts gescheitert seien, Emigrantenverbände nach Mißbrauch des Gastrechts öffentlich mahnen zu lassen. Als jüngstes Beispiel nennt Ruete kroatische ExilOrganisationen, die durch ihre radikalen Programme und teilweise terroristischen Methoden auffielen. Ihre Aktivitäten hielten bei der jugoslawischen Regierung das Trauma einer kroatisch-deutschen Verschwörung gegen den Vielvölkerstaat Jugoslawien lebendig. Ruete regt an, sich im Sinne einer glaubhaften Ostpolitik gegen Aktivitäten zu verwahren, die sich gegen die Integrität einzelner osteuropäischer Staaten richten.

Diehl entwirft ein außenpolitisches Aktionsprogramm. Ziel der Ostpolitik sei die Aufnahme diplomatischer Beziehungen zu allen Staaten des Warschauer Pakts und zu Jugoslawien. Die Kontakte zur Volksrepublik China müßten verstärkt werden, um die nach Abklingen des Vietnam-Krieges fällige Errichtung einer Handelsvertretung oder eine Aufnahme diplomatischer Beziehungen vorzubereiten. In der Entwicklungshilfe sollten die Mittel weniger in multilaterale Projekte als in ein eigenes Programm für den Aufbau von Infrastruktur in der Dritten Welt fließen. Der Zusammenarbeit innerhalb Europas, besonders mit Frankreich und Großbritannien, müsse wieder mehr Gewicht zukommen. Darüber dürfe allerdings nicht die Notwendigkeit nahezu ständiger Beratungen mit den USA vernachlässigt werden. Als Beitrag zur Reform der NATO sei ein deutsches Verteidigungskonzept zu erarbeiten. Der „eigentliche Prüfstein der Großen Koalition" werde allerdings die Deutschlandpolitik sein. Um hier Fortschritte zu erreichen, müßte die Bundesregierung Alleinvertretung von Alleinpräsenz trennen und dem "Regime in der SBZ eine gewisse Geschäftsfähigkeit" zubilligen. Anzustreben seien die Einrichtung eines Amtes für innerdeutsche Beziehungen, die Mitwirkung der DDR in internationalen Verträgen und Organisationen sowie die „Mobilmachung" der UNO für die deutsche Frage.

Ruete legt dar, daß während des Besuchs des sowjetischen Ministerpräsidenten Kossygin vom 6. bis 13. Februar 1967 in London der Abschlu $\beta$ eines bilateralen Vertrags über Freundschaft und friedliche Zusammenarbeit in Aussicht genommen worden sei. Die britische Regierung habe sich mit dem sowjetischen Vorschlag einverstanden erklärt, ohne zuvor ihren Konsultationsverpflichtungen gegenüber der NATO und ihren Verbündeten nachgekommen zu sein. Bei der nachträglichen Erörterung des geplanten Freundschaftsvertrags am 7. März 1967 im Ständigen NATO-Rat sei die Reaktion überwiegend kritisch gewesen; lediglich Kanada, Dänemark und Norwegen hätten sich positiv geäußert. Großbritannien habe zwar zugesichert, die Wünsche seiner Verbündeten zu berücksichtigen, wolle jedoch nicht den Wortlaut einzelner Vertragsbestimmungen zur Diskussion stellen. Ruete bezeichnet den sowjetischen Vorschlag als weiteren Versuch, die Bundesrepublik politisch zu 
isolieren. Daher müsse die Bundesregierung bemüht sein, die weitere Entwicklung im Sinne einer „Unteilbarkeit der Entspannung" zu beeinflussen.

Aus einer Unterredung mit dem Kanzler des Herzogtums Lancaster, Thomson, teilt Duckwitz dessen Vorschlag mit, das im Oktober 1966 seitens der Bundesregierung unterbreitete Angebot zum Devisenausgleich erneut zur Grundlage von Verhandlungen zu machen. Die Differenz zwischen der damals zu-

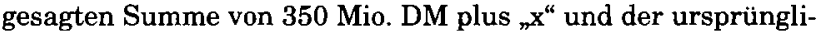
chen britischen Forderung in Höhe von 860 Mio. DM solle unter der Bundesrepublik, Großbritannien und den USA aufgeteilt werden. Duckwitz äußerte sich dazu zurückhaltend. Er stellt jedoch die Überlegung an, die „zivilen Einkäufe der öffentlichen Hand" in Großbritannien auf die noch zu leistenden Zahlungen der Bundesrepublik anzurechnen und den Rest durch Einsparungen, die der Abzug einer britischen Brigade aus der Bundesrepublik erbringen würde, auszugleichen.

\subsection{Botschafter von Walther, Moskau, an das Auswärtige} Amt

Walther berichtet von einer Wahlrede des Generalsekretärs der KPdSU am 10. März 1967, in der Breschnew ausführlich auf die Deutschland-Frage einging. Als Grund für diese Ausführungen müsse die neue Ostpolitik der Bundesregierung gelten, die in der UdSSR zunehmend als Gefährdung eingeschätzt werde. So habe Walther Informationen erhalten, daß die Aufnahme diplomatischer Beziehungen zu Rumänien als „besondere Perfidie" empfunden werde, um gleichsam einen Keil zwischen die Staaten des Warschauer Paktes zu treiben. Er weist darauf hin, daß bislang jede ostpolitische Initiative der Bundesregierung eine Versteifung sowjetischer Positionen zur Folge hatte. Vor diesem Hintergrund und angesichts der Haltung der amerikanischen Regierung, für die der Abschluß eines Nichtverbreitungs- und eines ABM-Abkommens Vorrang vor den Interessen der europäischen Verbündeten habe, rät er zu einem vorübergehenden Verzicht auf "spektakuläre“ Maßnahmen, wie eine Beantwortung der sowjetischen Erklärung vom 28. Januar 1967.

\subsection{Aufzeichnung des Ministerialdirektors Ruete}

Ruete nimmt Stellung zum Vorschlag des Ministerialdirektors Harkort vom 14. März 1967, einen mittelfristigen Kredit an die tschechoslowakische Regierung zum Kauf von Großröhren im Wert von ca. 250 bis 300 Mio. DM bei der Firma Hoesch über eine Bundesbürgschaft abzusichern, auch wenn dies den Richtlinien vom März 1965 über die Vergabe von Krediten an Ostblock-Staaten zuwiderlaufe. Ruete gibt dagegen zu bedenken, daß das tschechoslowakische Interesse an engeren Beziehungen zur Bundesrepublik vorwiegend ökonomische Gründe habe, während die Bundesregierung politische Ziele verfolge. 
Würden also die tschechoslowakischen Wünsche vorab und ohne Forderung nach Gegenleistungen befriedigt, verringere sich die tschechoslowakische Konzessionsbereitschaft im politischen Bereich. Auch angesichts der eher starren tschechoslowakischen Haltung in der Deutschland-Frage wäre eine Entscheidung, wie sie Harkort befürwortet, unangemessen und würde ein falsches Signal gegenüber den anderen Ostblock-Staaten darstellen. An einer parallelen Regelung der wirtschaftlichen Fragen und der Aufnahme von Beziehungen zwischen Bundesrepublik und Tschechoslowakei müsse festgehalten werden.

Lahr nimmt Stellung zu der vom Staatssekretär im Bundesministerium für Wirtschaft, Neef, in einer Besprechung mit dem Bundeskanzler vertretenen Ansicht, daß der Wiederaufnahme von Verhandlungen über einen Beitritt Großbritanniens zur EWG zunächst die Fusion der europäischen Gemeinschaften vorausgehen müsse. Kiesinger habe dann wenig später die Meinung geäußert, daß ihm dieser Gedanke einleuchte. Bei beiden Anlässen habe er, Lahr, versucht zu verdeutlichen, daß ein solches Votum praktisch ein "Nein" gegenüber den britischen Beitrittswünschen bedeute und als Abkehr von der bisherigen Haltung der Bundesregierung aufgefaßt werde. Die Fusion der Gemeinschaften und ein EWG-Beitritt Großbritanniens könnten, wie die Verhandlungen 1962/63 gezeigt hätten, sehr wohl parallel erörtert werden. Bundesministerium der Verteidigung

Lahr teilt Carstens mit, daß die Bundesregierung die Verhandlungen mit der UdSSR über den Flugverkehr zwischen Moskau und Frankfurt/Main wieder in Gang bringen möchte. Diese seien eingestellt worden, weil die Bundesregierung für Aeroflot eine Flugroute über Eger gewünscht habe, während die sowjetische Regierung auf einem Anflug über Berlin-Schönefeld beharre. Die daraufhin vom Auswärtigen Amt vorgeschlagene Streckenführung über Hamburg sei bei SACEUR auf Sicherheitsbedenken gestoßen. Lahr macht darauf aufmerksam, daß es sich um eine internationale Luftstraße handele, die auch von anderen Ostblock-Staaten beflogen werde. Fraglich sei daher, ob ihre Benutzung überhaupt eingeschränkt werden könne. Eine Wiederaufnahme der Gespräche sei dringlich, weil vermieden werden müsse, daß die Deutsche Lufthansa in dem schon seit Jahren herrschenden Konkurrenzkampf um den Luftverkehr nach Moskau zurückfalle. Lahr bittet um eine Stellungnahme, ob eine Änderung der Haltung von SACEUR möglich sei.

Ruete schildert den ungewöhnlichen Verlauf der Sitzung der Bonner Vierergruppe vom 15. März 1967. Offenbar in der Annahme, die Bundesregierung wolle ihre Position in wesentli- 
chen Punkten ohne vorherige Konsultation ändern, stellten die Vertreter der Drei Mächte eine Reihe von Fragen zu aktuellen deutschlandpolitischen Problemen. So baten sie um umgehende Unterrichtung über die bereits im Bundeskabinett verabschiedeten Entwürfe von Notstandsgesetzen. Weiterhin äußerten sie Bedenken gegen einen Wegfall der Widerrufsklausel im Interzonenhandel, da handelspolitische Maßnahmen im Fall von Berlin-Zugangskrisen ein Bestandteil der Eventualfallplanung seien. Um Unterrichtung wurde auch zur geplanten Änderung der Aufenthaltsbestimmungen für Staatsangehörige aus Ostblock-Staaten in Berlin (West) und zur möglichen Zulassung eines sowjetischen Handelskontors im Westteil der Stadt gebeten. Die Vertreter der drei Mächte wiesen darauf hin, daß es in der Frage des Handelskontors offensichtlich eine „totale Konfusion“ zwischen der Bundesregierung und dem Senat von Berlin gebe.

Ruete äußert sich zu Überlegungen, in Berlin (West) die Eröffnung einer sowjetischen Vertretung für Handelskontakte zu gestatten. In Gesprächen, die zwischen Staatssekretär Lahr und dem Berliner Senator König im November 1966 stattfanden, bestand Einvernehmen, daß lediglich kommerzielle Agenturen aus Ostblock-Staaten in Form von Dependancen zugelassen werden dürften. Es müsse alles vermieden werden, was als Bestätigung der kommunistischen Auffassung von Berlin als separater politischer Einheit fehlgedeutet werden könnte. Jüngste Äußerungen von König über die Zulassung eines sowjetischen Handelskontors hätten jedoch eine Klarstellung der Haltung des Senats von Berlin notwendig gemacht. Diese habe ergeben, daß sich der grundsätzliche Standpunkt des Senats nicht verändert habe, und daß dort zur Zeit noch keine „präzisen und praktikablen" Vorstellungen zu einer Intensivierung der Handelsbeziehungen mit Ostblock-Staaten vorlägen.

105 17.03. Aufzeichnung des Ministerialdirektors Diehl

Diehl faßt das Ergebnis von Diskussionen einer deutschlandpolitischen Arbeitsgruppe im Auswärtigen Amt zusammen und entwirft eine Konzeption für das Verhalten gegenüber der DDR. Danach sollte zunächst der Kontakt auf allen Ebenen intensiviert werden, und zwar durch die Errichtung eines "Amts für innerdeutsche Beziehungen" in Bonn und einer „Dienststelle Berlin“. Anschließend solle die Bildung eines paritätisch besetzten „Deutschen Rates" vorgeschlagen werden, der Fragen der innerdeutschen Beziehungen erörtern solle. Zudem könnte die Bundesregierung den innerdeutschen Handel fördern und die Teilnahme der DDR an internationalen Abkommen, die der Abrüstung und Sicherheit dienen, sowie ihre Mitgliedschaft in allen technischen internationalen Organisationen unterstützen - stets unter dem Vorbehalt, daß die DDR ein Teil der deutschen Nation sei. Zu einem späteren Zeitpunkt seien dann im Rahmen der UNO Gespräche zwischen den Vier Mächten, der Bundesrepublik und der DDR zur Vorbereitung eines Friedens- 
vertrags und eines europäischen Sicherheitssystems aufzunehmen. Ausschlaggebend für die Durchführung dieser Konzeption sei es, der DDR eine „gewisse, beschränkte Geschäftsfähigkeit" zuzubilligen und zwischen Alleinvertretung und $\mathrm{Al}-$ leinpräsenz begrifflich und praktisch zu trennen.

106

107

\subsection{Aufzeichnung des Ministerialdirektors Ruete}

Ruete faßt amerikanische Informationen zu den angestrebten Verhandlungen zwischen USA und UdSSR über eine Rüstungsbegrenzung auf dem Gebiet offensiver und defensiver Nuklearraketen zusammen. Die amerikanische Regierung sei an solchen Gesprächen sehr interessiert, denn sie wolle das Wettrüsten auf dem Gebiet der antiballistischen Raketen (ABM), das sich nach der Aufstellung eines ABM-Systems rund um Moskau zu entwickeln drohe, vermeiden. Die Installierung eines amerikanischen Abwehrsystems würde lediglich hohe Kosten verursachen, das Rüstungspatt unverändert lassen und zu einer Verschärfung der Spannungen im Ost-West-Verhältnis führen. Im Gegensatz zum Vorschlag vom 21. Januar 1964 über ein Einfrieren strategischer Kernwaffenträger, der auf sowjetische Ablehnung stieß, wollten die USA jetzt auf Ortsinspektionen verzichten und sich in erster Linie auf SatellitenAufklärung verlassen. Das geplante Abkommen solle sich zudem auf die Zahl der Abschußrampen beschränken. Der für die USA maßgebende Gesichtspunkt sei die Aufrechterhaltung der bestehenden relativen Stabilität.

108

21.03. Staatssekretärbesprechung

Staatssekretär Schütz erklärt zu der beabsichtigten Neuregelung der Kirchenverwaltung für die Gebiete des Deutschen Reiches unter fremder Verwaltung, daß die Einsetzung von

S. 489 
vier Apostolischen Administratoren durch den Heiligen Stuhl die beste Lösung sei. Sie verhindere schwerwiegendere Entscheidungen für den „deutschen Osten". Staatssekretär Nahm weist auf den Vorteil hin, daß dadurch das Reichskonkordat von 1933 unberührt bleibe. Allerdings würde die Stellung der Kapitularvikare beeinträchtigt. Staatssekretär Krautwig bestätigt, daß insbesondere das Amt des Kapitularvikars des ehemals zur Diözese Breslau gehörenden, aber nun in der DDR liegenden Kirchenbezirks Görlitz durch die Ernennung eines Apostolischen Administrators für Breslau zum Drehpunkt dafür werden könne, ob im Falle einer Änderung der Regelung für die Ostgebiete ein „Dammbruch in der Zone“ zu verhindern sei. Die Staatssekretäre kommen zu dem Ergebnis, daß der Einsetzung von Administratoren in den Verwaltungsbezirken Allenstein, Landsberg, Breslau und Oppeln zugestimmt werden könne, wenn Görlitz hiervon ausgenommen werde und der zuständige Kapitularvikar im Amt bleibe. an Bundesminister Brandt

Duckwitz informiert über den Fortgang der Dreier-Verhandlungen. Zwischen den beteiligten Staaten zeichneten sich jeweils bilaterale Vereinbarungen ab, die jedoch nur gemeinsam als Paket in Kraft treten sollten. Bei der amerikanischdeutschen Übereinkunft gaben sich die USA für das laufende Jahr mit einer Vereinbarung zwischen den beiden Zentralbanken zufrieden und befürworteten darüber hinaus die Einführung eines Rotationssystems für eine amerikanische Division und einige Luftwaffeneinheiten. Im Mittelpunkt der Verhandlungen stand ein Entwurf für das deutsch-britische Übereinkommen, in dem die britische Regierung die Zahlung von 50 Mio. DM für 1967 und von 150 Mio. DM für das erste Quartal 1968 akzeptierte. Die Summe für zivile Beschaffungen der öffentlichen Hand in Großbritannien wurde auf 250 Mio. DM erhöht. Im Gegenzug erklärte sich die britische Regierung bereit, den geplanten Truppenabzug zu vermindern und nicht vor dem 1. Januar 1968 damit zu beginnen. Duckwitz empfiehlt die Annahme dieser Vereinbarung als Maximum des Erreichbaren.

In einem Gespräch mit dem sowjetischen Botschafter bestätigte Schütz, daß der geplante Austausch von Gewaltverzichtserklärungen weiterhin vertraulich behandelt werden solle. Zarapkin fragte unter Hinweis auf die Äußerung des Bundeskanzlers Kiesinger, daß er zu einer solchen Erklärung in jeder denkbaren Form bereit sei, ob die Bundesregierung auch gegenüber der DDR einen Verzicht auf Gewalt erklären würde. Schütz erläuterte daraufhin unterschiedliche rechtliche Formen eines Gewaltverzichts. Mit der DDR werde die Bundesregierung jedoch keine Gewaltverzichtserklärungen austauschen, obwohl Bereitschaft vorhanden sei, in die Erklärung gegenüber 
der UdSSR einen Hinweis aufzunehmen, daß sich der Gewaltverzicht auch auf deren Verbündete erstrecke. Zu einer Anerkennung der DDR als Nebenwirkung werde es nicht kommen.

Mangold informiert über die Sitzungsperiode der auf den 9. Mai 1967 vertagten Konferenz der 18-Mächte-Abrüstungskommission. Thema der Verhandlungen war das angestrebte Nichtverbreitungsabkommen, zu dem aber kein Textentwurf vorgelegt wurde. Die Gespräche des amerikanischen Delegationsleiters Foster mit einzelnen Regierungen von EURATOM-Staaten ergaben, daß sich die Bedenken gegen das Abkommen nicht so schnell überwinden ließen. Folglich müsse für die Zeit der Konferenzpause mit intensiven Konsultationen sowohl innerhalb der westlichen Allianz als auch zwischen USA und UdSSR gerechnet werden. Die größten Chancen für eine Durchsetzung der Wünsche der Bundesrepublik gebe es im Bereich der Sicherheitskontrollen; die übrigen Anregungen der Bundesregierung wollten die USA zunächst nur in sehr geringem Umfang berücksichtigen, da sie das „deutsche Etikett" trügen. Es könne mit der festen amerikanischen Absicht gerechnet werden, am 9. Mai 1967 zusammen mit der UdSSR einen Vertragsentwurf vorzulegen. Die Position der Nichtkernwaffenmächte werde dadurch beeinträchtigt, daß es ihnen bisher nicht gelungen sei, sich auf eine gemeinsame Haltung zu verständigen.

Katzenbach spricht den amerikanischen Vorschlag an, für einen Teil der in der Bundesrepublik stationierten Truppen eine Rotation einzuführen. Dieses System zeichne sich durch seine von weltpolitischen Spannungen unabhängige Automatik aus und verspreche den USA eine erhebliche Devisenersparnis. Hinsichtlich des angestrebten Nichtverbreitungsabkommens betont Schütz, daß vor einem Vertragsschluß noch einige besondere Probleme geklärt werden müßten, so z. B. die Zukunft der deutsch-französischen atomaren Forschungsprojekte. Er hoffe allerdings, daß das Abkommen bis Ende Mai zustandekommen werde. Auf die Frage, wie er die Aussichten für einen Beitritt Indiens zu einem Nichtverbreitungsabkommen einschätze, führt Katzenbach aus, daß Indien keinen Bedarf an Atomwaffen habe, da ihm die USA im Falle einer chinesischen Bedrohung helfen würden. Abschließend weist er darauf hin, daß noch offene Punkte im Ständigen NATO-Rat in der Zeit bis zum 19. April 1967 erörtert werden sollten.

\section{31.03. Aufzeichnung des Staatssekretärs Schütz}

Schütz gibt den Inhalt eines privaten Gesprächs mit dem Leiter des Instituts für Internationale Politik und Wirtschaft in Prag vom Vorabend wieder. Snejdarek habe bedauert, daß 
durch die starrere Haltung der UdSSR und der DDR die Normalisierung zwischen dem "sozialistischen Lager“ und der Bundesrepublik sowie die notwendige Annäherung zwischen den kommunistischen Regierungsparteien in den Ostblock-Staaten und den sozialdemokratischen Parteien in Westeuropa verzögert werde. Es sei von entscheidender Bedeutung, auf Parteienebene einen ständigen, qualitativ hochstehenden Kontakt zu pflegen, beispielsweise durch Besuche führender SPD-Politiker in Prag. Gleichfalls sei bedauerlich, daß die Stellung der DDR innerhalb des Warschauer Pakts durch die ersten Schritte der neuen Bundesregierung in der Ostpolitik stärker geworden sei. Aus sowjetischer Sicht könne „im Augenblick in Europa ohne Ulbricht oder gar gegen Ulbricht" nichts entschieden werden. Snejdarek äußerte sich positiv zu einer Aufnahme diplomatischer Beziehungen zwischen der Bundesrepublik und Jugoslawien. Auch ein Botschafteraustausch mit der Tschechoslowakei könne noch im Verlauf des Jahres möglich sein, doch müsse hier mit Geduld vorgegangen werden, weil „der Druck von Moskau und Ostberlin sehr stark“ sei.

114

\subsection{Staatssekretär Schütz an Botschafter Grewe,} Paris (NATO)

Schütz verweist auf die amerikanische Zusicherung, daß erst nach einem befriedigenden Abschluß der Konsultationen das angestrebte Nichtverbreitungsabkommen abgeschlossen werden solle. Die USA hätten sich allerdings nicht darauf festgelegt, bis zum Abschluß dieser Gespräche mit der Vorlage eines amerikanisch-sowjetischen Vertragsentwurfs bei der Konferenz der 18-Mächte-Abrüstungskommission zu warten; darauf müsse jedoch die Bundesregierung bestehen. Die bilateralen Gespräche und die Verhandlungen in der NATO würden folglich in der Zeit bis zum 19. April 1967 ihre „entscheidende Phase“ durchlaufen. Auf der bevorstehenden Sitzung des Ständigen NATO-Rats am 4. April 1967 müsse deutlich werden, daß die Bundesregierung noch keinem Vertragsentwurf zugestimmt habe und an beschleunigten Beratungen interessiert sei.

01.04. Vortragender Legationsrat I. Klasse Herrmann, Sofia, an das Auswärtige Amt

Herrmann berichtet über ein Gespräch mit dem bulgarischen Außenminister. Baschew bezeichnete die Normalisierung des Verhältnisses $z$ wischen der Bundesrepublik und Bulgarien zwar als wünschenswert, warnte aber vor überstürzten Entscheidungen. Er räumte ein, daß auf bilateraler Ebene bis auf die unausgeglichene Handelsbilanz keine Probleme existierten. Einer Aufnahme diplomatischer Beziehungen stünden aber die deutschlandpolitischen Positionen der Bundesregierung entgegen. Auch sei es nicht realistisch, wenn die Bundesregierung hinsichtlich der Wahrnehmung der Interessen von Berlin (West) Bedingungen stelle. Herrmann lehnte eine „Verquickung wirtschaftlicher und politischer Fragen" ab und wies darauf hin, daß die bulgarische Haltung den angestrebten Botschafteraus- 
tausch auf Jahre hinaus verschieben würde. Unter Hinweis auf die mit Rumänien getroffene Regelung solle deutlich gemacht werden, daß eine pragmatische Lösung keine „Preisgabe des eigenen Standpunktes" sei.

116

117

118
04.04. Aufzeichnung des Botschafters Schnippenkötter

Schnippenkötter legt den Entwurf einer Kabinettsvorlage zur Abschaffung der TTD-Regelung vor. Er erörtert die Argumente für und gegen eine solche Maßnahme. Ein möglicher Vorteil wäre, daß die Bundesrepublik ihre Bereitschaft zur Entspannung zeigen und einen Vorwand beseitigen könnte, der von der DDR benutzt werde, um die Ausreise von Privatpersonen ins westliche Ausland zu unterbinden. Gegen die Abschaffung des TTD-Systems gibt Schnippenkötter jedoch zu bedenken, daß die Bundesrepublik dazu beitragen würde, die DDR als zweiten deutschen Staat in Erscheinung treten zu lassen. Vermutlich würde die DDR ihren Bürgern auch keine Reiseerleichterungen zugestehen, sondern vielmehr die „bisherige Erpressungspolitik" bestätigt sehen. Schließlich würden die Grundlagen der Deutschlandpolitik gefährdet, da sich alle NATO-Partner durch das TTD-System zur Viermächte-Verantwortung für Deutschland als Ganzes bekannt hätten. Schnippenkötter kommt zu dem Ergebnis, daß es keine überzeugenden Gründe zur Abschaffung des TTD-Systems gäbe. Eine solche Maßnahme sei nur im Rahmen einer neuen Deutschlandpolitik zu erwägen und dann mit Gegenleistungen der DDR zu verknüpfen, um nicht die Glaubwürdigkeit der Bundesrepublik in der Deutschland-Frage zu gefährden.

\section{7}

04.04. Bundeskanzler Kiesinger an Präsident Johnson

S. 530

Kiesinger greift den Vorschlag von Johnson auf, einen intensivierten und persönlichen Meinungsaustausch zu führen. Mit Blick auf die Dreier-Verhandlungen teilt er dessen Auffassung, daß Stärke und Gliederung der NATO-Streitkräfte von verteidigungspolitischen und nicht von ökonomischen Gesichtspunkten abhängig gemacht werden sollten. Da die in der DDR stationierten sowjetischen Streitkräfte in den letzten Jahren ständig verstärkt worden seien, dürften Truppenreduzierungen der NATO-Partner grundsätzlich nur bei einer entsprechenden Verminderung der sowjetischen Streitkräfte in der DDR durchgeführt werden. Hinsichtlich des Nichtverbreitungsabkommens würdigt Kiesinger die amerikanische Zusicherung, mittels Konsultationen eine für die Bundesrepublik annehmbare Lösungen zu finden. Die Bundesregierung werde sowohl „das hohe Ziel internationaler Entspannung und Friedenssicherung wie die Lebensinteressen" der Bundesrepublik berücksichtigen.

\subsection{Botschafter Herwarth von Bittenfeld, Rom, an das} Auswärtige Amt

Herwarth berichtet von Gesprächen des Bundesministers Brandt im Vorfeld der WEU-Ministerratstagung am 4./5. April 1967 in Rom. Der Generalsekretär im französischen Außenmi- 
nisterium habe die Bereitschaft des Staatspräsidenten de Gaulle angedeutet, an der geplanten Konferenz der Regierungschefs der EWG-Staaten in Rom unter der Voraussetzung teilzunehmen, daß die Frage eines britischen Beitritts zur EWG nicht auf der Tagesordnung stehe. Alphand habe weiter den Vorschlag der Bundesregierung abgelehnt, den Präsidenten der EWG-Kommission noch bis zu zwölf Monaten nach der Vereinigung der Exekutiven der europäischen Gemeinschaften im Amt zu belassen. Statt dessen bestehe die französische Regierung darauf, daß Hallstein am 31. Dezember 1967 zurücktrete. Der britische Außenminister Brown habe bereits für Mitte Mai 1967 eine Grundsatzerklärung zum EWG-Beitritt angekündigt. Alphand habe sich schließlich skeptisch über die Pläne der Bundesregierung geäußert, die ${ }_{\eta}$ an alle" gerichtete sowjetische Erklärung vom 28. Januar $1967 \mathrm{zu}$ beantworten, da eine Fortsetzung der Polemik zu nichts führe. an das Auswärtige Amt

Forster berichtet vom Verlauf der WEU-Ministerratstagung am 4./5. April 1967 in Rom. Der Unterstaatssekretär im italienischen Außenministerium, Lupis, informierte über den Besuch des Vorsitzenden des Obersten Sowjet. Podgornyj habe zwar den Willen zur Verbesserung der Beziehungen zu den westeuropäischen Staaten erkennen lassen, gleichzeitig aber auch einen starren Standpunkt gegenüber der Bundesrepublik eingenommen. Bundesminister Brandt erläuterte, daß die von der DDR mit Polen und der Tschechoslowakei abgeschlossenen Freundschaftsverträge eine Aufnahme diplomatischer Beziehungen zwischen der Bundesrepublik und den Ostblockstaaten erschwerten. Der britische Außenminister Brown berichtete über die Besuche des sowjetischen Ministerpräsidenten Kossygin und des polnischen Außenministers Rapacki in London. Die UdSSR wolle einen Keil zwischen die westlichen Verbündeten treiben. Dagegen sei bei Rapacki gegenüber früher eine spürbare Zurückhaltung hinsichtlich einer möglichen Teilnahme der USA an einer europäischen Sicherheitskonferenz zu beobachten gewesen. Dazu stellte Brandt fest, daß diese Frage vor Einberufung einer solchen Konferenz geklärt werden müßte. Es sei ebenso auszuschließen, daß die DDR ,einer staatlichen Anerkennung näherkommen" könne. amerikanischen Vizepräsidenten Humphrey

Kiesinger weist darauf hin, daß er die Mißverständnisse im deutsch-amerikanischen Verhältnis beseitigen wolle. Es gehe bei der Wiederbelebung des deutsch-französischen Vertrags von 1963 nicht darum, „von Amerika und dem atlantischen Bündnis wegzukommen". Vielmehr solle Frankreichs Haltung gegenüber der NATO positiver gestaltet werden. Humphrey stellt fest, daß die NATO angesichts der veränderten Lage in Europa in eine neue Situation eingetreten sei. Zwar sei die UdSSR 
vorsichtiger geworden, doch sei damit noch nicht der Zustand der Entspannung erreicht. Auch die NATO müsse ihrerseits eine neue Rolle übernehmen. Dazu sei ein stärkeres Europa nötig. Hinsichtlich der Kennedy-Runde verweist Humphrey auf die amerikanischen innenpolitischen Implikationen. Das Einbeziehen der Nahrungsmittelhilfe sei mit Blick auf den bevorstehenden Mangel auf dem Nahrungsmittelsektor in der Welt eine Verpflichtung der Industriestaaten. Beim Abkommen über die Nichtverbreitung von Kernwaffen sieht der Vizepräsident das Hauptproblem in der sowjetischen Weigerung, die EURATOMSicherheitskontrollen anzuerkennen. Damit die Bundesrepublik nicht von Inspektoren aus der UdSSR „oder aus den Satellitenstaaten belästigt werde“, müßten die Kontrollen von EURATOM und IAEO harmonisiert werden. Amt

Oncken faßt die Ergebnisse der Sitzung des Ständigen NATORats vom Vortag zusammen. Der Leiter der amerikanischen Abrüstungsbehörde erläuterte den revidierten amerikanischen Entwurf eines Nichtverbreitungsabkommens. Foster führte aus, daß die Aufnahme einer Verpflichtung der Nuklearstaaten zur Beendigung des Wettrüstens in die Präambel am sowjetischen Widerstand scheitere. Der im Vertrag nicht vorgesehene Schutz vor nuklearer Erpressung sei Angelegenheit der UNO. Hier könne allenfalls an einen Kompromiß auf Grundlage der von der Bundesregierung vorgeschlagenen "Wohlverhaltensklausel" gedacht werden. Foster widersprach dem von Botschafter Grewe vorgebrachten Einwand, daß NATO-Partner, die nicht an der Konferenz der 18-Mächte-Abrüstungskommission in Genf teilnähmen, bei der Vertragsformulierung benachteiligt würden. Oncken hebt abschließend hervor, daß sich die amerikanische Kritik wegen der Verzögerungen beim angestrebten Vertragsabschluß in erster Linie gegen die Bundesrepublik gerichtet habe. Da sich die USA offensichtlich der Unterstützung der anderen Ratsmitglieder bedienen wollten, um die Bundesrepublik zum Nachgeben zu veranlassen, rät Oncken von einer weiteren Erörterung im Ständigen NATO-Rat ab und empfiehlt statt dessen bilaterale Konsultationen.

122 06.04. Botschafter von Walther, Moskau, an das Auswärtige Amt

Walther teilt Einzelheiten aus einem Gespräch mit dem derzeitigen und mit dem ehemaligen amerikanischen Botschafter in Moskau, Thompson und Bohlen, mit. Hinsichtlich des Zustandekommens eines Nichtverbreitungsabkommens zeigten sich beide Diplomaten angesichts der italienischen Haltung pessimistisch. Walther sah dagegen in der gegenwärtigen Verweigerung der UdSSR lediglich die „alte russische Taktik“, bis zum letzten Moment „völlige Unnachgiebigkeit“ zu zeigen. Bohlen hielt an seiner schon auf der Konferenz von Jalta 1945 gezeigten Überzeugung fest, daß sich die USA und die UdSSR 
einigen müßten, um auf der Welt „eine Gleichgewichtslage zu schaffen". Er gab darüber hinaus zu erkennen, daß die Ablehnung des Status quo in Europa durch die Bundesrepublik einer solchen Einigung entgegenstehe; ebenso stelle die ablehnende Haltung der Bundesregierung in der Frage der Nichtverbreitung ein „Gefahrenmoment für die amerikanisch-sowjetischen Beziehungen" dar.

Kiesinger stellt die Fortsetzung der Wirtschaftshilfe für den Tschad trotz der schwierigen Finanzlage in Aussicht. Tombalbaye bezeichnet es als langfristiges Ziel, daß Afrika und Europa als „kolossale Macht ein drittes Element in der Welt" darstellen sollten. Allerdings sei eine Intensivierung der Beziehungen zur Bundesrepublik effektiver und damit „noch wünschenswerter" als die Zusammenarbeit mit der EWG. Dazu könnten vermehrte Reisen deutscher Geschäftsleute in den Tschad beitragen. Der Präsident bittet schließlich um Mithilfe beim Aufbau eines neuen Rundfunksenders in Fort Lamy und um die Genehmigung von Fleischexporten in die Bundesrepublik. Kiesinger sichert die Prüfung dieser Anliegen zu und erklärt, die Zusammenarbeit mit Frankreich auf dem Gebiet der Entwicklungshilfe auch im Hinblick auf Afrika „in Zukunft noch enger" gestalten zu wollen. britischen Außenminister Brown in London

Brandt empfiehlt, unmittelbar nach dem britischerseits angestrebten EWG-Beitrittsantrag die Verhandlungen aufzunehmen. Dies sei aus terminlichen Gründen jedoch nicht möglich, wenn der Antrag bereits im Mai gestellt würde. Der Versuch, mit der DDR Probleme von praktischer Bedeutung für die Bevölkerung anzugehen, sei ergebnislos geblieben. Die DDR gebe sich nun "starrer und feindseliger als je“. Dennoch bleibe die innerdeutsche Entspannung ein notwendiger Beitrag zur europäischen Entspannung. Während unter der Regierung Erhard die Wiedervereinigung das zentrale Ziel der Außenpolitik gewesen sei, mache sich die jetzige Bundesregierung die Bewahrung des Friedens zum Hauptziel, durch das die deutsche Einheit erreicht werden solle. Brown versichert, da $\beta$ die Wiedervereinigung zu den „absoluten Prioritäten“ der britischen Politik gehöre. Zur Frage der Nichtverbreitung betont Brandt die psychologische Bedeutung einer Regelung, nach der die westlichen Nuklearstaaten ihre zivilen Kernananlagen internationalen Sicherheitskontrollen unterwerfen würden. Zudem müsse eine Verbindung von EURATOM- und IAEO-Kontrollen gefunden werden. 
125

126

127

\subsection{Aufzeichnung des Vortragenden Legationsrats I. Klasse} Jung

Jung erörtert die Positionsvorteile der Bundesrepublik gegenüber der DDR. Dazu zählt er das Zögern der Dritten Welt vor einer weiteren Aufwertung der DDR, das TTD-System sowie die Zurückhaltung der Alliierten beim Ausbau der politischen und wirtschaftlichen Kontakte. Ein „unkontrollierter Abbau“ dieser Trümpfe würde die DDR ihrem außenpolitischen Nahziel näherbringen und die Glaubwürdigkeit der Deutschlandpolitik der Bundesrepublik beeinträchtigen. Jung schränkt jedoch ein, daß die voraussichtliche weitere Konsolidierung der DDR und die von der Bundesregierung eingeschlagene Entspannungspolitik zu gewissen Rücksichtnahmen zwängen. Es sei mit Rückwirkungen auf die Haltung des Auslands bis hin zur Anerkennung der DDR zu rechnen. Daher empfiehlt Jung Gegenleistungen des Ostens einzuhandeln wie die Bestätigung der Zugehörigkeit von Berlin (West) zur Bundesrepublik und die Garantie eines freien Zugangs zur Stadt. Die Bundesregierung solle jedoch gegenüber der DDR erst dann Konzessionen machen, wenn der Staatsratsvorsitzende Ulbricht einen Entspannungsbeweis bezüglich Berlins erbracht habe. britischen Außenminister Brown in London

Brown sichert $z u$, daß Großbritannien vorerst keine Kredite mit einer Laufzeit von mehr als fünf Jahren an die DDR vergeben werde. Für zwei bis fünfjährige Kredite schlägt er einen Informationsaustausch vor. Zum Devisenausgleich fordert Brown eine grundsätzliche Regelung für die kommenden Jahre, zumal die britische Regierung nicht jedes Jahr erneut „durch die erbärmliche Prozedur" gehen wolle, die zur jetzigen Vereinbarung geführt habe. Für die erste WEU-Ratssitzung nach $\mathrm{Ab}$ schluß der Dreier-Verhandlungen kündigt er eine Erklärung mit dem Ziel an, von der Verpflichtung entbunden zu werden, eine festgelegte Anzahl von Truppen auf dem europäischen Kontinent unterhalten zu müssen. Brandt wendet ein, daß der beabsichtigte Abzug einer britischen Brigade ebenso wie auch der amerikanische Rotationsplan "schwerwiegende Probleme“ aufwerfe, die Folgen für die NATO und das Ost-West-Verhältnis nach sich ziehen würden. Zur technologischen Kooperation mit Großbritannien schlägt Brandt einen Besuch des Staatssekretärs Lahr im Mai in London vor. Hinsichtlich der Lage in Rhodesien bittet Brown mit dafür Sorge zu tragen, da $\beta$ die von der UNO beschlossenen Boykottmaßnahmen von Unternehmen aus der Bundesrepublik eingehalten werden.

\subsection{Aufzeichnung des Staatssekretärs Schütz}

Schütz notiert die Ergebnisse von Gesprächen mit dem jugoslawischen Sonderbotschafter Belovski und mit dem tschechoslowakischen Stellvertretenden Außenminister Klička anläßlich der Jubiläumstagung der Europäischen Wirtschaftskommission am 11. April 1967 in Genf. Belovski machte deutlich, 
daß sich die positive jugoslawische Einstellung gegenüber der neuen Bundesregierung ändern könnte, wenn nicht baldige Fortschritte hinsichtlich der Aufnahme diplomatischer Beziehungen zu verzeichnen seien. Klička wies darauf hin, da $\beta$,jede Aktion gegen Ostberlin" den Normalisierungsprozeß mit den osteuropäischen Staaten erschwere. Zwar habe die tschechoslowakische Regierung dafür Verständnis, daß die Bundesrepublik die DDR nicht anerkennen wolle, aber eine „offenbare Isolierungspolitik könne auch von Prag nicht hingenommen“ werden. Klička lehnte schließlich die Entsendung einer Delegation zur Weiterführung der offiziellen Kontakte ab. Statt dessen bat er darum, als "Übergangslösung“ einen Handelsvertrag mit der Tschechoslowakei in Erwägung zu ziehen.

Frank informiert über die Sitzung des EWG- und EURATOMMinisterrats am 10./11. April 1967 in Brüssel. Die von Bundesminister Brandt abgegebene Erklärung über die Entwicklung der Europäischen Gemeinschaften fand allgemeine $\mathrm{Zu}$ stimmung. Dabei hoben der belgische und der niederländische Außenminister, Harmel und Luns, vor allem die Aussagen von Brandt über die Beziehungen der EWG zu Drittstaaten, die Notwendigkeit einer zügigen Fusion der Exekutiven und einer Verschmelzung der europäischen Gemeinschaften hervor. Der französische Ständige Vertreter Boegner teilte diese Ausführungen, äußerte sich jedoch nicht zu den Außenbeziehungen. Hinsichtlich des spanischen Antrags auf Assoziierung mit der EWG bezeichnete es Staatssekretär Lahr als eine „europäische Aufgabe", die demokratischen Kreise in Spanien durch eine entgegenkommende Politik der EWG zu stärken. Da keine Einigung über ein gemeinsames Vorgehen erzielt werden konnte, wurden die Ständigen Vertreter beauftragt, Vorschläge für ein Assoziierungsabkommen auszuarbeiten und dem Rat vorzulegen. Ein gleiches Verfahren wurde für die Abkommen mit den Maghreb-Staaten vereinbart. Botschaft in Ottawa

Jung informiert über eine Korrespondenz mit der Ständigen Vertretung bei der NATO in Paris. Am 5. April 1967 berichtete Botschafter Grewe über die kanadische Absicht, in Kanada lebende "ehemalige SBZ-Bürger" vor einer Einreise in die DDR wegen möglicher Repressalien aufgrund des Staatsbürgerschaftsgesetzes vom 20. Februar 1967 zu warnen. Am 7. April 1967 wurde der Ständigen Vertretung die Weisung erteilt, die kanadische Vertretung zu bitten, auf einen Aufschub dieser Warnung zumindest solange hinzuwirken, bis die Prüfung des Staatsbürgerschaftsgesetzes durch die Bundesregierung abgeschlossen sei. Zur weiteren Information wurde der Wortlaut eines Musterantwortschreibens des Bundesministeriums für gesamtdeutsche Fragen übermittelt. Darin wurde die Vermutung geäußert, daß „ehemalige SBZ-Flüchtlinge“ bei einem Besuch 
in der DDR „nicht stärker gefährdet sein werden als bisher". Daraufhin teilte die Ständige Vertretung am 12. April 1967 mit, daß die kanadische Delegation dem Wunsch entsprechen und die Stellungnahme der Bundesregierung zunächst abwarten wolle.

130

131

\subsection{Aufzeichnung des Ministerialdirigenten Sahm}

Sahm nimmt Stellung zu der Frage des Stimmrechts von Berlin (West) im Bundesrat. Aus dem Schriftwechsel des Bundesministers Brandt mit Bundesratspräsident Lemke gehe hervor, daß das Berliner Stimmrecht „bis zur Grenze der alliierten Vorbehalte auszuschöpfen" sei. Nur bei abschließenden Entscheidungen zu Gesetzen sollten die Berliner Stimmen nicht mitgezählt werden. Da sich das Auswärtige Amt bisher immer mit den Westmächten abgestimmt und der amerikanische Gesandte Hillenbrand davor gewarnt habe, daß jede Erweiterung des Stimmrechts für Abgeordnete aus Berlin (West) ohne Zustimmung der Alliierten „eine ernste Verstimmung auslösen“ könne, rät Sahm jedoch zu Konsultationen.

\subsection{Aufzeichnung des Botschafters Schnippenkötter,}

\section{z.Z. Washington}

Zur Vorbereitung der Sitzung des Bundesverteidigungsrats am 18. April 1967 faßt Schnippenkötter die Ergebnisse seiner Verhandlungen mit dem Leiter der amerikanischen Abrüstungsbehörde, Foster, vom 10. bis 14. April 1967 in Washington zusammen. Einige Wünsche der Bundesregierung zur Abrüstung und Entspannung konnten erfüllt werden, indem der Nuklearverzicht der Nichtkernwaffenstaaten in einen sachlichen und zeitlichen Zusammenhang mit der Abrüstung gestellt wurde. Bei der friedlichen Nutzung der Kernenergie und bei den Sicherheitskontrollen orientiert sich der neue amerikanische Entwurf für Artikel III eines Nichtverbreitungsabkommens zwar weitgehend an dem Vorschlag der Bundesregierung, bleibt aber insofern noch diskriminierend, als er einseitig die Kernwaffenstaaten von Kontrollen auf ihrem Territorium freistellt. Schnippenkötter weist abschließend darauf hin, daß die USA am 20. April 1967 die Zustimmung des Ständigen NATO-Rats erbitten wolle, um dann bei der Konferenz der 18-MächteAbrüstungskommission in Genf den Entwurf des Vertrags vorzulegen.

\subsection{Botschafter Grewe, Paris (NATO), an das Auswärtige Amt}

Grewe berichtet über die Sitzung des Ständigen NATO-Rats. Der französische Botschafter de Leusse lehnte einen gemeinsamen Beschluß des NATO-Rats über das Nichtverbreitungsabkommen ab, da die französische Regierung weder den Vertragstext noch die amerikanische Verhandlungsinitiative billigen könne. Die Frage der Nichtverbreitung müsse von den Regierungen in eigener Verantwortung entschieden werden. Der

\section{LXVIII}


amerikanische Vertreter „polemisierte lebhaft“ gegen diese Haltung, da sie den „Rat als politisches Organ überhaupt bedeutungslos" mache. In der anschließenden Diskussion wurde versucht, den kleinsten gemeinsamen Nenner zu finden, auf den sich die NATO bis zum angestrebten Ende der Konsultationen am 20. April 1967 einigen könnte. Dabei bezeichnete Cleveland die Anerkennung der Wünschbarkeit eines Nichtverbreitungsabkommens, das Einverständnis zur Vorlage eines amerikanischen Entwurfs und die Nichtfestlegung der Mitgliedstaaten auf den Vertragstext als Mindestinhalt einer solchen Formel.

Ungerer faßt für die Sitzung des Bundesverteidigungsrats am 18. April 1967 den Stand der EURATOM-Verhandlungen über ein Nichtverbreitungsabkommen zusammen. Die Kommission habe dem Rat am 10. Februar 1967 mitgeteilt, daß der amerikanische Entwurf des Artikels III eines Nichtverbreitungsabkommens vom 31. Januar 1967 den im EURATOM-Vertrag von 1957 festgelegten Grundsatz der Gleichheit der Mitgliedstaaten verletze. Bisher habe sich die Bundesrepublik nicht mit dem Vorschlag durchsetzen können, daß die Mitgliedstaaten eine einheitliche Haltung zum amerikanischen Entwurf einnehmen sollten. Vielmehr habe sich gezeigt, daß die Mehrheit im Ausschuß der Ständigen Vertreter die Antwort der Kommission ,in eigenem Namen und unter ausschließlich eigener Verantwortung" billige. Ungerer konstatiert abschließend, daß die Diskussion zumindest indirekt, nämlich über die Gespräche der Kommission und einzelner Mitgliedstaaten mit den USA, zur Neuformulierung des Artikels III und damit zur teilweisen Berücksichtigung der Bedenken der Bundesrepublik geführt hätten.

134 18.04. Gespräch des Bundeskanzlers Kiesinger mit dem israelischen Botschafter Ben Natan

Ben Natan führt aus, daß die Bundesrepublik viel dazu beitragen könne, eine Assoziierung Israels mit der EWG zu beschleunigen. Hinsichtlich der für $1967 \mathrm{zu}$ erwartenden Wirtschaftshilfe drückt er die Hoffnung auf denselben Betrag aus, den die Bundesrepublik bereits im vergangenen Jahr bezahlt habe, als die Verhandlungen langwierig und zum Teil nicht angenehm verlaufen seien. Insgesamt seien die bilateralen Beziehungen aber auf einem guten Weg. Kiesinger erinnert daran, daß die Nahostpolitik der Bundesregierung immer auch unter dem Einfluß des Verhältnisses der arabischen Staaten zur DDR stünde. Hinsichtlich einer Assoziierung Israels mit der EWG verweist er auf die „bestimmten Vorstellungen“ Frankreichs über die Begrenzung der Gemeinschaft. Zum Nichtverbreitungsabkommen erklärt Ben Natan, daß Israel zu keiner Zeit von den USA Kontrollbestimmungen verlangt habe. Die israelische Regierung strebe vielmehr ein allgemeines Abkommen der drei Westmächte und der UdSSR an, grundsätzlich keine Waffen mehr in den Nahen Osten zu liefern. 
135

\subsection{Botschafter Knappstein, Washington, an das} Auswärtige Amt

Knappstein faßt den Stand der deutsch-amerikanischen Konsultationen über ein Nichtverbreitungsabkommen zusammen. Er vermutet, daß das von Präsident Johnson veranlaßte „überraschende Einlenken" bei der Formulierung strittiger Punkte auf den Wunsch zurückzuführen ist, einen offenen Gegensatz zur Bundesrepublik und die damit verbundenen Folgen für die NATO zu vermeiden. Der Bundesrepublik komme nun eine Schlüsselposition zu, in der sie ihre berechtigten Interessen wahren solle, ohne dabei als „Störenfried“ dargestellt werden zu können. Die Bundesregierung müsse sich darüber klar werden, welche Forderungen sie noch aufrechterhalten wolle. Zu den offenen Verfahrensfragen empfiehlt der Botschafter die Formulierung eines Vorbehalts, der aber nicht die amerikanisch-sowjetischen Gespräche behindern solle. Schließlich gelte es, die Haltung zum Nichtverbreitungsabkommen im Zusammenhang mit der Entspannungs- und Ostpolitik zu sehen und dabei nicht zuletzt auch die amerikanische Unterstützung der Deutschlandpolitik zu sichern.

Hassouna bittet um eine Erklärung der Bundesregierung zum Selbstbestimmungs- und Heimatrecht der Palästinenser. Er lehnt die Verteilung der Flüchtlingshilfe durch die UNRWA ab und fordert statt dessen entweder Zahlungen an die Arabische Liga oder an die Aufnahmestaaten. Zur Frage einer Assoziierung Israels mit der EWG erklärt Hassouna, daß dadurch "große Schwierigkeiten" im Verhältnis zwischen den arabischen Staaten und der EWG entstehen könnten. Entscheidend sei, daß die Bundesrepublik keine führende Rolle bei der Vermittlung zwischen Israel und der EWG übernehme. Brandt erklärt, daß er die Verteilung von Flüchtlingshilfe über die UNRWA für den besseren Weg halte, aber dennoch das Problem der Bundesregierung vortragen wolle. Es sei auch zu prüfen, ob angesichts der bevorstehenden Konferenz der Arabischen Liga am 9. Mai 1967 eine öffentliche Erklärung über die Gespräche mit Hassouna abgegeben werden könne. Dazu stellt der Generalsekretär nachdrücklich fest, daß dies notwendig sei, zumal der "heruntergelassene Vorhang" zwischen der Bundesrepublik und den arabischen Staaten „ohne die Liga niemals wieder aufgezogen werden" könne. Außenminister Rusk

Brandt bezeichnet den Verlauf der Konsultationen vom 10. bis 14. April 1967 in Washington als erfolgreich. Er dankt für die Bereitschaft, auch langfristig für das deutsche Reaktorprogramm angereichertes Uran oder Plutonium zur Verfügung zu stellen. Durch die amerikanische Zusicherung, ihre zivilen Nuklearanlagen internationalen Sicherheitskontrollen zu un- 
terwerfen, seien die deutschen Bedenken wegen einer möglichen Beeinträchtigung der Wettbewerbsfähigkeit ausgeräumt worden. Eine baldige Vereinbarung zwischen EURATOM und LAEO solle nun von allen Beteiligten nachdrücklich gefördert werden. Brandt würdigt abschließend die amerikanische $\mathrm{Zu}$ stimmung zu einer Neuformulierung des Artikels III des Entwurfs für ein Nichtverbreitungsabkommen, wonach sich die Dreijahresfrist lediglich auf einen Abschluß des Abkommens zwischen IAEO und EURATOM beziehe.

Kiesinger weist darauf hin, daß die vom Auswärtigen Amt in Vorbereitung der Gespräche anläßlich der offiziellen Trauerfeierlichkeiten für den verstorbenen ehemaligen Bundeskanzler Adenauer angefertigten Aufzeichnungen in wichtigen Punkten von seinen eigenen Vorstellungen abweichen. Zur Gesprächsmappe für die Unterredungen mit Präsident Johnson bemängelt er den fehlenden Hinweis auf die bislang von deutscher Seite geforderte Befristung des Nichtverbreitungsabkommens auf zehn Jahre. Bei der Unterlage für das Gespräch mit Staatspräsident de Gaulle wendet er sich gegen den Vorschlag, noch vor der Sommerpause offizielle Verhandlungen mit Großbritannien aufzunehmen. Kiesinger rät zu größerer Zurückhaltung, da der französischen Regierung zuerst Gelegenheit gegeben werden müsse, sich dazu zu äußern. Zur Vorlage für die Unterredung mit Premierminister Wilson spricht sich der Bundeskanzler hinsichtlich der deutsch-britischen technologischen Zusammenarbeit dafür aus, auf französische Interessen Rücksicht zu nehmen. Es dürfe nicht noch einmal „der Eindruck einer das deutsch-französische Verhältnis abwertenden zwielichtigen Politik entstehen ${ }^{“}$. amerikanischen Außenminister Rusk

Rusk äußert den Wunsch, Mißverständnisse zu beseitigen, die in der letzten Zeit aufgekommen seien. Gerüchte, nach denen die USA die Denuklearisierung der Bundesrepublik betrieben, seien ebenso "verrückt" wie der Gedanke einer amerikanischsowjetischen Vereinbarung über die Nichtverbreitung von Kernwaffen "hinter dem Rücken der Europäer". Zum Hinweis von Brandt über eine zeitliche Begrenzung des Nichtverbreitungsabkommens erklärt Rusk, daß dem Vertrag bei der Ratifizierung vielleicht eine Präambel vorangestellt werden könne. Bei den Verhandlungen der Konferenz der 18-Mächte-Abrüstungskommission in Genf gebe es bisher keine Einigung mit der UdSSR. Vielmehr seien noch ernsthafte Probleme zu erwarten. Zum Vietnamkrieg stellt Rusk fest, daß sich die Gegenseite trotz großer Verluste verschlossen zeige und keine Bereitschaft zu Konzessionen andeute. Es müsse etwas geschehen, „denn so wie es jetzt sei, könne es nicht unbegrenzt weitergehen". 

Ministerpräsident Moro

Moro erwartet von der bevorstehenden Konferenz der Staatsund Regierungschefs der EWG am 29./30. Mai 1967 in Rom den Auftakt zu einer „vertrauensvolleren Wiederaufnahme des europäischen Dialogs“. Er sieht bei der französischen Regierung eine gelassene und aufgeschlossene Bereitschaft, auch Themen wie einen möglichen britischen EWG-Beitritt zu besprechen. Zur Nichtverbreitung von Kernwaffen bemerkt er, daß der amerikanische Abkommensentwurf vom 14. April $1967 \mathrm{Anla} \beta$ zu Zweifeln und Besorgnissen biete. Kiesinger teilt diese Einschätzung und weist auf einige Fragen hin, die trotz eines nicht unerheblichen amerikanischen Entgegenkommens offen geblieben seien. Dazu zähle die ungenügende Berücksichtigung einer europäischen Einigung, denn ein vereintes Europa brauche eine moderne Verteidigungsorganisation. Zudem sei es für die Bundesrepublik schwierig, gegenüber der UdSSR, die eine so „unnachgiebige Härte in den großen nationalen Fragen Deutschlands zeige", Verpflichtungen einzugehen. Kiesinger resümiert, daß die Erwartungen beider Staaten hinsichtlich eines Nichtverbreitungsabkommens - abgesehen von spezifisch deutschen Fragen - fast identisch seien.

141 24.04. Aufzeichnung des Bundesministers Brandt

Brandt skizziert die Ergebnisse einer inoffiziellen Unterredung mit dem dänischen Ministerpräsidenten am 23. April 1967 in Kopenhagen. Krag erläuterte das dänische Interesse an einer Auflockerung des TTD-Systems. Brandt stellte entsprechende Beratungen der Bonner Vierergruppe in Aussicht. Zur Frage eines EWG-Beitritts kündigte Krag an, daß Dänemark den Antrag gleichzeitig mit Großbritannien stellen wolle. Er zeigte sich jedoch besorgt darüber, daß das britische Gesuch bevorzugt behandelt werden könnte. Brandt sicherte abschließend zu, sich um die Möglichkeit einer Sitzung des Kontaktausschusses der dänischen Minderheit in Süd-Schleswig zu kümmern, da dieser bereits seit längerer Zeit nicht mehr getagt habe. Staatspräsident de Gaulle in Köln

Kiesinger erläutert, daß sich bei den deutsch-amerikanischen Beziehungen eine "seltsame Lage" entwickelt habe, die dazu Anlaß gebe, mit den USA offen zu sprechen. Die amerikanische Regierung plane einseitig umfangreiche Truppenreduzierungen, ohne den Versuch zu unternehmen, auch einen Abbau der sowjetischen Truppen in der DDR zu erreichen. Da der $\mathrm{Zu}-$ stand der NATO nicht mehr befriedigend sei, müsse die Substanz des Bündnisses überprüft und die gemeinsame Interessenlage festgestellt werden. De Gaulle bemerkt dazu, daß sich die Bundesrepublik gegenüber den USA aufgrund der nachlassenden sowjetischen Bedrohung, der Verständigung mit Frankreich und wegen der allgemeinen Stellung in der Welt sogar in 
der besseren Position befinde. Eine gemeinsame Haltung gegenüber den USA könne die Bundesrepublik mit Frankreich zusammenbringen. Zur Nichtverbreitung von Kernwaffen stellt Kiesinger fest, daß die Bundesregierung das Abkommen nach dem gegenwärtigen Stand der Dinge nicht unterzeichnen könne, weil sie keine „ewige politische Bindung“ gegenüber der UdSSR eingehen wolle. Ein befristeter Vertrag böte zudem den Vorteil, daß während dessen Laufzeit die Abrüstung vorangetrieben werden könnte.

Zur Frage eines britischen EWG-Beitritts erklärt Wilson, daß eine Mitgliedschaft wirtschaftlich zwar einen hohen Preis fordere, langfristig aber dennoch einen Gewinn für Großbritannien darstelle. Auch der europäischen Einheit könne so ein neuer Aufschwung verliehen werden. Für den Fall, daß der in Kürze zu erwartende Beitrittsantrag abgelehnt würde, warnt Wilson vor einer ernsten Situation, aus der " neue Gruppierungen“" entstünden. Nur ein wirtschaftlich starkes Europa könnte auch den politischen Zusammenhalt festigen. Kiesinger stellt zur Nichtverbreitung von Kernwaffen fest, daß die Bundesrepublik die Befristung eines entsprechenden Abkommens auf zehn Jahre anstrengen werde.

Ruete nimmt Stellung zu der von Staatssekretär Schütz am 8. April 1967 gebilligten Reinschrift einer Kabinettsvorlage des Auswärtigen Amts. Er gibt zu bedenken, daß die darin vorgeschlagene Abschaffung der TTD-Regelung nicht die Anregung von Abteilung II berücksichtigte, dafür bei der DDR Gegenleistungen einzufordern. Konzessionen könnten beispielsweise in Form von Reiseerleichterungen bestehen. Die Verwirklichung dieses Vorschlags würde „vor den Augen der Öffentlichkeit" die Bemühungen der Bundesregierung um größere Freizügigkeit für DDR-Bürger demonstrieren und den Eindruck vermeiden, als ob die Bundesregierung „dem Druck des Ostens in der TTDFrage" ausweiche. Schließlich könnte ein immer noch möglicher einseitiger Verzicht auf die TTD-Regelung dann als Vorleistung und Entspannungsgeste dargestellt werden.

Ruete legt einen Sprechzettel für die Sitzung des Bundeskabinetts am 26. April 1967 zum Stand der Dreier-Verhandlungen und zum amerikanischen Rotationsplan vor. Es sei ein wichtiger deutscher Verhandlungserfolg, daß der Devisenausgleich mit den USA erstmals nicht mehr ausschließlich durch die Beschaffung militärischer Güter erfüllt werden müßte. Auch bei den Verhandlungen mit Großbritannien seien die angekündigten drastischen Verminderungen der Rheinarmee mit dem Abzug von nur einer Brigade und von zwei Luftwaffenstaffeln abgewendet worden. Der von den USA vorgelegte Rotationsplan 
sehe den Abzug von zwei Brigaden und sechs Jagdbomberstaffeln vor, die innerhalb von $30 \mathrm{bzw} .10$ Tagen wieder in die Bundesrepublik zurückverlegt werden könnten. Sowohl die abgezogenen britischen Truppen wie auch die amerikanischen Einheiten blieben der NATO assigniert. Das Bundesministerium der Verteidigung sehe in dem Rotationsplan kein schwerwiegendes oder unannehmbares Sicherheitsrisiko. Trotz der verbleibenden politischen Bedenken empfiehlt Ruete die Annahme des Rotationsplans, um die sehr günstige Devisenregelung nicht zu gefährden und die ständigen deutsch-amerikanischen Friktionen in der Truppenfrage beizulegen. ehemaligen Ministerpräsidenten Ben Gurion

Ben Gurion würdigt die Leistung des am 19. April 1967 verstorbenen Konrad Adenauer beim „materiellen Aufbau und der moralischen Wiederaufrichtung" von Israel und bei der Gestaltung des deutsch-israelischen Verhältnisses. Kiesinger betont, daß die Bundesrepublik trotz ernster Schwierigkeiten versuchen werde, den Betrag der Anleihe im Rahmen des diesjährigen Wirtschaftshilfeabkommens auf dem bisherigen Stand zu halten. Zur angestrebten Assoziierung Israels mit der EWG erklärt er, die Bundesrepublik wolle sich keinesfalls - wie es vielleicht den Anschein habe - „hinter dem Rücken anderer verstecken“. Jedoch lasse der von der EWG-Kommission zu erwartende Bericht voraussichtlich keine günstigen Schlußfolgerungen zu. Abschließend gibt Ben Gurion seine Einschätzung über die weltpolitische Lage und die Bedeutung der deutschfranzösischen Beziehungen für die Idee eines geeinten Europa wieder.

\section{Präsident Johnson}

Kiesinger verweist auf die Zweifel, die in der Bundesrepublik angesichts der amerikanischen Europapolitik bestünden. So stelle sich die Frage, warum die USA die Zahl der in der Bundesrepublik stationierten Jagdbomber um die Hälfte verringern wolle, ohne mit der UdSSR über vergleichbare Maßnahmen $\mathrm{zu}$ verhandeln. Auch hinsichtlich der Nichtverbreitung könnten die USA ihren Einfluß auf die UdSSR ausüben, „um die Kriegsgefahr zu verringern“. Die Bundesrepublik trete für eine Befristung des Vertrags auf zehn Jahre ein. Zudem strebe sie nach echter Konsultation und nach staatlicher Wiedervereinigung, die von den Verbündeten unterstützt werde. Johnson bemerkt dazu, daß auch in der amerikanischen Öffentlichkeit Zweifel über die Haltung der Bundesrepublik aufgekommen seien. Es werde danach gefragt, ob die USA weiterhin für 500000 amerikanische Soldaten in Europa jährlich 1 Milliarde Dollar ausgeben sollten. Eine Befristung des Nichtverbreitungsabkommens sei angesichts der sowjetischen Widerstände nicht durchsetzbar. Johnson ermuntert Kiesinger zur offenen Aussprache, die zu jeder Zeit stattfinden könne. Das bilaterale 
Verhältnis dürfe nicht getrübt werden. Es werde „allen Kolumnisten, Kommunisten und Primadonnen der Welt nicht gelingen, ihn mit dem deutschen Volk zu entzweien". Graf York von Wartenburg

York von Wartenburg notiert die Ergebnisse eines Gesprächs des Bundesministers Brandt mit dem israelischen Außenminister am 24. April 1967. Eban äußerte die Hoffnung, daß sich die Bundesregierung vor allem gegenüber Frankreich für eine Assoziierung Israels mit der EWG einsetzen werde. Die israelische Regierung messe einer solchen Unterstützung ebenso groBes Gewicht bei wie seinerzeit dem Abschluß des Abkommens vom 10. September 1952 über die Wiedergutmachung oder dem Botschafteraustausch vom 12. Mai 1965. Brandt sicherte eine kooperative Haltung zu. Allgemein strebe die Bundesregierung in der EWG eine vernünftige Regelung der Wirtschaftsbeziehungen zum gesamten Mittelmeerraum an. Er bestätigte, daß das deutsch-israelische Verhältnis kein Verhandlungsobjekt bei den Gesprächen mit den arabischen Staaten über eine Wiederaufnahme der diplomatischen Beziehungen sein könne.

Lahr nimmt Stellung zu einer Aufzeichnung der Politischen Abteilung II über die Frage einer Anerkennung der OderNeiße-Linie im Falle einer Wiedervereinigung. Er teilt die darin vertretene Auffassung, daß die sowjetische Garantie gegenüber den angeblichen revanchistischen Absichten der Bundesrepublik Deutschland das wesentliche Kettenglied sei, das Polen an die UdSSR binde. Eine bedingte Anerkennung der Oder-Neiße-Linie würde daher das Verhältnis zwischen der Bundesrepublik und Polen aus seiner Erstarrung lösen. Auch die sowjetische Regierung käme dann nicht umhin, über die gegenwärtig starre Haltung in der Deutschland-Frage nachzudenken. Trotz der zu erwartenden innenpolitischen Schwierigkeiten empfiehlt Lahr einen entsprechenden Vorstoß. Denn die Bundesregierung müsse bei einer Aufrechterhaltung der Ziele Wiedervereinigung und Wiederherstellung der Grenzen von 1937 damit rechnen, beides zu verlieren. Lindenberg

Meyer-Lindenberg stellt eine Verbesserung der deutsch-französischen Beziehungen seit dem Regierungswechsel in der Bundesrepublik fest. Die französische Bereitschaft zu einer Intensivierung der Beziehungen sei zum einen darauf zurückzuführen, daß die neue Bundesregierung über eine breite parlamentarische Mehrheit verfüge, und zum anderen darauf, daß sie gegenüber den amerikanischen Wünschen eine feste Haltung eingenommen habe. Auch die Einbeziehung der DeutschlandFrage in eine gesamteuropäische Friedensordnung entspreche 
dem Grundgedanken der französischen Ostpolitik. Bei den Bemühungen um die politische Zusammenarbeit in Europa sieht Meyer-Lindenberg allerdings Schwierigkeiten wegen der französischen Haltung gegenüber einem britischen EWG-Beitritt. Bundesministerium für Wirtschaft, z.Z. London

Thieme berichtet über die Abschlußsitzung der DreierVerhandlungen am 27./28. April 1967 in London. Der von den Regierungen bereits gebilligte Entwurf eines deutsch-britischen Abkommens über Devisenausgleich und Truppenverminderung gelte für den Zeitraum vom 1. April 1967 bis zum 31. März 1968. Danach werde die britische Regierung eine Heeresbrigade und ein Hubschraubergeschwader nach Großbritannien verlegen. Der im deutsch-amerikanischen Abkommensentwurf ausgeführte Rotationsplan sehe den Abzug von bis zu 35000 amerikanischen Soldaten aus der Bundesrepublik vor, die jedoch der NATO unterstellt bleiben und im regelmäßigen Rotationsverfahren mit anderen Einheiten in der Bundesrepublik ausgetauscht würden. Die finanziellen deutsch-amerikanischen Absprachen für die Periode vom 1. Juli 1967 bis zum 30. Juni 1968 beträfen militärische Beschaffungen in den USA und eine Vereinbarung zwischen den Notenbanken beider Staaten. Nach Ansicht des Bundesministeriums der Verteidigung seien die Truppenreduzierungen vertretbar geworden, nachdem sowohl Großbritannien als auch die USA einige Modifizierungen vorgenommen hätten. Allerdings habe die Aufnahme eines Hinweises in das Begleitschreiben der drei Delegationsleiter an ihre Regierungen über die Notwendigkeit zukünftiger Ausgleichszahlungen nicht verhindert werden können.

Brandt informiert, daß das neu eingerichtete Amt des Parlamentarischen Staatssekretärs mit dem SPD-Abgeordneten Jahn besetzt worden sei. Zu dessen Aufgabenbereich zähle die Pflege der Verbindungen des Auswärtigen Amts zu Bundestag und Bundesrat, deren Ausschüssen und zu den Parteien. Darüber hinaus könne der Bundesminister ihm weitere Aufgaben aufgrund besonderer Weisung übertragen. Zu diesem Zweck sei der Parlamentarische Staatssekretär über Angelegenheiten von politischer oder sonstiger grundsätzlicher Bedeutung laufend zu unterrichten. Ferner sei er befugt, Auskünfte und Aktenvorlagen zu verlangen. Er führe die Amtsbezeichnung „Der Parlamentarische Staatssekretär des Bundesministers des Auswärtigen“.

\section{02.05. Aufzeichnung des Ministerialdirektors Ruete}

Ruete faßt die Ergebnisse der Konsulationsgespräche mit Japan am 24. April 1967 zur Frage eines Nichtverbreitungsabkommens zusammen. Die japanische Regierung trete ebenfalls dafür ein, daß die Nuklearstaaten die gleichen Verpflichtungen zur nuklearen Abrüstung übernehmen sollten wie die Nicht- 
nuklearstaaten. Die japanische Delegation habe auch ihren Wunsch zum Ausdruck gebracht, daß eine friedliche Nutzung der Kernenergie gewährleistet sein und die Möglichkeit zur Durchführung von Nuklearexplosionen zu diesem Zweck offengehalten werden müsse. Bezüglich der Sicherheitskontrollen stehe Japan regionalen Kontrollsystemen wegen der eigenen IAEO-Unterstellung wenig aufgeschlossen gegenüber. Schließlich sei deutlich geworden, daß3 die Festschreibung einer unbefristeten Geltungsdauer in einem nicht unter gleich starken Vertragspartnern geschlossenen Abkommen als eine „amoralité juridique" aufgefaßt werde.

Schnippenkötter beschäftigt sich mit den Einwänden der UdSSR gegen den Vorschlag der Bundesregierung über den Austausch von bilateralen Gewaltverzichtserklärungen und setzt sich mit dem „Karlsbader Aktionsprogramm" vom 26. April 1967 auseinander, in dem die Ostblock-Staaten den Abschluß eines Gewaltverzichtsvertrages aller europäischen Staaten vorschlugen. Weil in einem solchen Vertrag die DDR als gleichberechtigter Vertragspartner einbezogen würde, sollte der Westen ihn ablehnen. Darüber hinaus würde diese Entwicklung den Bemühungen der Bundesregierung, das Deutschland-Problem gerade mit dem Mittel des bilateralen Gewaltverzichts zu lösen, entgegenwirken. Im Hinblick auf die Einbeziehung der in der Bundesrepublik stationierten fremden Truppen sei es wünschenswert, wenn auch die Drei Mächte eigene Angebote an die UdSSR richteten. Dem sowjetischen Botschafter Zarapkin solle deshalb vermittelt werden, daß es der Bundesregierung darauf ankomme, den anderen Teil Deutschlands "so wenig, wie mit dem Zweck des Gewaltverzichts verträglich, zu diskriminieren“. Gleichzeitig sollten Bundeskanzler Kiesinger und Bundesminister Brandt öffentlich für den Austausch von Erklärungen zwischen den Mitgliedstaaten der beiden Bündnisse eintreten, so daß ein „Netz von Gewaltverzichten“ deren jeweilige Gebiete, d.h. auch die DDR, überziehe. Auswärtige Amt

Grewe berichtet über die Diskussion im Ständigen NATO-Rat anläßlich des Abschlusses der Dreier-Verhandlungen. Seitens der übrigen NATO-Mitgliedstaaten sei vor allem bedauert worden, da $\beta$ das Prinzip der Rückverlegung amerikanischer und britischer Truppen praktisch bereits angenommen sei. Sie hätten deshalb nicht ausgeschlossen, daß ähnliche Erklärungen wie die der Bundesrepublik, Großbritanniens und der USA mit der gleichen politisch-militärischen Zielsetzung abgegeben würden. Ferner sei darauf hingewiesen worden, daß das Ergebnis der Dreier-Verhandlungen gerade jene Regierungen dem Druck der Öffentlichkeit aussetze, die ihre Streitkräfte auf dem bisherigen Stand halten wollten. Er, Grewe, habe demgegenüber ausgeführt, daß die beabsichtigte Rückverlegung von Truppen 
keine Ideallösung darstelle, sondern vielmehr Resultat einer realistischen Einschätzung harter Tatsachen sei. Er würde es für verhängnisvoll halten, wenn die britischen und amerikanischen Maßnahmen zu einem "Schneeballsystem" bei den übrigen Verbündeten führten.

156

\subsection{Aufzeichnung des Botschafters Emmel}

Emmel berichtet über die Besprechungen der Gemischten Kommission der Bundesrepublik und Jugoslawiens vom 24. bis 29. April 1967 in Belgrad. Das angestrebte Ziel, einige Konzessionen zu gewähren, andererseits aber „Kapital“ für zu führende Wirtschaftsverhandlungen in der Hand zu behalten, sei in vollem Umfang erreicht worden. Gleichzeitig seien mit der Übergabe eines jugoslawischen Entwurfs für ein langfristiges Handelsabkommen, der eine Berlin-Klausel enthalte, die Voraussetzungen für die Aufnahme von Wirtschaftsverhandlungen noch in diesem Jahr geschaffen worden. Der Botschafter tritt dafür ein, möglichst bald mit den seit 1964 ausstehenden Verhandlungen zur Regelung der Beschäftigung jugoslawischer Gastarbeiter in der Bundesrepublik zu beginnen. Sonst werde die derzeitige positive Einstellung Jugoslawiens gegenüber der Bundesrepublik schlagartig einen neuen Tiefpunkt erreichen und auch durch die künftigen Wirtschaftsverhandlungen nicht wieder hergestellt werden.

\subsection{Aufzeichnung des Referats II A 7}

Referat II A 7 nimmt zu der neuen Ministerweisung an die NATO-Militärbehörden Stellung, die am 9. Mai 1967 vom Ausschuß für Verteidigungsplanung (DPC) beraten werden solle. Die Revision des seit 1956/57 geltenden Konzepts der „massive retaliation" sei notwendig geworden, weil es kaum noch strategische Vorteile biete. Es lasse letztlich nur die Wahl zwischen Kapitulation und Selbstzerstörung, erlaube aber keinen differenzierten Einsatz von Atomwaffen. Dabei sei ein nuklearer Überraschungsangriff die am wenigsten wahrscheinliche, ein kleinerer Angriff mit begrenzten Zielen die wahrscheinlichste Form eines Angriffs. Schließlich sei zu bedenken, daß der Einsatz strategischer oder taktischer Nuklearwaffen zur Verwüstung von Deutschland führen würde. Es liege daher im Interesse der Bundesrepublik, auch eine konventionelle Option in die NATO-Strategie einzubeziehen und damit die Glaubwürdigkeit der Abschreckung wiederherzustellen. Die Bundesregierung wolle erreichen, daß sie die Möglichkeit eines Einspruchsrechts auf politischer Ebene gegen den Einsatz von Nuklearwaffen auf dem Gebiet der Bundesrepublik erhalte. Die Umstellung auf eine Strategie der „flexible response“ beruhe auf einem Konzept der Krisenbeherrschung. Sie sei annehmbar, weil sie ein ausgewogenes System konventioneller und nuklearer Verteidigung erlaube. Allerdings müsse dem Bestreben der USA entgegengetreten werden, die nukleare Komponente noch weiter in den Hintergrund treten zu lassen, zumal die französische Atomstreitmacht den amerikanischen Nuklearschirm nicht ersetzen könne. 
Diehl führt aus, daß die Einrichtung von Raketenabwehrsystemen unwirtschaftlich und militärisch fragwürdig sei. Könnten die Raketen zur Fernabwehr von Langstreckenraketen in großer Höhe leicht durch Täuschungsflugkörper abgelenkt werden, so berge die Alternative, eine Nahabwehr auf der letzten Strecke der Flugbahn, die Gefahr starker Strahlungs- und Fall-out-Schäden. Der Aufbau eines Raketenabwehrsystems müsse zudem durch umfangreiche Maßnahmen zum Schutz der Zivilbevölkerung flankiert werden. $\mathrm{Zu}$ bedenken sei ebenfalls, daß das militärische Kräfteverhältnis nicht grundlegend verändert würde und das Gleichgewicht des Schreckens bestehen bleibe. Dagegen sei vorstellbar, daß die Bedeutung der Nuklearmächte der „zweiten Kategorie“, also Großbritanniens, Frankreichs und der Volksrepublik China, abnehme, da ein Abwehrsystem gegenüber einem schwachen Gegner auch mit einfach konstruierten Flugkörpern durchaus wirkungsvoll sein könne. Angesichts der Enge des Raumes in Europa, dessen dichter Besiedelung und der schwer tragbaren finanziellen Lasten sei es unwahrscheinlich, daß die europäischen Mitgliedstaaten der NATO ein eigenes Raketenabwehrsystem aufzubauen versuchten. Diehl empfiehlt stattdessen, dem zivilen Bevölkerungsschutz den Vorrang zu geben. Kaiser Haile Selassie I.

Haile Selassie I. erläutert den geplanten Bau eines „Mehrzweckprojekts" in Äthiopien. Gedacht sei an eine Fabrik, deren primäre Aufgabe die Produktion landwirtschaftlichen Geräts sei, die aber gleichzeitig auch Munition herstellen könne. Er erinnere daran, daß Somalia von der UdSSR „ungeheure Waffenmengen" erhalten habe. Der äthiopische Kaiser spricht den Wunsch aus, daß sich die Bundesrepublik etwa in Form einer Anleihe an der Finanzierung der "Mehrzweckfabrik“ beteiligen werde. Der Bundeskanzler erinnert an die Schwierigkeiten, denen die Bundesrepublik nach Bekanntwerden der Waffenlieferungen an Israel ausgesetzt gewesen sei, und verweist darüber hinaus auf die schlechte Finanzlage. Gleichwohl werde er sich ernsthaft für das Vorhaben einsetzen. Eine deutsch-äthiopische Sachverständigenkommission solle das Projekt prüfen. Die Bundesrepublik wisse, daß Äthiopien einen Hort der Freiheit und Menschenwürde in Afrika darstelle. türkischen Außenminister Çaglayangil

Çaglayangil teilt über den Besuch seines polnischen Amtskollegen in der Türkei mit, daß die polnische Regierung von der neuen Bundesregierung enttäuscht sei. Rapacki habe hervorgehoben, daß vor allem die Frage der Oder-Neiße-Linie für Polen von vitaler Bedeutung sei und es darüber tatsächlich einmal zum Krieg kommen könne. Er, Çaglayangil, habe erwidert, daß er zwar den polnischen Wunsch nach Klärung der Grenz- 
frage verstehe; allerdings sei dann die polnische Haltung in der Frage der Teilung Deutschlands unverständlich. Darauf habe Rapacki geantwortet, er könne sich vorstellen, daß einmal ein Tag kommen werde, an dem sich Polen an allem, was außerhalb seiner Grenzen vorgehe, desinteressiert zeige. Zur Situation in Zypern führte Brandt aus, daß die Bundesregierung eine friedliche Lösung auf dem Verhandlungswege wünsche, zuvor jedoch die weitere Entwicklung in Griechenland abwarten müsse. Çaglayangil erwiderte, niemand könne erwarten, daß die Zurückhaltung der Türkei noch lange anhalten werde. Die türkische Bevölkerung in Zypern werde „auf die gemeinste Weise behandelt". in Sofia

Ruete bittet die Handelsvertretung, gegenüber dem bulgarischen Außenminister Baschew erneut den Wunsch der Bundesregierung nach einer Normalisierung des bilateralen Verhältnisses zum Ausdruck zu bringen. Ein Botschafteraustausch werde nicht von Vorbedingungen abhängig gemacht. Allerdings müßten unter Wahrung der beiderseitigen Standpunkte pragmatische Regelungen etwa in der Frage des Rechtsschutzes für Deutsche mit Wohnsitz in Berlin (West) gefunden werden. Dann ließen sich auch innenpolitische Hemmnisse in der Bundesrepublik gegenüber einem Ausgleich des Handels mit Bulgarien überwinden und die wirtschaftlichen Beziehungen intensivieren. Die Bundesregierung sei zu baldigen Verhandlungen über die Aufnahme diplomatischer Beziehungen bereit. Auswärtige Amt

Sattler berichtet, er habe Papst Paul VI. darüber in Kenntnis gesetzt, daß das Bundeskabinett noch keinen Beschluß über die vom Heiligen Stuhl geplante Neuregelung der Kirchenverwaltung in den Ostgebieten des Deutschen Reichs unter fremder Verwaltung gefaßt habe. Allerdings bestehe Interesse daran, daß im Falle der Ernennung von vier Apostolischen Administratoren die Stellung der Kapitularvikare für Breslau, Ermland und Schneidemühl unverändert bleibe. Der Papst habe darauf hingewiesen, daß die anstehenden Veränderungen aus pastoralen Gründen notwendig seien und es sich dabei um eine rein kirchliche Maßnahme handele, die das Konkordat zwischen dem Deutschen Reich und dem Heiligen Stuhl von 1933 nicht berühre. Ferner habe Paul VI. darauf aufmerksam gemacht, daß gegen den Verbleib der Kapitularvikare im Amt kirchenrechtliche Einwände bestünden. Dessenungeachtet werde der Heilige Stuhl die gegenwärtigen Verhältnisse in diesen Gebieten als Provisorium betrachten; ein späterer Friedensvertrag werde nicht präjudiziert. 
163

11.05. Aufzeichnung des Vortragenden Legationsrats I. Klasse Scheske

Scheske berichtet vom Besuch zweier Angehöriger der sowjetischen Botschaft im Referat II A 7. Damit hätten sie deutlich machen wollen, daß die Botschaft auch auf Gebieten, auf denen bisher kein Kontakt bestanden habe, mit dem Auswärtigen Amt ins Gespräch kommen wolle. Ihnen sei erläutert worden, daß die Bundesregierung den im Rahmen der Dreier-Verhandlungen am 27./28. April 1967 in London beschlossenen Truppenrückverlegungen in der Hoffnung zugestimmt habe, daß die UdSSR nun ihrerseits Streitkräfte aus der DDR abziehen werde. Die sowjetischen Diplomaten hätten diese Sichtweise als "mechanistisch und unpolitisch" bezeichnet. Auf ihre Frage, ob das neue Konzept einer "flexible response" eine Niederlage für Bundesminister Schröder bedeute, sei geantwortet worden, daß diese Strategie schon seit Jahren de facto angenommen sei. Ihnen sei ferner erklärt worden, daß die Bundeswehr auf eine Ausrüstung mit nuklearen Trägerwaffen nicht verzichten könne.

164

\subsection{Aufzeichnung des Ministerialdirigenten Graf von Hardenberg}

Hardenberg informiert darüber, daß der marokkanische $\mathrm{Au}-$ ßenminister Laraki in Gesprächen mit Staatssekretär Lahr und Bundestagspräsident Gerstenmaier erneut um eine umfangreiche Ausrüstungshilfe gebeten habe. Es sei zu prüfen, ob der bereits 1966 vorgelegte, seinerzeit aber abgelehnte Antrag der Bundesregierung den zuständigen Ausschüssen des Bundestags nochmals zugeleitet werden sollte. Dafür spreche, daß die von der marokkanischen Regierung übergebene Materialliste keine Waffen enthalte und der Bundesverteidigungsrat 1966 dem Anliegen bereits zugestimmt habe. Allerdings müsse in Gesprächen mit einzelnen Ausschußmitgliedern deutlich gemacht werden, daß die Zahlung der mit einer Laufzeit von drei Jahren vorgesehenen 8 Mio. DM erst 1968 einsetzen und sich jeweils innerhalb des Gesamtansatzes im Bundeshaushalt für Ausrüstungshilfe bewegen würde.

Rom übermittelt Informationen aus einem Gespräch mit dem malischen Präsidenten. Modibo Keito bezeichnete den Beschluß, den der malische Ministerrat in seiner Abwesenheit über die Errichtung einer Handelsvertretung in Ostberlin gefaßt habe, als „rechtsgültig, aber völlig inopportun“. Es treffe jedoch nicht zu, daß Mali der DDR den Vorrang vor der Bundesrepublik gebe. Allerdings habe sich die DDR zur Übernahme der gesamten Unterhaltskosten der Vertretung bereiterklärt. Demgegenüber sei der Vorschlag Malis, die im August 1966 vorgenommene Schließung der malischen Botschaft in Bonn durch eine entsprechende Regelung zur Entlastung der anfallenden Devisenkosten zu verhindern, von der Bundesregierung abgelehnt worden. Der Botschafter äußerte die Be- 
sorgnis über die möglichen Konsequenzen dieser Entscheidung sowohl für die bilateralen Beziehungen als auch für das Verhältnis Malis zur EWG.

166
11.05. Parlamentarischer Staatssekretär Freiherr von und zu Guttenberg, z.Z. Washington, an Bundeskanzler Kiesinger

Guttenberg berichtet, daß er der amerikanischen Regierung die Bedenken der Bundesregierung gegen ein unbefristetes Nichtverbreitungsabkommen erläutert habe. Außenminister Rusk habe dazu ausgeführt, daß seitens der USA über die zeitliche Verknüpfung eines Nichtverbreitungsabkommens mit der Laufzeit des NATO-Vertrages von 1949 bzw. über eine Beendigung des Abkommens im Falle eines europäischen Zusammenschlusses nachgedacht werde. Dagegen werde eine zeitliche Befristung oder eine zeitlich begrenzte Beitrittsmöglichkeit vor allem auf sowjetischer Seite auf Schwierigkeiten stoßen. Rusk habe angedeutet, daß sich die USA noch mit anderen Lösungen für die Frage der nuklearen Nichtverbreitung befaßten, falls ein Abkommen nicht zustande komme. Guttenberg bemerkt abschließend, daß Präsident Johnson unter gewissen Bedingungen bereit sei, ein Scheitern der Verhandlungen in Kauf zu nehmen. In diesem Falle müsse die Bundesregierung zu vermeiden suchen, daß ihr dafür die Verantwortung zugewiesen werde.

\subsection{Aufzeichnung des Ministerialdirigenten Frank}

Frank begründet die Weisung an Botschafter Pauls, Tel Aviv, nicht an der erstmals in Jerusalem stattfindenden Militärparade am 15. Mai 1967 anläßlich des israelischen Nationalfeiertags teilzunehmen. Mit dieser Parade wolle Israel dokumentieren, daß die Stadt uneingeschränkter Teil des israelischen Staatsgebietes sei. Die Bundesregierung habe sich bisher an den von der UNO-Generalversammlung beschlossenen Grundsatz über den internationalen Status von Jerusalem gehalten und dadurch verhindert, in der Palästina-Frage auf die eine oder andere Seite gezogen zu werden. Auch wegen der Bemühungen der DDR um Anerkennung durch die arabischen Staaten sei eine einseitige Parteinahme unangebracht. Nach der Wiederaufnahme der diplomatischen Beziehungen mit Jordanien sollte die Bundesrepublik Rücksicht auf die außenpolitische Stellung von König Hussein nehmen. Frank stellt abschließend fest, daß die israelische Regierung keine Sympathie und Unterstützung erwarten dürfe, wenn sie durch nicht mit den "westlichen Freunden" abgestimmte Schritte die arabischen Staaten provoziere.

12.05. Staatssekretär Schütz, z.Z. Tokio, an die Botschaft in Washington

Schütz bittet darum, im amerikanischen Außenministerium die Bedenken der Bundesregierung dagegen vorzutragen, da $\beta$ die USA und die UdSSR auf der Konferenz der 18-Mächte-Ab- 
rüstungskommission einen gemeinsamen Entwurf für ein Nichtverbreitungsabkommen ohne Artikel III vorlegen wollten. Stattdessen sollte in Genf ein vollständiger Entwurf unterbreitet werden, der den vertraglichen Verpflichtungen und Interessen von EURATOM Rechnung trage. Falls sich die UdSSR einer konstruktiven Mitarbeit versage, müsse in einem dann getrennt vorzulegenden amerikanischen Entwurf eine Formulierung gefunden werden, nach der Staaten, die auf ihrem Territorium keine Kontrollen zuließen, selbst auch nicht an der Kontrolle fremder Territorien teilhaben dürften. Auswärtige Amt

Lahn berichtet über die enttäuschte Reaktion in der VAR auf den Verlauf der Gespräche des Generalsekretärs der Arabischen Liga vom 18. bis 21. April 1967 in Bonn. Eine einstimmige Entscheidung der Arabischen Liga über eine Wiederaufnahme der diplomatischen Beziehungen werde schwerlich zu erreichen sein, da die Bundesregierung einem von den arabischen Staaten gewünschten sichtbaren Wandel der IsraelPolitik aus übergeordneten, nicht nur außenpolitischen Gründen nicht zustimmen könne. Darüber hinaus werde für die VAR der wirtschaftliche Anreiz zu einer Normalisierung des bilateralen Verhältnisses immer schwächer. Schließlich berechtige die offene Übernahme der kommunistischen Thesen in der Deutschlandpolitik zu der Annahme, daß die ägyptische Regierung einen Botschafteraustausch mit der Bundesrepublik nur unter der Voraussetzung der Akkreditierung eines Botschafters der DDR in Kairo zulassen werde. Staatssekretär Lahr, z.Z. Tokio

Hardenberg informiert über den Abschluß der Kennedy-Runde. Auf dem gewerblichen Sektor würden mit Ausnahme Großbritanniens und Japans die Zollsenkungen der EWG und der übrigen Teilnehmer etwa gleich groß sein. Für Chemie-Erzeugnisse habe eine Einigung erzielt werden können, die neben einem ersten Zollabbau in einem zweiten Schritt auch die Abschaffung des ,American Selling Price umfasse. Mit Blick auf das geplante Getreideabkommen hätten sich die Teilnehmerstaaten auf eine Nahrungsmittelhilfe für Staaten der Dritten Welt einigen können, deren Kosten für die Bundesrepublik etwa 100 Mio. DM jährlich betragen würden. Auf dem Agrarsektor seien dagegen zwar nur bescheidene Ergebnisse, insbesondere eine Regelung für die Einfuhr dänischen Lebendviehs und argentinischen Gefrierfleisches in die EWG, erzielt worden. Damit sei aber ein Anfang zum Abbau des Agrarprotektionismus gemacht worden. 
171 17.05. Botschafter Grewe, Paris (NATO), an das Auswärtige Amt

Grewe berichtet, daß der amerikanische Botschafter bei der NATO, Cleveland, in der Sitzung des Ständigen NATO-Rats über die Absicht der USA informiert habe, der Konferenz der 18-Mächte-Abrüstungskommission einen gemeinsamen amerikanisch-sowjetischen Entwurf für ein Nichtverbreitungsabkommen gegebenenfalls zunächst ohne die strittigen Artikel III und Artikel IV, Absatz 2 zu unterbreiten. Dazu habe er, Grewe, erklärt, daß die Bundesregierung ihre Bedenken gegenüber einem solchen Vorgehen aufrechterhalte. Während der italienische Botschafter bei der NATO, Alessandrini, für einen völligen Wegfall des Artikels III plädiert habe, seien die Vertreter Großbritanniens, Kanadas und der Niederlande dafür eingetreten, wenigstens die zwischen den USA und der UdSSR unstrittigen Textteile dieses Kontrollartikels aufzunehmen. Alessandrini und sein belgischer Kollege de Staercke hätten sich darüber hinaus dafür ausgesprochen, den Revisionsartikel IV im Entwurf auszusparen.

Balken teilt mit, der norwegische Verteidigungsminister Tidemand habe ihn darauf hingewiesen, daß die Entsendung von Bundeswehrpersonal zum NATO-Oberkommando Europa Nord in Norwegen nach wie vor "ein heißes Eisen“ sei. Das Drängen der Bundesregierung nach einer Verstärkung des deutschen Stellenanteils erschwere es innenpolitisch, still und unauffällig auf eine Normalisierung der militärischen Zusammenarbeit hinzuarbeiten. In Norwegen bestehe der Eindruck, die Bundesrepublik strebe letztlich doch danach, die Verfügungsgewalt über Nuklearwaffen zu erhalten. Eine Weigerung der Bundesregierung, dem Nichtverbreitungsabkommen beizutreten, würde das deutsch-norwegische Verhältnis schwer belasten.

Schütz berichtet über ein Gespräch mit einem Mitglied der Konsultativkonferenz der Volksrepublik China in Hongkong. Fe Yi-Ming führte aus, daß die Kluft in den Beziehungen zwischen der Volksrepublik China und der UdSSR unüberbrückbar geworden sei. Die Volksrepublik China habe das Bemühen der neuen Bundesregierung um Frieden und Entspannung in Europa mit Interesse zur Kenntnis genommen. Dagegen sei es ihr immer schwerer gefallen, Solidarität mit der DDR zu üben, da die heftigsten Angriffe auf die chinesische Regierung aus Ostberlin gekommen seien. Auf den umfangreichen bilateralen Handel angesprochen, meinte der Staatssekretär, daß die Bundesrepublik an Wirtschaftsbeziehungen mit der Volksrepublik China interessiert sei. Sein Hinweis, daß die Bundesrepublik die Verbindungen und das Gespräch nicht abreißen lassen wolle, sei mit Interesse aufgenommen worden. 
Ruete nimmt Stellung zum Wunsch der tschechoslowakischen Regierung, als Übergangslösung zur Herstellung amtlicher Beziehungen zunächst ein Handelsabkommen abzuschließen. Dies bestätige den bereits früher gewonnenen Eindruck, daß die Tschechoslowakei um der wirtschaftlichen Vorteile eines Waren- und Zahlungsabkommen willen eine Berlin-Regelung zu akzeptieren bereit sei, dies jedoch für den Austausch von Handelsvertretungen nicht zugestehen wolle. Dagegen verfolge die Bundesregierung die Absicht, parallel zu einem Handelsabkommen den Austausch amtlicher Vertretungen zu regeln. $\mathrm{Da}$ mit einer baldigen Aufnahme diplomatischer Beziehungen nicht gerechnet werden könne, sei eine solche Übergangslösung erwägenswert. Ein Handelsabkommen allein sei aber keine Alternative, da es die amtlichen Beziehungen weiterhin ungeregelt lasse. Ruete schlägt vor, der Tschechoslowakei mitzuteilen, daß die Bundesregierung zum Abschluß eines Handelsabkommens bereit sei, jedoch gleichzeitig die Frage der amtlichen Vertretungen klären wolle. Bundeskanzleramt

Blomeyer-Bartenstein informiert darüber, daß der Kontakt zwischen den in der Bundesrepublik residierenden katholischen Bischöfen und ihren Generalvikaren in der DDR immer mehr erschwert werde. So wolle die DDR für die zu Bistümern in der Bundesrepublik gehörenden Diözesanteile eine möglichst große Selbständigkeit erreichen. Innerhalb der katholischen Kirche werde der Wunsch geäußert, als Antwort auf solche „Abschnürungsmaßnahmen“ die Einsetzung von Apostolischen Administratoren in diesen Gebieten anzustreben. Dieses Anliegen sei aber sowohl bei den Bischöfen als auch beim Heiligen Stuhl auf große Zurückhaltung gestoßen. Statt dessen erwäge der Heilige Stuhl, die Generalvikare in Schwerin, Magdeburg, Erfurt und Meiningen zu erzbischöflichen bzw. bischöflichen Kommissaren zu ernennen - mit allen Vollmachten eines Generalvikars und mit einem "Mandatum speciale“ des Papstes ausgestattet. Blomeyer-Bartenstein bemerkt hierzu, daß seitens des Auswärtigen Amts keine Bedenken bestünden. Auswärtige Amt

Koehler berichtet über den Besuch des Bundestagspräsidenten vom 13. bis 19. Mai 1967 in Pakistan. Gerstenmaier habe die Prüfung eines Beitrags der Bundesregierung zur Schließung der Finanzierungslücke für das Projekt des Indus-Staudamms zugesagt. Im Gespräch mit dem pakistanischen Präsidenten habe er erklärt, daß er zwar das Bemühen Pakistans um gute Beziehungen zur UdSSR und zur Volksrepublik China verstehe, jedoch vor der Gefahr einer Abhängigkeit von übermächtigen kommunistischen Nachbarn warne. Ayub Khan habe erwi- 
dert, daß die Volksrepublik China keine Aggressionspolitik gegenüber ihren Nachbarn verfolge. Dagegen seien ständig wachsende Bemühungen Indiens zu verzeichnen, sein Militärpotential zu steigern. Zur Abschreckung sei Pakistan deshalb gezwungen, sich die notwendigen Waffen dort zu besorgen, wo man sie anbiete. Zur Deutschland-Frage habe der Präsident ausgeführt, daß er gegenüber der UdSSR bis in die jüngste Vergangenheit den Alleinvertretungsanspruch der Bundesrepublik bekräftigt habe.

Schlitter äußert sich kritisch dazu, daß die amerikanische Verteidigungshilfe wegen des Militärputsches am 20./21. April 1967 eingestellt worden sei. Dadurch werde die Position der zivilen Mitglieder der griechischen Regierung, die eine Rückkehr zur parlamentarischen Demokratie anstrebten, geschwächt. Angesichts der realen Machtverhältnisse sei es eine Illusion, die Junta unter ein "kaudinisches Joch“ beugen zu wollen. Der sowohl von König Konstantin als auch von einer Mehrheit der Regierung getragene Wunsch nach einer Rückkehr zur Demokratie sei nur dann erfolgreich, wenn die radikalen Kräfte nicht durch äußeren Druck in die Richtung eines Nationalbolschewismus getrieben würden.

Brandt berichtet über ein Treffen mit einem ihm persönlich bekannten tschechoslowakischen Gesprächspartner. Dieser teilte mit, daß er von einflußreichen Persönlichkeiten der tschechoslowakischen Partei- und Staatsführung gebeten worden sei, bei der Bundesregierung die Bereitschaft zu Gesprächen über die Möglichkeiten künftiger Zusammenarbeit ohne Vorbedingungen zu sondieren. Dabei sollten die DDR und das Münchener Abkommen von 1938 als Themen ausgeklammert werden, nicht jedoch Berlin, für das eine beiderseits akzeptable Form gefunden werden könne. Für die Aufnahme diplomatischer Beziehungen sei es wahrscheinlich noch zu früh. Brandt schlug daraufhin vor, den Referenten Bahr und Legationsrat I. Klasse Wilke nach Prag zu entsenden.

Ruete informiert über die Absicht der belgischen Regierung, eine Reorganisation ihrer Streitkräfte in der Bundesrepublik durchzuführen. Dazu habe der belgische Verteidigungsminister am 18. Mai 1967 in Bonn Bundesminister Schröder erläutert, daß einzelne Einheiten zwar reduziert, die Mittel im belgischen Verteidigungshaushalt in den kommenden Jahren aber erhöht würden. Poswick habe in diesem Zusammenhang betont, daß die belgische Regierung trotz der Belastungen für die Zahlungsbilanz keinen Ausgleich für die Devisenkosten der in der Bundesrepublik stationierten Truppen verlangen werde. Jedoch sei eine gewisse Kompensation in der Form von Beschaffungskäufen für die Bundeswehr in Belgien wünschenswert. 

Auswärtige Amt

Sattler berichtet, daß eine gemeinsame Presseerklärung der Bundesregierung und des Heiligen Stuhls zur Ernennung von vier Apostolischen Administratoren für die Ostgebiete des Deutschen Reichs unter fremder Verwaltung nicht zustande komme. Der Abteilungsleiter im Päpstlichen Staatssekretariat, Samorè, habe darauf verwiesen, daß die Neuregelung der Kirchenverwaltung in diesen Gebieten näherer Erläuterungen bedürfe, um die Entscheidung später sowohl gegenüber der Bundesrepublik als auch gegenüber Polen verteidigen zu können. Dabei sei herauszustellen, daß die Ernennung der Administratoren von seelsorgerischen Erwägungen geleitet werde und einen späteren Friedensvertrag nicht präjudiziere. Auf die Bitte des Botschafters, wenigstens die Formulierung Ostgebiete Deutschlands" bzw. "deutsche Ostgebiete " aufzunehmen, habe Samorè erklärt, daß der Heilige Stuhl bislang immer nur von Gebieten gesprochen habe, ${ }_{n}$ die durch das Potsdamer Abkommen 1945 der polnischen Verwaltung unterstellt wurden“.

181 24.05. Botschafter Grewe, Paris (NATO), an das Auswärtige Amt

Grewe berichtet über die Sitzung des Ständigen NATO-Rats zur Nahost-Krise. UNO-Generalsekretär U Thant sei wegen seines vorschnellen Handelns beim Rückzug der UNEFTruppen aus der VAR kritisiert worden; gleichwohl sei festgestellt worden, daß die UNO das geeignete Gremium zur Beilegung der Krise bleibe. Die Diskussion habe deutlich gemacht, daß die Sympathien zwar auf Seiten Israels lägen; jedoch lieBen die Erklärungen der Vertreter Griechenlands, Italiens und der Türkei deren Bemühen erkennen, den Draht zur arabischen Seite nicht abreißen zu lassen. Die Mehrheit der NATOMitgliedstaaten sei sich offenbar bewußt, daß auch bei einem friedlichen Ausgang der Krise mit einer Schwächung der westlichen Position im Nahen Osten zu rechnen sei. Auswärtige Amt

Knappstein äußert sich zum Vorschlag der amerikanischen Botschaft, regelmäßige bilaterale Konsultationen über Fragen der Ostpolitik durchzuführen. Wegen des komplizierten Vorganges politischer Entscheidungsfindung in den USA, deren Rückwirkungen auf die europäischen Verbündeten nicht immer voll einkalkuliert würden, sei jede Vertiefung des laufenden Meinungsaustausches wünschenswert. Beispielsweise wären Konsultationen der Abteilungsleiter beider Außenministerien nützlich. Wichtig sei, daß nicht ein bloßer Informationsaustausch, sondern eine qualitative Konsultation zustandekomme. Die Bundesregierung bedürfe zur Durchsetzung ihrer neuen Ostpolitik vor allem gegenüber der UdSSR auch der aktiven Unterstützung der USA. Um zu vermeiden, daß durch ein einseitiges Vorgehen der Bundesregierung die USA ihr Interesse als eine 
der vier für Deutschland verantwortlichen Mächte vernachlässigt sehen könnte, sei es ratsam, nur in engster Fühlungnahme mit dem amerikanischen Partner vorzugehen. Auswärtige Amt

Grewe teilt mit, daß der amerikanische Botschafter bei der NATO den Ständigen NATO-Rat über den Inhalt eines in Genf übergebenen neuen sowjetischen Entwurfs für ein Nichtverbreitungsabkommen unterrichtet habe. Cleveland habe ausgeführt, daß die ablehnende Haltung der sowjetischen Regierung gegen die amerikanischen Vorschläge zum Kontrollartikel III und zum Revisionsartikel IV, Absatz 2 vorauszusehen gewesen sei. Hinter der Wiederaufnahme des „Kossygin-Vorschlags“ vom Februar 1966, wonach die Nuklearmächte sich jeder Anwendung von bzw. Drohung mit Atomwaffen gegenüber Nichtnuklearmächten enthalten müßten, stünden wahrscheinlich taktische Erwägungen. So sei die UdSSR gezwungen gewesen, auf Formulierungen der USA zu antworten und dabei die Wünsche der eigenen Verbündeten zu berücksichtigen. Abschließend habe Cleveland erklärt, daß die USA nicht mit einer baldigen Einigung über den Wortlaut des Artikels III rechneten.

Ruete informiert, da $\beta$ die Studiengruppe zur Überprüfung der künftigen Aufgaben der Allianz (Harmel-Studie) ihre Arbeit aufgenommen habe. In der Untergruppe 1 über die politischen Ziele der NATO, für die der Abteilungsleiter im britischen AuBenministerium, Watson, und Staatssekretär Schütz als Berichterstatter benannt worden seien, habe Übereinstimmung darüber bestanden, daß die Entspannung im Ost-West-Verhältnis nur ein Weg bzw. ein Instrument sei, um das eigentliche Ziel einer europäischen Friedensordnung zu erreichen. Trotz der Versuche von Ostblock-Staaten, das Bündnis zu spalten, sei die Entspannung „unteilbar". Allerdings sei darauf hingewiesen worden, daß dies bilaterale Ost-West-Kontakte nicht auschließen dürfe. Die Untergruppe 3 habe sich die Aufgabe gestellt, Elemente einer Verteidigungs- und Rüstungskontrollpolitik herausarbeiten, welche die Freiheit des Westens weiterhin verbürge, zugleich aber einen Beitrag zur Schaffung einer dauerhaften europäischen Friedensordnung leiste. Ruete berichtet abschließend, daß Frankreich zwar bisher ohne Vorbehalte bei der Harmel-Studie mitgearbeitet habe, jedoch Schwierigkeiten zu erwarten seien, sobald die Untergruppe 1 mit der Ausarbeitung verbindlicher Grundsätze für die Ost-West-Politik beginne.

Ruete stellt fest, daß es der DDR gelungen sei, jene osteuropäischen Staaten, die noch Anfang des Jahres zu Verhandlungen mit der Bundesregierung über die Aufnahme diplomatischer Beziehungen bereit gewesen seien, von solchen Gesprächen abzuhalten. Gleichzeitig deuteten diese aber vertraulich an, an 
einer diskreten Fortführung der Kontakte interessiert zu sein. Um die eingetretene „Flaute“ zu überwinden, schlägt Ruete vor, daß die Bundesregierung öffentlich ihren Entspannungswillen weiter bekräftige. Ferner sei eine Ausweitung der persönlichen Kontakte nützlich, etwa durch Besuche osteuropäischer Journalisten oder Reisen von amtlichen Vertretern und Bundestagsabgeordneten nach Osteuropa. Der Wirtschaft als Instrument der Ostpolitik komme besondere Bedeutung $\mathrm{zu}$. Auch Gesten wie die Zahlung von Entschädigungsleistungen an ungarische Staatsangehörige dienten der Verbesserung des Verhältnisses. Abschließend bemerkt Ruete, daß sich langfristig das Interesse der Tschechoslowakei, Ungarns und Bulgariens an Beziehungen zur Bundesrepublik durchsetzen werde.

Schütz erläutert die Haltung der Bundesregierung zur NahostKrise. Es sei anzunehmen, daß der ägyptische Präsident Nasser die Konzentration ägyptischer Truppen auf der Sinai-Halbinsel und die am 23. Mai 1967 verfügte Sperrung des Golfs von Akaba mit der sowjetischen Regierung abgesprochen habe. Allerdings sei die UdSSR nicht an einer direkten Konfrontation mit den USA interessiert. Auch sei ein für Israel existentiell bedrohliches ägyptisches Vorgehen wegen des dann zu befürchtenden energischen amerikanischen Gegenschlags zu bezweifeln. Ein Zusammenbruch Jordaniens würde andere gemäßigte arabische Staaten gefährden und insgesamt zu einer schweren Niederlage für den Westen führen. Nur eine energische westliche Aktion zur Freihaltung des Golfs von Akaba könne nach Ansicht der Bundesregierung die VAR zum Einlenken bewegen, die "Strangulierung" Jordaniens verhindern und Israel von einer militärischen Aktion abhalten. Die Bundesregierung sei skeptisch, ob die UdSSR den französischen Vorschlag zur Durchführung einer Vier-Mächte-Konferenz annehmen werde. Der Westen solle sich nicht der Gefahr aussetzen, daß durch hinhaltende sowjetische Manöver Gegenmaßnahmen erschwert würden.

Der Schah erläutert ausführlich die politische und wirtschaftliche Situation des Iran. Er betont, daß der Iran trotz der Politik der westlichen Staaten gegenüber der VAR und im Konflikt zwischen Pakistan und Indien das Vertrauen in das Bündnis mit dem Westen nicht verloren habe, zukünftig aber eine unabhängige Politik anstrebe. Dies bedeute, daß er militärisch für alle Eventualfälle gerüstet sein wolle. Der Schah äußert die Hoffnung, hierfür wie auch für die umfangreichen Sozial- und Wirtschaftsreformen Unterstützung von der Bundesrepublik zu erhalten. Anschließend weist er auf die bedeutende Rolle der Ölversorgung im Zusammenhang mit der Weltpolitik hin. Im Falle einer erneuten Sperrung der Ölzufuhr könne Europa wegen des Schneeballeffekts auch keinen Ersatz aus neuen 
Förderstaaten wie Libyen und Algerien erwarten. Dagegen bleibe der Iran eine "offene“ Versorgungsquelle. Eine wirtschaftliche und militärische Unterstützung des Iran hätten die westlichen Freunde nicht zu bedauern. Kiesinger verweist auf die wirtschaftliche Krise der Bundesrepublik, stellt jedoch eine Fortsetzung der Hilfe für den Iran in Aussicht, sobald die finanziellen Schwierigkeiten überwunden seien.

Meyer-Lindenberg berichtet, daß der israelische Botschafter am Vortag Bundesminister Brandt erklärt habe, für Israel stelle die vom ägyptischen Präsidenten Nasser verfügte Sperrung des Golfs von Akaba den Casus belli dar. Die u. a. von den USA bereits 1957 abgegebene Garantie des freien Zugangs zum Golf müsse nun eingelöst werden. Dagegen erwarte Ben Natan von der UNO keine Lösung der Krise. Die UdSSR wolle offenbar wie früher in Berlin einen Spannungsherd schaffen und sei auf dem besten Weg, "Schiedsrichter im Nahen Osten“ zu werden. Einen Krieg zur Durchsetzung ihrer Ziele strebe sie aber vermutlich nicht an. Der Botschafter habe schließlich den Wunsch geäußert, die Bundesregierung möge Israel mit Gasmasken für die Zivilbevölkerung unterstützen und prüfen, ob darüber hinaus etwaiges „,verdächtiges Material“ über dritte Staaten wie z.B. Frankreich geschickt werden könne. MeyerLindenberg fährt fort, daß sich Bundeskanzler Kiesinger bei einer anschließenden Besprechung im Bundeskanzleramt für die Lieferung von Gasmasken an Israel direkt durch die Lieferfirmen ausgesprochen habe. Dagegen habe Bundesminister Schröder Zweifel an der Opportunität und Durchführbarkeit des Vorhabens geäußert. sowjetischen Botschafter Zarapkin

Zarapkin erklärt zur „Notlandung“ eines sowjetischen Militärflugzeuges am 25. Mai 1967 in der Nähe von Augsburg, daß sich die Botschaft umgehend im Auswärtigen Amt darum bemüht habe, ein Gespräch mit dem Piloten zu arrangieren und Vorkehrungen für die Übergabe des Düsenjägers an sowjetische Behörden zu treffen. Trotz gegenteiliger Zusagen von Ministerialdirektor Ruete seien aber das Flugzeug wie auch der Flugzeugführer Jepatko amerikanischen Stellen übergeben worden. Schütz erwidert, daß die Bundesregierung für den Zwischenfall nicht verantwortlich sei. Das Auswärtige Amt sei gleichwohl bereit, sich für die Übergabe der MIG 17 einzusetzen. Es halte eine Begegnung von Jepatko mit Botschaftsangehörigen für wünschenswert; jedoch habe der Wunsch des Piloten, nicht mit sowjetischen Vertretern sprechen zu wollen und in amerikanischen Gewahrsam zu kommen, respektiert werden müssen. Im übrigen habe die Bundesregierung den Eindruck, da $\beta$ es sich gar nicht um eine Notlandung, sondern um eine Landung aus freien Stücken gehandelt habe. 

Lindenberg

Meyer-Lindenberg faßt ein Gespräch des Staatssekretärs Schütz mit dem israelischen Botschafter zusammen. Ben Natan teilte mit, da $ß$ der Chef des Bundeskanzleramts, Knieper, eine Entscheidung darüber zugesagt habe, ob die Lieferung von Gasmasken an Israel durch das Bundesministerium der Verteidigung oder das Bundesministerium des Innern vorgenommen werde; Israel erhoffe sich 20000 bis 30000 Stück. Schütz machte auf die Erklärung des Auswärtigen Amts aufmerksam, daß das Prinzip der Freiheit der Meere gewahrt bleiben solle. Der Botschafter wies darauf hin, daß das Bundesministerium für Wirtschaft die Verschiffung von 30000 Zündern nach Israel für die später an die Bundeswehr zu liefernden Granaten bis auf weiteres untersagt habe, obwohl dafür bereits Anfang des Jahres eine Ausfuhrlizenz erteilt worden sei. Schütz sagte eine Prüfung der Angelegenheit zu. Abschließend wies er noch einmal auf den Grundsatz der Bundesregierung hin, sich nicht in regionale Konflikte einzumischen.

Loeck berichtet, daß sich in den jugoslawischen Äußerungen über die Ausgestaltung des Verhältnisses zur Bundesrepublik ein neuer Akzent bemerkbar mache. Während bisher das Interesse an der Aufnahme diplomatischer Beziehungen im Vordergrund gestanden habe, so werde nun von Regierungsvertretern wie von der Presse die Frage nach Verhandlungen über ein Gastarbeiterabkommen und nach Entschädigung für NSOpfer gestellt. Allerdings könne daraus kein grundsätzlicher Wandel der jugoslawischen Deutschlandpolitik abgeleitet werden. Vielmehr befürchte Jugoslawien angesichts der Ostpolitik der neuen Bundesregierung, den fahrenden Zug als letzter besteigen und materielle Einbußen hinnehmen zu müssen. Loeck empfiehlt, nach dem Besuch des Staatsratsvorsitzenden der DDR, Ulbricht, vom 22. Mai bis 4. Juni 1967 in Belgrad zunächst durch den Ausbau der "faktischen Beziehungen“ mit Jugoslawien das politische Klima zu verbessern.

Pauls informiert, daß nach Auskunft des Leiters der Attachéabteilung des israelischen Generalstabs eine militärische Auseinandersetzung zwischen Israel und den beteiligten arabischen Staaten unvermeidlich sei. Jeder weitere Tag des Zuwartens werde die israelische Armee mehr Blut kosten. Bei einem ersten Schlag durch die israelische Luftwaffe in den frühen Morgenstunden mit der Sonne im Rücken könne sich die Armee für die Vernichtung der ägyptischen Streitkräfte verbürgen. Die Entscheidung der israelischen Regierung, die Entwicklung weiter abzuwarten, sei sowohl in Offizierskreisen als auch unter Reservisten nicht populär. Der Botschafter bewertet den „ganz ungewöhnlichen Freimut" dieser Stellungnahme 
dahingehend, daß die Gefahr eines Putsches der israelischen Armee gegenwärtig zwar gering sei, jedoch nicht ausgeschlossen werden könne.

193

30.05. Generalkonsul Kempff, Helsinki, an das Auswärtige Amt

Kempff berichtet über den Besuch des Außenministers der DDR in Helsinki. Winzer habe geradezu ,in beknieender Form“ die Notwendigkeit einer diplomatischen Anerkennung der DDR zu vermitteln versucht, damit jedoch keinerlei Eindruck gemacht. Der finnische Außenminister Karjalainen habe erklärt, daß die Neutralitätspolitik Finnlands sowie die im Pariser Friedensvertrag von 1947 festgelegten Verpflichtungen es nicht erlaubten, in dieser Frage Steliung zu beziehen. Neben dem materiellen Mißerfolg sei aber noch ein atmosphärischer $\mathrm{zu}$ verzeichnen, denn die „Zonenmenschen“ seien den finnischen Gastgebern mit ihrer Aufdringlichkeit auf die Nerven gegangen. Ministerpräsident Moro in Rom

Die Gesprächspartner stimmen darin überein, daß die Konferenz der Staats- und Regierungschefs der EWG-Staaten am 29./30. Mai 1967 nützlich gewesen und das Optimum des Erreichbaren erzielt worden sei. Kiesinger erklärt, daß die Bundesregierung auf dem Weg zur europäischen Einigung zu jeder nur möglichen Zusammenarbeit mit der italienischen Regierung bereit sei. Er betont, daß die seit Anfang des Jahres angestrebte Wiederbelebung des deutsch-französischen Vertrags von 1963 sich gegen keinen anderen Staat richte und den Weg zur europäischen Einheit nicht stören solle. Vielmehr halte er die Knüpfung von Parallelkontakten für wünschenswert; den Gedanken einer Exklusivität der Zuammenarbeit mit Frankreich müsse er entkräften. Zum geplanten Nichtverbreitungsabkommen erläutert der Bundeskanzler, daß nicht beabsichtigt sei, den bereits 1954 erklärten Verzicht auf die Herstellung von Nuklearwaffen zu widerrufen oder sich auch nur die Tür für einen späteren Zugang offenzuhalten. Für die Bundesrepublik handele es sich hier um eine Frage der nationalen Würde und des nationalen Ranges. Moro führt aus, daß sich das Nichtverbreitungsabkommen nicht zum Schaden für die Solidität des atlantischen Bündnisses auswirken dürfe. Auch für Italien handele es sich um das Problem der „natürlichen Gleichheit der Nationen“.

Ruete stellt fest, daß sich die Beziehungen zwischen der Bundesrepublik und der UdSSR in einem Stadium der Stagnation befänden. Daher schlägt er vor, dem sowjetischen Botschafter Zarapkin die neue Ostpolitik der Bundesregierung noch einmal darzulegen. Falls Bundesminister Brandt dabei ein sowjeti- 
sches Interesse an der Intensivierung des Dialogs feststellen könne, solle er ein Gespräch mit seinem Amtskollegen Gromyko in Moskau oder an einem dritten Ort anregen.

196

30.05. Aufzeichnung des Ministerialdirigenten Berger

Berger nimmt Stellung zu einer Kabinettsvorlage des Bundesministeriums für Wirtschaft (BMWi) mit dem Vorschlag, den seit 1961 für den Interzonenhandel geltenden Widerrufsvorbehalt für Warenbegleitscheine abzuschaffen. Zur Begründung werde darauf verwiesen, daß durch die Beibehaltung dieser Klausel Anlagegeschäfte mit der DDR zunehmend an westliche Konkurrenten verlorengingen. Dagegen liege aus Sicht des Auswärtigen Amts der Verdacht nahe, daß die DDR die Klausel nur vorschiebe, um ihr politisches Interesse zu verschleiern, Anlagen möglichst nicht im Interzonenhandel, sondern aus dem Ausland zu beziehen. Berger weist ferner darauf hin, daß den Drei Mächten im Falle einer Aufhebung der Widerrufsklausel Konsultationen zugesagt worden seien. Er regt an, der Vorlage nur mit der Maßgabe zuzustimmen, daß die Gespräche mit den Verbündeten vorher zum Abschluß gebracht worden seien.

Lahr berichtet über die Konferenz der Staats- und Regierungschefs der EWG-Staaten am 29./30. Mai 1967 in Rom. Staatspräsident de Gaulle führte aus, daß ein organisatorischer Ausbau der Gemeinschaften notwendig und eine Verstärkung der politischen Kontakte der Sechs wünschenswert sei. $\mathrm{Zu}$ den Möglichkeiten einer Öffnung gegenüber dritten Staaten solle zunächst geprüft werden, ob die vor kurzem gestellten Beitrittsanträge Großbritanniens, Irlands und Dänemarks den Charakter der Gemeinschaft veränderten. Bundeskanzler Kiesinger wies darauf hin, daß die augenblickliche gefährliche weltpolitische Situation ein Mindestmaß an solidarischem Verhalten erfordere. Deshalb sollten weitere Treffen der Sechs auf Regierungsebene folgen. Der niederländische Ministerpräsident de Jong erklärte, daß die Sechs nicht das ganze Europa darstellten und deshalb eine Wiederaufnahme politischer Konsultationen ohne Großbritannien wenig sinnvoll wäre. Kiesinger betonte, daß die Bundesregierung einen britischen Beitritt befürworte, hierüber jedoch unter den Sechs zunächst grundsätzliche Übereinstimmung bestehen müsse. Die Staats- und Regierungschefs beschlossen, den Fusionsvertrag zum 1. Juli 1967 in Kraft treten zu lassen und den britischen Beitrittsantrag gemäß Artikel 237 des EWG-Vertrages von 1957 zu behandeln. Auswärtige Amt

Grewe teilt mit, daß die bisherige Diskussion im Ständigen NATO-Rat über die Nahost-Krise eine Schwäche und Uneinigkeit offenbart habe, die in krassem Gegensatz zu den Deklamationen im Rahmen der Studie über die zukünftigen Aufga- 
ben der Allianz (Harmel-Studie) stehe. Während vom Vertreter der USA die Notwendigkeit einer Lösung im UNO-Rahmen betont worden sei, habe sich der britische Botschafter bei der NATO auf ein Bekenntnis zur Freiheit der Schiffahrt im Golf von Akaba beschränkt. Der französische Vertreter wiederum habe erklärt, daß Frankreich weder Partei ergreifen noch sich engagieren werde. Grewe gibt abschließend der Hoffnung Ausdruck, daß sich der NATO-Rat im Falle einer das Bündnisgebiet direkt betreffenden Krise aktiver zeigen werde. Er habe seine Kollegen bereits darauf hingewiesen, daß jetzt ein „test case" für Krisenkonsultationen vorliege.

199

200

201
01.06. Aufzeichnung des Ministerialdirektors MeyerLindenberg

Meyer-Lindenberg äußert sich zur Frage eines Beitrages der Bundesregierung zum UNO-Treuhandschaftsfonds für Opfer der südafrikanischen Apartheidpolitik. Er stellt fest, daß die Bundesrepublik neben Luxemburg der einzige EWG-Mitgliedstaat sei, der noch nicht einmal einen symbolischen Beitrag in Aussicht gestellt habe. Dagegen habe die DDR eine freiwillige Zahlung in Höhe von 5000 Dollar angekündigt. Meyer-Lindenberg schlägt vor, eine Entscheidung im Bundeskabinett herbeizuführen mit dem Ziel, 40000 Dollar für den UNO-Treuhandschaftsfonds bereitzustellen.

\subsection{Aufzeichnung des Staatssekretärs Lahr}

Lahr regt an, Israel wieder eine Wirtschaftshilfe von 160 Mio. $\mathrm{DM}$ zu den gleichen Bedingungen wie 1966 anzubieten. Wegen der gegenwärtigen Krise im Nahen Osten solle der israelischen Regierung jedoch vorerst nur die Bereitschaft der Bundesregierung vertraulich angekündigt und die Unterzeichnung auf einen späteren Zeitpunkt verschoben werden. Ferner sei zu erklären, daß die Höhe des Betrags kein Präjudiz für zukünftige Zahlungen darstelle. Andernfalls bestehe die Gefahr, daß die Wirtschaftshilfe für Israel den Charakter einer „Rente“ annehme und die Bundesregierung künftig jede Bewegungsfreiheit verlieren werde.

\subsection{Botschafter Knappstein, Washington, an das} Auswärtige Amt

Knappstein übermittelt Informationen zu den Kontakten zwischen den USA und der UdSSR während der Nahost-Krise. Die sowjetische Regierung habe in einer Note der amerikanischen Regierung vorgeschlagen, da $\beta$ beide ihren jeweiligen Einflu $\beta$ auf Israel bzw. die VAR mit dem Ziel geltend machen sollten, die gegenwärtige Situation zu entspannen. Darauf hätten die USA geantwortet, daß einem freien Zugang zum Golf von Akaba besondere Bedeutung zukomme und die UdSSR als eine der wichtigsten Seemächte ihre diesbezügliche Haltung noch nicht öffentlich dargelegt habe. Nach Ansicht des amerikanischen Außenministeriums sei die sowjetische Regierung an einer

S. 850 
friedlichen Lösung der Krise nicht wirklich interessiert. Der Verdacht sei nicht auszuschließen, daß die UdSSR im Nahen Osten und in der Dritten Welt langfristig eine „Schiedsrichterrolle" anstrebe.

Als Erwiderung auf Äußerungen des polnischen Außenministers in Ankara werden Grundzüge der Ostpolitik dargelegt. Die Bundesregierung habe wiederholt auf die Anwendung von Gewalt zur Regelung offener Fragen verzichtet und die DDR ausdrücklich in den Vorschlag über den Austausch von Gewaltverzichtserklärungen einbezogen. Die polnische Regierung argumentiere widersprüchlich, wenn sie einerseits diese Äußerungen als unglaubwürdig hinstelle, andererseits aber einen Verzicht der Bundesregierung auf die Gebiete östlich von Oder und Neiße fordere. Wenn Rapacki feststelle, daß das Bestehen zweier deutscher Staaten eine „anomale Realität" sei, so erkenne er gerade damit das Prinzip der Nationalstaatlichkeit an. Deshalb sei seine These nicht haltbar, daß die Existenz der DDR gleichzeitig eine von der Bundesrepublik zu akzeptierende Realität darstelle. Solange die Menschen in der DDR ihren politischen Willen nicht frei artikulieren könnten, werde die Bundesregierung „das Regime, das diesem Teil Deutschlands aufgepropft worden" sei, nicht anerkennen. Sie strebe jedoch ein geregeltes Nebeneinander der unterschiedlichen politischen Ordnungen beider Teile Deutschlands an.

Truckenbrodt informiert, daß die Vertreter der Drei Mächte in einer Besprechung über die von der Bundesregierung gewünschte Änderung des Verfahrens zur Einbeziehung von Berlin (West) in völkerrechtliche Verträge der Bundesrepublik erklärt hätten, noch nicht zu konkreten Verhandlungen hierüber ermächtigt zu sein. Der Ministerialdirigent regt an, die Botschafter Frankreichs, Großbritanniens und der USA um entsprechende Weisungen der Regierungen zu bitten, damit sie konstruktiv an der Ausarbeitung einer neuen Regelung mitwirken könnten.

Der Staatssekretär resümiert eine Unterredung mit den Botschaftern der Drei Mächte, McGhee, Roberts und François Seydoux. Schütz berichtete, daß zwar noch keine Kabinettsentscheidung über die Beantwortung des Schreibens des Vorsitzenden des Ministerrates der DDR, Stoph, vom 10. Mai 1967 vorliege; in jedem Fall werde aber die Bundesregierung ihre Bereitschaft mitteilen, auf einer "geeigneten Ebene" Gespräche über innerdeutsche Fragen zu führen. Es sei ebenfalls noch nicht entschieden, ob und wie auf ein Schreiben des Verkehrsministers der DDR, Kramer, reagiert werde, in dem Kon- 
takte auf Ministerebene zur Beseitigung der Erschwernisse im gegenwärtig ohne Vertragsbasis abgewickelten innerdeutschen Eisenbahngüterverkehr angeregt würden.

Der Botschafter teilt mit, daß in der niederländischen Regierung der Eindruck bestehe, auf der Konferenz der Staats- und Regierungschefs der EWG-Mitgliedstaaten am 29./30. Mai 1967 in Rom fast allein als „Antagonist“ Frankreichs aufgetreten zu sein. Sie sei deshalb besorgt und überlege, ob es nicht besser sei, sich künftig still zu verhalten. Dann könne aber auch nicht mehr erwartet werden, daß die Niederlande weiter für die Anliegen der Bundesrepublik eintrete. Knoke meint abschließend, solche Äußerungen spiegelten die Sorge darüber wider, daß eine volle europäische Integration scheitern und stattdessen eine von de Gaulle initiierte Renationalisierung der westeuropäischen Staaten folgen könnte. Ein „deutsch-nationales Gesicht Deutschlands“ drei Jahrzehnte nach der "Hitler-Hypothek des Zweiten Weltkriegs" würde die weitere Zusammenarbeit mit den Niederlanden erheblich erschweren.

\section{Auswärtige Amt}

Grewe berichtet, daß der amerikanische Vertreter in der Arbeitsgruppe für Verteidigungsfragen (DPWG) die Frage aufgeworfen habe, welche vergleichbaren Maßnahmen die übrigen NATO-Partner ergreifen würden, wenn die USA im Spannungsfall der Alarmstufe „militärische Bereitschaft“ ihrerseits Truppenverbände nach Europa zurückverlegten. Die amerikanische Regierung wolle vermeiden, dann allein als diejenige dazustehen, die eine Eskalation in Gang setze. Stanley habe auf Rückfrage bestätigt, daß ein direkter Zusammenhang zwischen den Maßnahmen der anderen Alliierten und einer amerikanischen Truppenverlegung bestehe. So werde insbesondere von der Bundesregierung erwartet, da $\$$ sie bei Verkündung der Alarmstufe „militärische Bereitschaft" z.B. Reservisten zur Territorialverteidigung einziehe. Grewe meint, daß eine solche Mitwirkung der Bundesregierung nur die Entscheidung zur Rückverlegung amerikanischer Einheiten in die Bundesrepublik verzögern würde. das Auswärtige Amt

Braun teilt mit, daß der ägyptische Vertreter bei der UNO in New York, El Kony, im Sicherheitsrat überraschend die Bereitschaft seiner Regierung erklärt habe, einem Waffenstillstand mit Israel zuzustimmen. Vertreter der mit der VAR verbündeten arabischen Staaten, die von dieser Entscheidung vorab nicht unterrichtet gewesen seien, hätten sich verbittert gezeigt und Präsident Nasser als den „Zertrümmerer des arabischen Nationalstolzes" bezeichnet. Der israelische Außenminister Eban 
habe angekündigt, daß ein Rückzug israelischer Truppen nur im Rahmen einer Friedensordnung erfolgen werde. Er habe ferner erklärt, daß sich Israel von direkten Verhandlungen der Kriegsparteien mehr verspreche als von einer Vermittlung durch die UNO. Der Botschafter meint abschließend, die Reaktionen der arabischen Staaten hätten gezeigt, daß sie sich von der UdSSR nicht nur im Stich gelassen, sondern durch deren Propaganda vor Kriegsbeginn auch in die Irre geführt fühlten. Dagegen werde von den arabischen Vertretern bei der UNO die neutrale Haltung der Bundesregierung während der Krise anerkannt. Auswärtige Amt

Knappstein übermittelt Einschätzungen des außenpolitischen Beraters Walt Rostow. Es sei eine der erstaunlichsten Lehren der gegenwärtigen Nahost-Krise, daß weder die USA noch die UdSSR eine wirkliche Kontrolle über ihre „Schützlinge" hätten ausüben können. Um solche eigenmächtigen Handlungen künftig zu verhindern, sei eine engere Abstimmung mit der sowjetischen Regierung notwendig. Eine tragfähige Friedensregelung müsse erreichen, da $\beta$ die Existenz Israels gesichert und von den arabischen Staaten anerkannt werde. Gleichzeitig sei eine neue Maschinerie zur Friedenserhaltung und zur wirtschaftlichen Zusammenarbeit im Nahen Osten notwendig. Hierfür sei eine Mitwirkung der sowjetischen Regierung unerläßlich, ohne daß ihr damit aber schon die Tür zum Nahen Osten geöffnet werde. Der Botschafter hebt die amerikanische Bereitschaft hervor, zu einer „peaceful competition“ mit der UdSSR zurückzukehren, so daß auch in letzter Zeit in den Hintergrund getretene Projekte wie das Nichtverbreitungsabkommen belebt werden könnten. Daraus ergäben sich neue Möglichkeiten für die Entspannungspolitik der Bundesregierung. Auswärtige Amt

Sachs informiert über ein Arbeitsessen der Leiter der Ständigen Vertretungen bei EWG und EURATOM in Brüssel vom Vortag. Zur Frage der weiteren Behandlung des britischen Beitrittsantrages erklärte der französische Botschafter, daß zuerst eine allgemeine Aussprache unter den Außenministern der Mitgliedstaaten stattfinden sollte. Auf der Grundlage dieser Gespräche müsse sodann ein Bericht erarbeitet werden, der zur eingehenderen Sachdiskussion der einzelnen, mit dem Beitritt zusammenhängenden Komplexe dienen könnte. Boegner regte zudem an, eine Stellungnahme erst nach Neubildung der Kommission am 1. Juli 1967 einzuholen. Die übrigen Botschafter wiesen darauf hin, daß es schwierig sein werde, ohne jede Fühlungnahme mit Großbritannien zu arbeiten, da unter Umständen konkrete Angaben über die britischen Vorstellungen benötigt würden. 

Auswärtige Amt

Grewe berichtet von einer Sitzung des Ständigen NATO-Rats über die Rolle des Bündnisses bei der Wiederherstellung des Friedens im Nahen Osten. Der NATO-Generalsekretär erklärte, daß angesichts der Bedeutung von Stabilität und Frieden im Mittelmeerraum, des Schutzes der Südost-Flanke der NATO, der freien Durchfahrt durch den Suez-Kanal und der ungestörten Erdölversorgung sich das Bündnis nicht passiv und uninteressiert verhalten dürfe. Grewe informiert, daß die Äußerungen von Brosio in unterschiedlicher Art und Weise Zustimmung fanden. Insbesondere von amerikanischer Seite gebe es die Tendenz, die Konsultationen innerhalb der NATO zu aktivieren.

211 09.06. Botschafter Freiherr von Braun, New York (UNO), an das Auswärtige Amt

Braun informiert über eine Sitzung des UNO-Sicherheitsrats, die auf Antrag Syriens angesichts des israelischen Angriffs einberufen wurde. Der Sicherheitsrat habe einstimmig eine Resolution verabschiedet, in der zu einem sofortigen Waffenstillstand aufgerufen wurde. Die sowjetischen Vertreter seien sich erst im Verlauf der Sitzung bewußt geworden, daß die Kampfhandlungen, die trotz wiederholter Annahme des Waffenstillstandsappells sowohl durch Israel als auch durch Syrien fortgesetzt worden seien, die Stabilität der syrischen Regierung gefährdeten. Der sowjetische Botschafter Fjodorenko habe erklärt, daß Israel „eine ähnliche Politik wie Hitler" treibe. Im Gegenzug habe die israelische Delegation auf die Zusammenarbeit zwischen der UdSSR und dem Deutschen Reich in den Jahren 1939 bis 1941 verwiesen. Auswärtige Amt

Mez informiert über die Haltung des Sudans in der NahostKrise. Der Abbruch der Beziehungen zu Großbritannien und den USA habe ein Vakuum geschaffen, in das die DDR, die UdSSR und die Volksrepublik China einzudringen versuchten. Daher regt er an, dem sudanesischen Oppositionsführer und früheren Ministerpräsidenten el Mahdi so rasch wie möglich verbindliche Zusagen über Wirtschaftshilfe zu geben. Da mit einer erneuten Übernahme der Regierung durch el Mahdi gerechnet werden könne, werde sich dies im Falle einer Wiederaufnahme der diplomatischen Beziehungen positiv auswirken. Der Sudan müsse sich wegen der eingestellten amerikanischen Wirtschaftshilfe „notgedrungen andere Quellen“ erschließen.

Böker nimmt zu einer von Südafrika gewünschten rüstungswirtschaftlichen Zusammenarbeit im Bereich der Luftverteidigung Stellung. Anläßlich eines als privat deklarierten Besuchs 
des südafrikanischen Verteidigungsministers Botha bei Bundesminister Schröder sei das Projekt einer Luftabwehrrakete besprochen worden. Darüber habe das Auswärtige Amt jedoch erst durch eine südafrikanische Note erfahren. Böker gibt zu bedenken, daß sich durch ein derartiges Vorhaben die Stellung der Bundesrepublik in Afrika - und damit in der UNO - sehr verschlechtern würde. Er empfiehlt, dem Bundesministerium der Verteidigung die Bedenken des Auswärtigen Amts mitzuteilen, damit die Bundesregierung nicht in eine „politisch unmögliche Lage“" gebracht werde.

Pauls informiert über ein Gespräch mit einem israelischen Generalstabsoffizier. Die von der Bundesrepublik gelieferten Panzer des Typs M 48 hätten sich hervorragend bewährt. Außerdem habe der Offizier erwähnt, daß das Bundesministerium der Verteidigung modernstes sowjetisches Kriegsmaterial zum Zweck des technischen Vergleichs und der Ausbildung von Israel erwerben könne.

Schnippenkötter nimmt Stellung zu dem Schreiben des Bundesministers Schröder vom 30. Dezember 1966 über einen Austausch von Manöverbeobachtern mit der UdSSR. Das Bundesministerium der Verteidigung habe zwischenzeitlich einer solchen Maßnahme zugestimmt, so daß die Position von Schröder, ein Austausch werde "psychologisch negative Folgen für die Bundeswehr" haben, als überholt gelten dürfe. In der Frage der Akkreditierung von Militärattachés habe das Bundesministerium der Verteidigung am 22. Juni 1966 mitgeteilt, daß die noch vorhandenen Bedenken im Falle übergeordneter politischer Gesichtspunkte zurückgestellt würden. Der Botschafter hält daher eine Beantwortung des Schreibens von Schröder für nicht erforderlich.

\section{Klasse Jung}

Jung faßt eine Hausbesprechung unter Vorsitz des Bundesministers Brandt vom 3. Mai 1967 über Temporary Travel Documents zusammen. Ministerialdirektor Ruete sprach sich gegen die Abschaffung des TTD-Systems aus, da sonst der Eindruck entstehen könne, daß die Grundlagen der Deutschlandpolitik aufgegeben würden. Bundesminister Brandt erklärte, er neige einer Abschaffung zu; sie passe in eine selbstbewußte Politik hinein. Darauf entgegnete Ministerialdirigent Sahm, daß mit dem „Ausschwärmen von SBZ-Propagandisten“ in verbündete und befreundete Staaten zu rechnen sei und sich die Stellung der Bundesrepublik innerhalb der NATO ändern werde. Dagegen machte Brandt darauf aufmerksam, daß die Hälfte der Aktivitäten der Auslandsvertretungen der Bundesrepublik auf „Demarchen wegen Zonen-Emblemen“ entfielen. 

an das Auswärtige Amt

Braun gibt ein differenziertes Bild aus den Sitzungen des UNO-Sicherheitsrats über die Lage im Nahen Osten. Die USA, Großbritannien, Frankreich sowie die UdSSR wollten nach Beendigung der Krise die neu entstandenen Probleme wie Grenzfragen, Jerusalem, Rüstungsbegrenzung und Flüchtlinge in der UNO behandeln. Hingegen sei auf seiten Israels und der arabischen Staaten eine deutliche Abneigung gegen dieses Verfahren zu verspüren. Das Verhalten der Bundesrepublik werde von den meisten Delegationen als neutral erachtet und gebe keinen Anlaß zur Kritik. Allerdings habe die sowjetische Delegation damit begonnen, gegenüber den arabischen Staaten die Bundesrepublik der „Komplizenschaft“ mit den USA zu bezichtigen. Die Glaubwürdigkeit der UdSSR sei jedoch derart erschüttert, daß solche Verleumdungen vorläufig wenig Wirkung zeigten. Braun regt an, ein möglichst großzügig angelegtes Hilfsprojekt für den Nahen Osten vor dem Bundestag anzukündigen.

Wilke gibt die Gespräche des Referenten Bahr am 12./13. Juni 1967 in Prag über die Gestaltung des bilateralen Verhältnisses wieder. Der tschechoslowakische Botschafter a.D. Sedivý erklärte, daß zunächst nur die Möglichkeit einer Normalisierung auf wirtschaftlichem Gebiet bestehe. Der Alleinvertretungsanspruch der Bundesrepublik könne nicht akzeptiert werden, weil die Tschechoslowakei mit der DDR verbündet sei. Bahr betonte, daß bei der Aufnahme von diplomatischen Beziehungen die Frage der Berlin-Klausel einfacher zu regeln sei als bei einem Austausch von Handelsvertretungen. Darauf erwiderte Sedivý, daß weder von einer Berlin-Klausel noch von einer Währungsgebietsklausel die Rede sein dürfe. Eine Einbeziehung von Berlin (West) müsse durch eine gesonderte Erklärung erreicht werden. Bahr fragte, wie eine Anerkennung des Münchener Abkommens von 1938 als ex tunc ungültig wirken würde. Die Frage wurde von tschechoslowakischer Seite ausweichend beantwortet. Ein solcher Schritt der Bundesrepublik würde zwar „stimulierend" wirken, jedoch wäre damit weder der Alleinvertretungsanspruch aus der Welt geschafft, noch der Status quo in Europa voll anerkannt. Bahr warnte davor, daß günstige Gelegenheiten, wie sie in der Ostpolitik der neuen Bundesregierung begründet seien, vorübergehen könnten. Auswärtige Amt

Schütz informiert über das Gespräch des Bundesministers Brandt mit den Außenministern der Drei Mächte am 13. Juni 1967 anläßlich der NATO-Ministerratstagung in Luxemburg. Brandt erklärte, daß die DDR eine Isolierungspolitik gegenüber der Bundesrepublik verfolge. Der Bundesregierung sei an innerdeutschen Kontakten gelegen; sie sei bereit, Regelungen 
zu akzeptieren, ohne daß eine Seite von der anderen die „politische Kapitulation“ verlange. Es sei gutzuheißen, wenn auch die drei Mächte dies als einen innerdeutschen Vorgang darstellten, der ein Beitrag zur Entspannung sei. Allerdings dürfe daraus nicht der Schluß gezogen werden, daß es einen zweiten deutschen Staat gebe. Der amerikanische Außenminister Rusk beurteilte die Politik der Bundesregierung als konstruktiv. Auch der britische und der französische Außenminister, Brown und Couve de Murville, ermutigten die Bundesregierung ausdrücklich, ihre Ostpolitik fortzusetzen. Auswärtige Amt

Grewe berichtet über die NATO-Ministerratstagung am 13./14. Juni 1967 in Luxemburg, auf der alle vordringlichen Fragen der internationalen Politik erörtert wurden: Naher Osten, OstWest-Beziehungen, die Zukunft der Allianz, Europa und Vietnam. Die Außenminister betonten übereinstimmend, daß eine stabile Friedensregelung im Nahen Osten gefunden werden müsse. Hinsichtlich einer diesbezüglichen Zusammenarbeit der USA mit der UdSSR äußerte sich der amerikanische Außenminister skeptisch. Rusk regte gemeinsam mit seinen britischen und kanadischen Amtskollegen, Brown und Martin, an, Israel angesichts der militärischen Erfolge zur Mäßigung in den Waffenstillstandsverhandlungen $\mathrm{zu}$ raten. iranischen Botschafter Malek

Malek beschwert sich darüber, wie das Auswärtige Amt auf die iranischen Warnungen vor und während des Besuchs von Schah Mohammed Reza Pahlevi vom 27. Mai bis 4. Juni 1967 in der Bundesrepublik reagiert habe. Angesichts der Demonstrationen drängt er auf eine persönliche Stellungnahme des Bundeskanzlers und auf ein entschiedenes Vorgehen gegen die an den Ausschreitungen Beteiligten. Kiesinger zeigt sich insbesondere über die Vorfälle in Berlin (West) sehr verärgert. Er erklärt, daß alles getan werde, um die Verantwortlichen - ein „Bodensatz übler Elemente“ - zu belangen. indischen Botschafter Banerji

Banerji erklärt, daß Indien weiterhin auf ausländische Hilfeleistungen angewiesen sei. Die aufgrund einer zweijährigen Dürre benötigten Lebensmittel-Importe könnten nur bei einer Erhöhung der finanziellen Zuwendungen bezahlt werden. Um dies zu gewährleisten, habe sich die Weltbank an das IndienKonsortium, in dem die Bundesrepublik über eine einflußreiche Position verfüge, gewandt. Daher regt der indische Botschafter Maßnahmen der Bundesregierung zur Erleichterung der 
Rückzahlungsbedingungen früherer Kredite oder die Bereitstellung neuer Gelder an. Kiesinger verweist auf die schwierige Haushaltslage der Bundesrepublik. an das Auswärtige Amt

Herrmann bittet darum, eine vom Auswärtigen Amt erhaltene Weisung für ein Gespräch mit dem bulgarischen Außenminister über die Aufnahme von diplomatischen Beziehungen bis auf weiteres zurückstellen zu dürfen. Er rechne mit einer ausweichenden Reaktion von Bashew. Die bulgarische Regierung sei seit dem Abschluß des Freundschaftsvertrags vom 12. Mai 1967 mit der UdSSR bemüht, die bisherige „Gefolgschaft gegenüber Moskau" nach Möglichkeit noch zu überbieten. Sollte der Bundesregierung jedoch ein Botschafteraustausch mit einem weiteren Ostblock-Staat gelingen, sei eine veränderte $\mathrm{Si}$ tuation gegeben. sowjetischen Botschafter Zarapkin

Mit Blick auf eine Verbesserung der Beziehungen zwischen der Bundesrepublik und der UdSSR erläutert Brandt vierzehn Themen, die Gegenstand von Regierungsgesprächen sein könnten. Zarapkin erwidert, daß die sowjetische Regierung die Aufnahme diplomatischer Beziehungen der Bundesrepublik zu den osteuropäischen Staaten gutheiße. Jedoch dürfe damit nicht der Gedanke verbunden sei, die DDR einzukreisen und zu isolieren; vielmehr sei eine Normalisierung des Verhältnisses zwischen der Bundesrepublik und der DDR erforderlich. Er macht ferner darauf aufmerksam, daß Grundzüge einer „Verhärtung“ in den Beziehungen zwischen der UdSSR und der Bundesrepublik eingetreten seien. Brandt betont, daß kein Gesprächspartner von dem anderen erwarten könne, daß alle Forderungen noch vor Aufnahme von Verhandlungen in "unterwürfiger

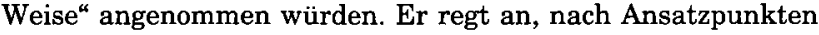
für eine Verbesserung der Beziehungen zu suchen. amerikanischen Botschafter McGhee

Kiesinger erklärt, daß sich die Haltung der westeuropäischen Regierungen allmählich auf den Abschluß eines zeitlich befristeten Nichtverbreitungsabkommens zubewege, und macht deutlich, daß er selbst eine Befristung für wesentlich halte. McGhee entgegnet, aus einer Befristung ließe sich der Schluß ziehen, daß gewisse Staaten zu einem späteren Zeitpunkt in den Besitz von Atomwaffen gelangen wollten. Die Frage eines Nichtverbreitungsabkommens werde beim geplanten Besuch des Bundeskanzlers in Washington das einzige Thema sein, bei dem auf eine Entscheidung gedrängt werde. McGhee bestätigt, daß sich die Bundesregierung in der Nahost-Krise neutral verhaiten habe, und erklärt die Versorgung mit Erdöl, die auf- 
grund der Sperrung des Suez-Kanals erschwert worden sei, als vordringlich. Abschließend betont Kiesinger, er wolle in Washington insbesondere deutlich machen, daß die Bundesrepublik nicht von den USA ,wegdrifte“.

Schütz nimmt Stellung zu den Verhandlungen der Konferenz der 18-Mächte-Abrüstungskommission in Genf. Mit Blick auf den gemeinsamen amerikanisch-sowjetischen Entwurf für eine Nichtverbreitungsabkommen regt er öffentliche Zurückhaltung, gepaart mit diskreten diplomatischen Bemühungen, an. Die Einbeziehung der EURATOM-Kontrolle in die Kontrollen eines Nichtverbreitungsabkommens mittels Verifikation durch die IAEO sei eine der wesentlichen westlichen Positionen. In diesem Punkt dürften die USA in den Verhandlungen nicht nachgeben, außer für den Fall, daß die UdSSR doch noch Sicherheitskontrollen im eigenen zivilen Bereich zuließe. Ferner sei die unbefristete Geltungsdauer eines Abkommens umstritten. Schütz rät, mit den USA über das Zeitelement auf hoher politischer Ebene zu verhandeln und in Genf diesbezüglich selbst nicht hervorzutreten. Auswärtige Amt

Schiller berichtet von Gesprächen mit dem Unterstaatssekretär im amerikanischen Außenministerium, Eugene Rostow, und dem Sonderbeauftragten des amerikanischen Präsidenten für den Nahen Osten, Bundy, über das Erdölembargo arabischer Staaten gegenüber den USA und Großbritannien. Er habe insbesondere die Sorge der Bundesregierung zum Ausdruck gebracht, daß möglicherweise die Versorgung nicht gesichert sei. Zugleich habe er sich gegen eine Erklärung der OECD über einen drohenden Notstand ausgesprochen, die nur zu einem „Run auf das OÖl" und zu Forderungen nach Regelungen zugunsten anderer Energiequellen - etwa der Kohle - führen werde. Zudem habe er darauf hingewisen, daß eine Frontbildung gegen die arabischen Staaten zu einer Ausweitung des Erdölembargos auf Kontinentaleuropa führen könnte. Lindenberg

Meyer-Lindenberg notiert, daß der jordanische Botschafter in London anläßlich eines Besuchs in der Bundesrepublik am 15. Juni 1967 im Auswärtigen Amt eine Soforthilfe der Bundesregierung für arabische Flüchtlinge angeregt habe. Juma erklärte, daß die Abreise des designierten jordanischen Botschafters aus Bonn nicht auf Veranlassung der VAR geschehen sei, sondern weil Sharif zu "Propagandaarbeiten" in Amman benötigt werde. Jordanien werde wegen der von Israel besetzten Territorien „lieber mit dem Teufel paktieren“, als diese Gebiete aufzuge- 
ben. Ferner sei die Position des ägyptischen Präsidenten angeschlagen; der Sturz von Nasser sei nur noch eine Frage der Zeit. Auswärtige Amt

Grewe berichtet von einer Debatte im Ständigen NATO-Rat über die Situation im Nahen Osten. NATO-Generalsekretär Brosio bezeichnete die sowjetischen Waffenlieferungen an die VAR und Algerien sowie die Frage der Kontinuität von Erdöllieferungen als vordringliche Probleme. Der amerikanische Botschafter Cleveland betonte, daß die UdSSR versuche, durch Militärhilfe ihre politische Position in den arabischen Staaten auszubauen. Die UdSSR werde nach den arabischen Fehlleistungen die Zustimmung zur Entsendung weiterer sowjetischer Berater fordern. Brosio erklärte, daß der Politische Ausschuß $\beta$ das Problem der Waffenlieferungen und des Gleichgewichts der Kräfte im Nahen Osten prüfen werde. an das Auswärtige Amt

Braun resümiert ein Gespräch mit dem rumänischen Ministerpräsidenten am Rande der UNO-Generalversammlung. Maurer beurteilte die Ostpolitik der Bundesregierung als geeignet, die Teilung Europas langsam zu beseitigen und erklärte seinen Willen, den „Eisernen Vorhang beiseite zu ziehen“. Er äußerte abschließend seine Sorge über das rumänische Handelsbilanzdefizit.

Harkort stellt fest, daß die Bundesregierung die Beteiligung von Industrieunternehmen aus der Bundesrepublik an der Leipziger Frühjahrsmesse erstmals gefördert habe. Sie habe die NATO-Mitgliedstaaten von der Änderung ihrer bisherigen Position unterrichtet. Dies werde auch in der NATO Folgen haben. Harkort regt daher eine Neudefinition des Begriffs der offiziellen Teilnahme an. Lindenberg

Meyer-Lindenberg skizziert die Grundzüge der Nahost-Politik, die auf dem Prinzip der Nichteinmischung beruhe. Ziele seien die Wiederaufnahme diplomatischer Beziehungen zu den arabischen Staaten, die Verhinderung der völkerrechtlichen Anerkennung der DDR und die Wahrung wirtschaftlicher Interessen. Meyer-Lindenberg regt an, in Gesprächen mit verbündeten, befreundeten und den am Konflikt beteiligten Regierungen zu erklären, daß eine Friedensregelung eine Anerkennung Israels durch die arabischen Staaten, die freie Schiffahrt für Israel im Golf von Akaba und im Suez-Kanal, die Lösung des arabischen Flüchtlingsproblems, den Verzicht auf Annexionen 
und eine einvernehmliche Regelung für die Stadt Jerusalem umfassen solle. Gleichzeitig seien die humanitären Hilfsaktionen in den von den Kriegsereignissen betroffenen Staaten fortzusetzen. Washington

Schütz bittet, an hoher Stelle die Besorgnis der Bundesregierung auszudrücken, daß das in den westlichen Konsultationen gefundene Ergebnis zum Kontrollartikel eines Nichtverbreitungsabkommens gefährdet sein könnte. Dieser im amerikanisch-sowjetischen Entwurf vom 11. Juni 1967 ausgesparte Artikel enthalte für die Bundesrepublik eines der wichtigsten Kriterien zugunsten der Annehmbarkeit des Abkommens: die „Verifikationslösung“, also die Überprüfung der als gleichwertig anerkannten EURATOM-Kontrollen durch die IAEO. Knappstein solle zudem in Erfahrung bringen, weshalb der bislang in Artikel III festgeschriebene Schutz des internationalen Austausches von Kernmaterial, Ausrüstungen und Informationen aufgegeben worden sei. Ministerpräsident Lynch

Lynch betont, daß eine überwältigende Mehrheit der Bevölkerung und des Parlaments in Irland das Gesuch vom 10. Mai 1967 um Beitritt zu den Europäischen Gemeinschaften befürworte. Wegen der ausgeprägten wirtschaftlichen Beziehungen zu Großbritannien sei ein Beitritt jedoch nur gemeinsam möglich. Kiesinger erklärt, beide Gesuche zu unterstützen. Lynch weist darauf hin, daß zunächst drei Fragen zu lösen seien: Zum einen müsse die Notwendigkeit einer Erweiterung der Gemeinschaft erörtert werden, zum andern solle die Anpassung der Landwirtschaftspolitik Großbritanniens an diejenige der EWG geklärt werden, schließlich sei über die Rolle des britischen Pfundes als Leitwährung nachzudenken. Irland selbst habe keine politischen Vorbehalte, benötige aber eine Übergangsfrist für die eigene Industrie. Kiesinger versichert, daß die Bundesregierung versuchen wolle, die französische Regierung für eine Aufnahme Großbritanniens zu gewinnen.

Ruete faßt den Verlauf einer Besprechung mit Vertretern der Drei Mächte vom 22. Juni 1967 zusammen. Es sei die Möglichkeit einer Mitbenutzung des Luftkorridors von Berlin (West) nach Frankfurt/Main durch die sowjetische Fluggesellschaft Aeroflot bei der Errichtung eines Linienflugverkehrs zwischen der Bundesrepublik und der UdSSR erörtert worden. Von seiten der Drei Mächte sei auf die Gefahr eines verkehrswidrigen Verhaltens der Aeroflot in dieser Luftstraße und auf die dadurch bedingten Auseinandersetzungen in der Luftsicherheitszentrale der Vier Mächte hingewiesen worden. Zudem hätten 
sie Bedenken wegen der Sicherheit von Berlin (West) geäußert. Von deutscher Seite sei betont worden, daß die Sicherheit der Stadt Vorrang vor dem Aufbau einer Flugverbindung zwischen Frankfurt/Main und Moskau habe. Die Deutsche Lufthansa könne jedoch nicht auf Dauer von dem Verkehr nach Moskau und weiter nach Ostasien ausgeschlossen werden.

Brandt bittet, dem britischen Außenminister Brown mitzuteilen, daß sich auf der Tagung des EWG-Ministerrats vom Vortag alle Teilnehmer bis auf Frankreich für die Aufnahme von Beitrittsverhandlungen mit Großbritannien ausgesprochen hätten. Über den Zeitpunkt der Anhörung einer britischen Delegation sei keine Übereinstimmung erzielt worden. Brandt legt Brown nahe, auf der Tagung des WEU-Ministerrats am 4./5. Juli 1967 in Den Haag unter dem Tagesordnungspunkt "Gedankenaustausch über die wirtschaftliche Lage in Europa ${ }^{*}$ den britischen Standpunkt vorzutragen.

Lahn berichtet über den Stand des Raketen- und Flugzeugbaus in der VAR. Die von ausländischen Technikern in den letzten Jahren mit großem finanziellem Aufwand entwickelten Raketen seien während der militärischen Auseinandersetzungen mit Israel aufgrund von Mängeln am Steuerungssystem nicht einsatzfähig gewesen. Da die ausländischen Experten die VAR in Kürze verließen, könne das Programm als beendet betrachtet werden. Hingegen seien im Bereich des Flugzeugbaus noch etwa 250 zumeist deutsche Techniker im Triebwerk- und Zellenbau beschäftigt.

Bahr notiert, daß gegenüber der UdSSR die Möglichkeit bestehe, auf eine Abzweigung der geplanten sowjetisch-italienischen Erdgasleitung in Richtung Süddeutschland und Berlin (West) hinzuwirken beziehungsweise die Verlängerung der in Frankfurt/Oder endenden Erdölleitung "Linie der Freundschaft" anzuregen. Ein solches Projekt könne den Entspannungswillen der Bundesrepublik unter Beweis stellen, einen für den Bundeshaushalt kostenneutralen wirtschaftlichen Aufschwung bewirken und dem sowjetischen Interesse nach verstärkten Lieferungen von Rohstoffen Rechnung tragen. Eine daraus resultierende Abhängigkeit in der Energieversorgung hält er angesichts der sehr geringen Mengen im Vergleich zum Gesamtbedarf für unwahrscheinlich. Bahr regt daher Sondierungen auf staatlicher Ebene mit der UdSSR an. Er betont, daß ein derartiges Projekt dazu beitragen könne, die Barrieren gegen die Ostpolitik der Bundesregierung abzubauen. 


\section{Klasse Lankes}

Lankes nimmt Stellung zu der Möglichkeit eines Austauschs von Gewaltverzichtserklärungen mit der Tschechoslowakei. Die Angelegenheit sei im Januar 1967 auf Wunsch der tschechoslowakischen Regierung zurückgestellt worden. Wenn nun die Bundesregierung vorschlagen würde, in den abzugebenden $\mathrm{Er}$ klärungen von den zwischen beiden Staaten bestehenden Grenzen auszugehen, könnte der tschechoslowakischen Seite vielleicht ein neuer Anreiz zu Verhandlungen gegeben werden. Die Grenzfrage würde damit offiziell und verbindlich ohne Erwähnung des Münchener Abkommens von 1938 angesprochen werden. britischen Botschafter Roberts

In der Frage der durch die Stationierung der Rheinarmee verursachten Devisenabflüsse erklärt Roberts, daß erneute Gespräche nicht vor Herbst 1967 aufgenommen werden sollten. Kiesinger entgegnet unter Hinweis auf die anstehende mittelfristige Finanzplanung, daß der Devisenausgleich im Zusammenhang mit der Konjunktur gesehen werden müsse. Bezüg. lich eines britischen Beitritts zu den Europäischen Gemeinschaften hebt er die unverändert positive Haltung der Bundesregierung hervor; sie versuche, zwischen den Mitgliedstaaten zu vermitteln und zu beschwichtigen. Mit Blick auf die französische Haltung lehnt er Kraftakte als sinnlos und schädlich ab. Notwendig sei die Stärkung Europas. Der erste Schritt hierzu könne jedoch nicht darin bestehen, die Verbindungen zu den USA zu lösen, deren Schutz noch unentbehrlich sei. französischen Botschafter François Seydoux

Kiesinger erklärt, daß während des Nahost-Konflikts die Sympathien in der Bundesrepublik eindeutig bei Israel gelegen hätten. Diese Reaktion belege, daß es keine Spur von Antisemitismus mehr gebe. Ferner sei die öffentliche Meinung für eine Stärkung Europas. Seydoux erkennt darin ein gemeinsames Ziel und verweist darauf, daß Staatspräsident de Gaulle die Möglichkeit eines unabhängigen Europas schon heute als gegeben ansehe. Der Bundeskanzler gibt zu bedenken, daß eine Abwendung von den USA, wie sie de Gaulle vertrete, gefährlich sei. Die Bundesrepublik benötige die Anwesenheit und den Schutz amerikanischer Streitkräfte. Er empfiehlt, mit einer Intensivierung der Zusammenarbeit zwischen der Bundesrepublik, Frankreich und Italien zu beginnen, um nicht immer nur zuzuwarten, „bis ein institutionalisiertes politisches Europa stehe“. 

Auswärtige Amt

Grewe berichtet von einer Sondersitzung des Ständigen NATORats vom Vortag zur Lage im Nahen Osten. Als Grundlage eines Friedens seien folgende Prinzipien genannt worden: Anerkennung der staatlichen Existenz Israels, Erhaltung der Integrität aller Staaten in der Region, Lösung des Flüchtlingsproblems, Garantie der freien Schiffahrt, Beendigung des Wettrüstens und Regelung für den Status der Stadt Jerusalem. Die Verwirklichung dieser Grundsätze sei jedoch allenfalls im Wege eines langwierigen und schwierigen Prozesses möglich. Die UdSSR ergänze erneut die Waffenbestände der arabischen Staaten. Ministerialdirigent Böker habe darauf hingewiesen, daß die UdSSR versuche, den Nahost-Konflikt für ihre deutschlandpolitischen Ziele auszunutzen. Es bestehe eine gewisse Gefahr, daß die VAR, Syrien und der Irak die DDR anerkennen könnten. Daher habe er um solidarisches Verhalten der NATOMitgliedstaaten gebeten.

243 03.07. Gespräch des Bundesministers Brandt mit dem österreichischen Vizekanzler Bock

Bock führt aus, daß er mit Brandt als dem amtierenden Vorsitzenden des Ministerrats der Europäischen Gemeinschaften über eine Fortführung der Verhandlungen für eine Assoziierung Österreichs sprechen wolle. Zwar habe sich die UdSSR bislang unter Hinweis auf den österreichischen Staatsvertrag von 1955 ablehnend geäußert, doch sei die Neutralität kein Bestandteil dieses Vertrages. Österreich werde „trotz russischer Bedenken" nicht vor einem Arrangement mit der EG zurückschrecken, und es würde ein Zurückweichen der Gemeinschaft als „Eingriff in seine Souveränität" betrachten. Die italienische Erklärung, sich aufgrund der jüngsten Anschläge in Südtirol einer Assoziierung Österreichs widersetzen zu wollen, habe „schockiert“. Brandt sichert daraufhin zu, den österreichischen Antrag bei den EG-Verhandlungen unterstützen und schon am folgenden Tag mit dem italienischen Außenminister Fanfani darüber sprechen zu wollen.

\section{03.07. Aufzeichnung des Staatssekretärs Schütz}

Aus einem Gespräch mit dem israelischen Botschafter Ben Natan notiert Schütz die Bitte, den Antrag Israels auf Assoziierung mit der EG bei den bevorstehenden Verhandlungen in Brüssel zu unterstützen und die seit Juni 1967 bestehenden Restriktionen bei Waffenlieferungen in den Nahen Osten rückgängig zu machen.

Harkort legt dar, er habe am Vortag weisungsgemä $\beta$ dem israelischen Botschafter mitgeteilt, daß die Bundesregierung bereit sei, das Kapitalhilfeabkommen für $1967 \mathrm{zu}$ unterzeichnen. Gegen diesen Schritt spreche jedoch, daß die UNO offensicht- 
lich beabsichtige, eine Resolution zur Nahost-Krise zu verabschieden, in der der Rückzug der israelischen Truppen gefordert werde. Da Israel voraussichtlich nicht Folge leisten und somit in Gegensatz zur großen Mehrheit der Staaten geraten werde, sei die Unterzeichnung des Abkommens nicht unbedenklich, da es als eine eindeutige Parteinahme gewertet werden könne. Harkort weist auf die Gefahr arabischer Boykottmaßnahmen gegen die Bundesrepublik hin. Der Abschluß eines neuen Geheimabkommens mit Israel sei daher auf einer Direktorenbesprechung im Auswärtigen Amt erwogen, jedoch wieder verworfen worden. Harkort regt vielmehr an, Bundesminister Brandt solle Ben Natan um Verständnis dafür bitten, daß die Unterzeichnung vorläufig verschoben werden müsse. Auswärtige Amt

Oncken berichtet von der Sitzung des Ständigen NATO-Rats am 5. Juli 1967. Mit Blick auf die Kontrollbestimmungen des geplanten Nichtverbreitungsabkommens wurde die Gleichwertigkeit einer Überwachung von Atomanlagen durch EURATOM mit Kontrollen durch die IAEO erörtert. Der amerikanische NATO-Botschafter vertrat die Meinung, daß sich die Haltung Frankreichs grundlegend geändert habe. Cleveland berief sich dabei auf Äußerungen von französischer Seite, daß keine Vorbehalte gegen die Anwendung von IAEO-Kontrollen bei der Durchführung eines Nichtverbreitungsabkommens bestünden. Der Botschafter betonte, daß es schwierig sein werde, gegenüber den blockfreien Staaten eine Berücksichtigung von Kontrollen durch EURATOM im Abkommen durchzusetzen, wenn von französischer Seite kein Interesse mehr bestehe. Oncken teilt weiter mit, der französische Gesandte bei der NATO, Schricke, habe dagegen glaubhaft versichert, daß die Position der französischen Regierung unverändert geblieben sei. Sie werde möglicherweise einem Verifikationsabkommen zwischen IAEO und EURATOM zustimmen, falls Frankreich selbst davon nicht betroffen werde. Cleveland wolle lediglich „einen Keil“ zwischen Frankreich und die übrigen EURATOM-Staaten treiben. Houphouet-Boigny

Houphouet-Boigny äußert Verständnis für die deutschlandpolitischen Probleme der Bundesrepublik und sagt $\mathrm{zu}$, in der UNO die Forderung nach einer Wiedervereinigung Deutschlands zu unterstützen. Im weiteren Verlauf der Unterredung regt er an, die Präsenz der Bundesrepublik an der Elfenbeinküste "ständig sichtbar" zu machen, etwa dadurch, daß sich Firmen direkt vor Ort um Aufträge bemühen. Kiesinger, der einen Überblick über die Ostpolitik der Bundesregierung gibt, bezeichnet diesen Vorschlag als interessant. Als besonderes handelspolitisches Problem spricht Houphouet-Boigny den unbefriedigenden Absatz von Bananen aus der Republik Elfenbeinküste in der Bundesrepublik an. 

Blomeyer-Bartenstein

Blomeyer-Bartenstein äußert sich zur Übernahme konsularischer Tätigkeiten in den von Israel im Nahost-Krieg besetzten Gebieten durch die Botschaft in Tel Aviv. Er empfiehlt, bei der israelischen Regierung einen Vorbehalt hinsichtlich der Zugehörigkeit dieser Gebiete zu Israel einzulegen. Vor dem NahostKrieg sei beispielsweise die konsularische Betreuung deutscher Staatsangehöriger in der Altstadt von Jerusalem und im Ostteil der Stadt durch die Botschaft in Amman erfolgt. Diese Aufgabe müsse nun die Vertretung in Tel Aviv übernehmen. Dies könne von den arabischen Staaten und von der UNO als Anerkennung der israelischen Oberhoheit in der Altstadt und in Ost-Jerusalem gewertet werden. Darüber hinaus habe Israel mittlerweile die Neustadt von Jerusalem mit der Altstadt sowie mit Ost-Jerusalem formell administrativ vereinigt. Dieser Schritt sei am 5. Juli 1967 durch die UNO verurteilt worden. Angesichts dieser Entwicklung erscheint Blomeyer-Bartenstein der im Auswärtigen Amt gefaßte Beschluß, lediglich einen formlosen mündlichen Vorbehalt einzulegen, nicht mehr ausreichend. Daher fügt er den Entwurf eines Aide-mémoires bei. Auswärtige Amt

Oncken berichtet von den Bemühungen, zu einer Vereinbarung zwischen dem Oberbefehlshaber der NATO-Streitkräfte in Europa, Lemnitzer, und dem französischen Generalstabschef Ailleret über das Zusammenwirken von Frankreich und der NATO im Krisen- und Verteidigungsfall zu gelangen. Bislang habe sich die Formulierung einer von Lemnitzer an Ailleret zu richtenden schriftlichen Billigung der Befehlsgewalt von Ailleret über die französischen Truppen in der Bundesrepublik als schwierig erwiesen, weil sie nicht als nachträgliche Zustimmung zum französischen Ausscheiden aus der NATO-Integration erscheinen dürfe. Seitens der Bundesrepublik werde eine Kompromißformel befürwortet, die Ailleret in einem Schreiben vom 10. Mai 1967 an Lemnitzer vorgeschlagen habe.

Bahr unterbreitet Empfehlungen für die Gesprächsführung beim Besuch des Staatspräsidenten de Gaulle am 12./13. Juli 1967 in Bonn. Die Vorstellungen der Bundesregierung bezüglich eines Sicherheitssystems für Europa könnten zu einem wichtigen Thema werden. In diesem Zusammenhang sollte auch der Stufenplan „Gewaltverzicht - Sicherheitssystem - Friedensordnung“ erläutert werden. Zu erwägen sei, ob Frankreich im Rahmen der Entspannungsbemühungen gegenüber Polen etwa die Verläßlichkeit der Bundesrepublik garantieren wolle. Weiterhin könne angesprochen werden, ob Frankreich als Garantiemacht bereitstünde, falls der Gewaltverzicht gegenüber der Tschechoslowakei in besonders feierlicher Form nach dem „Vorbild Locarno“ vertraglich geregelt werden solite. Bahr macht 
zudem darauf aufmerksam, daß in der Frage eines Nichtverbreitungsabkommens auf einer Klärung der französischen Haltung zu einer Verifikationslösung zwischen EURATOM und IAEO bestanden werden müsse. Wenn Frankreich sich selbst bei einer Regelung ausnehme, könne nicht mehr von EURATOM gesprochen und wohl auch keine für die UdSSR akzeptable Lösung erzielt werden.

Haeften resümiert den Stand der Diskussion über den FanfaniPlan. Zu der vom italienischen Außenminister im September 1966 in der NATO vorgeschlagenen Untersuchung über eine internationale Zusammenarbeit, um den technologischen Rückstand Europas gegenüber den USA aufzuholen, verabschiedete der NATO-Ministerrat am 13./14. Juni 1967 einen Bericht und einen Resolutionsentwurf, die im wesentlichen den Vorstellungen der Bundesregierung entsprachen. Sie enthielten z.B. den Hinweis, daß die technologische Zusammenarbeit in Europa in erster Linie in den Europäischen Gemeinschaften, die „atlantische Zusammenarbeit" dagegen in der OECD stattfinden sollte. Jedoch hätte deutlicher zum Ausdruck gebracht werden müssen, daß sich die Tätigkeit der NATO auf wehrtechnische Forschungen beschränken solle. Auswärtige Amt

Oncken berichtet über die erste Reaktion des britischen Vorsitzenden der Arbeitsgruppe für Verteidigungsplanung der NATO auf Pressemeldungen, daß infolge von Kürzungen im Bundeshaushalt Truppenverringerungen notwendig werden könnten. Hockaday regte an, der NATO einen entsprechenden Vorschlag zu unterbreiten. Das Vorhaben der Bundesregierung könne dann im Ausschuß für Verteidigungsplanung der NATO erörtert werden, wo es vermutlich - angesichts der "großzügig“ behandelten amerikanischen, belgischen und britischen Wünsche nach Rückverlegung von Truppen aus der Bundesrepublik nur auf geringe Kritik stoßen werde. Hockaday riet, das Argument zu verwenden, da $\beta$ die Truppenreduktionen mit einer Verbesserung der Kampfkraft der Bundeswehr einhergingen. Er verwies auf die amerikanische Position, daß die Personalstärken der Bundeswehr-Verbände und die Kriegsbevorratung zu niedrig seien. sowjetischen Botschafter Zarapkin

In dieser Unterredung werden strittige Fragen nicht erörtert. Kiesinger erläutert die Politik der Bundesregierung gegenüber der UdSSR. Unter Ausklammerung der zur Zeit nicht lösbaren Deutschland-Frage strebe sie eine Verbesserung der Beziehungen an. Auf den von Zarapkin angesprochenen Vorschlag eines kollektiven Sicherheitssystems für Europa erklärt Kiesinger, 
es sei kein normaler Zustand, daß sich in Europa seit zwanzig Jahren amerikanische und sowjetische Truppen gegenüberstünden. Allerdings könne auf die Anwesenheit amerikanischer Soldaten erst nach der Schaffung eines wirklich zuverlässigen Sicherheitssystems verzichtet werden. Zarapkin vertritt die Ansicht, daß sich Äußerungen von Politikern aus der Bundesrepublik - beispielsweise über eine Auflösung der Verteidigungsbündnisse, zu kernwaffenfreien Zonen oder Truppenreduktionen - mit einem Teil der Karlsbader Vorschläge vom 26. April 1967 zur Sicherheit in Europa deckten. Kiesinger zeigt sich überzeugt, daß kollektive Sicherheit in Europa idealerweise durch Abrüstung erreicht werden sollte. Dies würde auch die Mittel freimachen, um Hunderten von Millionen notleidender Menschen in der Dritten Welt durch "gemeinsame Taten des Friedens" zu helfen. Zarapkin betont dagegen, daß zur Zeit eine vollständige Abrüstung nicht möglich sei.

Kiesinger informiert Johnson über die Beschlüsse des Bundeskabinetts vom 6. Juli 1967 zur mittelfristigen Finanzplanung bis 1971. Sie sähen zwar Kürzungen bei den eingeplanten $\mathrm{Zu}$ wachsraten im Verteidigungshaushalt vor, zögen jedoch nicht automatisch eine Verminderung der Personalstärke der Bundeswehr nach sich. Eine solche Entscheidung sei schon deshalb nicht getroffen worden, weil die Verbündeten selbstverständlich vorab dazu konsultiert worden wären. Diesbezügliche Pressemeldungen hätten folglich einen ebenso geringen Wahrheitsgehalt wie „wilde Gerüchte“, daß die Haushaltsbeschlüsse Anzeichen einer politischen Neuorientierung der Bundesregierung seien. Kiesinger betont, daß er vor allem die Verteidigungsstärke des Heeres erhalten wolle und daß schon ab 1969 wieder eine Steigerung der Ausgaben für die Bundeswehr vorgesehen sei.

Sahm faßt ein Gespräch mit dem niederländischen Gesandten zusammen. Jorissen äußerte die Befürchtung, daß die aus finanziellen Erwägungen möglicherweise notwendige Verkleinerung der Bundeswehr einen ,übermächtigen“ Druck auf die niederländische Regierung zur Folge haben könnte, die Dienstzeit in den Streitkräften herabzusetzen und Einsparungen im Verteidigungshaushalt vorzunehmen. Weiterhin bedauerte er, daß die Bundesregierung ihre Verbündeten nicht vor der Beschlußfassung konsultiert habe. Sahm erläuterte daraufhin, daß es sich bei der Entscheidung vom 6. Juli 1967 lediglich um Vorab-Beschlüsse über einen haushaltsmäßigen Rahmen handele.

Bahr erhält Weisungen für die bevorstehenden Verhandlungen mit der tschechoslowakischen Regierung über den Abschluß von Abkommen zum Waren- und Zahlungsverkehr sowie über den 
Austausch von Handelsvertretungen. Er solle klarstellen, daß die Bundesrepublik unverändert die Aufnahme diplomatischer Beziehungen anstrebe. Hinsichtlich einer Einbeziehung von Berlin (West) in die Abkommen müsse er versuchen, eine Festschreibung der „bisherigen Praxis“ im bilateralen Handel zu erreichen. Hierfür wäre die verbindliche tschechoslowakische Zusicherung unerläßlich, daß Berlin (West) zumindest de facto in das Warenverkehrsprotokoll von 1961 eingebunden war. Die in Prag zu errichtende Handelsvertretung sollte über konsularische Befugnisse - wie etwa das Recht zur Ausstellung von Pässen und Sichtvermerken - verfügen. Sie solle zudem $\mathrm{Zu}$ gang zum tschechoslowakischen Außenministerium erhalten und auch in kulturpolitischen Angelegenheiten tätig werden können. Hinsichtlich der Rechtswirksamkeit des Münchener Abkommens von 1938 solle auf den bekannten Standpunkt der Bundesregierung verwiesen werden, daß das Abkommen nicht mehr gültig sei. in Paris

Meyer-Lindenberg übermittelt eine Weisung für ein weiteres Gespräch des Botschaftsrats I. Klasse Fechter mit dem ägyptischen Botschaftsrat Charaf. Fechter solle erklären, daß Behauptungen, die Bundesregierung habe während der NahostKrise 500 Freiwillige über Luxemburg nach Israel entsandt und außerdem dem stellvertretenden israelischen Verteidigungsminister Peres Kredite zum Kauf französischen Rüstungsmaterials zugesagt, „absolut unwahr" seien. Sie träfen ebensowenig zu wie die bereits im Mai und Juni 1967 von ägyptischer Seite verbreiteten Meldungen, die Bundesrepublik liefere Waffen an Israel. Die angebliche Abreise der Freiwilligen vom Flughafen Luxemburg aus sei sogar vom luxemburgischen Verkehrsminister Boucher in einer schriftlichen Erklärung dementiert worden. Abschließend äußert Meyer-Lindenberg die Ansicht, daß diese Gerüchte zum großen Teil von der DDR und der UdSSR ausgingen. der NATO in Paris

Schütz übermittelt ein Schreiben an den NATO-Generalsekretär. Darin informiert er Brosio über den Beschluß des Bundeskabinetts vom 6. Juli 1967 zur mittelfristigen Finanzplanung bis 1971. Die aufgrund der Konjunkturschwäche unumgänglich gewordenen Streichungen im Bundeshaushalt machten Kürzungen gegenüber den Anforderungen des Bundesministeriums der Verteidigung erforderlich. Damit bleibe der Verteidigungsetat „hinter der bisherigen Planung erheblich“ zurück. Schütz betont, daß sich die Bundesregierung der Risiken dieser Entscheidung bewußt sei. 

Bundesminister Brandt

Walther berichtet aus einer Unterredung mit einem sowjetischen „Verbindungsmann" über die vierzehn Gesprächspunkte, die von Bundesminister Brandt am 16. Juni 1967 dem sowjetischen Botschafter Zarapkin übergeben wurden. Die Tatsache, daß der Gesprächspartner sofort die Anerkennung der DDR durch die Bundesregierung als Voraussetzung nicht nur für eine Verbesserung der bilateralen Beziehungen, sondern auch für erfolgreiche Gespräche über andere Fragen forderte, lasse auf eine Verhärtung in der sowjetischen Haltung schließen. Auch Erläuterungen von Walther, daß durch ein Gewaltverzichtsabkommen die von der UdSSR geforderte Anerkennung der Realitäten in Deutschland in der Praxis "effektuiert" würde und daß eine Bestätigung der Nachkriegsgrenzen aufgrund der Beschlüsse von Potsdam von 1945 zu einer reinen Prozedurfrage geworden sei, konnten dem Gespräch keine positive Wendung geben. bei der NATO in Paris

Sahm legt dar, wie auf eine weitere Erörterung von Schadensersatzforderungen der übrigen NATO-Partner gegenüber Frankreich zu reagieren sei. Die Ansprüche seien in dem französischen Ausscheiden aus der militärischen NATO-Integration begründet. $\mathrm{Zu}$ berücksichtigen sei, daß die Bundesregierung weiterhin an einer engen und dauerhaften Zusammenarbeit mit Frankreich Interesse habe. Daher sei es nicht zweckmäßig, der französischen Regierung eine vorbereitete, rechtlich und rechnerisch belegte Forderung zuzustellen; vielmehr müsse diese dazu veranlaßt werden bekanntzugeben, in welchem Umfang sie zu einem finanziellen Ausgleich bereit sei. Sahm regt an, die Vierzehn sollten für weitere Gespräche eine Verhandlungsdelegation beauftragen. Staatspräsident de Gaulle

De Gaulle erläutert die Haltung der französischen Regierung in der Nahost-Krise, die in der Kritik am israelischen Angriff vom 5. Juni 1967 von der öffentlichen Meinung in Frankreich abweiche. Weiterhin wünsche Frankreich, den Gemeinsamen Markt unverändert zu erhalten. Ein britischer Beitritt zur EG würde alles „umkrempeln“, denn Großbritannien sei anders als die übrigen sechs Mitgliedstaaten. Gegenüber der Bundesrepublik sei Frankreich zu einem besonderen und priviligierten Kontakt bereit, der enger sein solle als zu irgend einem anderen Staat. Kiesinger betont dagegen das Interesse der deutschen Industrie an einer Aufnahme Großbritanniens in die Gemeinschaft. Die EG müsse größer und stärker werden, wenn sie politisches Gewicht haben solle. Zur Verbesserung der bilateralen Zusammenarbeit schlägt er die Berufung eines Koordinators und die Bildung einer deutsch-französischen Industrie- 
kommission vor. Als wichtiges Gebiet der Kooperation sieht er die Politik gegenüber Osteuropa. Hier weist Kiesinger auf die von ihm neu gesetzten Akzente hin, so auf die gegenüber Polen herausgestellte „versöhnende Formel“, daß der in einem Friedensvertrag festzulegende Verlauf der deutsch-polnischen Grenze für beide Seiten annehmbar sein müsse. De Gaulle gibt zu bedenken, daß eines Tages Deutschland selbst eine Entscheidung in der Grenzfrage treffen müsse, die dann einen „ungeheuren Effekt" in den Ostblock-Staaten haben würde. Ministerpräsident Pompidou

Pompidou faßt Eindrücke seines Besuchs vom 3. bis 8. Juli 1967 in der UdSSR zusammen. Dort gelte zur Zeit die wirtschaftliche Entwicklung als vorrangige Aufgabe. Auffällig sei die $\mathrm{Zu}-$ nahme des individuellen Konsums, die sich in der steigenden Zahl der privaten Kraftwagen zeige. Dies halte er für wichtig, da das sowjetische politische System durch Individualismus „leicht ein bißchen erschüttert" werden könne. Aus Gesprächen mit Ministerpräsident Kossygin und dem Generalsekretär des ZK der KPdSU, Breschnew, habe er den Eindruck gewonnen, $\mathrm{da}$ die sowjetische Regierung angesichts der innenpolitischen Aufgaben an einer Beilegung internationaler Konflikte, wie im Nahen Osten und in Vietnam, interessiert sei. Das DeutschlandProblem wolle sie zur Zeit ${ }_{n}$ im Eisschrank lassen". So sei nicht mit einer Krise aufgrund der „Annäherungsbemühungen “ der Bundesrepublik gegenüber den Ostblock-Staaten zu rechnen. Kiesinger pflichtet bei, daß auch er im Verhältnis zur UdSSR keine erheblichen Entwicklungen erwarte. Die Ostpolitik werde mit viel Geduld fortgeführt. In der Frage einer Anerkennung der DDR müsse die Bundesregierung jedoch hart bleiben, wenn sie zur Lösung menschlicher Probleme beitragen wolle. Staatspräsident de Gaulle

De Gaulle legt dar, daß der Weg zur deutschen Wiedervereinigung nur über ein Arrangement mit dem Osten führe; ndabei könne Deutschland mit Frankreich und nur mit Frankreich rechnen“. Die Verständigung zwischen Ost und West sei notwendig, um Europa vor politischer und wirtschaftlicher Dominanz durch die USA zu bewahren, unter der es aus französischer Perspektive keine "raison de vivre" mehr gebe. Dem ziehe Frankreich in aller Aufrichtigkeit eine Wiedervereinigung Deutschlands vor. Kiesinger verweist darauf, daB die UdSSR allein durch ihre Größe und ihre Atomwaffen Westeuropa gefügig machen könne. Deshalb müßten bis zu einer Lösung der europäischen Frage die USA in Europa militärisch präsent bleiben. De Gaulle betont dagegen, daß zur Zeit die Volksrepublik China das größte Problem für die UdSSR darstelle, die sich folglich mit dem Westen arrangieren müsse. Europa dürfe nicht dem „Atlantismus“ anheimfallen. Dies aber werde bei einer Aufnahme Großbritanniens in die EG geschehen, die sich 
dann von einer Gemeinschaft zu einer Freihandelszone wandeln werde. Auch lehne er eine politische Struktur Europas ab, in der Frankreich seine nationale Persönlichkeit verlöre. Kiesinger räumt ein, daß er ursprünglich eine europäische Integration befürwortet habe, damals allerdings ,noch ziemlich unerfahren" gewesen sei. De Gaulle habe ihn überzeugt, daß die Verantwortung für die Nationen nicht durch eine übernationale Bürokratie ersetzt werden könne. Auch ohne Supranationalität sei eine europäische politische Union zu erzielen.

Bundeskanzler Kiesinger und Staatspräsident de Gaulle fassen die Ergebnisse der vorangegangenen Gespräche zusammen. Hervorgehoben wird die Notwendigkeit zur Verbesserung der Kooperation, vor allem auf den Gebieten Wirtschaft und Technologie. Für diese Bereiche werde die Einrichtung bilateraler Kommissionen erwogen. Bestätigt wird der Vorschlag, in jedem der beiden Staaten einen Beauftragten zur Koordinierung der Zusammenarbeit zu ernennen. Bundesminister Schiller und der französische Wirtschaftsminister Debré teilen aus ihren Gesprächen mit, daß die beiden Regierungen hinsichtlich der internationalen Finanzpolitik übereinstimmten. Mit Blick auf Stimm- und Ziehungsrechte im Internationalen Währungsfonds bestehe Einvernehmen, daß die sechs EG-Staaten eine „Sperrminorität" erhalten sollten. Debré berichtet aus seiner Unterredung mit Bundesminister Strau $\beta$, daß auch in Steuerfragen die Ansichten harmonierten. Bundesminister Schröder führt aus, daß er mit seinem französischen Amtskollegen Messmer darüber gesprochen habe, wie die vereinbarten gemeinsamen Studien über die Sicherheit Europas in den siebziger Jahren organisiert werden sollen.

Ruete legt eine Zusammenfassung von drei Schriftstücken vor, die einem Ingenieur aus der Bundesrepublik im Juni 1967 in Kasachstan von einer Angehörigen der rußlanddeutschen Minderheit übergeben wurden. Bei den zweifellos authentischen Dokumenten handele es sich erstens um Aufzeichnungen über Gespräche, die eine wolgadeutsche Delegation 1965 mit Vertretern des Zentralkomitees der KPdSU und mit dem damaligen Vorsitzenden des Präsidiums des Obersten Sowjet, Mikojan, führte, zweitens um ein vermutlich Anfang 1966 abgesandtes Schreiben an Mikojan. In den Schriftstücken werde die Wiederherstellung der Wolgadeutschen Republik und die völlige Rehabilitierung der rußlanddeutschen Volksgruppe gefordert, die immer noch ein Opfer der „antileninistischen Völkermordukase" von 1941, 1948 und 1955 sei. Seitens der KPdSU sei lediglich eine bessere politische Vertretung sowie mehr Eigenständigkeit im Bereich Bildung und Medien zugesichert worden. Ruete kommt zu dem Schluß, daß angesichts der prekären Lage der Rußlanddeutschen jeder Schritt der Bundesregierung gegenüber der UdSSR unterbleiben solle. 

Auswärtige Amt

Oncken berichtet von einer informellen Sitzung der Ständigen Vertreter bei der NATO über den Stand der Studie über die zukünftigen Aufgaben der Allianz (Harmel-Studie). Der dänische NATO-Botschafter Hjorth-Nielsen bezeichnete die Organisation des Projekts als „chaotisch“ und beklagte die fehlende Koordinierung der vier Untergruppen, von denen drei mit ihrer Arbeit nicht recht vorankämen und eine überhaupt überflüssig $z u$ sein scheine. Der kanadische Botschafter stimmte $z u$ und schlug vor, die Zahl der Untergruppen auf zwei zu reduzieren. Ritchie erläuterte dann die kanadische Auffassung von den zukünftigen Aufgaben der NATO. Dazu gehöre, daß sie eine Garantie gegen wiederaufkommenden Nationalismus und einen Sicherheitsrahmen für eine Wiedervereinigung Deutschlands biete. Die NATO solle ihre militärische Stärke beibehalten und sich gleichzeitig „nach Osten hin“ offnen. Während von französischer Seite ein großer Teil der Studie als thematisch „irrelevant" bezeichnet wurde, rieten die Vertreter anderer Staaten - darunter der USA, Großbritanniens und der Türkei - von voreiliger Kritik ab. amerikanischen Botschafter McGhee

Kiesinger bezeichnet Verlautbarungen in der Presse, daß die Bundeswehr um 60000 Mann verringert werden müsse, als „baren Unsinn“. Er betont, daß die für die Streitkräfte zur Verfügung stehenden Mittel sogar jährlich wachsen werden. Bereits am 12./13. Juli 1967 habe er den französischen Staatspräsidenten darauf hingewiesen, daß dessen Haltung gegenüber den USA der deutsch-französischen Kooperation möglicherweise „schweren Schaden“ zufügen werde. Er könne sich nämlich auf Dauer nicht für die Zusammenarbeit mit Frankreich aussprechen, wenn de Gaulle weiterhin so "gegen Amerika rede“. Die ablehnende Haltung des Staatspräsidenten zu einem britischen EG-Beitritt sei unerbittlich gewesen. Auf die Frage von McGhee, was unter der deutsch-französischen Studie über die Sicherheit Europas in den siebziger Jahren zu verstehen sei und ob dieses Vorhaben etwa "über die NATO hinausgehe“, antwortet Kiesinger, daß zunächst geplant worden sei, Möglichkeiten für eine bilaterale Zusammenarbeit auf den Rüstungssektor zu erörtern. Inzwischen sei der Themenkreis erweitert worden. Das Projekt sei jedoch noch recht vage, und es gebe keinen Grund für irgendwelche Besorgnisse in den USA.

Diehl stellt fest, daß auf der Besprechung der amerikanischen, britischen und deutschen Planungsstäbe vom 10. bis 12 . Juli 1967 in London als erstes Thema ein britischer Plan für „Europäische Sicherheit und Wiedervereinigung “ erörtert worden sei. Kernpunkt dieses Vorschlags waren zum einen Gespräche zwischen der Bundesrepublik und der DDR über eine Humanisie- 
rung des bilateralen Verhältnisses, zum anderen zwischen NATO und Warschauer Pakt über europäische Sicherheit. Nur wenn in beiden Verhandlungsrunden befriedigende Ergebnisse erzielt würden, sollten die dort ausgehandelten Vereinbarungen in Kraft treten. Trotz des Einwandes, daß solche Gespräche mit der UdSSR „zwangsläufig in einen ,Propagandazirkus ausarten müßten", überwog die Ansicht, wenigstens eine Vorkonferenz über weniger kontroverse Punkte aus dem Bereich der europäischen Sicherheit anzustreben. Die von der sowjetischen Regierung im Rahmen einer Sicherheitskonferenz verfolgten Ziele, wie etwa die Anerkennung von DDR und OderNeiße-Linie oder die Auflösung der NATO, seien allerdings abzulehnen. Es bestand Einvernehmen, daß zunächst die „Marschroute der Allianz" festgelegt werden müsse. Der Gedanke, die Diskussionen in der Harmel-Gruppe in diesem Sinne zu führen, wurde jedoch verworfen.

Diehl legt dar, daß sich bei der Besprechung der amerikanischen, britischen und deutschen Planungsstäbe vom 10. bis 12 . Juli 1967 in London die amerikanischen Teilnehmer beunruhigt gezeigt hätten: Erklärungen der Bundesregierung erweckten den Eindruck, als werde nicht mehr der Integration im westlichen Bündnis der Vorrang vor einer Wiedervereinigung gegeben. Die Bundesregierung sei offensichtlich wieder in die Illusion der fünfziger Jahre verfallen, eine große klärende Entscheidung durch einen Ausgleich mit der UdSSR erreichen zu können. Diehl selbst erläuterte, welche Bedeutung in der Bundesrepublik der europäischen Einigung und der NATO als Voraussetzungen für eine Verständigung mit der UdSSR beigemessen werde. Die Bundesregierung sei allerdings der Überzeugung, daß sich eine Wiedervereinigung Deutschlands nur im Rahmen einer geänderten "politischen Großwetterlage“ vollziehen könne. Daraufhin wurde von amerikanischer Seite die Politik der USA gegenüber der UdSSR erläutert, die durch eine "gewisse kooperative Bipolarität" gekennzeichnet sei. Es bestand Übereinstimmung, daß das europäisch-amerikanische Verhältnis noch keine echte Partnerschaft sei; die USA dürften von Europa nicht nur ein Mittragen der Lasten verlangen, sondern müßten es auch stärker an Entscheidungen beteiligen. Voraussetzung dafür sei allerdings, daß Europa „mit einer Stimme spreche“. Freiherr von Dungern

Dungern erörtert die Bedeutung der Atomwaffen für die Verteidigung der Bundesrepublik. Weder die amerikanischen Interkontinalraketen noch die etwa 7000 Raketen mittlerer Reichweite in Westeuropa stellten eine wirkungsvolle Abschreckung gegen einen konventionellen Angriff des Warschauer Paktes dar: Während der Einsatz der Erstgenannten unglaubwürdig sei, könnten die Mittelstreckenraketen auf sowjetischer Seite sogar 
die Hoffnung wecken, einen Krieg auf Europa begrenzen zu können. Dieses Dilemma könne überwunden werden, wenn auch ein konventioneller Angriff mit der Zündung von zehn bis zwanzig Kernwaffen mit einer Sprengwirkung von maximal 3 Kilotonnen beantwortet würde. Ihr Einsatz, der lediglich eine begrenzte atomare Verseuchung verursachen würde, wäre auch in einem dicht besiedelten Gebiet glaubhaft und würde der UdSSR klarmachen, daß nunmehr die Schwelle zum Atomkrieg überschritten sei. Dungern empfiehlt daher die Stationierung solcher „Kleinst-A-Waffen“. Weiterhin befürwortet er die Einführung der verbesserten Pershing-Langstreckenrakete. An ihrem Einsatz sollte die Bundesregierung nach dem „Zwei-Schlüssel-System " mitbeteiligt werden. So ließe sich ein gewisser Einfluß auf die amerikanische Nuklearstrategie nehmen. bei der NATO in Paris

Ruete nimmt Stellung zu dem geplanten Schriftwechsel zwischen dem Oberbefehlshaber der NATO-Streitkräfte in Europa, Lemnitzer, und dem französischen Generalstabschef Ailleret über das künftige Zusammenwirken zwischen Frankreich und der NATO im Krisen- und Verteidigungsfall. Die Bundesregierung befürworte weiterhin die von französischer Seite vorgeschlagenen Formulierungen. Allerdings sei es bislang nicht gelungen, ein Einvernehmen mit den USA zu erzielen. Ruete rät davon $a b$, den Inhalt der französischen Fassung über eine Pressemitteilung vorab publik zu machen und damit die Hoffnung zu verbinden, die französische Regierung könne sich dann nicht mehr von diesem Entwurf distanzieren. (Entwurf)

Brandt äußert sich besorgt darüber, daß der Beschluß des Bundeskabinetts vom 6. Juli 1967 über die mittelfristige Finanzplanung bis 1971 und insbesondere seine Auswirkungen auf den Verteidigungshaushalt in eine öffentliche Diskussion über neue Verteidigungskonzeptionen auszuarten drohe. Einer solchen Entwicklung müsse die Bundesregierung entgegenwirken, damit nicht der abträgliche Eindruck entstehe, als ob die Bundesrepublik sich nicht loyal an die erst Ende 1967 zu treffenden Entscheidungen zur NATO-Streitkräfteplanung halten werde. Auswärtige Amt

Grewe teilt mit, daß die Entwicklung der deutsch-französischen Beziehungen und insbesondere die geplanten gemeinsamen Studien über die Sicherheit Europas in den siebziger Jahren bei einigen NATO-Staaten eine bemerkenswerte Nachdenklichkeit ausgelöst hätten. Ursache sei eine zunehmende Skepsis gegenüber Staatspräsident de Gaulle und gegenüber der französischen Bereitschaft, auch nach 1969 in der NATO 
zu verbleiben. Es werde befürchtet, daß de Gaulle die Bundesrepublik in das „Fahrwasser seines Zusammenspiels mit Moskau" hineinziehe. Grewe teilt mit, er habe zu solchen Bedenken ausgeführt, daß eine verstärkte deutsch-französische Zusammenarbeit auf verteidigungspolitischem Gebiet gerade angesichts der inhaltlich unergiebigen französischen Beteiligung an den NATO-Gremien auch im Interesse der Allianz liege. Die Einflußmöglichkeiten der Bundesregierung auf Frankreich würden allerdings überschätzt; das einzige Druckmittel - die Androhung einer Kündigung des deutsch-französischen Vertrags von 1963 - verbiete sich nicht zuletzt angesichts der amerikanischen und britischen Politik gegenüber der UdSSR. Generalsekretär Brosio, NATO

Brosio bittet um eine Stellungnahme zu den vorgesehenen deutsch-französischen Studien über die Sicherheit Europas in den siebziger Jahren. In der NATO breite sich Besorgnis über den zukünftigen Kurs der französischen Politik aus. Angesichts jüngster sicherheitspolitischer Äußerungen von Brandt in der Öffentlichkeit warnt Brosio davor, dem sowjetischen Vorschlag eines multilateralen Garantie-Paktes als zukünftiges Sicherheitssystem in Europa, der offenbar für Frankreich attraktiv sei, zu weit zu folgen. Dies gefährde die Einheit des atlantischen Bündnisses. Unter Hinweis auf Ausführungen des Präsidenten Johnson im Oktober 1966 zur Entspannungspolitik bemerkt Brandt, daß innerhalb der Allianz offensichtlich mit zweierlei Maß gemessen werde. Die Bundesrepublik könne nicht allein die NATO-Solidarität verteidigen, während sich alle anderen Bündnispartner bemühten, „auf bilateralem Wege ihre Schäfchen ins Trockene zu bringen". Er halte es zudem für gefährlich, der sowjetischen Regierung die Schlagworte „europäische Sicherheit" und „Friedensordnung" zu überlassen; diese Begriffe müsse der Westen mit eigenen Vorstellungen ausfüllen.

Strätling teilt mit, daß er mit dem zuständigen Stellvertretenden Außenminister über die Ausreise von Volksdeutschen in Rumänien zu Angehörigen in der Bundesrepublik gesprochen habe. Flitan bat um eine nach Dringlichkeit abgestufte Liste von Ausreisewilligen. Strätling äußert abschließend die Ansicht, daß anläßlich des Besuchs des Bundesministers Brandt vom 3. bis 7. August 1967 in Rumänien mit einer "Geste“ im Bereich der Familienzusammenführung gerechnet werden könne. Auswärtige Amt

Bahr berichtet von ersten Verhandlungen mit der tschechoslowakischen Regierung über Abkommen zum Waren- und Zahlungsverkehr sowie über den Austausch von Handelsvertre- 
tungen. Gegenüber dem tschechoslowakischen Delegationsleiter bestand er auf einer Einbeziehung von Berlin (West) mittels eines Schriftwechsels; Babaček befürwortete dagegen eine mündliche Erklärung. Die Frage der Rechtswirksamkeit des Münchener Abkommens von 1938 schien ohne Bedeutung zu sein. Demgegenüber erwies sich als Hauptschwierigkeit, ob das tschechoslowakische Außenministerium oder das Außenhandelsministerium die zuständige Kontaktstelle der Vertretung der Bundesrepublik sein werde. Generalsekretär Brosio, NATO

Brosio teilt mit, daß die Ankündigung der Bundesregierung, bis 1971 den Verteidigungshaushalt in geringerem Maße als geplant steigen zu lassen, in der NATO „nicht unerhebliche Aufregung“ ausgelöst habe. Schröder erläutert, seit längerer Zeit sei klar gewesen, daß die Planung von 1961/62 zur Erweiterung der Bundeswehr auf 508000 Mann nicht finanzierbar sein würde. Eine Vergrößerung über die derzeitige Stärke von 456000 Mann hinaus sei nicht möglich. Dies bedeute jedoch keine Änderung in der verteidigungspolitischen Konzeption. Nun müsse eine vernünftige Struktur der Bundeswehr geplant und auf jeden Fall an ihrer Modernisierung, gerade im Bereich der Ausrüstung, festgehalten werden. Brosio macht darauf aufmerksam, daß es wichtig sei, wie diese Überlegungen präsentiert würden. So dürfe der NATO kein bereits gefaßter Beschluß der Bundesregierung vorgelegt, sondern den Mitgliedstaaten eine Mitsprache eingeräumt werden. Bundesminister Brandt

In Vorbereitung des Besuchs des Bundeskanzlers am 15./16. August 1967 in den USA macht Lilienfeld darauf aufmerksam, daß es die Hauptaufgabe von Kiesinger sein werde, das bisherige amerikanische Vertrauen in die Zuverlässigkeit der Bundesrepublik als NATO-Partner wiederherzustellen. Diese sei nämlich aufgrund der jüngsten Beschlüsse zum Verteidigungsetat, infolge der politischen Annäherung an Frankreich und wegen Äußerungen einzelner Politiker zur Sicherheitspolitik in Europa beschädigt worden. Kiesinger müsse klarstellen, daß die Bundesregierung trotz der Haushaltskrise und neuer außenpolitischer Akzente weiterhin ein loyaler Verbündeter der USA bleiben werde und das atlantische Bündnis als alleinige Grundlage für den militärischen Schutz Westeuropas ansehe. Gelinge dies nicht, werde es Präsident Johnson schwerfallen, dem innenpolitischen Druck in Richtung auf einen Abbau überseeischer Verpflichtungen der USA standzuhalten und der Bundesrepublik weitere Unterstützung in der Ost- und Deutschlandpolitik zu gewähren. 
Brandt informiert über die Absicht der libyschen Regierung, in der Bundesrepublik gepanzerte Fahrzeuge, Maschinen- und Infanteriegewehre sowie Munition zur Ausrüstung der Polizei zu kaufen. Obwohl noch kein offizieller Antrag von libyscher Seite vorliege, wolle er sich bereits jetzt gegenüber Bundesminister Schiller für eine Genehmigung dieses Geschäfts aussprechen, da Libyen nicht als Spannungsgebiet anzusehen sei und die Bundesrepublik aufgrund der Erdöl-Lieferungen nicht nur an guten bilateralen Beziehungen, sondern auch an der Verbesserung der inneren Sicherheit dieses Staates interessiert sei. britischen Botschafter Roberts

$\mathrm{Zu}$ den deutsch-französischen Regierungsbesprechungen vom 12./13. Juli 1967 teilt Kiesinger mit, daß der französische Staatspräsident einen britischen EG-Beitritt weiterhin ablehne. Dennoch nehme er nicht an, daß es zu einem zweiten Veto kommen werde. Weiterhin habe er de Gaulle gesagt, daß er nicht in die "sowjetische Sphäre gelangen wolle“. Außerdem belaste de Gaulle durch seine anti-amerikanischen Äußerungen die deutsch-französischen Beziehungen, denn nach deutscher Auffassung liege die stärkste Sicherheitsgarantie für die Bundesrepublik in der Anwesenheit amerikanischer Truppen. Auf die Frage von Roberts, ob die vereinbarten deutsch-französischen Untersuchungen über die Sicherheit Europas in den siebziger Jahren nicht eine Konkurrenz zur Studie über die zukünftigen Aufgaben der Allianz (Harmel-Studie) darstellen, betont Kiesinger, daß „die Richtlinien seiner Politik auf eine Konsolidierung der NATO zielten“. Angesichts der unumgänglichen Kürzungen bei den ursprünglich vorgesehenen Zuwachsraten im Verteidigungsetat habe er Bundesminister Schröder beauftragt, Alternativen entwickeln zu lassen, die vielleicht eine Reduktion der Bundeswehr um 60000 Mann ganz überflüssig machen würden.

Bahr gibt einen Zwischenbericht über die Verhandlungen in Prag über die handelspolitischen Abkommen und bittet um Instruktionen. Er teilt mit, daß die tschechoslowakische Regierung einer Einbeziehung von Berlin (West) mittels eines Schriftwechsels zugestimmt und mit geringen Änderungswünschen die Entwürfe der Bundesregierung akzeptiert habe, in denen die bisherige Praxis im bilateralen Handel fortgeschrieben werde. Über den Entwurf eines Abkommens über den Austausch von Handelsvertretungen bestehe ebenfalls Einvernehmen. Allerdings lehne die Tschechoslowakei eine Zuständigkeit des dortigen Außenministeriums für die Handelsvertretung der Bundesrepublik ab. Hinsichtlich der Befugnisse der in Prag zu errichtenden Vertretung bestehe die tschechoslowakische Regierung darauf, daß diese nur an Reisende in Wirtschaftsangelegenheiten Visa erteilen und Touristen nicht konsularisch be- 
treuen dürfe. Ferner könne sie nur auf Ersuchen tschechoslowakischer Stellen außerhalb des wirtschaftspolitischen Bereichs tätig werden. Trotz des Hinweises seiner Gesprächspartner, daß damit der Verhandlungsspielraum erschöpft sei, rät Bahr $\mathrm{zu}$ einem weiteren Versuch, auf die tschechoslowakische Haltung einzuwirken.

Sahm informiert über das Treffen der Rapporteure der Studiengruppe über die zukünftigen Aufgaben der Allianz (HarmelStudie) am 21. Juli 1967 auf dem Petersberg bei Bonn. Zu dem vom Abteilungsleiter im britischen Außenministerium, Watson, und von Staatssekretär Schütz gegebenen Bericht der Untergruppe I wurde angemerkt, daß die Möglichkeiten für Ost-WestKontakte von Watson zu optimistisch eingeschätzt würden. Die Frage des ehemaligen belgischen Außenministers, ob das Deutschland-Problem in die Harmel-Studie gehöre, wurde bejaht. Spaak informierte dann über den Bericht der Untergruppe II, der zu dem Schluß komme, daß die integrierte Verteidigung der NATO beibehalten werden müsse, aber der politischen Ergänzung bedürfe. Der stellvertretende Leiter der amerikanischen Vertretung bei der NATO, Farley, teilte mit, daß sich die Untergruppe III vor allem auf die politischen Probleme der Sicherheit konzentriere. Untergruppe IV habe sich nach den Ausführungen ihres Rapporteurs Patijn mit der Möglichkeit einer stärkeren Einflußnahme der Allianz in der Dritten Welt befaßt. Dazu wurde jedoch betont, daß die NATO aufgrund differierender Interessen der Mitglieder außerhalb ihres Territoriums keine gemeinsame Politik haben könne; sie sei „nicht der zweite Weltgendarm “. Abschließend wurde angeregt, der „Special Group" eine Zusammenstellung dieser vier Berichte als Schlußbericht der Studiengruppe zu übermitteln. Lindenberg

Aufgrund von Pressemeldungen im Vorfeld der Konferenz der Außenminister der Arabischen Liga vom 1. bis 5. August 1967 in Khartum weist Meyer-Lindenberg auf die Möglichkeit hin, daß zumindest einige arabische Staaten die jahrelangen $\mathrm{Be}$ mühungen der DDR um Anerkennung honorieren und die Aufnahme diplomatischer Beziehungen beschließen könnten. Meyer-Lindenberg rät vorsorglich zu einer Umschuldung der Handelsverbindlichkeiten der VAR und zur erneuten Ankündigung einer Unterstützung der Palästina-Flüchtlinge in Höhe von 50 Mio. DM.

Als Grundlage für Weisungen an Botschafter z.b.V. Bahr, z.Z. Prag, erörtert Sahm das weitere Vorgehen bei den Verhandlungen mit der tschechoslowakischen Regierung über die angestrebten handelspolitischen Abkommen. Die vorgeschlagenen Schreiben zur Einbeziehung von Berlin (West) könnten ausge- 
tauscht werden unter der Voraussetzung einer ausdrücklichen tschechoslowakischen Bestätigung, daß die Stadt tatsächlich in den bisherigen Warenverkehr eingebunden gewesen sei. Hinsichtlich der Befugnisse der Handelsvertretung der Bundesrepublik und ihres Zugangs zum Außenministerium dürfe nicht von den ursprünglichen Forderungen abgewichen werden; es sei zu vermeiden, hinter die 1963 und 1964 mit Rumänien, Ungarn und Bulgarien gefundenen Regelungen zurückzufallen. Vor allem könne nicht darauf verzichtet werden, daß die Handelsvertretung Deutsche konsularisch betreuen und selbständig auch in Bereichen außerhalb der Wirtschaftsbeziehungen tätig werden dürfe. Unter allen Umständen müsse zudem in den Abkommen auf einer Revisionsmöglichkeit bestanden werden.

$\mathbf{2 8 5}$

Sahm befürwortet den Vorschlag des Regierenden Bügermeisters von Berlin, Albertz, eine Wiederaufnahme der 1966 eingestellten Passierscheingespräche mit der DDR einzuleiten. Er macht jedoch darauf aufmerksam, daß begleitende diplomatische Schritte notwendig sein werden, damit nicht die These von der „besonderen politischen Einheit West-Berlin" gestärkt werde. Sahm kommt zu dem Schluß, daß ein Schriftwechsel zwischen Albertz und dem Stellvertretenden Vorsitzenden des Ministerrats der DDR, Abusch, im Einklang mit der bisherigen Vorgehensweise bei Passierscheingesprächen stehe. Auswärtige Amt

Aus einem Gespräch mit dem Stellvertretenden Außenminister Klička teilt Bahr mit, daß die tschechoslowakische Regierung in einen politischen Gedankenaustausch mit der Bundesregierung eintreten wolle, der allerdings unauffällig ablaufen müsse. Es sei die Hoffnung geäußert worden, das bilaterale Verhältnis werde sich „auch im Stadium minderer Form still so entwickeln", daß sich die angestrebten handelspolitischen Abkommen im gegebenen Augenblick als ein einsatz- und ver- 
wendungsfähiges Instrument erweisen würden. Daher habe die tschechoslowakische Regierung während der Verhandlungen auf umfangreiche wirtschaftliche Forderungen verzichtet. Nach tschechoslowakischer Ansicht könnten diplomatische Beziehungen jedoch erst aufgenommen werden, wenn sich die internationale Lage gebessert habe und ein Mindestmaß an Beziehungen zwischen der Bundesrepublik und der DDR bestehe. Ein völkerrechtlich verbindlicher Verzicht der Bundesrepublik auf die Änderung bestehender Grenzen unter Einschluß der DDR würde als ein realistischer Schritt auf dem Weg zu einem europäischen Sicherheitssystem gutgeheißen. Auswärtige Amt

Bahr übermittelt einen Zwischenbericht der Verhandlungen über ein Waren- und Zahlungsabkommen sowie über den Austausch von Handelsvertretungen. Die tschechoslowakische Delegation habe darauf bestanden, daß die in Prag zu errichtende Vertretung der Bundesrepublik nur Kontakt zum Außenhandelsministerium unterhalte. Zur Möglichkeit einer Revision der Abkommen schlage Bahr vor, eine mündliche Erklärung abzugeben. In der Frage, wie die Bundesrepublik in den Abkommen bezeichnet werde, habe sich die Tschechoslowakei lediglich zu einer schriftlichen Zusicherung bereit erklärt, daß der Begriff "nemecka spolkova republika“ allein aus sprachlichen Gründen gewählt worden sei. Sollten dagegen Bedenken bestehen, stünden die Verhandlungen "praktisch wieder am Anfang“. z.Z. Prag

Lahr erteilt Weisung, daß in den Abkommen mit der Tschechoslowakei über den Waren- und Zahlungsverkehr sowie über den Austausch von Handelsvertretungen die Bezeichnung "nemecka spolkova republika“ als adäquate Übersetzung für die Bundesrepublik Deutschland akzeptiert werden könne. Um Mißverständnissen vorzubeugen, müsse allerdings in einem Schreiben, das zu den Vertragsdokumenten zu nehmen sei, erläutert werden, daß dieser Begriff nicht aus politischen Gründen gewählt worden sei. Zudem sollte in der tschechoslowakischen Ausfertigung der Abkommen bei der ersten Nennung des tschechischen Begriffs die deutsche Bezeichnung „Bundesrepublik Deutschland" in Klammern folgen. Auswärtige Amt

Angesichts der isolationistischen Tradition der USA analysiert Knappstein die Grundlagen der nach dem Zweiten Weltkrieg übernommenen amerikanischen Sicherheitsgarantie für Europa. Sie basiere auf der Vorstellung von den atlantischen Nationen als einer Gemeinschaft und auf der Idee des Multilateralismus. Daneben gewinne die integrierte Struktur der Allianz 
an Bedeutung. Die USA könnten das enorme Risiko, das aus der Verpflichtung resultiere, die eigenen Atomwaffen zur Verteidigung der Verbündeten einzusetzen, nur akzptieren, wenn sie die zentrale Kontrolle über das nukleare Potential der NATO behielten. Schließlich sei der Gedanke einer amerikanisch-europäischen Lastenteilung im Rahmen einer Strategie der flexible response wichtig. Je mehr jedoch diese Voraussetzungen an Boden verlören, desto stärker träten in der amerikanischen Politik rein nationale Interessen in den Vordergrund, und desto eher seien die USA zu einer bilateralen Verständigung mit der UdSSR und zu einer gegenseitigen Garantie des Status quo in Europa bereit. Hierin liege, so Knappstein, die eigentliche Gefahr der Politik des Staatspräsidenten de Gaulle.

Sahm legt dar, daß der sowjetische Botschafter in Ost-Berlin in Schreiben an die Botschafter der Drei Westmächte gegen eine angebliche Einbeziehung von Berlin (West) in die geplante Notstandsgesetzgebung der Bundesrepublik protestiert habe. Abrassimow habe auf die vom Senat von Berlin vorbereiteten Gesetze zur Zivilverteidigung aufmerksam gemacht. Er habe darauf hingewiesen, daß es unzulässig sei, im Westteil der Stadt, in dem ja weiterhin Besatzungsrecht gelte, Regelungen einzuführen, die Vier-Mächte-Abmachungen widersprächen. Sahm wertet das Schreiben als ernstgemeinten Versuch der UdSSR, ein Mitspracherecht bei „rein West-Berliner Angelegenheiten" zu erreichen. Auf die drei Westmächte solle eingewirkt werden, in ihren Antwortschreiben auf den Vier-MächteStatus der ganzen Stadt hinzuweisen. Sie könnten auch argumentieren, daß sie Fragen, die Berlin (West) beträfen, mit der UdSSR erörtern wollten, wenn diese ihrerseits den drei Westmächten die Möglichkeit zur Wahrnehmung ihrer Rechte in Ost-Berlin eröffne. Auswärtige Amt

Brandt berichtet über das Gespräch mit dem rumänischen $\mathrm{Au}-$ ßenminister am 3. August 1967. Manescu vertrat die Ansicht, $\mathrm{da} B$ die Bundesregierung noch mehr für die Entspannung tun könne, wenn sie durch eine Anerkennung der Realitäten den Zustand der „Vereisung“ beende. Weiterhin erklärte Manescu die Bereitschaft zum Abschluß eines Kulturabkommens, jedoch unter Ausklammerung der „Berlinstatusfrage“. Brandt sprach das Abkommen über wirtschaftlich-technische Kooperation an, das im Anschluß an das Gespräch unterzeichnet werde. Da es die technisch-wissenschaftliche Zusammenarbeit ausklammere, sollte auf diesem Gebiet eine gemeinsame Kommission gebildet werden. Zur Einbeziehung von Berlin (West) in ein Kulturabkommen biete es sich an, einen Verweis auf den Geltungsbereich der Vereinbarung vom 31. Januar 1967 über die Aufnahme diplomatischer Beziehungen einzufügen. 

Auswärtige Amt

Brandt informiert über die Unterredung mit dem Generalsekretär der Kommunistischen Partei Rumäniens am 5. August 1967. Ceausescu forderte die Bundesregierung auf, ihre Opposition gegen eine Teilnahme der DDR an der ,internationalen Kommunikation" aufzugeben. Dann könne eine Atmosphäre des Vertrauens entstehen, die eine Voraussetzung darstelle für die Wiedervereinigung, an deren Zustandekommen er glaube. Wenn die Bundesregierung diese Politik noch nicht offen vertreten könne, so solle sie die DDR doch stillschweigend als Gesprächspartner akzeptieren. Der Vorschlag der Bundesregierung vom 7. Februar 1967 zur Abgabe von Gewaltverzichtserklärungen sei allerdings der Form nach nicht akzeptabel. Brandt betonte, daß die DDR nicht vom Handel und vom kulturellen Austausch ausgeschlossen werden dürfe. Bei vielen umgelösten Fragen könne die Formel des „Modus vivendi“ ${ }^{“}$ weiterhelfen. Die Aussicht auf Wiedervereinigung müsse allerdings erhalten bleiben. Wer den Deutschen diese Hoffnung nehme und ihnen statt dessen einen "sterilen Status quo" aufzwingen wolle, handele „töricht“.

Pauls äußert Bedenken gegen das ihm übermittelte Aidemémoire. Damit solle vor einer Ausübung konsularischer Tätigkeiten in den von Israel besetzten Gebieten - insbesondere in der Altstadt und im Ostteil von Jerusalem - durch die Botschaft in Tel Aviv gegenüber dem israelischen Außenministerium deutlich gemacht werden, daß die Bundesrepublik die durch den Nahost-Krieg erfolgten territorialen Gewinne Israels rechtlich nicht anerkenne. Allerdings berücksichtige die Formulierung des Aide-mémoires nicht, daß Israel zunächst dem Antrag der Bundesrepublik auf konsularische Betreuung von Deutschen in den besetzten Gebieten zustimmen müsse. Daher bestehe die Gefahr, daß die Botschaft in Tel Aviv zur Einholung eines förmlichen Exequaturs aufgefordert werde. Pauls übermittelt einen Gegenvorschlag, in dem hervorgehoben wird, daß den Botschaften in der VAR, in Jordanien und in Syrien die Wahrnehmung konsularischer Aufgaben in den besetzten Gebieten derzeit faktisch nicht möglich sei und das israelische Außenministeriums daher Angehörigen der Botschaft in Tel Aviv die Genehmigung zur ${ }_{n}$ mehrmaligen Einreise in die fraglichen Gebiete" erteilen möge. Bundesminister Brandt

Mit Blick auf den Besuch des portugiesischen Verteidigungsministers Gomes de Araújo vom 20. bis 24. November 1967 in Bonn gibt Müller-Roschach einen Überblick über die Zusammenarbeit mit Portugal auf militärischem Gebiet. Dabei nimmt er Stellung zu der vom Bundesministerium der Verteidigung beschlossenen fast völligen "Liquidierung“ aller Projekte infol- 
ge der veränderten strategischen Konzeption der NATO sowie der Kürzungen im Bundeshaushalt. Müller-Roschach weist darauf hin, daß solche Maßnahmen Portugal wirtschaftlich und finanziell schwer treffen würden und die bilateralen Beziehungen „zerstören “ könnten. Die militärische Kooperation basiere auf 21 Übereinkommen, durch die die Bundesrepublik gebunden sei. Eine Kündigung dieser Verpflichtungen würde der internationalen Vertragswürdigkeit schaden und könnte Schadensersatzforderungen nach sich ziehen. Auswärtige Amt

Sattler äußert sich zu offenen kirchenpolitischen Fragen. So sei unklar, ob die geplante Kurienreform noch im August 1967 eingeführt werde und wie sich die Politik des Heiligen Stuhls gegenüber Israel, gegenüber dem Vietnam-Krieg und in der Frage einer Neutralisierung Jerusalems entwickeln werde. Die Ausführungen des Abteilungsleiters im päpstlichen Staatssekretariat, Casaroli, am 4. August 1967 seien in diesen Punkten nur „mager" gewesen. Konkreter habe sich Casaroli zu den die Bundesrepublik betreffenden Fragen geäußert. So dementierte er den von einer Wochenzeitung gemeldeten erneuten polnischen Vorstoß mit dem Ziel der Einsetzung von ordentlichen Bischöfen in den kirchlichen Verwaltungsbezirken Allenstein, Landsberg/Warthe, Breslau und Oppeln. In der Frage der Bekenntnisschulen in einzelnen Ländern der Bundesrepublik verwies er auf die rechtlich bindenden Bestimmungen des Reichskonkordats von 1933. Bundesministerium der Verteidigung

Lahr teilt Carstens mit, daß das Auswärtige Amt die Stellungnahme des Bundesministeriums der Verteidigung zum südafrikanischen Vorschlag einer Zusammenarbeit bei der Entwicklung des Flugabwehrlenkwaffensystems "Cactus“ nicht billige. Das Bundesministerium der Verteidigung habe zwar eine Kooperation mangels Bedarf und Haushaltsmitteln abgelehnt, jedoch Interesse daran bekundet, über die weitere Entwicklung des Systems informiert zu werden, um möglicherweise in der Zukunft eine Verwendung bei der Bundeswehr erneut zu prüfen. Das Auswärtige Amt lehne dagegen jegliche Art der rüstungswirtschaftlichen Zusammenarbeit mit der Republik Südafrika - also auch die Erteilung von technischen Auskünften aus politischen Gründen ab. Auswärtige Amt

Böker berichtet aus einem Gespräch mit Präsident Gowon, der sich optimistisch über den Verlauf des Bürgerkriegs in Nigeria äußerte. Er vertrat die Ansicht, daß bis Ende 1967 die größten Schwierigkeiten überwunden sein dürften. Böker sicherte zu, 
daß die Bundesrepublik Beziehungen nur zur nigerianischen Zentralregierung unterhalten werde, und gab der Hoffnung Ausdruck, daß die Einheit Nigerias erhalten werden könne. Eine „Balkanisierung Afrikas“ entspreche weder europäischen noch afrikanischen Interessen. Kinshasa, an das Auswärtige Amt

Müllenheim-Rechberg informiert über die Ausschreitungen vom 14. August 1967 gegen die belgische, die amerikanische und die französische Botschaft. Vor allem an der belgischen Botschaft sei erheblicher Schaden entstanden. Zweifellos habe Präsident Mobutu die Demonstrationen inspiriert oder gebilligt. Sie seien ein Zeichen dafür, wie „blitzartig Anarchie und Chaos" in Kinshasa ausbrechen könnten. Da es dabei auch zu Mißhandlungen von Weißen durch den "Mob“ gekommen sei, regt Müllenheim-Rechberg eine Absprache mit den betroffenen westlichen Regierungen über Schutzmaßnahmen für ihre im Kongo lebenden Staatsangehörigen an. Auswärtige Amt

Sahm übermittelt einen Bericht über Gespräche, die der Staatssekretär im Bundesministerium der Verteidigung in Washington führte. Dabei werden Mitteilungen von Carstens gegenüber dem Bundeskanzler vom Vortag wiedergegeben. Der Staatssekretär habe Kiesinger mitgeteilt, daß der amerikanische Verteidigungsminister McNamara als Reaktion auf den Beschluß der Bundesregierung, den Verteidigungshaushalt in geringerem Maße als geplant steigen zu lassen, das System der Truppenrotation fortentwickeln wolle. Carstens habe diesen Überlegungen „nachdrücklich entgegengewirkt". Der Staatssekretär habe Kiesinger darauf aufmerksam gemacht, daß nun sogar mit einer Einbeziehung derjenigen Teile der amerikanischen Luftwaffe gerechnet werden müsse, die nach der Absprache zwischen Kiesinger und Präsident Johnson vom April 1967 noch aus der Rotation herausgenommen worden waren. Präsident Johnson in Washington

Im Rahmen eines „tour d'horizon“ zur Politik der Bundesregierung erläutert Kiesinger, daß beim Verteidigungshaushalt aufgrund der mittelfristigen Finanzplanung bis 1971 nur die ${ }_{n} \mathrm{Er}$ wartungen gekürzt" worden seien, nicht der tatsächliche Umfang, der sogar ansteigen werde. Er bedauert, daß die unzutreffende Einschätzung, die Bundeswehr müsse um 60000 Mann verringert werden, veröffentlicht worden sei. Mittlerweile sei festgelegt worden, daß ein möglicher Personalabbau 15000 Mann nicht überschreiten werde. Er selbst halte Kürzungen nicht für erforderlich. Johnson weist darauf hin, daß die innenpolitische Lage in den USA ihm im Falle einer Verkleine- 
rung der Bundeswehr keine andere Wahl lassen werde, als nachzuziehen. Aus den Gesprächen am 12./13. Juli 1967 mit dem französischen Staatspräsidenten teilt Kiesinger seinen Eindruck mit, daß die NATO über das Jahr 1969 hinaus fortbestehen werde. De Gaulle habe auch nichts einzuwenden gegen die amerikanische Präsenz in Europa, solange sich das Verhältnis zu Osteuropa nicht völlig geändert habe. Er fürchte jedoch den wirtschaftlichen und geistigen Einfluß der USA. Johnson äußert Verständnis für de Gaulle, der früher von amerikanischer und britischer Seite „nicht immer gut behandelt" worden sei. Auswärtige Amt

Sahm berichtet von einem Gespräch des Bundeskanzlers Kiesinger und des Bundesministers Brandt mit Außenminister Rusk, Verteidigungsminister McNamara und Finanzminister Fowler. Letztgenannter erläuterte die Bedeutung der Verhandlungen über die Schaffung zusätzlicher Liquidität im Internationalen Währungsfonds. Ein Scheitern könnte zu einer Finanzkrise wie in den dreißiger Jahren führen. Die Bundesregierung solle der französischen Regierung, die sich bislang einer Regelung verschlossen habe, die Gefahr einer Isolierung erläutern. Hinsichtlich der zukünftigen Stärke der Bundeswehr sicherte Kiesinger zu, daß den Verbündeten bis Jahresende ein klares Bild gegeben werde. McNamara wies darauf hin, daß personelle Kürzungen durch ein verbessertes Mobilmachungsverfahren "überkompensiert" werden könnten. Eine einseitige Truppenverminderung wie auch $\mathrm{zu}$ weitgehende Rotationsmaßnahmen des Westens seien politisch bedenklich. Kiesinger stellte die Bedeutung der sofort verfügbaren Abwehrkräfte heraus, besonders für einen so exponierten Staat wie die Bundesrepublik. Von amerikanischer Seite wurde daraufhin eingeräumt, daß das Konzept der „politischen Vorwarnzeit“ überprüft werden müsse; sie könne sich durch eine beiderseitige Truppenverminderung verlängern. Präsident Johnson in Washington

Johnson rät Kiesinger, eine mögliche Verkleinerung der Bundeswehr in der Öffentlichkeit sehr vorsichtig zu behandeln. Er solle darauf hinweisen, daß noch keine Entscheidung getroffen sei, daß ein Truppenabbau voraussichtlich nicht nötig sein und $\mathrm{da} ß$ jeder Schritt vorab mit den USA und der NATO abgesprochen werde. Hinsichtlich der Größenordnung personeller Einsparungen seien Zahlenangaben zu vermeiden. Johnson befürchtet eine Kettenreaktion vergleichbarer Maßnahmen bei den Verbündeten. Zum Schluß wäre dann die NATO „völlig demontiert" - allein als Folge eines "deutschen Schritts“. Kiesinger führt dagegen aus, daß er eine Truppenreduktion zwar nicht für erforderlich halte, sie dennoch nicht völlig ausschlieBen wolle. Er könne nicht in der Bundesrepublik den Eindruck 
entstehen lassen, er habe Johnson nachgeben müssen. Ein Personalabbau, der auf jeden Fall sehr gering ausfallen werde, sei ihm sogar von Generalen der Bundeswehr angeraten worden, um das zur Zeit unausgewogene Zahlenverhältnis zwischen Mannschaften, Unteroffizieren und Offizieren zu korrigieren.

Brandt faßt die Gespräche mit dem amerikanischen Außenminister am 15./16. August 1967 in Washington zusammen. Rusk ermunterte die Bundesregierung zur Fortführung ihrer Ostpolitik. Der Kabinettsbeschluß vom 6. Juli 1967 zur mittelfristigen Finanzplanung habe allerdings ein freundliches Kopfschütteln“ ausgelöst. Mit Blick auf den Verteidigungshaushalt sei wichtig, daß es nicht zu einer Entscheidung mit abträglichen Folgen in den USA oder in der NATO komme. Brandt habe auf den Zusammenhang zwischen der europäischen Sicherheit und der Deutschland-Frage hingewiesen, mit dem sich die Westmächte nicht nur „defensiv-verbal“ befassen sollten. Rusk habe betont, daß der Status quo nicht im Sinne der sowjetischen Vorstellungen zementiert werden dürfe. Im übrigen müsse die Bundesregierung auf diesem Gebiet die Führung übernehmen. In der Frage eines Nichtverbreitungsabkommens habe Rusk die Absprachen mit der Bundesregierung, auch zum Artikel III (Kontrollartikel), bestätigt.

Lahr weist Bach an, gegenüber Außenminister Zahedi darzulegen, daß das Ersuchen der iranischen Regierung um juristische Verfolgung der Ausschreitungen während des Besuchs des Schahs Mohammed Reza Pahlevi vom 27. Mai bis 4. Juni 1967 in der Bundesrepublik Folgen haben könnte, die der gewünschten Beruhigung in den Beziehungen zwischen beiden Staaten abträglich seien. So würden im Verlauf von Strafprozessen "Behauptungen aller Art" über den Iran und das Kaiserhaus aufgestellt und in der Presse „hochgespielt" werden. Zudem sei mit erneuten Demonstrationen zu rechnen. Daher empfehle die Bundesregierung dem Iran, nicht weiter auf einer Strafverfolgung zu bestehen. Bundesminister Brandt

Kiesinger teilt mit, daß er aufgrund von Äußerungen des Bundesministers des Auswärtigen Anfang August 1967 in Rumänien und auf dem Landesparteitag der SPD am 18. August 1967 in Bremen „nicht mehr so sicher sei“, ob es nicht substantielle Unterschiede in der politischen Konzeption zwischen Kiesinger und Brandt gebe. Darüber hinaus sei Brandt von der vereinbarten politischen Terminologie abgewichen. Dies habe zum einen wachsende Unruhe innerhalb der CDU zur Folge und 
gebe zum anderen dem Teil der Presse in der Bundesrepublik Auftrieb, der auf eine staatliche Anerkennung der DDR dränge. Kiesinger bittet um eine klärende Aussprache. Auswärtige Amt

Grewe äußert Skepsis, daß die Studie über die zukünftigen Aufgaben der Allianz (Harmel-Studie) mit einem substantiellen Ergebnis abgeschlossen werden könne. Angesichts der nachlassenden Bedrohung durch den Warschauer Pakt erschöpfe sich der Wille zur Reform der Allianz oftmals in Lippenbekenntnissen zur Zusammenarbeit. Grundsätzlich sei die Vorstellung, die NATO in ein Instrument der Entspannungspolitik umzuwandeln, „fragwürdig“. Erschwerend wirkten auch das komplizierte Berichtsverfahren in den Untergruppen und die Tatsache, daß der Gesamtbericht einstimmig gebilligt werden müsse. Befriedigend für die Bundesrepublik sei allerdings, daß der die Deutschland-Frage betreffende Teil des Berichts die Zustimmung der Verbündeten finden dürfte. Hinsichtlich der Zukunft der Allianz werden sich aber die Bündnispartner aufgrund der vorhersehbaren ablehnenden Haltung Frankreichs und eventuell auch Griechenlands mit allgemeineren Formulierungen zufrieden geben müssen. Grewe warnt sogar vor einem zu „perfekten“ Bericht, von dem eine desintegrierende Wirkung auf die NATO ausgehen könne.

Böker erörtert, wie sich die Bundesregierung gegenüber Griechenland angesichts der dort seit dem Militärputsch vom 20./21. April 1967 eingetretenen Entwicklung verhalten solle. Die innenpolitische Situation sei eindeutig zu mißbilligen und auf eine Wiederherstellung der demokratischen Ordnung zu drängen. Jedoch dürfe die Position Griechenlands innerhalb des westlichen Bündnisses nicht geschwächt werden. Ein Vorgehen, das einen Austritt aus der NATO provoziere, sei zu vermeiden, denn dies würde vor allem die Türkei strategisch isolieren. Es dürfe nicht übersehen werden, daß das neue „Regime“ die DDR stärker ablehne als die vorherige Regierung und wirtschaftlich nur mit dem Westen zusammenarbeiten wolle.

\section{Staatssekretär Lahr}

Walther macht darauf aufmerksam, daß die sowjetische Verbalnote vom 15. August $1967 \mathrm{mit}$ der Ankündigung, in Verhandlungen über eine direkte Flugverbindung zwischen Moskau und Frankfurt/Main eintreten zu wollen, nicht als „Silberstreif am politischen Horizont" gedeutet werden dürfe. Der Grund für die Gesprächsbereitschaft sei rein verkehrspolitischer Natur. Die verhandlungstaktische Situation der Bundesregierung sei jedoch im Augenblick günstig, denn die zu erwartende Weige- 
rung der drei Westmächte, der sowjetischen Luftfahrtgesellschaft Aeroflot den Einflug in das Bundesgebiet von Berlin aus zu gestatten, stärke die Argumention für eine Route über Eger. Auswärtige Amt

Böx berichtet über ein Gespräch mit dem polnischen Stellvertretenden Außenhandelsminister. Modrzewski zeigte sich besorgt über die rückläufigen Absatzmöglichkeiten für polnische Produkte in der Bundesrepublik. Um den Warenaustausch zu erleichtern, wolle er beim polnischen Außenminister Rapacki die Frage aufwerfen, ob den jeweiligen Handelsvertretungen $\mathrm{Pa}$ ß- und Sichtvermerksbefugnisse erteilt werden könnten. Ferner deutete Modrzewski die Möglichkeit der Einrichtung eines polnischen „trade promotion office“ bei den Europäischen Gemeinschaften an, das sich um die Pflege der Kontakte kümmern könnte, ohne dadurch aber ein offizielles oder inoffizielles Verhältnis herzustellen. Böx stellt abschließend fest, daß das Bestreben erkennbar gewesen sei, gegenüber den westlichen Wirtschaftsorganisationen ein größeres, von strikten politischen Gesichtspunkten unabhängigeres $\mathrm{Maß}$ an Bewegungsfreiheit zu gewinnen.

Ruete erörtert den Entwurf von gleichlautenden Schreiben der Botschafter François Seydoux de Clausonne (Frankreich), Roberts (Großbritannien) und McGhee (USA) an den sowjetischen Botschafter in Ost-Berlin. Damit solle der schriftliche Protest von Abrassimow vom 26. Juli 1967 gegen die vorgesehene Notstandsplanung in Berlin (West) zurückgewiesen werden. Allgemein falle der Antwortentwurf zur Zufriedenheit der Bundesregierung aus. Die Botschafter verwiesen nicht nur auf die Haltlosigkeit des Vorwurfs der Verfassungswidrigkeit, sondern sprächen Abrassimow insbesondere auch das Recht zur Kritik an den Verhältnissen in Berlin (West) ab. Die Formulierung in dem Entwurf, daß der Senat von Berlin nur im Rahmen einer "day to day" ausgeübten administrativen Kontrolle zur Notstandsplanung der drei Westmächte beitragen könne, werte allerdings dessen Stellung ab. Ruete empfiehlt, im Antwortentwurf diese drei Wörter streichen zu lassen. Auswärtige Amt

Walther berichtet über den Besuch des Berliner Senators König anläßlich der Internationalen Bekleidungsausstellung in Moskau. König habe den Ratschlag von Walther befolgt und den Pavillon der DDR nicht besucht; auch habe er von Besuchen bei den Botschaften der Drei Mächte abgesehen. Für den folgenden Tag sei ein Gespräch mit dem sowjetischen Außenhandelsminister Patolitschew vorgesehen. Der Botschafter führt weiter aus, daß er die Einladung zu einem Presseempfang an 
dem von sowjetischer Seite geplanten „Berliner Tag" nicht habe verhindern können. Er gibt seinen Eindruck wieder, daß die sowjetischen Gastgeber aber nicht die Absicht hätten, den Besuch politisch auszunutzen. Ministerialdirektor Ruete

Knappstein nimmt Stellung zu Äußerungen des Staatssekretärs im Bundesministerium der Verteidigung, Carstens, anläßlich der Gespräche des Bundeskanzlers Kiesinger am 15./16. August 1967 in Washington. Demnach sollten die bilateralen Konsultationen über die Truppenfrage zwischen dem Generalinspekteur der Bundeswehr, de Maizière, und dem amerikanischen General Spivy geführt werden. Der Botschafter weist auf die unterschiedlichen Auffassungen hin, die in den USA zwischen dem Verteidigungs- und dem Außenministerium über diese Frage bestünden. Während letzteres wegen der Gefahr einer „Erosion der Allianz" eine Rotation oder sogar Reduktion der Truppen skeptisch beurteile, neige das Verteidigungsministerium nicht zuletzt mit Blick auf die Truppenverstärkungen in Vietnam zu einem Abzug von Einheiten aus Europa. Der vom Abteilungsleiter im amerikanischen Außenministerium, Leddy, gemachte Vorschlag, die Außenministerien beider Staaten bei den Beratungen über die Truppenfrage zu beteiligen, sei daher in jedem Falle aufzugreifen.

Schnippenkötter erörtert zur Vorbereitung der Kabinettssitzung am folgenden Tag den amerikanisch-sowjetischen Entwurf vom 24. August 1967 für ein Nichtverbreitungsabkommen. Die UdSSR habe sich zugunsten der von den USA vorgeschlagenen, von der Bundesregierung aber abgelehnten Variante der Revisionsklausel entschieden. Damit sei eine Änderung des Abkommens nach Zustimmung aller Kernwaffenstaaten und aller Vertragsparteien, die gleichzeitig Mitglied des IAEO-Gouverneursrates seien, möglich. Da die Bundesrepublik dort jedoch kein ständiges Mitglied sei, bestehe nun die Gefahr ihrer „Majorisierung“. Der umstrittene Artikel III (Kontrollartikel) sei noch ausgespart worden. Grundsätzlich sei das Abkommen durch eine "Starrheit in den Verfahrensregeln" gekennzeichnet. Schnippenkötter schlägt daher vor, entweder eine Befristung auf 10 bis 15 Jahre anzustreben oder der vorgesehenen Durchführungskonferenz weitreichende Kompetenzen zuzuweisen.

Klaiber berichtet über ein Gespräch mit dem französischen Staatspräsidenten. De Gaulle teilte mit, daß er mit seinem bevorstehenden Besuch in Polen vom 6. bis 12. September 1967 die Entspannungspolitik fördern wolle. Er sei überzeugt, daß nach einer Zeit der „Détente ${ }^{4}$ eine „Entente ${ }^{*}$ und schließlich eine "Coopération" folgen könne. Nur so sei der Frieden in Euro- 
pa zu erhalten. De Gaulle bezeichnete nachdrücklich die europäische Sicherheit und die Lösung der Deutschland-Frage als „ein und dasselbe Problem “. Er wolle versuchen, in Polen das vorhandene Mißtrauen gegenüber der Bundesrepublik abzubauen. Klaiber bat, de Gaulle möge "die so heikle Frage" der Oder-Neiße-Linie in Polen „behutsam“ behandeln. Klaiber faßte die Ansicht von de Gaulle schließlich dahingehend zusammen, daß dieser nur im Falle neiner Wiedervereinigung einer Änderung der Oder-Neiße-Grenze nicht zustimmen werde“. Der Staatspräsident widersprach dem nicht.

Schütz faßt das Ergebnis eines Gesprächs mit den Botschaftern der Drei Mächte zusammen. Der amerikanische Botschafter McGhee legte dar, er werde dem Regierenden Bürgermeister von Berlin, Albertz, erklären, daß die Drei Mächte zwar nicht in die Strukturkommission für Berlin (West) eintreten, dafür aber gerne in beratender Funktion tätig sein würden. Schütz führte aus, daß die Drei Mächte über eine mögliche Antwort auf das Schreiben des Stellvertretenden Ministerpräsidenten der DDR, Abusch, vom 12. Januar 1967 an den Regierenden Bürgermeister von Berlin rechtzeitig informiert würden. Er sicherte schließlich auch eine Unterrichtung über das Vorgehen der Bundesregierung hinsichtlich des Stimmrechts von Berlin (West) im Bundesrat zu und stellte ebenso eine vorherige Benachrichtigung über die beabsichtigte "Sporterklärung " der Bundesregierung und über die Reaktion auf die Forderungen der DDR nach Erstattung der Postgebühren in Aussicht.

Sahm faßt die Ergebnisse eines Gesprächs des Parlamentarischen Staatssekretärs beim Bundeskanzler, Freiherrn von und zu Guttenberg, mit dem Unterstaatssekretär im amerikanischen Außenministerium, Eugene Rostow, am 15. August 1967 in Washington zusammen. Guttenberg erläuterte die noch unverbindlichen Streitkräfteplanungen, bei denen die Bundesregierung von einer Truppenstärke von 435000 bis 460000 Mann ausgehe. Die endgültige Konsultation über diese Frage müsse jedoch in der NATO stattfinden. Zu den von Rostow angesprochenen Auswirkungen möglicher Truppenreduzierungen der Bundeswehr auf die öffentliche Meinung in den USA bemerkte Guttenberg, es bestehe nicht der geringste Anla $B$, „irgendeine Überprüfung der grundsätzlichen deutschen NATO-Politik anzunehmen".

\section{07.09. Aufzeichnung des Botschafters Schnippenkötter}

Schnippenkötter regt an, den Vortragenden Legationsrat I. Klasse Lankes an den Beratungen der Harmel-Untergruppe III (u. a. Truppenverminderung) am 21. September 1967 in Washington teilnehmen zu lassen. Lankes könne bei dieser Gelegenheit den bilateralen Austausch über mögliche Folgen der Truppenverminderung auf die Entspannungspolitik vertiefen. Er 
solle besonders der im amerikanischen Verteidigungsministerium ausgeprägten Neigung entgegenwirken, die in den DreierVerhandlungen vereinbarte Rückverlegung amerikanischer und britischer Streitkräfte in ihrer Bedeutung für mögliche parallele sowjetische Truppenreduzierungen $\mathrm{zu}$ unterschätzen.

319 Auswärtige Amt

Böx berichtet über Gespräche mit dem Abteilungsleiter im französischen Außenministerium, Puaux, und mit Außenminister Couve de Murville am Vortag anläßlich des Besuchs des französischen Staatspräsidenten in Polen. Puaux bat ihn, die Bundesregierung möge die Äußerung von de Gaulle „minimisieren", wonach Zabrze (Hindenburg) „die polnischste aller Städte" sei. Der Staatspräsident habe sich vom Enthusiasmus hinreißen lassen. Die Formulierung sei dann auch nicht in die verteilten offiziellen Redetexte aufgenommen worden. Couve de Murville informierte Böx während einer gesellschaftlichen Veranstaltung über den weiteren Verlauf des Besuchs. Ihre Unterredung wurde von den polnischen Gastgebern, die ihrerseits mit de Gaulle sprachen, mit zunehmender Aufmerksamkeit verfolgt. Auf Nachfrage von de Gaulle behauptete der polnische Außenminister Rapacki „wider besseres Wissen“, Böx nicht zu kennen. Böx führt weiter aus, daß er daraufhin das Angebot des französischen Protokollchefs abgelehnt habe, de Gaulle vorgestellt zu werden, um nach der Äußerung von Rapacki eine „peinliche Situation“ zu vemeiden.

15.09. Aufzeichnung des Ministerialdirektors MeyerLindenberg

Meyer-Lindenberg nimmt zu einer Anfrage des Bundesministeriums der Verteidigung Stellung, ob dem Wunsch des israelischen Brigadegenerals Tal entsprochen werden könne, anläßlich eines Besuchs in der Bundesrepublik zu Gesprächen empfangen zu werden. Tal zeige großes Interesse an einer Besichtigung des Kampfpanzers "Leopard“ und könne außerdem über seine Erfahrungen als Oberbefehlshaber der israelischen Panzerverbände an der Sinai-Front während des Nahost-Krieges berichten. Der israelische Botschafter Ben Natan habe am Vortag sogar erklärt, daß er sich „persönlich brüskiert“ fühlen würde, wenn das Auswärtige Amt das Ansinnen ablehne. Meyer-Lindenberg spricht sich jedoch zum gegenwärtigen Zeitpunkt gegen einen Empfang von Tal aus, da dieser nicht nur von den arabischen, sondern auch von den Ostblock-Staaten propagandistisch genutzt und als Zeichen einer militärischen Zusammenarbeit mit Israel interpretiert werden könnte.

Ruete faßt die Ergebnisse eines Konsultationsgesprächs mit den Vertretern der Drei Mächte am 12. September 1967 über die Einrichtung eines Linienflugverkehrs der Deutschen Luft- 
hansa und der Aeroflot zwischen Frankfurt/Main und Moskau zusammen. Die Alliierten wiesen darauf hin, daß sich in der Vergangenheit der Luftweg durch die Korridore als einzig sicherer Zugangsweg nach Berlin erwiesen habe. Es sei jedoch die sowjetische Begründung zu befürchten, daß es sich bei den Korridoren um den der Souveränität der DDR unterliegenden Luftraum handele. Zwar würden die Alliierten auch weiterhin die Verantwortung für die Sicherheit von Berlin (West) tragen, aber es könne nicht ohne Folgen bleiben, wenn die Bundesregierung meine, für eine Verbindung der Deutschen Lufthansa nach Moskau die Sicherheit der Luftverkehrswege nach Berlin riskieren zu können.

Schütz weist die Botschaft an, unverzüglich im amerikanischen Außenministerium und in der Abrüstungsbehörde zum sowjetischen Entwurf vom 1. September 1967 für Artikel III (Kontrollartikel) eines Nichtverbreitungsabkommens Stellung zu nehmen. Dieser zeige zwar den „Beginn eines Verständnisses für gewisse Erfordernisse und Probleme" der Sicherheitskontrollen, bleibe aber doch weit hinter dem mit den Verbündeten abgesprochenen Entwurf der USA zurück. So sehe er nur die Anwendung von IAEO-Kontrollen vor, während nach dem amerikanischen Vorschlag auch EURATOM-Kontrollen - verifiziert durch die IAEO - anwendbar bleiben sollten.

Loeck erörtert die Hintergründe der Note vom 12. Juli 1967, mit der die jugoslawische Regierung erneut Forderungen nach einer Entschädigung für NS-Opfer erhoben habe. Er bemerkt, da $\beta$ die jugoslawische Regierung dies in dem Moment in den Vordergrund gerückt habe, als eine baldige Aufnahme diplomatischer Beziehungen zur Bundesrepublik unwahrscheinlich geworden sei. Seitdem werde das Angebot zur „Wiederaufnahme diplomatischer Beziehungen ohne Vorbedingungen" mit dem Hinweis ergänzt, daß die Frage eines Botschafteraustauschs mit Entschädigungszahlungen verknüpft werden müsse. Loeck spricht sich für eine Ablehnung der juristisch ohnehin nicht haltbaren Forderungen aus, weil „isolierte Zahlungen “ an Jugoslawien die Bemühungen der Bundesrepublik um gleichmäBige Fortschritte in ganz Osteuropa sehr beeinträchtigen würden. Statt dessen solle Jugoslawien als Ersatz für Enschädigungsleistungen eine angemessene und wirkungsvolle Wirtschaftshilfe möglichst bald zugesichert werden.

Lilienfeld faßt die Ergebnisse einer Unterredung zwischen Bahr und dem Staatssekretär im amerikanischen Verteidigungsministerium am 15. September 1967 in Washington zusammen. Nitze bemerkte zu den Truppenplanungen der Bundeswehr, es sei nicht leicht zu sehen, wie die Bundesrepublik 
trotz einer Verstärkung der Reserven die „effektive Kampfkraft bei Kürzung des Haushaltsplans aufrechterhalten könne“. Dadurch werde es der amerikanischen Regierung erschwert, gegenüber der Opposition im Kongreß glaubhaft zu erklären, daß sich die Kampfkraft der alliierten Verbände an den Flanken der amerikanischen 7. Armee laufend erhöhe. Lilienfeld zieht den Schluß, daß der amerikanische Verteidigungsminister den Planungen der Bundeswehr über eine Verbesserung des Mobilisierungssystems ein "positives Interesse“ entgegenbringe; doch würde auch McNamara im Falle ihrer Umsetzung zusätzliche amerikanische Rotationsmaßnahmen vorschlagen. Lilienfeld rät von Truppenkürzungen von mehr als 19000 Mann dringend $a b$, da Präsident Johnson darin eine Nichteinhaltung der durch Bundeskanzler Kiesinger am 15./16. August 1967 in Washington gemachten Zusagen sehen würde.

Botschafter Schnippenkötter erörtert den im Schreiben vom 18. September 1967 an Bundeskanzler Kiesinger unterbreiteten Vorschlag des Vorsitzenden des Ministerrats der DDR, Stoph, eine Vereinbarung über Gewaltverzicht zu schließen. Damit stelle sich erneut die Frage nach einer Einbeziehung der DDR in das Gewaltverzichtsangebot der Bundesrepublik an osteuropäische Staaten. Allerdings müsse dabei sichergestellt sein, daß die Unterscheidung zwischen ,innerdeutsch" und „international“ erhalten bleibe und nicht schon als Schritt zur Anerkennung gewertet werden könne. Zudem müsse ein Gewaltverzicht insbesondere an der Grenze zur DDR wirksam werden und die Aufrechterhaltung des Schießbefehls erschweren.

Schnippenkötter erörtert Artikel I des geplanten Nichtverbreitungsabkommens. Danach stehe es jedem nuklearen oder nichtnuklearen Vertragspartner frei, anderen Kernwaffenstaaten Unterstützung bei der Entwicklung oder Produktion von Kernwaffen zu gewähren, auch wenn diese selbst dem Abkommen nicht beiträten. Dadurch könne z. B. die Volksrepublik China sowjetische Unterstützung bei der Weiterentwicklung von Kernwaffen erhalten. Dagegen werde es aber den nuklearen Mitgliedstaaten durch Artikel VI verboten, einem nichtnuklearen Staat zu helfen, der kein Vertragspartner sei und erst später Kernwaffenstaat werde. Davon könnte auch ein bundesstaatlich vereintes Europa betroffen werden, das durch Frankreich und/oder Großbritannien Kernwaffenstaat würde. Es wäre daher zu klären, so resümiert Schnippenkötter, ob ein solches vereintes Europa unter die Bestimmungen des Artikels I fiele, weil es nicht Kernwaffenstaat im Sinne von Artikel VI sei. Zwar stehe dieser Auslegung die amerikanische Interpretation entgegen, aber es sei notwendig, daß diese "Schlupflöcher" für die Gegner der europäischen Einigung und einer ABM-Ausrüstung für Europa geschlossen würden. 

Freiherr von Braun, New York (UNO)

Meyer-Lindenberg informiert über die Ablehnung der Niederlande, an der von Bundesminister Brandt vorgeschlagenen $\mathrm{Au}-$ Benminister-Treffen zur Vorbereitung einer neuen Konferenz der EG-Staats- und Regierungschefs teilzunehmen. Der Abteilungsleiter im niederländischen Außenministerium, de Ranitz, habe die Zusage von einem Fortschritt in der Frage eines britischen Beitritts zur Gemeinschaft abhängig gemacht. Brandt plane daher ein informelles Gespräch der Außenminister anläßlich der EG-Ministerratstagung am 23./24. Oktober 1967 in Luxemburg. Während die Außenminister der anderen Mitgliedstaaten bereits ihre diesbezügliche Zustimmung gegeben hätten, stehe eine Erklärung des niederländischen Außenministers noch aus. Meyer-Lindenberg bittet daher Braun, den sich in New York aufhaltenden Luns aufzusuchen. Auswärtige Amt

Grewe bezweifelt ein Ausscheiden Frankreichs aus der NATO, das laut Vertrag frühestens nach dem 24. August 1969 möglich wäre. Denn damit wäre der Verlust des Vetorechts bei wichtigen politischen Entscheidungen der Allianz ebenso verbunden wie auch die Isolierung auf dem Rüstungssektor. Grewe äußert jedoch Zweifel, ob sich Staatspräsident de Gaulle trotz dieser Nachteile davon abhalten ließe, die „Politik der Unabhängigkeit Frankreichs konsequent " fortzusetzen. Vielmehr werde er den Verbleib in der Allianz vom Stand der Ost-West-Beziehungen in den Jahren 1968/69 abhängig machen. Grewe vermutet, daß die Bereitschaft, den Vertrag zu kündigen, zunehmen werde, wenn sich Frankreich gegenüber der UdSSR durch den Ausbau der bilateralen Beziehungen zu anderen westlichen Staaten absichern könnte. Grewe empfiehlt daher, daß sich die Bundesregierung auf entsprechende „Annäherungsversuche $^{\alpha}$ vorbereiten solle. Dieses französische Interesse würde der Bundesrepublik die Möglichkeit zu „selbstbewußter Bewegungsfreiheit" geben, solange sie nicht vor die Alternative Frankreich oder NATO gestellt werde.

Ruete erläutert die Themen, die auf der Sitzung der Nuklearen Planungsgruppe der NATO am 28./29. September 1967 in Ankara besprochen werden sollen. Es lägen zwei Studien von SHAPE über den Einsatz von nuklearer Sprengmunition (ADM) in der dünnbesiedelten Osttürkei und in der Bundesrepublik vor. Der Staatssekretär im Bundesministerium der Verteidigung, Carstens, wolle dazu erklären, daß die Entscheidung über einen ADM-Einsatz in der Bundesrepublik von der Überlegung bestimmt sein müsse, ob die Zivilbevölkerung durch Evakuierungsmaßnahmen geschützt werden könne. Hinsichtlich des amerikanischen Beschlusses, in den USA ein Raketenabwehrsystems (ABM) zu errichten, werde Carstens darauf hinweisen, 
daß sich dadurch der im geplanten Nichtverbreitungsabkommen fixierte „Machtabstand“ $z$ wischen nuklearen und nichtnuklearen Staaten noch vergrößere. Ruete stellt fest, daß die beabsichtigte Erklärung nicht den Eindruck erwecken dürfe, als ob die Bundesregierung ihre Haltung zum Nichtverbreitungsabkommen revidieren und eine Einführung des ABMSystems in Europa fordern wolle.

Ruete bemerkt, daß der Schriftwechsel zwischen dem französischen Generalstabschef, Ailleret, und dem Oberbefehlshaber der NATO-Streitkräfte Europa, Lemnitzer, über das Zusammenwirken von Frankreich und dem Bündnis im Krisen- und im Verteidigungsfall zwar hinter den Erwartungen der Vierzehn zurückbleibe, aber als „Maximum des Erreichbaren“ angesehen werden müsse. Unbefriedigend sei vor allem, daß die französische Regierung jedes Zusammenwirken mit den NATO-Streitkräften von der vorherigen Entscheidung abhängig mache, ob auch für Frankreich der Bündnisfall laut Artikel 5 des NATO-Vertrags von 1949 gegeben sei. Als günstig sei dagegen zu bewerten, daß die in der Bundesrepublik stationierten französischen Truppen im Falle ihres Einsatzes der NATO unterstellt werden könnten. Die Vereinbarung werde schließlich nur dann einen brauchbaren Rahmen für die militärische Zusammenarbeit liefern, wenn Frankreich zur Allianz halte und bereit sei, einer militärischen Bedrohung aus dem Osten mit den Verbündeten gemeinsam entgegenzutreten. Auswärtige Amt

Lahr informiert über seine Gespräche mit Mitgliedern der pakistanischen Regierung. Präsident Ayub Khan bekräftigte die unveränderte Haltung zur Deutschland-Frage, obwohl seine sowjetischen Gesprächspartner regelmäßig die Bundesregierung „in fast pathologischer Weise“ angriffen. Lahr begründete die Ablehnung des pakistanischen Wunsches nach Lieferungen von M 48 Panzern. Er verwies dabei u. a. auf die bereits zur Verfügung gestellten Spezialmaschinen und Waffenteile sowie auf die Gewährung von Entwicklungshilfe. Mit Blick auf das militärische Übergewicht Indiens erklärte Ayub Khan den Hauptzweck seiner bevorstehenden Reise nach Moskau: Pakistan brauche Waffen „und werde sie auch vom Teufel nehmen“. Zur Frage eines Nichtverbreitungsabkommens betonte Außenminister Pirzada, Indien dürfe keine Atommacht werden. Ayub Khan sprach sich gegen ein Abkommen aus, das es einem Staat untersage, selbst einmal Atomwaffen zu produzieren. Lahr kommt zu dem Ergebnis, daß die bilateralen Beziehungen zwar auf einem guten Stand seien, ein kritischer Punkt jedoch die Ausrüstungshilfe bleibe. 

Auswärtige Amt

Lilienfeld berichtet über den Besuch des Bundesministers Stoltenberg vom 17. bis 22. September 1967 in den USA. Stoltenberg habe zahlreiche Gespräche über die technisch-wissenschaftliche sowie politische Zusammenarbeit geführt. Eine besonders herzliche Atmosphäre habe bei den Unterredungen mit dem Leiter der NASA bestanden. Webb habe die Unterstützung bei der Durchführung der vorgesehenen gemeinschaftlichen Projekte in der Weltraumforschung betont. Lilienfeld resümiert, daß Stoltenberg über den „Rahmen seines Fachgebiets hinaus als einflußreicher Politiker" angesehen werde, der zu einer Vertiefung der bilateralen Beziehungen beitragen könne. Auswärtige Amt

Lahn teilt die Ergebnisse eines Gesprächs mit dem Abteilungsleiter im ägyptischen Außenministerium vom Vortag mit. Mansour wies auf den „bedeutenden Wandel“ der ägyptischen $\mathrm{Au}$ Benpolitik hin, der sich seit der Konferenz der Staats- und Regierungschefs der arabischen Staaten vom 29. August bis 1 . September 1967 in Khartum vollzogen habe. Es sei nicht nur beschlossen worden, die Nahost-Krise mit friedlichen Mitteln beizulegen, sondern auch die Politik der strikten Unabhängigkeit fortzusetzen. Dabei wollten die arabischen Staaten dem verstärkten sowjetischen Druck widerstehen und sich gleichzeitig dem Westen wieder annähern. Es sei jedem einzelnen nun freigestellt, die Beziehungen zu den USA, Großbritannien und der Bundesrepublik wieder aufzunehmen. Die VAR warte aber auf "irgendein Zeichen aus Bonn". Wenn sich die arabischen Staaten mit den Beziehungen zwischen der Bundesrepublik und Israel abfinden sollten, dürfe auch die Bundesregierung den arabischen Staaten nicht mehr ein gutes Verhältnis zum andern Teil Deutschlands verübeln. Zudem sei die „HallsteinDoktrin bald völlig überholt ${ }^{4}$. Daraufhin stellte Lahn die offenkundigen Unterschiede zwischen Israel und der DDR heraus.

Bahr informiert über seine Gespräche am 15. September 1967 in Washington. Der außenpolitische Berater des amerikanischen Präsidenten, Walt Rostow, und der Staatssekretär im Verteidigungsministerium, Nitze, erkundigten sich nach der künftigen Streitkräfteplanung der Bundeswehr. Nitze sprach sich dafür aus, daß die Bundesregierung nach „reinen Zweckmäßigkeitsüberlegungen“ auf der Basis der ihr zur Verfügung stehenden Mittel über die Truppenstärke entscheiden solle. Bahr vermutet, da $\beta$ im amerikanischen Verteidigungsministerium eine Reduzierung um 15000 bis 19000 Mann "keinen Schock hervorrufen" würde. Dagegen gehe Präsident Johnson nach den Worten von Rostow davon aus, daß es keinen Truppenabbau der Bundeswehr geben werde. 
Klaiber berichtet über ein Gespräch mit dem französischen Staatspräsidenten. De Gaulle wies darauf hin, daß seine Äußerungen am 9./10. September 1967 in Zabrze (Hindenburg) und in Sopot (Zoppot) „mißverstanden und falsch interpretiert ${ }^{\text {“ wor- }}$ den seien. Er räumte zwar ein, daß eine etwaige Anerkennung der Oder-Neiße-Linie durch die Bundesregierung weder die UdSSR noch Polen aus taktischen Gründen zur Aufgabe ihres maximalen Standpunktes bewegen könnte. Langfristig würde aber der östlichen Propaganda durch einen solchen, der Entspannung dienenden Schritt "das Wasser abgegraben werden“. Hinsichtlich eines britischen EG-Beitritts berief sich de Gaulle auf das Gutachten der EG-Kommission vom 29. September 1967, wonach die britische Währung und der britische Agrarmarkt einer Aufnahme entgegenstünden. Abschließend zeigte er sich bereit, einem Treffen der Außenminister der EG-Mitgliedstaaten am 23. Oktober 1967 in Brüssel zuzustimmen, um eine neue europäische Gipfelkonferenz vorzubereiten.

Ruete faßt die Ergebnisse der Sitzung des Kabinettsausschusses für innerdeutsche Angelegenheiten vom Vortag zusammen, in der die Standpunkte der Ressorts vorgetragen wurden. Unter Vorsitz des Bundesministers Wehner beriet der Ausschuß über den Vorschlag des Bundesministers Schiller, zusätzliche Kohle- und Energiegeschäfte mit der DDR bei gleichzeitiger Swing- und Saldierungskorrektur abzuwickeln. Der Parlamentarische Staatssekretär im Bundesministerium für Wirtschaft, Arndt, führte beschäftigungspolitische Gründe an, die für eine solche Erhöhung der Kohleausfuhr in die DDR sprächen. Um die damit angestrebte Verminderung der "sowjetzonalen $\mathrm{Ab}$ hängigkeit von der Sowjetunion" zu erreichen, sei jedoch eine gleichzeitige Reduzierung der Importe der DDR aus Polen und aus der UdSSR nötig. Die DDR habe bereits Interesse angedeutet, gegen eine Erhöhung des Swings von 200 auf 300 Mio. DM sowie gegen eine Vertagung des Saldierungszwangs von Mitte 1968 auf 1970 Ruhrkohle zu kaufen. Um den schon kursierenden Pressespekulationen über ein angebliches Verrechnen der Kohlelieferungen mit der von der DDR geforderten Begleichung der „Postschulden“ entgegenzutreten, sei ein schnelles Handeln nötig.

Schnippenkötter legt in Absprache mit dem Bundesministerium der Verteidigung eine Aufzeichnung zur amerikanischen Truppenpräsenz in der Bundesrepublik vor. Da Präsident Johnson angesichts des Vietnam-Krieges und der wachsenden innenpolitischen Schwierigkeiten keine Schwierigkeiten in Europa haben wolle, könnte sich eine Reduzierung der Bundeswehr um 19000 Mann auch auf die amerikanische Truppenpräsenz in der Bundesrepublik auswirken. Das amerikanische Außenministerium lege daher größten Wert auf die Aufrecht- 
erhaltung der aktiven Truppenstärke der Bundeswehr. Das amerikanische Verteidigungsministerium halte statt dessen ein "Gesundschrumpfen" und eine bessere Ausnutzung des Reservistenpotentials in der Bundesrepublik für zweckmäßig. Die Bundesregierung solle darauf hinweisen, daß der ursprünglich bis 1971 geplante Ausbau der Bundeswehr auf 508000 Mann bereits vor dem Beschluß vom 6. Juli 1967 über die mittelfristige Finanzplanung den USA als unrealistische Zielvorgabe bekannt gewesen sei. Die Beibehaltung der Personalstärke der amerikanischen Streitkräfte hänge schließlich auch davon ab, ob die Bundesrepublik den USA beim Devisenausgleich auch weiterhin entgegenkomme. Schnippenkötter empfiehlt, die Bemühungen um ein gemeinsames Konzept der Allianz für parallele Truppen- und Präsenzverminderung von NATO und Warschauer Pakt fortzusetzen.

Knoke berichtet über ein Gespräch mit dem Abteilungsleiter im niederländischen Außenministerium vom Vortag. De Ranitz zeigte sich enttäuscht über den Verlauf der EG-Ministerratstagung am 2./3. Oktober 1967 in Luxemburg. Zur Stellungnahme der EG-Kommission vom 29. September 1967 erklärte er, daß Staatspräsident de Gaulle „im Grunde nur erfreut sein “ könne. Denn die darin formulierten Auflagen (Ausgleich des Zahlungsbilanzdefizits, Aufgabe des Charakters des Pfund Sterling als Reservewährung) erschwerten den britischen EGBeitritt außerordentlich. Die Kommission habe de Gaulle nun mit Material versehen, „das ein Hinausziehen der Verhandlungen auf Jahre ermögliche“.

\section{z.Z. London}

Ruete faßt die Ergebnisse eines Gesprächs mit dem Unterstaatssekretär im britischen Außenministerium zusammen. Lord Hood teilte die Auffassung von Ruete, daß nach Beendigung der Studie über die zukünftige Aufgaben der Allianz (Harmel-Studie) unter Einbeziehung Frankreichs eine „openended study group" für die Probleme europäische Sicherheit und Deutschland-Frage eingerichtet werden sollte. Getrennt davon solle das Thema auch zwischen den Drei Mächten und der Bundesrepublik erörtert werden. Lord Hood führte weiter aus, da $B$ die am 16. Juni 1967 von Bundesminister Brandt dem sowjetischen Botschafter Zarapkin übergebenen 14 Punkte über Gewaltverzicht oder das Problem des "nuclear freeze“ in die Diskussion mit einbezogen werden sollten.

Diehl erörtert die Europapolitik der Bundesregierung. Es stelle sich die Frage, ob die EG durch Großbritannien und die anderen beitrittswilligen EFTA-Staaten erweitert werden solle, selbst wenn dadurch die militärische und politische Einigung behindert werde. Diehl empfiehlt, die wirtschaftliche Zusam- 
menarbeit der sechs EG-Mitgliedstaaten auszubauen, die Bemühungen um eine Erweiterung fortzusetzen und die Kooperation in der Sicherheits- und der Außenpolitik mit den interessierten Staaten zu vertiefen. Dabei sollten „gemeinsame Interessen, nicht die institutionelle Konstruktion" im Vordergrund stehen. Die Unterscheidung zwischen wirtschaftlichen und militärisch-politischen Strukturen vergrößere zudem die Aussicht, auch neutrale Staaten Westeuropas einzubeziehen. Wegen der Ablehnung Frankreichs hinsichtlich eines britischen EG-Beitritts sei schließlich zu überlegen, ob die politische Zusammenarbeit nicht besser ohne Großbritannien und „notfalls selbst ohne die Niederlande oder sogar andere Beneluxstaaten" zu organisieren sei. Bis eine Änderung der französischen Politik eingetreten sei, solle die Kooperation mit Großbritannien auf allen Ebenen gefördert werden, um eine spätere Mitgliedschaft vorzubereiten.

Hauthal vermerkt die Ergebnisse eines Gesprächs zwischen Staatssekretär Lahr und dem israelischen Botschafter anläßlich der Unterzeichnung des Wirtschaftshilfe-Abkommens am 4. Oktober 1967. Lahr erklärte mit Blick auf die schwierige Finanzlage der Bundesrepublik, daß sowohl die Höhe des Betrages von 160 Mio. DM als auch die Konditionen des Kredits möglicherweise künftig geändert werden müßten. Außerdem bitte die Bundesregierung, daß Israel einen größeren Teil der durch den Kredit beschafften Kapitalgüter aus der Bundesrepublik beziehe. Hinsichtlich der von Ben Natan beklagten schleppenden Assoziierungsverhandlungen zwischen der EG und Israel versicherte der Staatssekretär, daß Israel der deutschen Unterstützung gewiß sein könne. Auswärtige Amt

Knappstein berichtet über ein Gespräch des Gesandten von Lilienfeld mit dem Staatssekretär im amerikanischen Außenministerium, Eugene Rostow, am Vortag. Lilienfeld übergab eine Aufzeichnung mit Änderungswünschen zum amerikanischsowjetischen Entwurf vom 24. August 1967 für ein Nichtverbreitungsabkommen. Rostow bestätigte, daß weder die NATO noch der europäische Einigungsproze $\beta$ beeinträchtigt werden dürften; gleichzeitig komme aber auch der Einigung mit der UdSSR „im Interesse der Entspannung der Weltlage“ große Bedeutung zu. Es müsse alles versucht werden, um dem Politischen Ausschuß der UNO-Generalversammlung einen vollständigen Vertragsentwurf vorzulegen. Sonst gerate die UdSSR aufgrund ihres bereits vorliegenden Entwurfs in eine "taktisch sehr vorteilhafte Lage“, wodurch besonders die Bundesrepublik stärkstem Druck ausgesetzt würde. Knappstein resümiert, daß bei Rostow im Gegensatz zu früher eine "gewisse Ungeduld" erkennbar gewesen sei, die mit den als schleppend empfundenen EG-Beratungen über Artikel III zusammenhänge. 

Generalsekretär Brosio, NATO

Brosio informiert über die Mitteilung des französischen AuBenministers Couve de Murville, wonach Frankreich der Studie zur Untersuchung der zukünftigen Aufgaben der Allianz (Harmel-Studie) nicht zustimmen könne, wenn die NATO dadurch größere politische Aufgaben erhielte. Es sei daher zu überlegen, entweder einen auch von Frankreich gebilligten „interim report" zu verfassen oder aber auf der NATO-Ministerratstagung am 13./14. Dezember 1967 in Brüssel einen Bericht mit den unterschiedlichen Auffassungen vorzulegen. Brandt bemerkt dazu, daß die Bundesregierung keine Konfrontation mit der französischen Regierung wünsche. Um einen gemeinsamen, wenn auch verhältnismäßig kleinen Nenner zu finden, empfiehlt er, die "summaries" von den vier Berichten der Rapporteure zusammenzufügen. Brosio könne sich dann um die $\mathrm{Zu}$ stimmung der „Special Group" bemühen. Brosio sagt zu, diese Anregung auf dem Treffen der vier Rapporteure am 10./11. Oktober 1967 in Ditchley Park vorzubringen. Darüber hinaus sei aber ein Bericht über die gesamte Harmel-Studie anzufertigen, in dem die Meinungsverschiedenheiten offen erwähnt werden sollten.

Thierfelder faßt den Stand der Gespräche mit den Botschaften der Drei Mächte über die Frage einer Änderung des Verfahrens zur Einbeziehung von Berlin (West) in völkerrechtliche Verträge der Bundesrepublik zusammen. Die USA unterstützten die Vorstellungen der Bundesregierung, wonach Berlin (West) nicht mehr ausdrücklich genannt werde. Vielmehr solle Berlin (West) grundsätzlich als in Verträge der Bundesrepublik einbezogen gelten. Frankreich sei besorgt, daß eine Verfahrensänderung sowjetischen Protest hervorrufen und die Entspannungspolitik beeinträchtigen könnte. Zusammen mit Großbritannien befürchte es, daß ein Vertragspartner der Bundesrepublik gezwungen werden könnte, die Einbeziehung von Berlin (West) auch gegen seinen Willen zu akzeptieren. Thierfelder schlägt als Kompromiß vor, daß eine Einbeziehung nur dann wirksam werde, wenn die Anwendung eines Vertrags auf Berlin (West) nicht ausdrücklich ausgeschlossen werde. Bei bilateralen Verträgen der Bundesrepublik müsse ein solcher Ausschluß schriftlich in Form eines Notenwechsels oder einer Vertragsklausel festgelegt werden.

Monnet gibt seiner Hoffnung Ausdruck, daß der Bundestag die Resolutionen des Aktionskomitees zur politischen Einigung Europas in der Debatte am 13. Oktober 1967 annehme. Das Aktionskomitee habe sich von dem Gedanken leiten lassen, daß den Mitgliedstaaten und den assoziierten Staaten keine 
Schwierigkeiten erwachsen dürften. Auch solle die Entwicklung zu einem vereinten Europa die Vereinigung Deutschlands erleichtern. Kiesinger äußert die Vermutung, daß der Bundestag die Entwürfe nach der Erörterung in den zuständigen Ausschüssen annehmen werde. Er sieht jedoch Schwierigkeiten bei der Forderung nach baldigen Verhandlungen über einen britischen EG-Beitritt, denn Staatspräsident de Gaulle sei in dieser Frage "starr und unnachgiebig". Zunächst sei es das Wichtigste, die sechs EG-Mitgliedstaaten am Konferenztisch zu halten und Konflikte zu vermeiden. Hinsichtlich des Verhältnisses zu den USA erläutert Monnet die Notwendigkeit engerer Beziehungen auf der Grundlage der Gleichheit.

Loeck berichtet, daß eine weitere Verzögerung der bereits zugesagten Aufnahme von Verhandlungen über ein Anwerbeund Sozialversicherungsabkommen für Gastarbeiter nicht nur dem Verhältnis zu Jugoslawien, sondern der gesamten Osteuropapolitik der Bundesregierung Schaden zufügen könnte. Es sei möglich, daß die jugoslawische Regierung dann ihre verständnisvolle Haltung hinsichtlich einer Wiederaufnahme diplomatischer Beziehungen überprüfe. Hinzu komme, daß das bislang von den jugoslawischen Gastarbeitern in ihrer Heimat vermittelte positive Bild von der Bundesrepublik gefährdet würde. Jugoslawische Kritiker einer Normalisierung der Beziehungen könnten argumentieren, daß den Zusicherungen der Bundesregierung nicht zu trauen sei und die aus einem kommunistischen Staat Osteuropas stammenden Arbeitskräfte als

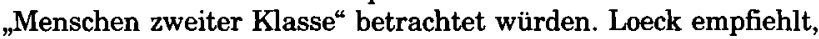
einen baldigen definitiven Verhandlungstermin zu bestimmen.

347 12.10. Gespräch des Bundesministers Brandt mit dem sowjetischen Botschafter Zarapkin

Zarapkin teilt mit, daß er beauftragt worden sei, das' Gespräch über einen Austausch von Gewaltverzichtserklärungen fortzusetzen. Dazu übergibt er eine Erklärung, in der die Bundesrepublik aufgefordert wird, Gewaltverzichtserklärungen auch mit der DDR auszutauschen. Brandt sichert eine „aufmerksame Prüfung zu. französischen Botschafter François Seydoux

Kiesinger betrachtet die durch die Äußerungen des Staatspräsidenten de Gaulle am 9./10. September 1967 in Zabrze (Hindenburg) und Sopot (Zoppot) ausgelöste Aufregung als beendet. Das von den deutschen Vertriebenen und Flüchtlingen beanspruchte Heimatrecht sei ,juristisch kein ausgefüllter Begriff" Es bedeute aber, daß sie zurückkehren könnten, auch wenn diese Gebiete, „die deutsches Land gewesen seien“, eines Tages endgültig einem anderen Staat zugesprochen würden. Der Bundeskanzler erläutert dann die in der „außerparlamentarischen 
Opposition“ - insbesondere in der Publizistik - verbreitete Neigung, die DDR völkerrechtlich anzuerkennen und zudem den Eindruck zu erwecken, als wolle die SPD in der Deutschlandpolitik sehr weit gehen, "während die CDU bremse". Hinsichtlich der dem Bundestag zur Abstimmung vorliegenden „Entschließungen des Aktionskomitees für die Vereinigten Staaten von Europa" betont er, daß die französischen Bedenken gegen den empfohlenen britischen EG-Beitritt zu berücksichtigen seien. Die Bundesregierung wolle eine möglichst große „Harmonie“ mit der französischen Politik herstellen. Lindenberg

Meyer-Lindenberg erörtert das Schreiben des französischen Außenministers Couve de Murville vom 11. Oktober 1967 an Bundesminister Brandt über eine Verstärkung der bilateralen Zusammenarbeit. Mit der Zustimmung zur Aufnahme regelmäßiger Treffen der Wirtschafts- und Finanzminister berücksichtige dieses Schreiben einen Ergänzungsvorschlag des Auswärtigen Amts zum deutsch-französischen Vertrag von 1963. Meyer-Lindenberg schlägt vor, daß Brandt während seines Aufenthalts am 16.117. Oktober 1967 in Paris ein Antwortschreiben übergeben und Ministerialdirektor Ruete als deutschen Delegationsleiter für die Arbeitsgruppe zur Anfertigung einer Studie über die europäische Sicherheit und die Verteidigung Europas in den siebziger Jahren benennen könnte. Eine Veröffentlichung des Schriftwechsels sei jedoch erst angebracht, wenn die Namen der Beauftragten für die Gesamtkoordinierung der deutsch-französischen Zusammenarbeit feststünden. Bundesminister Brandt

Knappstein berichtet von einem Gespräch mit dem amerikanischen Außenminister Rusk und dem Leiter der Abrüstungsbehörde, Foster. Rusk stellte kritische Fragen zur Bedeutung der Sicherheitskontrollen für EURATOM und erkundigte sich nach den Gründen, warum die Interessen von EURATOM durch die amerikanischen Vorschläge gefährdet seien. Die Verhandlungen über das Nichtverbreitungsabkommen müßten bis zur ersten Sitzung des Politischen Ausschusses der UNO-Generalversammlung am 6. November 1967 abgeschlossen sein. Bei der Verifikationsfrage bezeichnete Foster eine „zwei-Hüte-Lösung" als denkbar, wonach die EURATOM-Kontrollen gleichzeitig als IAEO-Kontrollen oder im Auftrag der IAEO angewandt werden könnten. Knappstein hält es für möglich, daß die USA ohne vorherige Konsultation mit EURATOM einen Kompromiß mit der UdSSR suchen könnten, wenn EURATOM selbst nicht rechtzeitig einen erfolgversprechenden Vorschlag unterbreiten könnte. Offensichtlich setze sich Foster für das 
Weiterverhandeln mit der UdSSR ein; auch habe er im Außenministerium bei Rusk die Zweifel genährt, ob die Kontrollfunktion für die Europäischen Gemeinschaften „wirklich eine vitale Bedeutung" habe. Außenminister Rusk

Brandt weist den Vorwurf mangelnder Kompromißbereitschaft bei den Verhandlungen über Artikel III (Kontrollartikel) eines Nichtverbreitungsabkommens zurück und drückt sein Erstaunen über die „immer häufiger werdenden Unterstellungen“ gegen die Bundesregierung aus. Die Bundesrepublik habe die im Abkommen vorgesehene Diskriminierung der Nichtkernwaffenstaaten hingenommen, weil sich die USA und Großbritannien freiwillig zu IAEO-Kontrollen in ihren zivilen Kernanlagen verpflichtet hätten, während Frankreich unverändert nur die EURATOM-Kontrollen akzeptiere. Diese Voraussetzung zur Zustimmung würde entfallen, wenn die EURATOM-Kontrollen nun durch eine entsprechende Formulierung für Artikel III gefährdet würden. Da Frankreich nämlich das Nichtverbreitungsabkommen nicht unterzeichne, würde die Einführung der IAEO-Kontrollen in EURATOM für die übrigen fünf Nichtkernwaffenstaaten einseitig eine doppelte Kontrolle und damit eine „unannehmbare Diskriminierung“ darstellen. Frankreich hingegen erhielte eine „nukleare Sonderstellung“. Es sei undenkbar, daß über die noch laufenden Beratungen der EG hinwegegangen würde. Dies würde ein schwerer Schlag nicht nur für das Zustandekommen eines weltweiten Nichtverbreitungsabkommens, sondern auch für das Verhältnis zwischen Europa und Amerika sein. das Auswärtige Amt

Braun berichtet über ein Gespräch mit dem polnischen Stellvertretenden Außenminister. Winiewicz bemerkte, daß die Bundesrepublik den Zeitpunkt der Aufnahme diplomatischer Beziehungen zu Rumänien unglücklich gewählt habe. Denn die DDR fühle sich in die Isolierung gedrängt. Doch Polen und die anderen osteuropäischen Staaten "würden ihre ostdeutschen Freunde nie verlassen“. Es werde noch viel Zeit vergehen, bis an die Aufnahme diplomatischer Beziehungen gedacht werden könne. Aus einem weiteren Gespräch mit dem belgischen Botschafter bei der UNO, Schuurmans, teilt Braun mit, daß sich Winiewicz in ähnlicher Form auch gegenüber dem belgischen Außenminister Harmel geäußert habe. Der bulgarische Außenminister Bashev habe sich gegenüber Harmel allerdings weniger abweisend gegen einen eventuellen Botschafteraustausch mit der Bundesrepublik ausgesprochen, ,als er es öffentlich tun müsse“. 

Auswärtige Amt

Bente berichtet über ein Gespräch mit dem Berater des libanesischen Präsidenten. El Khoury teilte mit, daß die libanesische Regierung angesichts der angespannten Lage im Nahen Osten künftig eine neutralere Politik unter stärkerer Anlehnung an den Westen führen wolle. Sie sei auch bereit, mit der Bundesrepublik über die Wiederaufnahme diplomatischer Beziehungen zu verhandeln, wobei sie aber mit Rücksicht auf den muslimischen Teil des Landes sehr behutsam vorgehen wolle. Bente begrüßte den Entschluß, erklärte jedoch, daß die Bundesregierung nicht bereit sei, diesen Schritt mit Wirtschaftshilfe zu verknüpfen. Daraufhin schlug el Khoury vor, die Beziehungen zunächst nur auf Geschäftsträgerebene wiederaufzunehmen. Bente resümiert, daß der Stand der Vorbesprechungen nunmehr die vorgesehene Entsendung des Vortragenden Legationsrats I. Klasse Gehlhoff nach Beirut als notwendig erscheinen lasse. Lindenberg

Meyer-Lindenberg faßt die Ergebnisse eines Gesprächs des Bundesministers Brandt mit dem israelischen Botschafter zusammen. Ben Natan zeigte sich besorgt, daß der UNOSicherheitsrat Beschlüsse fassen könnte, die den israelischen Interessen zuwiderliefen. Israel bestehe vor einem Rückzug aus den besetzten Gebieten auf Beendigung des Kriegszustands sowie auf Anerkennung durch die arabischen Staaten und auf der Festlegung der Grenzen in einem Friedensvertrag. Dabei seien die Waffenstillstandslinien vom 4. Juni 1967 allerdings überholt. Zum israelischen Antrag auf Assoziierung mit der EG gab Ben Natan den Eindruck wieder, daß sich Frankreich und Italien widersetzten, während die Bundesrepublik "nicht mehr ganz so warmherzig für Israel“ eintrete; hier sei „die Temperatur wieder etwas höher“ zu bringen. zösischen Außenminister Couve de Murville in Paris

Brandt übergibt die Antwort auf das Schreiben des französischen Außenministers vom 11. Oktober 1967 zur Verstärkung der bilateralen Zusammenarbeit. In dem anschließenden Gespräch über alle wesentlichen Fragen der bilateralen Beziehungen erläutert er u.a. das Verhältnis zu den osteuropäischen Staaten und konstatiert vor allem bei der DDR nur wenig Veränderung. Die Bundesregierung werde aber ihre Bemühungen um Entkrampfung beharrlich, wenn auch ohne Illusionen, fortsetzen. Couve de Murville bemerkt, daß die Situation durch die Entspannungspolitik schwieriger geworden sei, da die UdSSR die Kontrolle über die osteuropäischen Staaten behalten wolle und Polen sich mit der befreundeten DDR als Nachbarn „ruhiger" fühle als mit einem wiedervereinigten Deutschland. Zur Frage der Nichtverbreitung bekräftigt er, daß Frankreich 
das Abkommen nicht unterzeichnen werde. Ferner werde es sich innerhalb von EURATOM erst an der Diskussion beteiligen, wenn der Vertrag vorliege, z.B. die Bundesrepublik ihn unterzeichnet habe und es dann zu Schwierigkeiten beim Export/Import zwischen den Mitgliedstaaten kommen sollte. Die Studie über die zukünftigen Aufgaben der Allianz (HarmelStudie) bezeichnet er als „rein akademisches Exercitium“. Es dürfe nicht der Eindruck entstehen, als ob hier eine gemeinsame Außenpolitik definiert werde.

356

\subsection{Aufzeichnung des Legationsrats I. Klasse} Graf Schirndinger von Schirnding

17.10. Botschafter von Walther, Moskau, an das Auswärtige Amt

Walther führt aus, daß die sowjetische Regierung mit dem Memorandum vom 12. Oktober 1967 die „de facto Anerkennung Ostberlins" zur Voraussetzung eines Austauschs von Gewaltverzichtserklärungen mache und damit die "bedingungslose Anerkennung der DDR durch die BRD“ zu erreichen suche. Diese Politik beruhe zum einen auf dem wachsenden Einfluß der DDR, zum anderen auf der Fehleinschätzung, daß die Bundesrepublik „über kurz oder lang das SBZ-Regime anerkennen werde ${ }^{\star}$. Walther stellt fest, daß eine Einigung über den Austausch von Gewaltverzichtserklärungen erst dann möglich sei, wenn die UdSSR zu der Einsicht gelange, daß sie die Deutschlandpolitik der Bundesregierung falsch interpretiere. Er empfiehlt, zunächst die sowjetische Reaktion auf die Haltung der Bundesrepublik in der Berlin-Frage bei den angekündigten Wirtschafts- und Luftverkehrsverhandlungen abzuwarten.

Schirnding berichtet, daß der Erste Sekretär der französischen Botschaft über die Absicht informiert habe, den Teilnehmern an den Olympischen Winterspielen vom 6. bis 18. Februar 1968 in Grenoble eine vom IOC ausgestellte olympische Identitätskarte als Reisedokument auszugeben. $\mathrm{Da}$ die Sportler aus der DDR so von den TTD-Richtlinien befreit würden, erbat Ourmet eine Stellungnahme des Auswärtigen Amts. Schirnding empfiehlt mit Blick auf die bei den vergangenen Olympiaden praktizierte Regelung, keine Bedenken gegen das französische Anliegen zu erheben. Allerdings solle dies „als ein kleines Opfer“ dargestellt und darauf bestanden werden, daß die Identitätskarte für alle Teilnehmer gelte und dementsprechend kein Sportler ein anderes Ausweispapier vorlegen müsse. NATO

Brandt informiert über die Gespräche mit dem französischen Außenminister am 16./17. Oktober 1967 in Paris. Couve de Murville erklärte, daß in der Studie über die zukünftigen Aufgaben der Allainz (Harmel-Studie) keine Regelung akzeptabel 
sei, welche die Politik jedes Mitglieds in der Allianz zur Diskussion stelle. Das Bündnis solle vielmehr unverändert weiterarbeiten und die Konsultationen durch gegenseitige Informationen fortsetzen. Brandt gibt abschließend seinen Eindruck wieder, $\mathrm{da} B$,die französische Haltung noch nicht in jeder Beziehung festgelegt" sei. Die Bundesregierung werde sich weiterhin bemühen, Frankreich für eine Lösung zu gewinnen, die im gemeinsamen Interesse der Allianz liege.

Sahm informiert über die Schadenersatzansprüche, die von den vierzehn NATO-Mitgliedstaaten als Folge des französischen Ausscheidens aus der militärischen Integration der Allianz erhoben würden. Diese Forderungen bezögen sich zum einen auf den Verlust der in Frankreich gelegenen Infrastrukturanlagen, zum anderen auf die entstandenen Kosten für die Verlegung in andere NATO-Staaten. Es handle sich um eine Gesamtsumme von ca. 223,7 Mio. Pfund; hinzu kämen weitere 2,75 Mrd. Francs, die sich aus amerikanisch-französischen Vereinbarungen ergäben. Die USA dächten aus innenpolitischen Gründen daran, auf eine baldige Erfüllung ihrer Forderungen zu drängen. Eine kritische Zuspitzung des amerikanisch-französischen Verhältnisses sei dabei nicht ausgeschlossen. Um die Zusammenarbeit Frankreichs mit den Vierzehn weiterhin „eng und dauerhaft" zu halten, rät Sahm, die USA zu bitten, ihre bilateralen Ansprüche getrennt von den Forderungen der Vierzehn geltend zu machen. das Auswärtige Amt

Braun berichtet von einem Gespräch mit dem ägyptischen Außenminister über eine Wiederaufnahme der diplomatischen Beziehungen. El Riad beklagte die wirtschaftliche, militärische und politische Unterstützung der Bundesrepublik für Israel, die den arabischen Staaten während des Nahost-Krieges „schmerzlich durch die israelische Überlegenheit erneut zum Bewußtsein" gekommen sei. Die von der Bundesregierung damals eingenommene Neutralität sei fast ebenso schlimm wie direkte

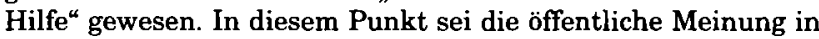
den arabischen Staaten sehr empfindlich. Für die Normalisierung der Beziehungen, die eine Angelegenheit aller arabischer Staaten sei, müsse ein günstiger Augenblick abgewartet werden. Braun resümiert, daß el Riad den Eindruck vermittelt habe, als ob die Bundesrepublik „vorläufig für Kairo diplomatisch uninteressant" sei. Auswärtige Amt

Grewe teilt zum Stand der Studie über die zukünftigen Aufgaben der Allianz (Harmel-Studie) mit, daß NATO-Generalsekretär Brosio auf einer vertraulichen Sitzung die Zusammenfas- 
sung der Berichte der vier Untergruppen der „Special Group“ vorgelegt habe. Diese Zusammenfassung solle den Mitgliedstaaten lediglich die Stellungnahme erleichtern und die einzelnen Berichte keinesfalls ersetzen. Auf Vorschlag von Grewe wurde vereinbart, zunächst die Prüfung der Berichte und der Zusammenfassung durch die einzelnen Regierungen abzuwarten. Es wurde ferner Einigung über eine Sitzung der Ständigen Vertreter am 25. Oktober 1967 erzielt, auf der die Voraussetzungen für eine Sitzung der „Special Group“ auf höherer Ebene unter Teilnahme des belgischen Außenministers Harmel geschaffen werden sollten. Erst danach solle dann die endgültige Formulierung des Harmel-Berichts erfolgen, der aus einem vertraulichen und einem für die Veröffentlichung bestimmten Teil bestehen werde. Premierminister Wilson in London

Zu dem auf der EG-Ministerratstagung in Luxemburg erörterten britischen Beitrittsantrag bemerkt Kiesinger, er wolle alles tun, um das Verfahren zu erleichtern. Er habe dem französischen Staatspräsidenten mitgeteilt, daß die öffentliche Meinung in Europa für eine britische Beteiligung sei. Da de Gaulle nicht von seinen Ansichten abgebracht werden könne, müsse er davon überzeugt werden, daß er den Beitritt nicht verhindern könne. Wilson erklärt, daß er es vorziehen würde, wenn die Verhandlungen der EG mit Großbritannien nicht erst nach internen Konsultationen der sechs Mitgliedstaaten, sondern sofort aufgenommen würden. Kiesinger erläutert die Sorge von de Gaulle, daß eine europäische Einheit zu einer atlantischen Gemeinschaft führen könne. Darauf erwidert Wilson, de Gaulle befürchte, „daß sich zu sechs Leuten, die miteinander Fußball spielen wollten, nunmehr ein neues Mitglied gesellen wolle, das nicht bereit sei, sich an die Regeln zu halten und statt Fußball Baseball zu spielen beabsichtige."

Kiesinger befürwortet den britischen EG-Beitritt, spricht sich aber mit Blick auf die französische Haltung für eine möglichst behutsame Vorgehensweise bei den prozeduralen Fragen aus. Für Staatspräsident de Gaulle bedeute die Bereitschaft zur Aufnahme Großbritanniens die Aufgabe einer Politik, die er seit 1950 „mit zunehmender Starrheit" verfolge. Daher müsse seine Forderung nach vorherigen Beratungen unter den Sechs erfüllt werden. Es sei zu hoffen, daß diese Verhandlungen bis etwa zur Jahreswende 1967/68 beendet werden könnten. AuBenminister Brown warnt, daß eine Verzögerung „eine ernste Wirkung" auf die Beziehungen zu Frankreich sowie auf die britische Einstellung zur NATO und zur Stationierung von Streitkräften haben könnte. Zur Klärung der durch die Stellungnahme der EG-Kommission vom 29. September 1967 aufgeworfenen Fragen schlägt Kiesinger einen Meinungsaustausch zwischen Experten beider Seiten vor, der parallel zu den 
internen Beratungen der Sechs geführt werden solle. Brown stimmt dem von Kiesinger vorgestellten Konzept zu, wonach die Beitrittsverhandlungen einerseits und die sich gleichzeitig vollziehende Weiterentwicklung der EG andererseits synchronisiert werden sollten.

Bundeskanzler Kiesinger stellt fest, daß die soeben von der EG-Ministerratstagung in Brüssel übermittelten Äußerungen des französischen Außenministers Couve de Murville offenbar einem Veto zum britischen EG-Beitritt gleichkommen. Er erläutert anschließend die Sorge des französischen Staatspräsidenten, daß sich die NATO im Zuge der Studie über die zukünftigen Aufgaben der Allianz (Harmel-Studie) zu ,einer Art Politische Atlantische Union" entwickeln würde; dies könne seine Entscheidung über den Verbleib in der NATO beeinflussen. Die Entspannungspolitik der Bundesregierung werde durch die sowjetische Forderung nach Anerkennung der DDR behindert. Durch den Versuch, das Verhältnis zu allen östlichen Staaten zu verbessern, solle ein Klima des gegenseitigen Verständnisses geschaffen werden, dem sich die DDR nicht auf Dauer entziehen könne. Der britische Verteidigungsminister Healey erläutert die Absicht, die Verteidigungskosten durch Truppenverlegungen zu verringern. Die Verlagerung des Schwerpunkts der britischen Verteidigung von „East of Suez" nach Europa sei von historischer Bedeutung. Die Bundesregierung möge daher ihrerseits den Beschluß überprüfen, die Bundeswehr um 19000 Mann zu reduzieren.

Wilson stimmt der Überlegung von Kiesinger zu, bei den kommenden Gesprächen über das weitere Vorgehen in der Frage des britischen EG-Beitritts insbesondere mit der italienischen Regierung zu sprechen. Er schlägt eine Intensivierung der technologischen Zusammenarbeit mit der Bundesrepublik vor. Vor allem sollten die entsprechenden Firmen direkt miteinander Kontakt aufnehmen können. Zu diesem Zweck sei es allerdings notwendig, daß Großbritannien der EG beitrete.

Lahr erörtert im Licht der EG-Ministerratstagung am 23./24. Oktober 1967 in Luxemburg die ablehnende Haltung Frankreichs zu einem britischen Beitritt. Der französische Außenminister habe darauf hingewiesen, daß die EG durch die britische Aufnahme von einer Wirtschafts- zu einer Handelsunion „denaturieren“ würde. Nach Ansicht von Couve de Murville hätten die Römischen Verträge von 1957 zwar eine erweiterungsfähige Gemeinschaft vorgesehen, aber die Entwicklung sei darüber hinweggegangen. Diese Argumentation stehe jedoch, so Lahr, in "diametralem Gegensatz“ zur Haltung der Partnerstaaten. Frankreich müsse nun damit rechnen, daß ei- 
nige von ihnen „renitent" würden. Zudem werde Großbritannien künftig „unsichtbar am Ratstisch der Gemeinschaft ${ }^{4}$ sitzen. Es sei nur schwer vorstellbar, daß es so zu Beschlüssen über die endgültige Gestaltung der EG, insbesondere über die Agrarfinanzierung komme, an der Frankreich am meisten interessiert sei. Europa sei für Frankreich nur ein „Operationsfeld unter anderem“, das für konkrete französische Interessen nützlich sein könne. Es stelle sich daher die Frage, ob der französischen Regierung tatsächlich an der EG gelegen sei oder sie einfach nur ihre Führungsrolle in der Gemeinschaft erhalten wolle.

Sahm faßt die Ergebnisse der Gespräche des Chefredakteurs des Deutschlandfunks, Barsig, am 6./7. Oktober 1967 in Belgrad zusammen. Demnach sei die jugoslawische Regierung bereit, ohne Vorbedingungen die diplomatischen Beziehungen wiederherzustellen. Da damit aber das Problem der jugoslawischen Wiedergutmachungsforderungen bestehen bleibe, komme es nun darauf an, entsprechende Illusionen „zu zerstören“. Kernpunkt sei die Frage, wie die Bundesregierung mit den Staaten verfahren werde, die - wie dies Jugoslawien 1957 getan habe - nun ebenfalls diplomatische Beziehungen mit der DDR aufnehmen wollten. Dem sei mit dem Hinweis auf die veränderte politische Lage in Europa zu begegnen. Zudem könnten den kommunistischen Staaten keine Maßregeln für sein Verhalten gegenüber anderen kommunistischen Staaten auferlegt werden; von den übrigen Staaten sei aber zu erwarten, daß sie die Spaltung Europas nicht durch die Anerkennung der DDR vertieften. Eine beim Botschafteraustausch abzugebende Erklärung müsse so zurückhaltend formuliert werden, wie es innenpolitisch gerade noch zulässig sei. Damit solle die Fehldeutung vermieden werden, die Bundesregierung wolle "ostpolitische Bewegung um jeden Preis“. Es müßte dann erklärt werden, daß der Abbruch der Beziehungen 1957 ebenso „richtig wie seine Perpetuierung heute falsch wäre“. Tel Aviv

Böker informiert Pauls über ein Gespräch mit dem ehemaligen Bundeskanzler Erhard vom Vortag. Erhard stimmte dem Vorschlag zu, im Rahmen seines Aufenthalts in Israel vom 30. Oktober bis 10. November 1967 weder die Altstadt von Jerusalem noch andere besetzte Gebiete zu besuchen. Böker führt weiter aus, die israelische Botschaft habe daraufhin "sehr heftig" gegen diese „Demonstration gegen Israel“" protestiert und die gesamte Reise in Frage gestellt. Sowohl Bundesminister Brandt als auch Erhard seien jedoch entschlossen, nicht nachzugeben. Erhard bitte zudem darum, in Israel darauf hinzuwirken, „daß keine weiteren Pressionen auf ihn ausgeübt" würden. 
Harkort nimmt zu der Vorlage des Bundesministeriums der Verteidigung für die Sitzung des Bundesverteidigungsrats am 3. November 1967 Stellung. Der vorgeschlagene Verkauf von 30 bis 50 Flugzeugen vom Typ Do 27 aus Bundeswehrbeständen an Portugal als Kompensation für die Verkleinerung des Luftwaffenstützpunktes Beja stoße auf grundsätzliche Bedenken des Auswärtigen Amts, da ein Einsatz dieser Flugzeuge zur Unterdrückung von Aufständen in den portugiesischen Kolonien möglich sei. Während die Abteilungen II und III das Projekt wegen der sonst zu erwartenden Verschlechterung der Beziehungen zu Portugal befürworteten, spreche sich Abteilung I mit Blick auf die ebenfalls absehbare „erhebliche Belastung" des Verhältnisses zu den afrikanischen Staaten dagegen aus. Harkort schlägt daher vor, das Bundesministerium der Verteidigung möge die Lieferung der Flugzeuge ablehnen. Erst wenn sich im Laufe der Verhandlungen zeige, daß Portugal großes Gewicht auf den Erhalt der Do27 lege und dafür auch Konzessionen beim Beja-Vorhaben einräume, könne eine Lieferung von höchstens 50 Maschinen erfolgen.

Schnippenkötter resümiert die Einschätzung der sowjetischen Demarchen gegen die Besuche ausländischer Staatsgäste in Berlin (West) auf der Besprechung der Bonner Vierergruppe vom 18. Oktober 1967. Von französischer Seite seien Bedenken gegen den Vorschlag der USA erhoben worden, daß der amerikanische Botschafter McGhee gegenüber dem sowjetischen Botschafter in Ost-Berlin, Abrassimow, „das Befremden der Verbündeten" bekunde. Daraufhin habe der britische Vertreter vorgeschlagen, die Bundesregierung solle diejenigen Regierungsgäste, die von der UdSSR zum Verzicht auf einen Berlin-Aufenthalt gedrängt würden, darauf hinweisen, daß den Drei Mächten ein Besuch der Stadt willkommen wäre. Außerdem seien sie mit der Wahrnehmung der Interessen von Berlin (West) im Ausland durch die Bundesregierung einverstanden. Schnippenkötter schlägt vor, den Entwurf einer entsprechenden Erklärung „der drei Berliner Schutzmächte“ auszuarbeiten. McGhee solle Abrassimow darüber in Kenntnis setzen und gleichzeitig das Befremden über die sowjetischen Demarchen ausdrücken. Außenminister Rusk

Brandt übermittelt eine Aufzeichnung zur Frage der Nichtverbreitung von Kernwaffen: Die EG-Kommission habe mitgeteilt, $\mathrm{da} ß$ der sowjetische Entwurf vom 1. September 1967 für Artikel III (Kontrollartikel) eines Nichtverbreitungsabkommens nur unter Berücksichtigung der Änderungsvorschläge der Bundesrepublik vereinbar sei mit dem EURATOM-Vertrag von 1957. Solange das Abkommen aber ausdrücklich IAEO-Sicherheitskontrollen vorschreibe, die nicht konform mit dem EURATOM- 
Vertrag seien, könne die Bundesregierung „keine andere Haltung einnehmen als bisher“. Am 27. Oktober 1967 hätten sich die fünf kernwaffenlosen EURATOM-Mitgliedstaaten auf eine gemeinsame Minimalposition geeinigt und Bemerkungen zur Kontrollregelung erarbeitet. Die Bundesregierung werde nun Modifikationen der eigenen Änderungsvorschläge im NATORat vorstellen. Falls die amerikanisch-sowjetischen Verhandlungen nicht zu einem EURATOM-vertragskonformen Entwurf führen würden, erwarte die Bundesregierung, daß die USA gemäß früherer Zusagen einen eigenen „realistischen westlichen Entwurf" vorlegen werde, der die zivilen Nuklearindustrien nicht mit Kontrollen diskriminiere.

Pauls berichtet über ein Gespräch mit dem israelischen Ministerpräsidenten. Eshkol erklärte, daß er dem Wunsch der Bundesregierung nicht entsprechen könne, auf die Besichtigung der Altstadt von Jerusalem durch den ehemaligen Bundeskanzler Erhard während dessen Besuch in Israel zu verzichten. Er ging auf den Vorschlag von Pauls ein, in einem persönlichen Telegramm an Erhard um Verschiebung der Reise zu bitten. Während Eshkol „betont konziliant“ sprach, brachte sein Kabinettschef "Schärfen ins Gespräch“. Das Auswärtige Amt habe seine Einwände erst erhoben, seitdem der Besuch des jordanischen Königs Hussein in Bonn bevorstehe. Pauls war sich mit Eshkol darüber einig, daß gegenüber der Presse Zurückhaltung angebracht sei und „störende Auswirkungen auf den so befriedigenden Stand der Beziehungen" vermieden werden müßten.

Knoke teilt Einzelheiten eines Gesprächs mit dem niederländischen Außenminister vom Vortag mit. Luns bezeichnete die französische Haltung zu einem britischen EG-Beitritt auf der Tagung vom 23./24. Oktober 1967 in Luxemburg als „de factoVeto". Es sei symptomatisch, daß diese Frage bei den Gesprächen zwischen Bundesminister Brandt und dem französischen Außenminister Couve de Murville am 16./17. Oktober 1967 in Paris offenbar nicht erörtert worden sei: Sehe so die deutschfranzösische Zusammenarbeit aus, „wie sie der Elysée-Vertrag stipuliere"? Auch der Zeitpunkt der außenpolitischen Debatte im Bundestag am 13. Oktober 1967 vor der Ministerratstagung sei nicht glücklich gewählt gewesen. Denn die dort geäußerte Absicht der Bundesregierung, Frankreich nicht unter Druck zu setzen, habe Staatspräsident de Gaulle ermutigt, „seine Forderungen noch höher zu schrauben". Luns kündigte an, den britischen EG-Beitritt und, damit verbunden, die politische $\mathrm{Zu}$ sammenarbeit der Gemeinschaft zu beschleunigen. Sollte dies nicht bald möglich sein, „sei die Entwicklung zum Nationalismus in Europa nicht mehr aufzuhalten“. 

König Hussein von Jordanien

Hussein legt die arabische Position im Nahost-Konflikt dar. Es sei nicht beabsichtigt, die Krise zum Gegenstand des Ost-WestGegensatzes zu machen. Kiesinger bedauert das Versäumnis der EG, ihre Kräfte im Sinne einer politischen Lösung zusammenzuschließen. Hussein führt die Unruhen in den besetzten Gebieten auf die „harte und rücksichtslose Behandlung durch die Israelis" ${ }^{4}$ zurück. Die Situation der palästinensischen Flüchtlinge sei sehr ernst, zumal der Winter in diesem Jahr sehr früh eingebrochen sei. Kiesinger widerspricht dem von Hussein wiedergegebenen Eindruck, daß die UdSSR bereit sei, an einer friedlichen Lösung des Konflikts mit den USA mitzuarbeiten. Abschließend bekräftigt der König, daß eine generelle Regelung nur bei einem israelischen Rückzug hinter die Waffenstillstandslinien vom 5. Juni 1967 möglich sei.

Schnippenkötter erörtert den Entwurf eines Schreibens der Drei Mächte, mit dem die sowjetische Protestnote vom 15. Oktober 1967 gegen die parlamentarische Arbeitswoche des Bundestages in Berlin (West) vom 16. bis 20. Oktober 1967 zurückgewiesen werden soll. Der Entwurf sei erst nach „zähen Verhandlungen" zwischen den Drei Mächten und im Rahmen der Bonner Vierergruppe entstanden. Die französische Botschaft habe erst nach wiederholten Rückfragen in Paris den von Bundesminister Brandt neu vorgeschlagenen Satz akzeptiert, wonach die Drei Mächte anerkennen, daß die Bundesrepublik für das Wohlergehen und die Lebensfähigkeit von Berlin (West) Verantwortung trage. Dieser Bestätigung des „politischen Gesamtzusammenhangs" komme vor allem deshalb besondere $\mathrm{Be}$ deutung zu, weil keine rechtliche Verbindung zwischen der Arbeitswoche des Bundestages und der Fürsorge der Bundesrepublik für die Lebensfähigkeit von Berlin (West) bestehe.

Lankes erörtert Möglichkeiten einer weiteren Ausgestaltung des Angebots auf Gewaltverzicht an die Ostblock-Staaten. Das sowjetische Memorandum vom 12. Oktober 1967 habe den unverhüllten Versuch der UdSSR gezeigt, über die Bereitschaft der Bundesregierung zum Austausch von Gewaltverzichtserklärungen die völkerrechtliche Anerkennung der DDR zu erreichen. Die „offenbar unumgängliche direkte Beteiligung Ostberlins “ könne erleichtert werden, wenn die Gleichbehandlung der DDR weniger auf die Form als auf den Inhalt ausgerichtet würde. Dabei müsse es jedoch immer klar erkennbar sein, daß der andere Teil Deutschlands für die Bundesrepublik kein Ausland sei. Dies sei möglich, wenn nicht nur für die DDR eine Sonderkategorie gebildet, sondern auch unter den anderen Adressaten eine Differenzierung beim Gewaltverzichtsangebot getroffen würde. Lankes schlägt unterschiedliche Angebote vor 
und empfiehlt, die Bundesregierung möge damit gegenüber den Ostblock-Staaten sowie gegenüber den verbündeten und den ungebundenen Staaten so gut wie möglich „Politik“ machen.

Schnippenkötter informiert darüber, daß nunmehr die ersten drei Kapitel der „Studie über eine Reduzierung der Streitkräfte der NATO im Bereich Europa-Mitte" vorliegen, die von einer Arbeitsgruppe des Generals a.D. Heusinger verfaßt worden seien. Die Studie behandele den Abbau der militärischen Konfrontation in Europa durch eine ausgewogene und schrittweise Verminderung der Streitkräfte auf beiden Seiten der „Demarkationslinie“. Durch die Reduzierung insbesondere der ausländischen Streitkräfte in beiden Teilen Deutschlands könnte der Status quo in Mitteleuropa aufgelockert, der Resignation in der Bevölkerung der DDR entgegenwirkt und die finanziellen Probleme der Truppenstationierung , an der Wurzel ${ }^{“}$ gepackt werden. Die NATO solle sich baldmöglichst mit dem Thema befassen, um über untereinander abgestimmte Vorschläge zu verfügen und der Öffentlichkeit ihre Entspannungsbereitschaft unter Beweis stellen zu können. Insgesamt gebe die Studie der Bundesregierung einen Planungsvorsprung, um die Richtung der Diskussion in der NATO zu beeinflussen.

Schnippenkötter kennzeichnet die Haltung der Bundesregierung gegenüber dem amerikanischen Engagement in Vietnam als zurückhaltend bekundete Solidarität. Dauer und Verlauf des Krieges ließen die Glaubwürdigkeit amerikanischer Verpflichtungen im öffentlichen Bewußtsein zweifelhaft erscheinen. Das Vertrauen in die Zusage für die Sicherheit Europas sei nicht abhängig von der Fortführung der Luftangriffe in Vietnam. Den USA solle daher mitgeteilt werden, daß die Bundesregierung im Hinblick auf eine erfolgreiche Entspannungspolitik in Europa ein besonderes Interesse an der Beendigung des Krieges habe, damit die sowjetische Regierung auf etwaige Vorschläge zu Truppenverminderungen zwischen NATO und Warschauer Pakt eingehe. Grundsätzlich gehe es zu weit, wenn von amerikanischer Seite erklärt werde, daß der VietnamKrieg „gewissermaßen Deutschlands wegen geführt“ werde. Auswärtige Amt

Mez berichtet von einem Gespräch mit dem ehemaligen sudanesischen Informationsminister. Daoud erklärte, daß Ministerpräsident Mahgoub einen Botschafteraustausch mit der Bundesrepublik nicht erst aufgrund eines gemeinsamen Beschlusses der Arabischen Liga vornehmen wolle. Vielmehr sehe er sich nunmehr in der Lage, die abgebrochenen diplomatischen Beziehungen sofort wiederaufzunehmen; jedoch müsse zuvor ein geeigneter Zeitpunkt gefunden werden. Die sudanesische Regierung sei außerdem vom Verlauf der Verhandlungen mit 
dem Ostblock über finanzielle Hilfe enttäuscht. Maghoub glaube daher, daß nur mit der Bundesrepublik und Großbritannien diplomatische Beziehungen wiederaufgenommen werden könnten. Mez regt an, eine geeignete Persönlichkeit zu Sondierungsgesprächen nach Khartum zu entsenden.

\section{Klasse Klarenaar}

Klarenaar äußert sich zum amerikanischen Vorschlag vom 29. September 1967, die Embargolisten für Ausfuhren in die kommunistischen Staaten Asiens zu erweitern und gleichzeitig für Exporte in die europäischen Ostblock-Staaten zu kürzen. Der Vorsto $\beta$ stehe in Zusammenhang mit dem Nuklearprogramm der Volksrepublik China, das nach amerikanischer Auffassung schneller als erwartet fortschreite. China werde in Kürze über Mittelstreckenraketen und Anfang des nächsten Jahrzehnts über Interkontinentalraketen verfügen. Die amerikanische Botschaft in Bonn habe eine vorläufige Liste mit Waren, die künftig einem Ausfuhrverbot unterliegen sollten, mit der Bitte um Prüfung und Ergänzung übergeben. Staatssekretär Lahr habe in einem Schreiben vom 23. Oktober 1967 das Verständnis der Bundesregierung für den amerikanischen Vorschlag zum Ausdruck gebracht, sich gleichzeitig jedoch eine endgültige Stellungnahme vorbehalten.

Bahr reagiert auf eine Bemerkung des Bundeskanzlers Kiesinger, der soeben auf einer Pressekonferenz die völkerrechtliche Anerkennung der DDR als Voraussetzung für den Austausch von Gewaltverzichtserklärungen mit der UdSSR abgelehnt habe. Bahr vermerkt dazu für Bundesminister Brandt, daß die Glaubwürdigkeit der gesamten Ostpolitik nun in Frage gestellt sein könnte. Der Dialog mit der UdSSR dürfe keinesfalls öffentlich oder nichtöffentlich abgelehnt oder sogar abgebrochen werden. Kiesinger könne dies nicht ohne Beteiligung des Bundesministers des Auswärtigen oder gar gegen dessen Willen festlegen. Er regt an, einen Brief an den Bundeskanzler zu richten und in der Öffentlichkeit deutlich zu machen, daß das Gespräch mit der UdSSR weitergeführt werde.

Brandt bittet, Ministerpräsident Eshkol mündlich mitzuteilen, daß der Besuch des ehemaligen Bundeskanzlers Erhard nach Israel die Zustimmung der Bundesregierung finde. Sie wolle jedoch den Eindruck einer Festlegung bezüglich des Status der Gebiete, die von Israel besetzt seien, vermeiden. Der Aufenthalt des Königs Hussein in der Bundesrepublik habe in diesem Zusammenhang keine Rolle gespielt. Die nunmehr gefundene Lösung, daß Erhard die Altstadt von Jersualem als Pilger besuche, könne von beiden Seiten als befriedigend angesehen werden. 
383

\subsection{Botschafter Freiherr von Braun, New York (UNO), an} das Auswärtige Amt

Braun informiert über ein Gespräch mit dem rumänischen Stellvertretenden Außenminister. Malitza betonte, daß die Politik zwischen Ost und West langfristig angelegt sein müsse. Zudem erklärte er, daß die UdSSR für die Anwesenheit amerikanischer Streitkräfte in Europa "dankbar" sei, weil damit der Vorwand für die weitere Präsenz sowjetischer Truppen und für die Kontrolle in den osteuropäischen Staaten gegeben sei. Die Hallstein-Doktrin habe nicht nur das "Anlehnungsbedürfnis“ der DDR an die sowjetische Seite, sondern auch den Wunsch der UdSSR nach Festigung ihrer dortigen Position verstärkt. Allerdings gebe es in der DDR Tendenzen, sich von dieser Abhängigkeit langsam zu lösen. Voraussetzung sei allerdings, daß sich die Bundesregierung nicht länger weltweit den Bestrebungen der DDR um die Anerkennung als Staat widersetze.

03.11. Botschafter Grewe, Brüssel (NATO), an das Auswärtige Amt

Grewe berichtet über eine Sitzung der Arbeitsgruppe für $\mathrm{Nu}-$ kleare Planung der NATO. Eine Übereinkunft hinsichtlich des Verfahrens zur Fertigstellung einer Studie über ein europäisches Raketenabwehrsystem sei erzielt worden. Zunächst solle SHAPE um einen mündlichen Vortrag über zusätzliche Luftverteidigungsmaßnahmen gebeten werden. Darüber hinaus seien Informationen über flankierende Zivilverteidigungsmaßnahmen für ein ABM-System einzuholen. Alle übrigen Teilfragen sollten jedoch von der Arbeitsgruppe selbst erarbeitet werden.

Harkort vermerkt, daß bislang noch keine Antwort auf die sowjetische Note vom 15. August 1967 zur Aufnahme von Luftverkehrsverhandlungen über eine Verbindung zwischen Frankfurt/Main und Moskau ergangen sei, um den Eindruck ,unangemessener Eile“ zu vermeiden und den Drei Mächten die Abfassung einer Stellungnahme zu ermöglichen. Als Ergebnis der Verhandlungen solle eine Streckenführung über Eger, mit der die amerikanische, britische und französische Regierung einverstanden seien, erreicht werden. Dabei werde sich zeigen, ob die von der UdSSR angestrebte Verbindung über Berlin vornehmlich politischen Interessen diene. In der Stellungnahme der Drei Mächte vom 24. Oktober 1967 seien keine Einwände gegen Verhandlungen mit der UdSSR gemacht worden. Jedoch sei die Bundesregierung gebeten worden, die Möglichkeit der Benutzung einer Luftstraße nach Berlin nicht zu erwähnen. Auswärtige Amt

Grewe übermittelt die Besorgnis des Vorsitzenden des Ausschusses für Verteidigungserhebung über die Stellungnahme des Militärausschusses zur NATO-Strategie (MC 14/3). Hockaday 
habe den Eindruck gewonnen, daß darin einige „bedenkliche Formulierungen" enthalten seien, die in der politischen Direktive der Verteidigungsminister vom Mai 1967 nicht zu finden wären. Die Komplexität der Abschreckung sei durch Einführung von Prioritäten zwischen den Stufen Direkt-Verteidigung, bewußte Eskalation und allgemeiner nuklearer Einsatz aufgehoben worden; dadurch werde das Risiko für einen potentiellen Gegner berechenbar. In Ermangelung realistischer Alternativen sollte zwar die MC 14/3 auf der NATO-Ministerratstagung am 13./14. Dezember 1967 in Brüssel angenommen werden. Sie sei aber dahingehend schriftlich zu interpretieren, daß amerikanische Truppen, die aus Europa rückzuverlegen seien, dennoch weiterhin als der NATO unterstellt bezeichnet würden. Zudem sollten die Formulierungen der Eskalationsstufen im Sinne der politischen Direktive verbessert werden. Auswärtige Amt

Grewe berichtet über eine Sitzung der Studiengruppe zur Untersuchung der zukünftigen Aufgaben der Allianz (,Special Group"). Der französische Botschafter bei der NATO deutete an, daß seine Regierung auf der NATO-Ministerratstagung am 13./14. Dezember 1967 in Brüssel keiner weitergehenden Erklärung zur Situation des Bündnisses zustimmen werde. Ferner betonte Roger Seydoux, daß auch die Bildung neuer ständiger Arbeitsgruppen von Frankreich nicht unterstützt werde. Unter Wiederholung aller Zweifel und Bedenken stimmte er schließlich der Abfassung eines Berichtsentwurfs durch NATO-Generalsekretär Brosio zu. Staatspräsident de Gaulle wolle keine Beschlüsse, die „das Gesicht der NATO so veränderten, daß er sie hinterher nicht wiedererkennen könne". Grewe weist darauf hin, daß der Verlauf der Sitzung einen Vorgeschmack auf die Schwierigkeiten gegeben habe, die von französischer Seite in Zusammenhang mit der Studie über die zukünftigen Aufgaben der Allianz (Harmel-Studie) noch zu erwarten seien. indischen Botschafter Chand

Kiesinger und Chand erörtern den Stand der bilateralen Beziehungen, die künftige Rolle der Volksrepublik China in Asien und die Situation in Indien. Chand erklärt, daß er den Wunsch der Bundesregierung nach Wiedervereinigung unterstütze. $\mathrm{Zu}$ dem führt er aus, daß Indien einen seiner Größe entsprechenden Anteil an Entwicklungshilfe von der Bundesrepublik er-

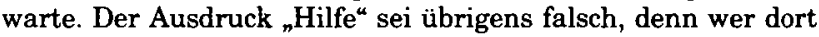
investiere, werde selbst den größten Nutzen haben. Kiesinger drückt die Bereitschaft aus, Indien im Rahmen des Möglichen weiterhin zu unterstützen. 
389

390

391

10.11. Gespräch des Bundeskanzlers Kiesinger mit dem ceylonesischen Botschafter Peiris

Peiris erläutert ein Entwicklungsprogramm für Nahrungsmittel, das in den kommenden Jahren die Selbstversorgung Ceylons mit Reis, Kartoffeln und Zwiebeln erhoffen lasse. Der Erfolg sei abhängig von Devisen für die Errichtung von Fabriken zur Konservierung und für den Kauf moderner Maschinen zur Tiefkühlung. Die Ernährungslage sei ein politischer Faktor, da die nächsten Wahlen das „Ende der Demokratie“ in Ceylon bedeuten könnten. Kiesinger verweist auf die Rezession in der Bundesrepublik und erklärt, daß die bevorstehenden Gespräche für weitere Überlegungen zur Entwicklungshilfe nützlich sein werden.

\subsection{Gesandter von Lilienfeld, Washington, an das} Auswärtige Amt

Lilienfeld übermittelt Informationen des amerikanischen Außenministeriums zu einem Nichtverbreitungsabkommen. Die USA gehen davon aus, daß die DDR kein Staat sei, und versuchen daher, jegliche internationale Aufwertung zu verhindern. Daher würde bei einer Hinterlegung der Ratifikationsurkunde der DDR in Moskau ein Vorbehalt einlegt werden. Falls die DDR dennoch versuche, ein Junktim zwischen einem mit der IAEO auszuhandelnden Kontrollabkommen und ihrer Mitgliedschaft in der IAEO herzustellen, werde die amerikanische Regierung dem nicht nachgeben. Vielmehr wollen die USA dann auf eine Kontrolle der DDR durch die IAEO verzichten, da die Verwendung von spaltbarem Material zur Waffenherstellung dort angesichts der ,tatsächlichen sowjetischen Kontrolle" kaum zu befürchten sei.

\subsection{Gespräch des Bundeskanzlers Kiesinger mit dem französischen Botschafter François Seydoux}

Kiesinger spricht Fragen an, die in Zusammenhang mit einem möglichen britischen EG-Beitritt stehen. Dem Wunsch Frankreichs folgend, sei zunächst eine interne Diskussion der Mitgliedstaaten anzustreben. Doch sei zu erörtern, wie lange eine solche Phase dauern solle und ob nicht parallel Gespräche zwischen Beamten der EG-Kommission und britischen Experten stattfinden könnten. Seydoux erinnert an die jüngsten Maßnahmen zur Stützung der britischen Währung und erwidert, daß Großbritannien zuerst seine „Angelegenheiten in Ordnung" bringen müsse. Der Bundeskanzler sieht wie Staatspräsident de Gaulle in der Bildung einer ,atlantischen Union" mit den USA keine Lösung für Europa. Er schlägt vielmehr mit Blick auf einen britischen EG-Beitritt folgendes Verfahren vor: zunächst Aufnahme von Verhandlungen, damit sich neue Gesichtspunkte und Fragestellungen ergäben, anschließend Beratungen, damit die Meinungsbildung innerhalb der Mitgliedstaaten stattfinden könne. Der Botschafter erklärt vertraulich, es sei damit zu rechnen, daß sich die französische Regierung weiterhin ablehnend verhalten werde. 
Diehl faßt die Besprechungen der Planungsstäbe der Bundesrepublik, Großbritanniens und der USA vom 30 . Oktober bis 1 . November 1967 in Washington zusammen. Dabei hätten die Sicherheit in Europa und die Deutschland-Frage im Zentrum gestanden. Mit der amerikanischen und britischen Seite habe Einvernehmen darüber bestanden, daß eine Auflösung der beiden Bündnissysteme abzulehnen sei. Die Erkenntnis sei vielmehr gewachsen, daß ein europäisches Sicherheitssystem am besten durch Vereinbarungen zwischen den Bündnissen begründet werden könne. Es seien jedoch die Nachteile solcher Übereinkommen mit dem Warschauer Pakt „schärfer“ erkannt worden, welche die Handlungsfreiheit innerhalb der NATO einschränkten sowie in deren Struktur eingriffen. Der Entwurf einer künftigen europäischen Friedensordnung könnte dem „kommunistischem Programm" entgegengestellt werden. Zur Studie über die zukünftigen Aufgaben der Allianz (HarmelStudie) könnten die Regierungen der Mitgliedstaaten erklären, daß sie nützlich sei; sie habe gezeigt, daß die NATO keineswegs inhaltslos geworden sei oder nach einer neuen Aufgabe suchen müsse.

Lahr nimmt Stellung zu einem Drahtbericht des Botschafters Klaiber, Paris, der auf Weisung des Bundeskanzlers Kiesinger erstellt und zeitgleich dem Auswärtigen Amt und dem Bundeskanzleramt zugeleitet worden sei. Auf diese Weise sei es Bundesminister Brandt nicht möglich gewesen, zuvor Einblick in den Drahtbericht und Stellung zu nehmen. Dies sei gravierend, da die von Klaiber bewertete französische Haltung zu einem britischen EG-Beitritt nicht "unbeträchtlich" von der Auffassung des Bundesministers abweiche. Insbesondere halte Brandt im Unterschied zu Klaiber die französischen Forderungen nach einer Einigung der sechs Mitgliedstaaten noch vor Aufnahme von Verhandlungen und nach vorab einzuleitenden wirtschaftspolitischen Maßnahmen in Großbritannien für unannehmbar. Eine Annahme solcher Forderungen würde dazu führen, daß es auf absehbare Zeit nicht zu Verhandlungen mit Großbritannien käme. Lahr ist besorgt, daß die Darstellung der Politik der Bundesregierung durch die Botschaft in Paris „aus der Sicht der Zentrale unter diesen Umständen zu wünschen übrig lassen könnte“.

Lahr beurteilt die französischen "préalables“ für einen Beitritt Großbritanniens zu den Europäischen Gemeinschaften. Neu hinzugekommen sei die Agrarfinanzierung, die nun vor einer Erweiterung festgelegt werden solle. Frankreich sehe der Neuregelung dieser Frage im Jahr 1969 wegen befürchteter Einnahmeausfälle für die eigene Landwirtschaft und aufgrund des provisorischen Charakters der derzeitigen Vereinbarungen "mit großer Sorge" entgegen. Auf die französische Forderung 
könne jedoch angesichts kaum abzuschätzender Lasten, die eine unbefristete Agrarfinanzierung für die Bundesrepublik nach sich ziehen würde, nicht eingegangen werden. Dies gelte um so mehr, als jede Regelung ohne Einigung nur „Stückwerk“ bleiben müsse.

Zarapkin fragt, ob die Äußerungen des Bundeskanzlers Kiesinger auf der Pressekonferenz vom 3. November 1967 als Antwort auf das Memorandum der sowjetischen Regierung vom 12 . Oktober $1967 \mathrm{zu}$ betrachten seien. Brandt antwortet, daß Kiesinger zweimal die Frage eines Austausches von Gewaltverzichtserklärungen aufgegriffen habe. Allerdings seien die Bemerkungen von der Presse nicht ganz korrekt wiedergegeben worden. Die Bundesregierung beabsichtige nicht, beim Austausch von Gewaltverzichtserklärungen „das Problem der Existenz von zwei Teilen Deutschlands" auszuklammern. Auch für die DDR müsse es in prinzipiellen Fragen gleiche Bedingungen geben, doch seien Umstände, die sich aus der "Geographie und sonstigen Faktoren" herleiten ließen, zu beachten. Der Botschafter überreicht Entwürfe für Gewaltverzichtserklärungen zwischen der Bundesrepublik und der UdSSR.

Harkort faßt die Ergebnisse eines am Vortag geführten Gesprächs mit britischen Sachverständigen über die Frage des Devisenausgleichs zusammen. Es habe Übereinstimmung darüber bestanden, der neuen britischen Konzeption des Devisenausgleichs zu folgen und gemeinsame Projekte im militärischen und zivilen Bereich innerhalb eines Zeitraumes von fünf Jahren zu fördern. Dabei scheide die Möglichkeit aus, daß die Bundesrepublik Vorauszahlungen für ein allgemeines Programm ohne konkrete Bindungen leiste. Der Devisenausgleich sei damit von britischer Seite ausdrücklich als Nebenprodukt der technologischen Zusammenarbeit im militärischen und zivilen Bereich genannt worden.

Ne Win gibt eine Einschätzung über die Verhältnisse in der Volksrepublik China, von der Birma nicht beherrscht werden wolle. Seit Juni 1967 seien die gegenseitigen Beziehungen gestört, da die birmanischen Kommunisten „blindlings" den Anordnungen aus der Volksrepublik China gefolgt seien und die Kulturrevolution zu kopieren versucht hätten. Birma betreibe jedoch eine Politik der Neutralität und wolle seine eigenen Entscheidungen treffen. Kiesinger legt insbesondere die Ostpolitik der Bundesregierung dar. Falls es zur Aufnahme von diplomatischen Beziehungen mit weiteren osteuropäischen Staa- 
ten einschließlich Jugoslawiens kommen sollte, könne sich eine Kettenreaktion der Anerkennung der DDR durch dritte Staaten als „vernichtend" für die Friedenspolitik der Bundesregierung erweisen. Ne Win betont, daß geteilte Staaten für Birma mittelbar ein Problem seien. Im kulturellen und wirtschaftlichen Bereich sei gelegentlich eine Zusammenarbeit mit beiden Teilen erforderlich. Er sei darauf bedacht, in keiner Weise ${ }_{n}$ die eine oder andere Partei gegen sich einzunehmen".

Loeck berichtet über Verhandlungen der Delegation eines Firmenkonsortiums aus der Bundesrepublik mit der Kroatischen sowie der Slowenischen Rundfunk- und Fernsehanstalt. Für den Aufbau eines zweiten Fernsehnetzes sei Jugoslawien die Gewährung eines Kredits mit einer Laufzeit von zehn Jahren in Aussicht gestellt worden. Im Wettbewerb mit dem französischen SECAM-System werde aus technischen Erwägungen das in der Bundesrepublik entwickelte PAL-System vorgezogen. Allerdings müßten die kommerziellen Bedingungen angemessen seien. Loeck regt daher an, einen Kredit mit einem Zinssatz von nicht mehr als drei Prozent sowie die erforderliche Hermes-Bürgschaft endgültig zuzusagen. Auswärtige Amt

Mirbach informiert über die beiden Gespräche des Bundeskanzlers Kiesinger mit Ministerpräsidentin Gandhi am 20./21. November 1967. Kiesinger habe sich nach der möglichen Reaktion Indiens auf eine Wiederaufnahme der diplomatischen Beziehungen zwischen der Bundesrepublik und Jugoslawien erkundigt. Ferner habe er die Hoffnung ausgesprochen, daß vor allem die Staaten der Dritten Welt die Entspannungspolitik der Bundesregierung nicht durch eine Aufwertung der DDR "stören" würden. Erst im zweiten Gespräch sei Gandhi darauf eingegangen und habe erklärt, daß die indische Regierung ihre Deutschlandpolitik nicht ändern werde. Gleichzeitig habe sie hinzugefügt, daß die indische Regierung „etwas mit ihrer eigenen Vertretung in Ost-Berlin tun müsse“. Allerdings sei sie nicht darüber informiert gewesen, ob und wann es zu einer Veränderung komme.

Schlitter berichtet über die Reaktion des griechischen Außenministers auf das Vermittlungsangebot des Bundesministers Brandt in der Zypern-Krise. Pipinelis habe auf das Angebot positiv reagiert und die Hoffnung ausgedrückt, da $B$ die Bundesregierung auf die türkische Regierung einwirke, um sie von den Bemühungen um eine friedliche Lösung zu überzeugen. Alle Vorschläge für eine friedliche Regelung der Streitfragen seien von der Türkei abgelehnt worden. Statt dessen verlange sie als Vorbedingung für eine Aufnahme von Gesprächen einen 
vorherigen Abzug der griechischen Truppen aus Zypern. Diese Forderung komme für Griechenland aber einer nationalen „Erniedrigung“ gleich.

Duckwitz faßt ein Gespräch des Bundesministers Brandt mit dem sowjetischen Botschafter Zarapkin vom 24. November 1967 zusammen. Brandt sagte eine Prüfung des Memorandums vom 21. November $1967 \mathrm{zu}$ und betonte, daß die Bundesregierung mit allen Mitgliedern des Warschauer Pakts Gewaltverzichtserklärungen austauschen wolle; dies gelte auch für die DDR. Da jedoch die bilateralen Verhältnisse von unterschiedlicher Struktur seien, müßten hierfür unterschiedliche Formen gefunden werden. Zudem erwäge die Bundesregierung eine Normalisierung der Beziehungen zu Jugoslawien. Zarapkin reagierte darauf mit der "vorsichtig formulierten Unterstellung", daß die Bundesrepublik eine Abwertung der DDR in Jugoslawien beabsichtige.

Ruete resümiert den Stand der Verhandlungen über ein Nichtverbreitungsabkommen für die nächste Sitzung des Bundeskabinetts. Er weist darauf hin, daß die entscheidenden Gespräche zwischen den USA und der UdSSR stattfänden und die Konferenz der 18-Mächte-Abrüstungskommission in Genf lediglich als Kulisse angesehen werden müsse. Angesichts der vorliegenden Entwürfe für Artikel III (Kontrollartikel) sei es wenig wahrscheinlich, daß ein von seiten der Bundesregierung gewünschtes Verifikationsabkommen zwischen EURATOM und IAEO erreicht werde, zumal die UdSSR unverhüllt IAEOKontrollen für alle nichtnuklearen Staaten fordere. Die USA neigten in Genf dazu, auf die sowjetischen Wünsche einzugehen. Innerhalb der amerikanischen Regierung werde darüber debattiert, ob einerseits eine Einigung mit der UdSSR unter Inkaufnahme weiterer Erosionen innerhalb der NATO anzustreben sei oder ob andererseits die Erhaltung und Festigung des europäischen Besitzstandes und des westlichen Zusammenhalts vorzuziehen sei. Ruete regt daher an, Bundeskanzler Kiesinger solle an Präsident Johnson appellieren, nichts zu tun, was die Bundesregierung „verletzen“ könnte.

Ruete gibt ein Gespräch mit dem rumänischen Botschafter über die Einbeziehung von Berlin (West) in ein Kulturabkommen wieder. Oancea betonte, daß anläßlich der Aufnahme der diplomatischen Beziehungen der Rahmen „in allen Bereichen“ festgesetzt worden sei. Eine darüber hinausgehende Erklärung könne die rumänische Regierung nicht abgeben. Vielmehr sollten beide Seiten die jeweiligen Rechtsstandpunkte respektieren. Ruete regte die Abgabe einer einseitigen schriftlichen Stellungnahme durch die Bundesregierung an. Darin solle zum Ausdruck gebracht werden, daß die bisherige Praxis auf dem 
Gebiet der Kulturbeziehungen ihre Fortsetzung finde. Darauf erwiderte Oancea, daß die rumänische Regierung keine Bedenken gegen den „internen Gebrauch“ einer solchen Erklärung habe.

Pauls hält Pressemeldungen in der Bundesrepublik mit einem Vergleich der Situation des geteilten und neu vereinten Jerusalem und des geteilten Berlin für bedenklich. Er regt an, solchen oberflächlichen Vergleichen entgegenzuwirken.

Bahr nimmt Stellung zu der von Ministerialdirektor Ruete am Vortag vorgeschlagenen Haltung hinsichtlich eines Nichtverbreitungsabkommens. Er regt an, daß sich das Bundeskabinett auf der nächsten Sitzung auf das Prinzip eines einheitlichen Vorgehens der EURATOM-Mitgliedstaaten in der Frage des Artikels III (Kontrollartikel) verständige. Zugleich sei mit Blick auf eine zeitliche Befristung des Abkommens von einem Schreiben des Bundeskanzlers Kiesinger an den amerikanischen Präsidenten abzuraten. Denn durch einen solchen Alleingang werde die Gefahr der Isolierung „eklatant“. Die Ständigen Vertretungen bei der NATO in Brüssel sowie bei den internationalen Organisationen in Genf sollen angewiesen werden, sich vorerst jeder Stellungnahme zu Artikel III (Kontrollartikel) zu enthalten. an die Botschaft in Washington

Puttkamer weist die Botschaft in Washington an, im amerikanischen Außenministerium Bedenken bezüglich der vorgesehenen Beitrittsregelung zu einem Astronautenbergungsabkommen vorzubringen. Die in Aussicht genommene Allstaatenklausel biete in Verbindung mit der Hinterlegung der Ratifikationsund Beitrittsurkunden sowohl in den USA als auch in der UdSSR als auch in Großbritannien keinen vollwertigen Ersatz für die bisher verwandte "Wiener Formel ${ }^{4}$, die eine einseitige Beitrittserklärung der DDR zu multilateralen völkerrechtlichen Verträgen verhindere. Sollte die amerikanische Regierung auf der Allstaatenklausel bestehen, müßten zumindest die vorgesehenen drei Depositare gewahrt werden, damit eine Hinterlegung seitens der DDR nur dort möglich sei, wo sie „ohnehin als Staat angesehen" werde.

Lahr formuliert die Zielsetzungen der Bundesregierung für eine Erweiterung der Europäischen Gemeinschaften. Zuerst sei unter den Mitgliedstaaten eine gründliche Erörterung notwendig, die möglichst auf der EG-Ministerratstagung am 18./19. Dezember 1967 in Brüssel abgeschlossen werden solle. Sodann sei mit Großbritannien Kontakt aufzunehmen. Die Gespräche soll- 
ten so geführt werden, daß ein Beitritt - ohne Zwischenregelungen auszuschließen - erzielt werde. Frankreich solle nicht im unklaren darüber gelassen werden, daß die Bundesregierung dem Konzept der „Zementierung“ der Europäischen Gemeinschaften vor weiteren Beitritten nicht folgen könne. Vielmehr seien definitive Lösungen nur in Verbindung mit einer Erweiterung zu akzeptieren.

Harkort spricht sich gegen die Lieferung von 80 Mörsern samt Munition nach Nigeria aus, obwohl die Politische Abteilung I des Auswärtigen Amts angeregt habe, gemäß britischer Empfehlungen im Politischen Ausschuß der NATO Anträge auf Lieferung von Munition und "leichten Waffen" wohlwollend von Fall zu Fall zu prüfen; die Zentralregierung in Lagos sei demnach in ihrem Kampf gegen die Sezessionsversuche Biafras, das von keiner afrikanischen oder sonstigen Regierung anerkannt worden sei, zu unterstützen. Harkort macht hingegen darauf aufmerksam, daß die Lieferung nicht geheimgehalten werden könnte.

Frank stellt fest, daß der EG-Beitritt Großbritanniens und anderer beitrittswilliger Staaten Ziel der Gemeinschaft bleiben müsse. Das politische und wirtschaftliche Interesse hieran könne auch nicht durch die Pressekonferenz des französischen Staatspräsidenten vom 27. November 1967 entkräftet werden, zumal de Gaulle wirtschaftliche Gegenargumente zum größten Teil nur vorgeschoben habe. Für die negative Haltung sei ausschlaggebend, daß Frankreich die ungeteilte Führungsrolle in Europa anstrebe. Frank regt einen Vertrag zwischen den sechs Mitgliedstaaten und Großbritannien über die Vorbereitung des Beitritts an, der die notwendige wirtschaftliche Sicherheit und die erforderliche politische Beruhigung in Europa schaffen könne. I. Klasse Gehlhoff

Gehlhoff faßt Gespräche des Bundesministers Wischnewski mit dem algerischen Außenminister am 26./27. November 1967 in New York zusammen. Bouteflika regte an, Algerien bei der Wiederaufnahme der diplomatischen Beziehungen der Bundesrepublik zu den arabischen Staaten künftig zum Schwerpunkt der Bemühungen zu machen. Die Bundesregierung wäre falsch beraten, eine "politique d'érosion" gegenüber der arabischen Welt betreiben zu wollen. Wischnewski betonte, daß die Bundesregierung in keiner Weise beabsichtige, die arabischen Staaten gegeneinander auszuspielen. Bouteflika erklärte, daß Algerien Anfang 1967 Kapitalhilfe aus der DDR abgelehnt habe. Dies müsse anerkannt werden. Wischnewski sagte finanzielle und technische Hilfe für die Zeit nach einem Botschafteraustausch zu. 
Groepper informiert über ein Gespräch mit dem türkischen Außenminister vom Vortag. Angesichts der Entwicklung der Zypern-Krise erklärte Çaglayangil, daß sich die Zyprioten türkischer Abstammung in einer Situation befänden, die der von „Schlachtvieh vergleichbar sei, das im Schlachthaus zur Schlachtung" bereitstehe. Eine Erklärung der griechischen Regierung, im Prinzip mit einem Abzug der illegal auf der Insel stationierten Truppen einverstanden zu sein, besage gar nichts. Der Abzug müsse sofort erfolgen. Zur Bemessung eines dafür „vernünftigen" Zeitraumes seien nur technische Gesichtspunkte ausschlaggebend. Falls Maßnahmen zum Schutz der türkischen Volksgruppe ausblieben, werde die Türkei Soldaten nach Zypern entsenden.

Der Staatssekretär resümiert sein Gespräch mit den Botschaftern der Drei Mächte. Es bestand Übereinstimmung darin, daß das unfreundliche Verhalten des sowjetischen Botschafters in Ost-Berlin gegenüber McGhee und Roberts auf neue Weisungen aus Moskau zurückzuführen sei. Vermutlich solle Abrassimow den Kontakt auf das Notwendigste beschränken, um dadurch die Position der DDR zu stärken und deren Befürchtung entgegenzuwirken, der Westen wolle mittels einer „Salamitaktik" engere Beziehungen zwischen Berlin (West) und der Bundesrepublik herstellen. Es sei gleichermaßen verwunderlich, daß die in Schreiben der Bundesminister Dollinger und Leber bekundete Bereitschaft zu Gesprächen über die von der DDR erbrachten Mehrleistungen im innerdeutschen Postverkehr sowie über eine Neuregelung des Güterverkehrs zurückgewiesen worden sei. Es stelle sich allerdings die Frage, „ob die SBZ bei einem solchen Verhalten nicht ihre Karte uberspielt". Die drei Botschafter sprachen schließlich die Bitte aus, auf die vom Bundesministerium der Finanzen vorgesehene Kürzung der Bundeshilfe für den Luftreiseverkehr nach Berlin (West) zu verzichten, da sonst mit einem Rückgang der Berlin-Besucher gerechnet werden müsse.

Frank berichtet, daß der Generaldirektor der IAEO, Eklund, am 17. November 1967 bei seinem Besuch in Bonn eine vertragliche Formalisierung des Verhältnisses zwischen EURATOM und IAEO für nicht möglich gehalten habe; die UdSSR betrachte EURATOM nach wie vor als militärische Organisation. Staatssekretär Lahr und Botschafter Schnippenkötter hätten darauf hingewiesen, daß gerade eine solche Zusammenarbeit bei der Verifizierung der EURATOM-Kontrollen im Rahmen eines Nichtverbreitungsabkommens nützlich sein könne. Die Bundesregierung wünsche durch EURATOM garantierte weltweite, nichtdiskriminierende Sicherheitskontrollen, die eine Gleichstellung in den wirtschaftlichen Bedingungen für eine friedliche Nutzung der Kernenergie gewährleisteten. Eklund 
habe ferner Verständnis geäußert für den Wunsch der Bundesregierung nach einem ständigen Sitz im Gouverneursrat der IAEO. Jedoch sei es nicht ratsam, dies über eine Satzungsänderung anzustreben, weil dann der Anteil der Entwicklungsländer auf Kosten der westeuropäischen Staaten gestärkt würde. Abschließend stellt Frank fest, daß Eklund nicht den Eindruck vermittelt habe, von den Argumenten der Bundesregierung überzeugt zu sein.

Böker teilt mit, daß das Bundesministerium der Finanzen (BMF) entgegen anderslautender Informationen der israelischen Forderung nach Zahlung von $\mathbf{4 0 0}$ Mio. DM für gesundheitsgeschädigte NS-Opfer nicht entsprechen wolle. Allerdings habe Bundesminister Strauß wohl tatsächlich zunächst erwogen, einer Entschädigung zuzustimmen. Inzwischen werde aber die Ansicht des Auswärtigen Amts auch vom BMF geteilt, daß ein rechtlicher Anspruch nicht bestehe und politisch ein Nachgeben wegen der Auswirkungen auf das Verhältnis der Bundesrepublik zu den arabischen Staaten höchst bedenklich wäre.

Böcker informiert über ein Gespräch mit dem südjemenitischen Außenminister vom Vortag anläßlich der Übergabe des Telegramms des Bundespräsidenten Lübke zur Anerkennung der Volksrepublik Jemen (Südjemen). Der Konsul I. Klasse erklärte die Bereitschaft der Bundesregierung, auf der Grundlage von diplomatischen Beziehungen an der wirtschaftlichen Entwicklung des neuen Staates mitzuwirken. Al-Dhalai erwiderte, daß er an einem Botschafteraustausch „mit allen Staaten“ interessiert sei. Böcker wies darauf hin, daß bisher kein arabischer und darüber hinaus überhaupt kein nichtkommunistischer Staat die DDR völkerrechtlich anerkannt habe. Zwar seien vereinzelt Konsulate der DDR in arabischen Staaten errichtet worden, allerdings mit der Zusicherung, daß dies keine Anerkennung beinhalte. Böcker meint abschließend, daß die Volksrepublik Jemen diplomatische Beziehungen mit der Bundesrepublik wünsche, jedoch noch nicht über ihre zukünftige Haltung zur DDR entschieden habe.

Brandt unterrichtet darüber, daß die Sondierungen des Chefredakteurs des Deutschlandfunks, Barsig, in Belgrad eine gute Grundlage für vertrauliche Verhandlungen mit der jugoslawischen Regierung über die Wiederaufnahme diplomatischer Beziehungen geschaffen hätten. Nur eine weitere Verzögerung böte der DDR die Möglichkeit, die Bemühungen um einen Botschafteraustausch zu stören. Ein Abwarten würde zudem in der Bundesrepublik den Eindruck erwecken, daß die Bundesregierung in einer entscheidungsreifen Angelegenheit nicht entschlußfreudig sei. In den Verhandlungen selbst müßten die 
Texte einer jugoslawischen Erklärung und einer Verlautbarung der Bundesregierung vereinbart sowie die Zuständigkeit der Botschaft in Belgrad auch für Berlin (West) zugesichert werden. Schließlich sei die ablehnende Haltung der Bundesregierung gegenüber den jugoslawischen Wiedergutmachungsforderungen herauszustellen. Lindenberg

Meyer-Lindenberg erörtert die Möglichkeit der Bildung einer europäischen Wirtschaftsgemeinschaft mit zehn Mitgliedern bzw. mit neun Mitgliedern (ohne Frankreich) - unter der Voraussetzung, daß die bestehende Gemeinschaft der Sechs erhalten bliebe. Im ersten Fall könne eine Annäherung des Integrationsstandes der Zehnergemeinschaft an den der Sechs in Stufen erreicht werden. Die Organe der größeren Gemeinschaft sollten den Organen der EG entsprechen, und Ratsentscheidungen sollten einstimmig getroffen werden, um dem Eindruck einer Majorisierung durch die Sechs entgegenzuwirken. Dagegen sei die Bildung einer zusätzlichen Gemeinschaft ohne Frankreich mit dem EWG-Vertrag von 1957 unvereinbar, da die Sechs zu einer gemeinsamen Handelspolitik verpflichtet seien und Maßnahmen der größeren EG zu Interessenkollisionen mit der Sechsergemeinschaft führen würden. Daher bleibe nur die Möglichkeit, zunächst bilateral in exploratorische Gespräche mit der britischen Regierung einzutreten.

Groepper berichtet, daß die türkische Zypernpolitik nach der Beilegung der unmittelbaren Kriegsgefahr einerseits geprägt sei vom Bemühen um innenpolitische Konsolidierung. Andererseits werde sie von einer tiefen Enttäuschung darüber bestimmt, daß eine Chance verpaßt worden sei, durch eine militärische Intervention den Schutz der türkischen Bevölkerung auf Zypern ein für allemal zu gewährleisten. Er äußert sich skeptisch zu den bevorstehenden Verhandlungen in der UNO, da Präsident Makarios im Rahmen eines multilateralen Gremiums stärker als in den bisher bilateral geführten Vermittlungsgesprächen seine für die Türkei unannehmbaren Forderungen einbringen könne. Groepper empfiehlt, alles zu tun, um ein Abgleiten des NATO-Mitglieds Türkei in "neutrales, wenn nicht gar neutralistisches Lager" zu verhindern.

Kiesinger führt aus, daß die von Präsident Johnson am 2. Dezember 1967 bekanntgegebene Entscheidung, die amerikanische zivile Nukleartätigkeit unter die Kontrolle der LAEO zu stellen, die UdSSR zwar nicht zur Nachahmung veranlassen werde. Es wäre jedoch erfreulich, wenn dieser Schritt in der UdSSR die Bereitschaft wecken würde, der Verifikation der EURATOM-Kontrollen durch die IAEO zuzustimmen. Andernfalls bestehe die Gefahr, daß der freie Markt für Kernstoffe und 
Kernenergie in Europa Schaden nehme. Es würde ihn, Kiesinger, einer schweren Sorge entheben, wenn es den USA bei der Konferenz der 18-Mächte-Abrüstungskommission gelänge, die UdSSR von der Notwendigkeit zu überzeugen, den EURATOMKontrollen in einem Nichtverbreitungsabkommen hinreichend Ausdruck zu verleihen. Außerdem würdigt der Bundeskanzler die Bereitschaft der amerikanischen Regierung, sich in Genf nachdrücklich für eine Befristung des Abkommens einzusetzen. Abschließend weist er auf die Regierungserklärung des Bundesministers Schröder vom Vortag hin, in der die Zusage an den amerikanischen Präsidenten bestätigt worden sei, daß keine Verkleinerung der Bundeswehr in Aussicht genommen werde.

Frank teilt mit, daß der belgische Außenminister Harmel ein Treffen der fünf EG-Partner ohne Frankreich für unumgänglich halte, um sich in der Frage des britischen Beitritts abzustimmen. Gegebenenfalls könnten im Anschluß daran gemeinsam mit Frankreich weitere Vorbereitungen zur EG-Ministerratstagung am 18./19. Dezember 1967 in Brüssel getroffen werden. Dazu hätten die Benelux-Staaten einen Plan entworfen, der vorsehe, vor dem eigentlichen Beitritt einen für den Antragssteller verbindlichen Stufenplan auszuarbeiten. Die Übergangszeit solle Teil des Beitrittsvertrags sein und durch ein „Programm für die Zusammenarbeit“ auf allen Vertragsgebieten gefüllt werden. Die volle Mitgliedschaft solle erst nach Abschluß dieser „Vorschaltphase“ vollzogen werden, wenn Großbritannien alle Rechte und Pflichten zu übernehmen in der Lage sei. Frank bemerkt, daß die britische Regierung bereits ablehnend zu diesem Plan Stellung genommen habe. Großbritannien akzeptiere keine Übergangsphase und keine Form einer Assoziierung, sondern wolle von Anfang an vollgültiges Mitglied der Europäischen Gemeinschaften sein.

421 07.12. Aufzeichnung des Vortragenden Legationsrats

\section{Klasse Schwörbel}

Schwörbel berichtet über den Besuch des portugiesischen Verteidigungsministers vom 20. bis 24. November 1967 in Bonn. Bundesminister Schröder legte die Gründe dar, die zur Überprüfung der militärischen Zusammenarbeit geführt hätten. Zwar sei die Bundesregierung grundsätzlich an einer Fortsetzung interessiert, jedoch müßten insbesondere die Rechtsstellung der in Portugal stationierten Bundeswehreinheiten geklärt sowie die uneingeschränkte logistische Nutzung des Flughafens Beja gesichert werden. Schröder weist ferner darauf hin, daß die Bundesrepublik bisher Rüstungskäufe für 750 Mio. DM in Portugal getätigt habe und der Bedarf jetzt gedeckt sei. Gomes de Araújo erwiderte, daß Portugal zwar grundsätzlich zur Verlängerung bestehender Verträge um 5 bis 6 Jahre bereit sei. Dies sei jedoch etwa davon abhängig, daß bei der logistischen Nutzung von Beja die Einlagerung von Munition aus- 
genommen werde. Auch sei das von Schröder in Frage gestellte Junktim zwischen den deutschen Vorhaben in Portugal und den Rüstungskäufen der Bundesrepublik von Anfang an vereinbart worden und sei nicht ohne weiteres aufzuheben. Auswärtige Amt

Grewe informiert über die Sitzung der „Special Group“ der NATO, die sich mit der dem Ministerrat vorzulegenden Studie über die zukünftigen Aufgaben der Allianz (Harmel-Studie) befaßt habe. Nur Frankreich habe versucht, bestimmte Themen aus dem Entwurf auszuklammern. Dagegen hätten die übrigen Verbündeten ihre Sonderinteressen zurückgestellt. Die Niederlande und die USA hätten nicht ohne Schärfe gegen den französischen Standpunkt Stellung bezogen. Er, Grewe, sei um einen Ausgleich bemüht gewesen, da der Bundesregierung daran gelegen sein müsse, einem Optionszwang zwischen Frankreich und den übrigen NATO-Mitgliedstaaten aus dem Wege zu gehen. Es sei nicht zu erwarten, daß sich Staatspräsident de Gaulle auf der NATO-Ministerratstagung am 13./14. Dezember 1967 in Brüssel wegen des Harmel-Berichts zum endgültigen Ausscheiden aus der NATO entschließen werde, da er den größten Teil seines „nuisance value“ verlieren würde. Dann wäre die UdSSR wohl kaum noch bereit, Frankreich einen Preis für seine Distanzierung vom Bündnis zu bezahlen. Dennoch sei nicht auszuschließen, daß die harte Haltung einiger NATOPartner der französischen Regierung keinen anderen Ausweg als den des Eklats lassen werde.

Ruete berichtet, daß nach Auskunft der Vertreter der Drei Mächte in der Bonner Vierergruppe eine Befolgung der NATOEmpfehlungen für die Vergabe von „Temporary Travel Documents" (TTDs) an Teilnehmer aus der DDR bei internationalen Sportveranstaltungen zunehmend Opfer von den gastgebenden NATO-Staaten verlange. Die Wettkämpfe würden nun häufig in "neutrale" oder Ostblock-Staaten verlegt, da die „sowjetzonalen Mannschaften" etwa auf der Bezeichnung "DDR ${ }^{4}$ bestünden. Der Vertreter des Auswärtigen Amts habe die Verbündeten darüber informiert, daß die Bundesregierung den Plan, in Form einer ${ }_{n}$ Sporterklärung" zum innerdeutschen Sportverkehr Stellung zu nehmen, aufgegeben habe. Statt dessen solle in neuen Richtlinien möglicherweise unterschieden werden zwischen den von DDR-Sportlern gezeigten Staatssymbolen (Fahne, Hymne) und der verwendeten Herkunfstbezeichnung ${ }_{n} \mathrm{DDR}^{4}$ auf Schildern, in Programmen, bei Ansagen und auf Sportkleidung. Ruete spricht sich abschließend dafür aus, möglichst rasch den Standpunkt der Bundesregierung zu klären, um die Loyalität der Verbündeten gegenüber den bestehenden NATOEmpfehlungen vom 1. Dezember 1966 nicht zu strapazieren. 
Sahm führt aus, daß die UdSSR mit den am 8. Dezember 1967 gegen die Ostpolitik der Bundesregierung vorgebrachten Angriffen Einfluß auf die Bemühungen um die Wiederaufnahme diplomatischer Beziehungen mit Jugoslawien nehmen wolle. Es sei aber auch denkbar, daß die sowjetische Regierung damit eine „Geräuschkulisse als Alibi“ aufbaue, um den Verdacht auszuschließen, sie verhandele in den Gesprächen mit der Bundesregierung über den Austausch bilateraler Gewaltverzichtserklärungen auf Kosten der Interessen ihrer Verbündeten. Durch die neuerliche Bezugnahme auf das Potsdamer Abkommen von 1945 habe die UdSSR vermutlich im Zusammenhang mit dem Anlaß der Erklärung - dem NPD-Parteitag in Hannover - eine Einmischung in innerdeutsche Angelegenheiten rechtfertigen wollen. Sahm spricht sich dafür aus, gemeinsam mit den Drei Mächten „kurze, kräftige Antwortnoten“ abzugeben. amerikanischen Außenminister Rusk in Brüssel

Brandt versichert, daß die Bundesregierung vor einer Veröffentlichung ihrer Pläne zur Umstrukturierung der Bundeswehr die Verbündeten konsultieren werde. Rusk erwidert, daß die amerikanische Regierung durch die Ankündigung des Rotationsplans den Forderungen nach Truppenreduzierungen in Europa zwar habe begegnen können. Er frage sich aber, ob sie auch in Zukunft dem Druck der Öffentlichkeit werde standhalten können, wenn Verbündete wie Belgien, Kanada und Luxemburg - insbesondere ohne Konsultationen - einen Streitkräfteabbau beschlössen. Zu einem Nichtverbreitungsabkommen meint er, daß er eine Benachteiligung der zivilen Nuklearindustrie in der Bundesrepublik durch die Einführung zusätzlicher LAEO-Kontrollen nicht erkennen könne. Hinter der französischen Politik vermute er ein Doppelspiel: Einerseits erkläre die französische Regierung der UdSSR, daß sie nichts gegen IAEO-Kontrollen bei den fünf EG-Partnern einzuwenden habe, was die Aufmerksamkeit auf die "Störenfriede" in Bonn lenke; andererseits verweise die Bundesregierung darauf, daß Frankreich gegen IAEO-Kontrollen in den übrigen EURATOMStaaten Einwände erheben würde. Es müsse endlich geklärt werden, „was Paris wirklich wolle“.

Harkort teilt mit, daß die sowjetische Regierung auf das Angebot zur Fortsetzung der im Oktober 1966 abgebrochenen Wirtschaftsverhandlungen geantwortet habe, eine Wiederaufnahme habe nur Zweck, wenn eine Stellungnahme zu den seinerzeit von der UdSSR unterbreiteten Vorschlägen erfolge. Er gibt zu bedenken, daß die Bundesregierung auf die gewünschte Garantie, keine Wiederholung des von 1962 bis 1964 geltenden Embargos für die Lieferung von Großrohren zuzulassen, zwar mit einer „good-will-Erklärung“ reagieren könne. Bezüglich der 
geforderten vollen Liberalisierung der Einfuhren in die Bundesrepublik sowie der erwarteten Einräumung der für die EGStaaten geltenden Meistbegünstigungszölle bestehe die starre sowjetische Haltung fort. Harkort schließt daraus, daß die sowjetische Regierung an Wirtschaftsgesprächen derzeit nicht interessiert sei und die Verhandlungen nur dann fortsetzen wolle, wenn ihre Forderungen vorbehaltlos erfüllt würden.

Sahm informiert darüber, daß die DDR die Bezeichnung der beiden „Büros für innerdeutschen Handel" in „Ministerium für

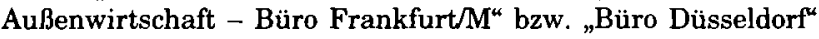
geändert habe. Im Kontaktausschuß sei festgestellt worden, daß dieses Vorgehen zwar als Verstoß gegen die öffentliche Ordnung gewertet werden könne. Es sei jedoch fraglich, ob die DDR durch ein polizeirechtliches Vorgehen zur Wiederverwendung der alten Bezeichnungen zu veranlassen sei. Das Bundesministerum für gesamtdeutsche Beziehungen (BMG) habe angeregt, auf eine Änderung in "Ministerium für Außenwirtschaft, Büro für innerdeutschen Handel" hinzuwirken. Sahm ist demgegenüber der Meinung, daß die These vom nichtzwischenstaatlichen Charakter der innerdeutschen Kontakte gegenüber dem Ausland nur schwerlich aufrechtzuerhalten sei, wenn geduldet würde, daß sowjetzonale Stellen in der Bundesrepublik als Organe von DDR-Ministerien in Erscheinung träten. Die vom BMG erwogene Kompromißbezeichnung sollte nur bei einer angemessenen Gegenleistung der DDR akzeptiert werden, beispielsweise der Zulassung eines „Büros der Treuhandstelle für den Interzonenhandel in der SBZ". Vorher müsse allerdings geprüft werden, ob dies nicht als erster Schritt auf dem Weg zum Austausch von Handelsvertretungen interpretiert werden könnte.

Ruete resümiert das Gespräch des Bundesministers Brandt mit den Außenministern der Drei Mächte anläßlich der NATOMinisterratstagung in Brüssel. Brandt führte aus, daß die Bundesregierung ungeachtet der sowjetischen Vorwürfe vom 8. Dezember 1967 die vertraulichen Gespräche über den Austausch von Gewaltverzichtserklärungen mit der UdSSR fortsetzen wolle. Der amerikanische Außenminister Rusk bezeichnete die Wiedervereinigung als „erledigt", falls die Bundesregierung in Verbindung mit einem Gewaltverzicht die Demarkationslinie als Staatsgrenze der DDR bestätigen sollte. Der französische Außenminister Couve de Murville erklärte, daß die Bundesregierung über die Anerkennung der DDR oder Grenzfragen verhandeln könne, nicht jedoch über Berlin. Der britische AuBenminister Brown wies darauf hin, daß die britische Präsenz in Berlin (West) nicht mehr zu halten sei, wenn die Bundesregierung die DDR anerkenne. Rusk betonte, daß die USA der Bundesregierung keine Blanko-Vollmacht für ihre Gespräche geben könnten, sondern Konsultationen erwarteten: ${ }_{\text {Berlin ist }}$ nicht verwundbar, weil es von den Vereinigten Staaten vertei- 
digt wird“. Ruete ergänzt hierzu abschließend, daß Rusk laut Informationen aus seinem Mitarbeiterkreis gegenwärtig nicht die „Büchse der Pandora des Deutschlandproblems“ öffnen und sich neben Vietnam nicht noch ein weiteres Problem aufhalsen wolle.

Böker informiert, daß der libanesische Präsident Hélou gegenüber Vortragendem Legationsrat I. Klasse Gehlhoff am 7. Dezember 1967 in Beirut den Wunsch nach Wiederaufnahme diplomatischer Beziehungen mit der Bundesrepublik geäußert habe. Gehlhoff habe erwidert, daß die Mehrzahl der arabischen Regierungen in dieser Angelegenheit bereits Kontakt zur Bundesregierung aufgenommen habe. Ihnen sei jedoch deutlich gemacht worden, daß für eine solche Normalisierung kein wirtschaftlicher oder politischer Preis gezahlt werde. Böker meint, $\mathrm{da} ß$ wegen der innenpolitischen Spannungen im Libanon und dessen „diffiziler" Stellung in der arabischen Welt nicht mit einer baldigen positiven Entscheidung gerechnet werden könne. sowjetischen Botschafter Zarapkin

Duckwitz übergibt dem sowjetischen Botschafter ein Aidemémoire zum Stand der Gespräche über einen Gewaltverzicht. $\mathrm{Zu}$ der darin enthaltenen Feststellung, daß die sowjetische Regierung bisher nicht von einer Einbeziehung der DDR ,in entsprechender völkerrechtlicher Form" gesprochen habe, bemerkt Zarapkin, die UdSSR habe ihren Standpunkt immer klar ausgedrückt. Auch der Austausch derartiger Erklärungen zwischen der Bundesrepublik und der DDR habe zu den gleichen Bedingungen wie mit anderen sozialistischen Staaten zu erfolgen. Der Staatssekretär erinnert dagegen daran, daß Bundesminister Brandt zwar zu Gesprächen hierüber bereit sei. Der Charakter solcher Erklärungen müsse jedoch jeweils der „Struktur der Beziehungen zwischen der Bundesrepublik Deutschland und den einzelnen Ländern Rechnung tragen“.

\section{z.Z. Brüssel}

Ruete nimmt Stellung zum Schreiben des Präsidenten Johnson vom 11. Dezember 1967 an Bundeskanzler Kiesinger. Er bemerkt, daß der amerikanische Entwurf vom 2. November 1967 für Artikel III (Kontrollartikel) eines Nichtverbreitungsabkommens im Vergleich zu den sowjetischen und britischen Vorschlägen der relativ beste sei. Der amerikanische Außenminister Rusk habe zudem gegenüber Bundesminister Brandt zu erkennen gegeben, daß er eine bessere Lösung nicht für möglich halte. Während etwa der seitens der Bundesregierung vorgetragene Wunsch nach befristeter Geltungsdauer unerwähnt bleibe, deute die Konzentration des Schreibens auf Artikel III 
und die Verifikationsfrage darauf hin, daß die USA möglichst rasch mit der UdSSR zu einer Einigung über die noch offenen Punkte des Abkommens gelangen wollten. Duckwitz

Walther äußert sich zum sowjetischen Memorandum vom 21. November 1967 über den Ausausch von Gewaltverzichtserklärungen sowie zur sowjetischen Erklärung vom 8. Dezember 1967. Er weist darauf hin, daß die aus westlicher Sicht unvereinbar scheinende Kombination von vertraulichen Gesprächen und öffentlichem Vorgehen vor dem Hintergrund der russisch-sowjetischen Mentalität sowie des Hangs zu Formalistik und Legalistik verstanden werden müsse. So verfolge das Memorandum zwar den Zweck, die Bundesregierung zu einer Änderung ihrer ostpolitischen Positionen zu bewegen. Mit den in der Erklärung vom 8. Dezember 1967 enthaltenen Angriffen gegen die Bundesregierung sei aber keineswegs beabsichtigt, dieses Ziel zu konterkarieren. Vielmehr meine die sowjetische Regierung, einen als bevorstehend empfundenen Kurswechsel in der Ostpolitik durch ein Ansprechen der Öffentlichkeit in der Bundesrepublik beschleunigen zu können. Nach Lektüre beider Texte sehe er seine Einschätzung bestätigt, daß die „Finnlandisierung“ der Bundesrepublik das „Endziel der Russenpolitik“ sei. Auswärtige Amt

Ruete berichtet über die Erörterung der Ost-West-Beziehungen auf der NATO-Ministerratstagung am 13./14. Dezember 1967. Der niederländische Außenminister Luns wies auf die große Bedeutung einer politischen Zusammenarbeit der NATOStaaten hin. Gerade dadurch könne der eigentliche Zweck der Allianz, eine Entspannung herbeizuführen, betont werden. Die kanadischen und dänischen Außenminister äußerten sich positiv über die bilateralen Kontakte der europäischen Bündnispartner zu den osteuropäischen Staaten. Martin erklärte, die NATO müsse in eine "dynamische Suche nach einer europäischen Regelung" eintreten. Tabor regte an, die Funktion der NATO als "Werkzeug des Friedens" durch intensivere politische Konsultationen zu verbessern. Der amerikanische Außenminister Rusk führte aus, daß er diejenigen nicht verstehe, die aus Europa eine dritte Kraft zwischen den USA und der UdSSR machen wollten. Der Antagonismus dieser beiden Weltmächte sei doch gerade eine Folge der amerikanischen Entschlossenheit, die Sicherheit Europas wie auch anderer Gebiete zu gewährleisten.

Pauls übermittelt die Einschätzung des israelischen Generalstabs, daß von der Mission des Sonderbevollmächtigten der UNO für den Nahen Osten, Jarring, keine Lösung des israe- 
lisch-arabischen Konfliktes zu erwarten sei. Vielmehr könne eine Entspannung allein durch einen Gesinnungswandel der arabischen Staaten erfolgen, der sich in deren Bereitschaft zur Aufnahme direkter Friedensverhandlungen mit Israel zeigen müsse. Andernfalls müsse mit einer weiteren militärischen Auseinandersetzung gerechnet werden. Ferner werde auf das Rüstungsungleichgewicht verwiesen, das vor allem durch sowjetische und französische Lieferungen an arabische Staaten entstehe, während israelische Bestellungen bereits bezahlter leichter Kampfflugzeuge in Frankreich nicht ausgeführt würden. Der israelische Generalstab müsse sich daher energisch den noch so gut gemeinten Absichten von Politikern widersetzen, strategisch wertvolles Gebiet gegen zweifelhafte Friedensgarantien zu räumen. Auswärtige Amt

Ruete teilt mit, daß der NATO-Ministerrat am 13./14. Dezember 1967 wider Erwarten eine schnelle Einigung bezüglich der Studie über die zukünftigen Aufgaben der Allianz (HarmelBericht) erzielt habe. Der französische Außenminister Couve de Murville habe sich schließlich bereit erklärt, den in seinen strittigen Abschnitten überarbeiteten Bericht anzunehmen und einer Veröffentlichung zuzustimmen. Es habe sich gezeigt, wie sehr die von Frankreich vorgebrachten Bedenken durch taktische Überlegungen bestimmt gewesen seien. Der Vorgang bestätige auch den Eindruck, daß die französische Regierung zur Zeit einen Bruch mit der Allianz vermeiden wolle.

Ruete notiert, daß er den jugoslawischen Gesandten Lučić vom Beschluß des Bundeskabinetts in Kenntnis gesetzt habe, in Bonn Gespräche über die Wiederaufnahme diplomatischer Beziehungen mit Jugoslawien aufzunehmen. Sollten die Verhandlungen erfolgreich verlaufen, wolle die Bundesregierung sehr schnell eine positive Entscheidung herbeiführen. Lučić habe die Vermutung geäußert, daß der unerwartete Besuch des Außenministers der DDR, Winzer, vom 11. bis 13. Dezember 1967 in Belgrad auf die Sorge hindeute, daß der geplante Botschafteraustausch zwischen Belgrad und Bonn die Beziehungen zwischen Belgrad und Ost-Berlin beeinträchtigen könnte. Er, Ruete, habe versichert, dies läge nicht in der Absicht der Bundesregierung. Bundesminister Brandt

Sachs faßt ein Gespräch von Brandt mit dem französischen Außenminister vom Vortag zusammen. Couve de Murville legte dar, daß Großbritannien zunächst die Voraussetzungen zur Gesundung der britischen Wirtschaft schaffen müsse, insbesondere die Sanierung der Zahlungsbilanz und die Regelung 
der Schulden gegenüber den Staaten des Sterlingblocks; erst dann könne ein Beitritt zur EG vollzogen werden. Deshalb werde sich die französische Regierung auf der EG-Ministerratstagung am 18./19. Dezember 1967 in Brüssel gegen die Aufnahme von Beitrittsverhandlungen aussprechen. Sie sei auch nicht zu Expertengesprächen mit Großbritannien oder auch nur zu exploratorischen Gesprächen der EG-Kommission bereit. Allerdings seien Zwischenlösungen auf dem industriellen und dem landwirtschaftlichen Sektor denkbar. Wenn die wirtschaftliche und finanzielle Situation eine britische Vollmitgliedschaft erlaube, würden die „echten“ Beitrittsverhandlungen mit Großbritannien nur noch kurze Zeit in Anspruch nehmen.

Ruete vermerkt, daß die DDR nach dem Besuch des Staatsratsvorsitzenden Ulbricht am 11./12. Dezember 1967 in der UdSSR in Verhandlungen mit der Deutschen Bundesbahn über den innerdeutschen Güterzugverkehr und mit dem Senat von Berlin über die bauliche Nutzung von Reichsbahngelände eingewilligt und auf ihren hartnäckig vertretenen Aufwertungsforderungen nicht weiter bestanden habe. $\mathrm{Er}$ stellt fest, daß die DDR derzeit einerseits eine psychologische Einschüchterungskampagne gegen die Deutschland- und Berlinpolitik der Bundesregierung verfolge, andererseits jedoch eine faktische Verschlechterung im innerdeutschen Verhältnis oder gar militärische Vorbereitungen für eine krisenhafte Zuspitzung vermeiden wolle.

Harkort informiert darüber, daß die zwischen dem Auswärtigen Amt und dem Bundesministerium für Verkehr (BMV) abgestimmte Antwort auf die sowjetische Note vom 15. August 1967 über die Aufnahme von Luftverkehrsverhandlungen auf Anraten des Botschafters von Walther nicht übergeben worden sei. Statt dessen habe der Botschafter im sowjetischen Außenministerium lediglich mündlich die Bereitschaft der Bundesregierung übermittelt, eine sowjetische Delegation in Bonn zu empfangen; Voraussetzung sei die sowjetische Bereitschaft, von dem Vorschlag einer Streckenführung über Eger Gebrauch zu machen. Gegenüber diesem Vorgehen habe das BMV jetzt Bedenken geäußert und auf einer schriftlichen Übergabe bestanden. Harkort meint, daß tatsächlich Wert auf eine formgerechte Beantwortung gelegt werden solle, da sich das Auswärtige Amt andernfalls bei innenpolitischen Auseinandersetzungen dem Vorwurf aussetzen würde, die Möglichkeit des Zustandekommens einer für beide Seiten wichtigen Luftverkehrslinie nicht genützt zu haben. Walther solle deshalb gebeten werden, die Verbalnote nunmehr zu übergeben. 

amerikanischen Botschafter McGhee

McGhee versichert, daß die amerikanische Regierung die Besorgnisse der Bundesregierung im Zusammenhang mit einem Nichtverbreitungsabkommen würdige und nicht auf eine Entscheidung dränge. Kiesinger erläutert, daß die Bundesregierung weiterhin für einen britischen EG-Beitritt eintrete, jedoch eine Krise der Gemeinschaft verhindern wolle. Ihre Marschrichtung sei deshalb, die "Englandfrage" auf der Tagesordnung des EG-Ministerrats zu halten und entsprechende Kompromißvorschläge zu machen. Zur Ostpolitik führt der Bundeskanzler aus, daß das Bestreben nach einer Verbesserung des Verhältnisses mit „Deutschlands östlichen Nachbarn einschließlich der Sowjetunion“ nicht als „Rapprochement an Rußland mit gleichzeitiger Entfernung von den Vereinigten Staaten" verstanden werden dürfe. Auch eine Aufnahme diplomatischer Beziehungen mit Jugoslawien wäre keineswegs als Aufgabe der Hallstein-Doktrin zu werten. Der Botschafter erwidert, daß die USA die Bundesregierung solange bei der Durchsetzung ihres Alleinvertretungsanspruchs unterstützen würden, solange diese selbst daran festhalte.

Sachs berichtet über ein Gespräch des Bundesministers Brandt mit seinen niederländischen, belgischen, italienischen und luxemburgischen Amtskollegen im Anschluß an die EG-Ministerratstagung in Brüssel. Luns schlug vor, daß die Fünf durch bilaterale Abkommen Großbritannien enger an den Kontinent binden sollten. Harmel regte an, die Bundesregierung solle die Initiative für ein weiteres Treffen der Fünf ergreifen. Fanfani warnte vor übereilten Schlußfolgerungen. Brandt äußerte abschließend die Befürchtung, daß eine zu pessimistische Einstellung Großbritannien weiter von Europa entfernen könnte. Zudem könne es bedenkliche Folgen haben, wenn der „deutschen Jugend" angesichts eines ungelösten nationalen Problems zusätzlich auch noch die Hoffnung auf die europäische Einigung genommen werde. Auswärtige Amt

Sachs faßt den Verlauf der EG-Ministerratstagung am 18./19. Dezember 1967 in Brüssel zusammen. Der französische Außenminister Couve de Murville erklärte, daß vor der Aufnahme von Beitrittsverhandlungen die wirtschaftliche und monetäre Konsolidierung Großbritanniens gesichert sein müsse. Danach werde die Aushandlung eines Abkommens verhältnismäßig schnell gehen. Frankreich nehme daher nicht eine ablehnende, sondern nur eine abwartende Haltung ein. Couve führte weiter aus, daß die Gemeinschaft mit den Antragstellem nicht über deren Wirtschaftslage zu beraten habe. Während Artikel 237 des EWG-Vertrags von 1957 lediglich Abkommen zur Anpassung der Institutionen bzw. zur Festlegung von Übergangszei-

\section{CLXXX}


ten vorsehe, zielten die von den übrigen EG-Partnern gewünschten Verhandlungen auf gänzlich außerhalb des Vertrags liegende Themen. Die übrigen Delegationen vertraten den Standpunkt, daß ohne Verhandlungen mit Großbritannien weitere Fortschritte in der Beitrittsfrage nicht zu erzielen seien. Die Minister kamen schließlich überein, in einer Schlußerklärung ihre Standpunkte festzuhalten und mitzuteilen, daß die Anträge auf der Tagesordnung des Rats blieben. Bundesminister Brandt bedauerte, daß der Weg für eine vertragsgemäße Behandlung der Beitrittsanträge nicht freigemacht worden sei.

Ruete informiert darüber, daß sich die Vertreter der Drei Mächte sehr zufrieden über den Entwurf einer Antwortnote geäußert hätten, mit der die Bundesregierung auf die sowjetische Erklärung vom 8. Dezember 1967 über ein Anwachsen des „Neonazismus“ in der Bundesrepublik reagieren wolle. Sie hätten sich dafür ausgesprochen, diesen Text der sowjetischen Regierung einige Tage vor Übergabe ihrer eigenen Noten übergeben zu lassen, zumal eine Zweiteilung der westlichen Antworten die doppelte Aufmerksamkeit der öffentlichen Meinung wecken werde. Ruete paraphrasiert anschließend den Inhalt der untereinander abgestimmten Erklärungen der amerikanischen und der britischen Regierung. Darin sollten die sowjetischen Beschuldigungen zurückgewiesen und ferner festgestellt werden, daß die 1945 abgeschlossenen Viermächtevereinbarungen keine Grundlage mehr für eine Einmischung in die inneren Verhältnisse der Bundesrepublik darstellen könnten. Die Bundesrepublik sei jetzt ein demokratischer Staat, von dem keine Bedrohung des Friedens in Europa ausgehe. Ruete regt abschließend an, die Antwortnote der Bundesregierung unverzüglich in Moskau zu übergeben.

Böker führt aus, daß der ägyptische Wirtschaftsminister gegenüber Bundesminister Wischnewski den Vorschlag unterbreitet habe, die Abteilung für die Wahrnehmung der Interessen der Bundesrepublik Deutschland bei der italienischen Botschaft in Kairo auf Grundlage der Gegenseitigkeit durch einen höherrangigen Leiter aufzuwerten. Ferner habe Zaki signalisiert, daß die ägyptische Regierung jetzt in schriftlicher Form ein politisches Signal der Bundesregierung erwarte. Böker meint, daß sich die Bundesregierung vor dem Hintergrund des Bestrebens der VAR, in absehbarer Zeit sowohl mit der Bundesrepublik als auch mit der DDR diplomatische Beziehungen ohne Risiko für sich selbst aufzunehmen, nicht auf solche „Ersatz-Botschaften “ in Kairo und Bonn einlassen solle. Allerdings solle dem ägyptischen Wunsch nach stärkerer finanzieller Beteiligung an Projekten der Technischen Hilfe entsprochen werden. 

das Auswärtige Amt

Braun faßt Gespräche mit dem rumänischen Außenminister Manescu sowie mit dessen Stellvertreter Malitza zusammen. Manescu bat, Bundesminister Brandt mitzuteilen, er möge auf dem beschrittenen Weg der Entspannungspolitik energisch fortschreiten und insbesondere den Dialog mit dem ,anderen deutschen Staat" vorantreiben. Auch er, Manescu, halte die Mauer in Berlin für schlecht. Jedoch könne nur ein Entgegenkommen gegenüber der DDR, etwa in Form der Zulassung eines Beobachters bei der UNO, wirksam sein. Die UNO sei ein geeigneter Ort, um das Verhältnis zwischen beiden deutschen Staaten zu ordnen. In vorangegangenen Unterredungen führte Malitza dazu aus, daß im Unterschied zur Atmosphäre in der UNO direkte Gespräche zwischen der Bundesrepublik und der DDR schwierig und vorbelastet seien. Es dürfe nicht vergessen werden, daß Antworten auf Schreiben der Bundesregierung nicht in Ostberlin, sondern in Moskau verfaßt würden.

Ruete erörtert konkrete Möglichkeiten der DDR und der UdSSR zur Störung und Behinderung von Berlin (West) und des Berlinverkehrs sowie notwendige Gegenmaßnahmen der Bundesrepublik und der Drei Mächte. Er vermerkt, daß weiteren verfassungsrechtlichen Schritten der DDR zur Untermauerung ihrer Eigenstaatlichkeit zu begegnen sei durch Erklärungen, die mit den Westmächten abgestimmt werden müßten. Die Gegenmaßnahmen im Falle der Behinderung des Zugangs nach Berlin (West) seien in entsprechenden Eventualfallpapieren mit den drei Verbündeten bereits festgelegt. Dagegen habe eine gemeinsame Planung erst noch für den Fall stattzufinden, daß die DDR die bestehenden Vereinbarungen und Praktiken aufkündige, die sich auf das Währungsgebiet der DM-West bezögen. Schließlich seien in der DDR weitere Schauprozesse gegen in der Bundesrepublik ansässige „Nazis in hohen Stellungen" möglich.

Frank resümiert ein Gespräch des Bundesministers Wischnewski mit dem algerischen Botschafter in Rom am 22. Dezember 1967 in Frankfurt am Main. Aid Challal teilte mit, daß seine Regierung ernsthaft die Normalisierung der Beziehungen zur Bundesrepublik anstrebe. Sie wolle ihre Verbindungen zu Europa nicht mehr so einseitig auf Frankreich ausrichten, sondern stärker auffächern. Der Bundesrepublik komme hier eine besondere Rolle zu. Algerien wünsche u.a. die Reaktivierung bestehender Verträge und den Abschluß eines Abkommens zur Investitionsförderung. Auch die Beschäftigung algerischer Arbeitnehmer in der Bundesrepublik sowie die Förderung des Tourismus solle Gegenstand von Expertengesprächen sein. Wisch- 
newski erklärte die Bereitschaft zur Wiederaufnahme des Kapitalhilfeprogramms sowie zur Gewährung von Technischer Hilfe. Er wies aber darauf hin, daß die Beschäftigung ausländischer Arbeitnehmer in den letzten zwei Jahren generell nachgelassen habe, weil die Bundesrepublik zur Zeit selbst eine gewisse Arbeitslosigkeit erlebe. Auswärtige Amt

Strätling berichtet über ein Gespräch mit dem Generalsekretär der Kommunistischen Partei Rumäniens. Ceausescu hob hervor, daß der Entschluß der Bundesregierung zur Wiederaufnahme der diplomatischen Beziehungen mit Jugoslawien zwar die Ernsthaftigkeit der neuen Ostpolitik unterstreiche. Allerdings sollte sie noch weiter gehen und die nach dem Zweiten Weltkrieg geschaffenen Realitäten anerkennen. Er äußerte sich besorgt über das Anwachsen der NPD in der Bundesrepublik. Es sei unverständlich, daß sie nicht wie seinerzeit die KPD verboten werde. Strätling machte darauf aufmerksam, daß sich leider eine Entwicklung zu wiederholen scheine, die schon während der Weimarer Republik festzustellen gewesen sei. Damals hätten „ausländische Mächte und Presseorgane den demokratischen Kräften in Deutschland kein Vertrauen entgegengebracht und dadurch indirekt die verfassungsfeindlichen Kräfte unterstützt“. Darauf erwiderte der Generalsekretär, daß heutzutage die Unterzeichnerstaaten des Potsdamer Abkommens von 1945 eine „Aktivlegitimation“ zur Verhinderung eines Wiederauflebens des Nationalsozialismus besäßen. Strätling übermittelt abschließend den Eindruck, daß Ceausescu sich mit diesen Äußerungen einer Aufgabe habe entledigen wollen, die er am 14./15. Dezember 1967 in Moskau „wegen der Nichtübereinstimmung in anderen, die Bundesrepublik betreffenden Fragen" akzeptiert habe. britischen Botschafter Roberts

Roberts unterrichtet den Bundesminister darüber, daß die britische Regierung nicht mehr mit einem Beitritt zu den Europäischen Gemeinschaften rechne, solange Staatspräsident de Gaulle im Amt sei. Da sie aber nicht solange warten wolle, schlage sie Konsultationen mit den Fünf über Möglichkeiten der Zusammenarbeit in den technologischen, rüstungswirtschaftlichen, entwicklungs- und außenpolitischen Bereichen vor, die nicht von den Römischen Verträgen erfaßt würden. Brandt erwidert, daß er solche Verhandlungen für wenig aussichtsreich halte. Stattdessen ergäben sich jeweils im Vorfeld der WEU-Ratstagungen Ansatzpunkte für Gespräche zwischen den Fünf und Großbritannien, da der französische Vertreter an den Vorbereitungen hierzu nicht teilnehme. Der Bundesminister fährt fort, daß er an ein Verfahren denke, das in einer überschaubaren Zeit zur Mitgliedschaft Großbritanniens führe 
und in der Zwischenzeit bereits Mitwirkungsmöglichkeiten an den Entscheidungen der Gemeinschaftsorgane schaffe. Die von Roberts angeregten „Aushilfskonstruktionen“ könnten vielleicht eine gewisse psychologische Wirkung haben, während ein wirtschaftspolitisch durchschlagender Erfolg nicht zu erwarten sei.

\section{CLXXXIV}




\section{Literaturverzeichnis}

AAPD

ACHTER GESAMTBERICHT 1964/65

ADAP, D

ADENAUER, Erinnerungen IV

AdG

AMTSBLATT DER EUROPÄISCHEN

GEMEINSCHAFTEN

ANNUARIO PONTIFICIO

AUSSENPOLITIK DER DDR

BAHR, Zu meiner Zeit

BARZEL, Es ist noch nicht zu spät

BEN GURION UND ADENAUER
Akten zur Auswärtigen Politik der Bundesrepublik Deutschland, hrsg. im Auftrag des Auswärtigen Amts vom Institut für Zeitgeschichte. Jahresband 1949/50. Jahresband 1963 (Teilbände I-III). Jahresband 1964 (Teilbände I-II). Jahresband 1965 (Teilbände I-III). Jahresband 1966 (Teilbände I-II), München 1994-1997.

Achter Gesamtbericht über die Tätigkeit der Gemeinschaft (1. April 1964 - 31. März 1965), hrsg. von der Kommission der Europäischen Wirtschaftsgemeinschaft, [Brüssel] 1965.

Akten zur deutschen auswärtigen Politik 19181945. Serie D (1937-1941). Band II: Deutschland und die Tschechoslowakei (Oktober 1937 September 1938). Band VII: Die letzten Wochen vor Kriegsausbruch (9. August bis 3. September 1939), Baden-Baden 1950 bzw. 1956.

Konrad Adenauer, Erinnerungen 1959 - 1963. Fragmente, Stuttgart 1968.

Archiv der Gegenwart, zusammengestellt von Heinrich Siegler, Bonn/Wien/Zürich $1955 \mathrm{ff}$.

Amtsblatt der europäischen Gemeinschaften (EGKS, EWG, EURATOM), Brüssel 1958ff.

Annuario Pontificio per l'anno 1967. 1968, Città del Vaticano 1967 bzw. 1968.

Dokumente zur Außenpolitik der Regierung der Deutschen Demokratischen Republik. Band I: 7. Oktober 1949 bis 25. März 1954. Band II: 25. März 1954 bis 14. Mai 1955, hrsg. vom Deutschen Institut für Zeitgeschichte. Band XII: 1964. Band XV: 1967, hrsg. vom Institut für Internationale Beziehungen an der Deutschen Akademie für Staats- und Rechtswissenschaft "Walter Ulbricht" in Zusammenarbeit mit der Abteilung Rechts- und Vertragswesen des Ministeriums für Auswärtige Angelegenheiten der Deutschen Demokratischen Republik, Berlin [Ost]1954-1971.

Egon Bahr, Zu meiner Zeit, München 1996.

Rainer Barzel, Es ist noch nicht zu spät, München/Zürich 1976.

Yeshayahu A. Jelinek und Rainer A. Blasius, Ben Gurion und Adenauer im Waldorf Astoria. Gesprächsaufzeichungen vom israelisch-deut- 


\begin{tabular}{|c|c|}
\hline & $\begin{array}{l}\text { schen Gipfeltreffen in New York am 14. März } \\
\text { 1960. Dokumentation, in: Vierteljahrshefte für } \\
\text { Zeitgeschichte } 45 \text { (1997), S. 309-344. }\end{array}$ \\
\hline BRANDT, Begegnungen und Einsichten & $\begin{array}{l}\text { Willy Brandt, Begegnungen und Einsichten. } \\
\text { Die Jahre 1960-1975, München/Zürich } 1978 .\end{array}$ \\
\hline BT ANLAGEN & $\begin{array}{l}\text { Verhandlungen des Deutschen Bundestages. } \\
\text { Anlagen zu den Stenographischen Berichten, } \\
\text { Bonn } 1950 \mathrm{ff} \text {. }\end{array}$ \\
\hline BT STENOGRAPHISCHE BERICHTE & $\begin{array}{l}\text { Verhandlungen des Deutschen Bundestages. } \\
\text { Stenographische Berichte, Bonn } 1950 \mathrm{ff} \text {. }\end{array}$ \\
\hline BULLETIN & $\begin{array}{l}\text { Bulletin des Presse- und Informationsamtes } \\
\text { der Bundesregierung, Bonn } 1951 \mathrm{ff} \text {. }\end{array}$ \\
\hline BULLETIN DER EWG & $\begin{array}{l}\text { Bulletin der Europäischen Wirtschaftsgemein- } \\
\text { schaft, hrsg. vom Sekretariat der Kommission } \\
\text { der Europäischen Wirtschaftsgemeinschaft, } \\
\text { Brüssel } 1958 \mathrm{ff} \text {. }\end{array}$ \\
\hline CARSTENS, Erinnerungen & $\begin{array}{l}\text { Karl Carstens, Erinnerungen und Erfahrun- } \\
\text { gen, hrsg. von Kai von Jena und Reinhard } \\
\text { Schmoeckel, Boppard am Rhein } 1993 \text {. }\end{array}$ \\
\hline CHARTER OF THE UNITED NATIONS & $\begin{array}{l}\text { Charter of the United Nations. Commentary } \\
\text { and Documents, hrsg. von Leland M. Goodrich } \\
\text { und Edvard Hambro, 2. Auflage, London } 1949 .\end{array}$ \\
\hline CONGRESSIONAL RECORD & $\begin{array}{l}\text { Congressional Record. Proceedings and Debates } \\
\text { of the } 79 \text { th Congress. Second Session, Bd. 92, } \\
\text { Teil } 5 \text { (May 23, 1946, to June 12, 1946). } \\
\text { Proceedings and Debates of the 85th Congress. } \\
\text { Second Session, Bd. 104, Teil } 13 \text { (August } 6 \text {, } \\
1958 \text {, to August, 13, 1958). Proceedings and } \\
\text { Debates of the 90th Congress. First Session, } \\
\text { Bd. } 113 \text { (January 23, 1967, to February 3, } \\
\text { 1967), hrsg. vom United States Government } \\
\text { Printing Office, Washington D.C. o.J. }\end{array}$ \\
\hline $\begin{array}{l}\text { COUVE DE MURVILLE, Politique } \\
\text { Étrangère }\end{array}$ & $\begin{array}{l}\text { Maurice Couve de Murville, Une politique } \\
\text { étrangère, Paris } 1971 \text {. }\end{array}$ \\
\hline $\mathrm{DDF}$ & $\begin{array}{l}\text { Documents diplomatiques français. } 1954 \text { ( } 21 \\
\text { juillet }-31 \text { décembre } 1954 \text { ). } 1955 \text {, I ( } 1 \text { janvier } \\
30 \text { juin } 1955 \text { ). } 1957 \text {, II ( } 1 \text { juillet - } 31 \text { décembre), } \\
\text { hrsg. vom Ministère des Affaires Etrangères, } \\
\text { Commission de Publication des Documents } \\
\text { Diplomatiques Français, Paris } 1987 \text { bzw. } 1991 .\end{array}$ \\
\hline DEPARTMENT OF STATE BULLETIN & $\begin{array}{l}\text { The Department of State Bulletin. The Official } \\
\text { Weekly Record of United States Foreign Policy, } \\
\text { Washington D.C. } 1949 \mathrm{ff} \text {. }\end{array}$ \\
\hline DEPORTATION & $\begin{array}{l}\text { Deportation, Sondersiedlung, Arbeitsarmee. } \\
\text { Deutsche in der Sowjetunion } 1941 \text { bis } 1956 \text {, } \\
\text { hrsg. von Alfred Eisfeld und Victor Herdt, Köln } \\
1996 \text {. }\end{array}$ \\
\hline
\end{tabular}


DEUTSCH-ISRAELISCHER DIALOG

DOCUMENTS ON DISARMAMENT

DOKUMENTE ZUR BERLIN-FraGE

DzD I/3

$\mathrm{DzD}$ II/1

DzD III

DzD IV

DzD V/1

ERSTER GESAMTBERICHT 1958

EUROPA-ARCHIV
Der deutsch-israelische Dialog. Dokumentation eines erregenden Kapitels deutscher Außenpolitik. Teil I: Politik, Bd. 1, hrsg. von Rolf Vogel, München /New York/London /Paris 1989.

Documents on Disarmament, hrsg. von der United States Arms Control and Disarmament Agency, Washington D.C. $1964 \mathrm{ff}$.

Dokumente zur Berlin-Frage 1944-1966, hrsg. vom Forschungsinstitut der Deutschen Gesellschaft für Auswärtige Politik e.V., Bonn, in Zusammenarbeit mit dem Senat von Berlin, 3. Auflage, München 1967.

Dokumente zur Deutschlandpolitik. I. Reihe: Vom 3. September 1939 bis 8. Mai 1945. Band 3: 1. Januar bis 31. Dezember 1942. Britische Deutschlandpolitik, 2 Teilbände, hrsg. vom Bundesministerium für innerdeutsche Beziehungen, bearbeitet von Rainer A. Blasius, Frankfurt am Main 1989.

Dokumente zur Deutschlandpolitik. II. Reihe: Vom 9. Mai 1945 bis 4. Mai 1955. Band 1: Die Konferenz von Potsdam, 3 Teilbände, hrsg. vom Bundesministerium des Innern, bearbeitet von Gisela Biewer, Neuwied 1992.

Dokumente zur Deutschlandpolitik. III. Reihe: Vom 5. Mai 1955 bis 9 . November 1958, 4 Bände, hrsg. vom Bundesministerium für gesamtdeutsche Fragen, Frankfurt am Main 19611969.

Dokumente zur Deutschlandpolitik. IV. Reihe: Vom 10. November 1958 bis 30. November 1966, 12 Bände, hrsg. vom Bundesministerium für innerdeutsche Beziehungen, Frankfurt am Main 1971-1981.

Dokumente zur Deutschlandpolitik. V. Reihe: Vom 1. Dezember 1966 bis 20. Oktober 1969. Band 1: 1. Dezember 1966 bis 31. Dezember 1967, 2 Teilbände, hrsg. vom Bundesministerium für innerdeutsche Beziehungen, bearbeitet von Gisela Oberländer, Frankfurt am Main 1984 .

Erster Gesamtbericht über die Tätigkeit der Gemeinschaft (Januar 1958 - September 1958), hrsg. von der Kommission der Europäischen Wirtschaftsgemeinschaft, [Brüssel] 1958.

Europa-Archiv. Zeitschrift für Internationale Politik, Bonn $1946 \mathrm{ff}$. 
Literaturverzeichnis

FRUS 1964-1968

DE Gaulle, Discours et messages

DE GAULLE, Lettres, notes et carnets

GREWE, Rückblenden

HANSARD

JOURNAL OFFICIEL 1967

LAHR, Zeuge

LNTS

KIESINGER, Jahre

MENDE, Wende

NEUNTER GESAMTBERICHT 1965/66

OSTERHELD, Außenpolitik

DER PARIAMENTARISCHE RAT
Foreign Relations of the United States 19641968. Band XI: Arms Control and Disarmament. Band XIII: Western Europe Region, Washington D.C. 1997 bzw. 1995.

Charles de Gaulle, Discours et messages. Band 3: Avec le renouveau (Mai 1958 - juillet 1962). Band 4: Pour l'effort (Août 1962 - décembre 1965). Band 5: Vers le terme (Janvier 1966 avril 1969), [Paris] 1970.

Charles de Gaulle, Lettres, notes et carnets. Janvier 1961 - décembre 1963, [Paris] 1986.

Wilhelm G. Grewe, Rückblenden 1976-1951, Frankfurt am Main/Berlin/Wien 1979.

Parliamentary Debates (Hansard). House of Commons, Official Report. Fifth Series. Band 732 (Session 1966/67) bis Band 756 (Session 1967/68), London [1966-1968].

Journal Officiel. Débats parlementaires Assemblée Nationale 1967, Paris 1967.

Rolf Lahr, Zeuge von Fall und Aufstieg. Private Briefe 1934-1974, Hamburg 1981.

League of Nation Treaty Series. Publication of Treaties and International Engagements registered with the Secretariat of the League, hrsg. vom Publications Sales Department of the League of Nations, Genf $1926 \mathrm{ff}$.

Kurt Georg Kiesinger, Dunkle und helle Jahre. Erinnerungen 1904-1958, hrsg. von Reinhard Schmoeckel, Stuttgart 1989.

Erich Mende, Von Wende zu Wende 19621982, München/Berlin 1986.

Neunter Gesamtbericht über die Tätigkeit der Gemeinschaft (1. April 1965 - 31. März 1966), hrsg. von der Kommission der Europäischen Wirtschaftsgemeinschaft, [Brüssel] 1966.

Horst Osterheld, Außenpolitik unter Bundeskanzler Ludwig Erhard 1963-1966. Ein dokumentarischer Bericht aus dem Kanzleramt, Düsseldorf 1992.

Der Parlamentarische Rat. Akten und Protokolle, hrsg. vom Deutschen Bundestag und vom Bundesarchiv. Bd. 8: Die Beziehungen des Parlamentarischen Rates zu den Militärregierungen, bearbeitet von Michael F. Feldkamp, Boppard am Rhein 1995. 
LA POLITIQUe Étrangère

PUBLIC PAPERS, JOHNSON

PUBLIC PAPERS, KENNEDY

SENATE, Hearings before the Committee on Armed Services

SIEBENTER GESAMTBERICHT 1963/64

STRAUSS, Erinnerungen

STATISTISCHES JAHRBUCH

UN GENERAL ASSEMBLY, 19th Session, Plenary Meetings

UN GENERAL ASSEMBLY, 22nd Session, Plenary Meetings

\section{UN GENERAL ASSEMBLY OFFICIAL RECORDS, Resolutions}

La Politique Étrangère de la France. Textes et Documents. Notes et Etudes Documentaires. 1966. 1967, hrsg. vom Ministère des Affaires Étrangères, Paris 1967 bzw. 1968.

Public Papers of the Presidents of the United States. Lyndon B. Johnson. Containing the Public Messages, Speeches, and Statements of the President. November 22, 1963, to December 31, 1964. January 1 to December 31, 1966. January 1 to December 31, 1967, Washington D.C. 1965-1968.

Public Papers of the Presidents of the United States. John F. Kennedy. Containing the Public Messages, Speeches, and Statements of the President. January 1 to November 22, 1963, Washington D.C. 1964.

Hearings before the Committee on Armed Services and the Subcommittee on Department of Defense of the Committee on Appropriations, United States Senate, 90th Congress, First Session, January 23, 24 and 25, hrsg. vom United States Government Printing Office, Washington D.C. 1967.

Siebenter Gesamtbericht über die Tätigkeit der Gemeinschaft (1. April 1963 - 31. März 1964), hrsg. von der Kommission der Europäischen Wirtschaftsgemeinschaft, [Brüssel] 1964.

Franz Josef Strauß, Die Erinnerungen, Berlin 1989.

Statistisches Jahrbuch für die Bundesrepublik Deutschland, hrsg. vom Statistischen Bundesamt, Stuttgart $1956 \mathrm{ff}$.

United Nations. Official Records of the General Assembly. Nineteenth Session. Plenary Meetings. Verbatim Records of Meetings. 1 December 1964 - 1 September 1965, 2 Bände, New York 1966.

United Nations. Official Records of the General Assembly. Twenty-second Session. Plenary Meetings. Verbatim Records of Meetings. 19 September - 19 December 1967, 24 April - 12 June 1968 and 23 September 1968, 2 Bände, New York 1971.

United Nations. Official Records of the General Assembly. Resolutions (Supplement Nr. 1), 5th Emergency Special Session. 17, - 18. September 1967, New York 1967. 
Literaturverzeichnis

UNITED NATIONS RESOLUTIONS I

UNITED NATIONS RESOLUTIONS II

UNTS

YEARBOOK OF THE UNITED NATIONS

ZEHNTER GESAMTBERICHT 1966/67
United Nations Resolutions. Series I: Resolutions Adopted by the General Assembly, hrsg. von Dusan J. Djonovich, New York 1972 ff.

United Nations Resolutions. Series II: Resolutions and Decisions Adopted by the Security Council, hrsg. von Dusan J. Djonovich, New York $1988 \mathrm{ff}$

United Nations Treaty Series. Treaties and International Agreements. Registered or Filed and Recorded with the Secretariat of the United Nations, [New York] 1946/47ff.

Yearbook of the United Nations, hrsg. vom Office of Public Information, United Nations, New York $1965 \mathrm{ff}$.

Zehnter Gesamtbericht über die Tätigkeit der Gemeinschaft (1. April 1966 - 31. März 1967), hrsg. von der Kommission der Europäischen Wirtschaftsgemeinschaft, [Brüssel] 1967. 


\section{Abkürzungsverzeichnis}

\begin{tabular}{|c|c|c|c|}
\hline $\begin{array}{l}\mathrm{AA} \\
\mathrm{ABC}\end{array}$ & $\begin{array}{l}\text { Auswärtiges Amt } \\
\text { atomare, biologische und }\end{array}$ & $\mathrm{BKC} / \mathrm{L}$ & $\begin{array}{l}\text { Berlin Kommandatura } \\
\text { Commandant/Letter }\end{array}$ \\
\hline & chemische Waffen & BM & Bundesminister/ium \\
\hline ABM & Anti-Ballistic Missile & BMF & Bundesminister/ium der \\
\hline ACDA & (United States) Arms & & Finanzen \\
\hline & $\begin{array}{l}\text { Control and Disarmament } \\
\text { Agency }\end{array}$ & BMG & $\begin{array}{l}\text { Bundesminister/ium für } \\
\text { gesamtdeutsche Fragen }\end{array}$ \\
\hline ACE & Allied Command Europe & BMI & Bundesminister/ium des \\
\hline $\mathrm{ADM}$ & Atomic Demolition & & Innern \\
\hline & & BML & Bundesminister/ium für \\
\hline ADN & $\begin{array}{l}\text { Allgemeiner Deutscher } \\
\text { Nachrichtendienst }\end{array}$ & & $\begin{array}{l}\text { Ernahrung, Landwırt- } \\
\text { schaft und Forsten }\end{array}$ \\
\hline AEG & $\begin{array}{l}\text { Allgemeine Elektricitäts- } \\
\text { Gesellschaft }\end{array}$ & BMV & $\begin{array}{l}\text { Bundesminister/ium für } \\
\text { Verkehr }\end{array}$ \\
\hline AFCENT & $\begin{array}{l}\text { Allied Forces Central } \\
\text { Europe }\end{array}$ & BMVtg. & $\begin{array}{l}\text { Bundesminister/ium der } \\
\text { Verteidigung }\end{array}$ \\
\hline AFNORTH & $\begin{array}{l}\text { Allied Forces Northern } \\
\text { Europe }\end{array}$ & $\mathrm{BMwF}$ & $\begin{array}{l}\text { Bundesminister/ium für } \\
\text { wissenschaftliche } \\
\text { Forschung }\end{array}$ \\
\hline $\mathrm{AG}$ & Aktiengesellschaft & & \\
\hline AK & Arbeitskreis & BMWi & $\begin{array}{l}\text { Bundesminister/ium für } \\
\text { Wirtschaft }\end{array}$ \\
\hline ANF & Allied Nuclear Force & BND & Bundesnachrichtendienst \\
\hline Anl./Anlg. & Anlage/Anlagen & BP & British Petrol \\
\hline AP & Associated Press & BPA & Bundespresseamt \\
\hline APAG & $\begin{array}{l}\text { Atlantic Policy Advisory } \\
\text { Group }\end{array}$ & BQD & $\begin{array}{l}\text { Berlin Quadripartite } \\
\text { Documents }\end{array}$ \\
\hline AWP & $\begin{array}{l}\text { Allied Working Party on } \\
\text { International Accounting } \\
\text { of Post and Telecommuni- }\end{array}$ & BRD & $\begin{array}{l}\text { Bundesrepublik } \\
\text { Deutschland }\end{array}$ \\
\hline & cations & BT & Bundestag \\
\hline ATO & Allied Travel Office & BVtg.- Rat & Bundesverteidigungsrat \\
\hline $\mathrm{AZ}$ & Aktenzeichen & $\mathrm{CDU}$ & Christlich-Demokratische \\
\hline BAOR & British Army on the Rhine & & Union Deutschlands \\
\hline BDI & $\begin{array}{l}\text { Bundesverband der } \\
\text { Deutschen Industrie }\end{array}$ & CENTAG & $\begin{array}{l}\text { Central Army Group } \\
\text { Central Europe }\end{array}$ \\
\hline BGB & Bürgerliches Gesetzbuch & CENTO & $\begin{array}{l}\text { Central Treaty } \\
\text { Organisation }\end{array}$ \\
\hline BGBl. & Bundesgesetzblatt & CFA & Communauté Financière \\
\hline BKA & Bundeskanzleramt & $8 \pi$ & Africaine \\
\hline
\end{tabular}




\begin{tabular}{|c|c|c|c|}
\hline CIA & $\begin{array}{l}\text { Central Intelligence } \\
\text { Agency }\end{array}$ & ENDC & $\begin{array}{l}\text { Eighteen Nations } \\
\text { Disarmament Committee }\end{array}$ \\
\hline $\mathrm{COCOM}$ & $\begin{array}{l}\text { Coordinating Committee } \\
\text { for East-West Trade Policy }\end{array}$ & ERP & $\begin{array}{l}\text { European Recovery } \\
\text { Program }\end{array}$ \\
\hline COMECON & $\begin{array}{l}\text { Council for Mutual } \\
\text { Economic Aid/Assistance }\end{array}$ & EURATOM & $\begin{array}{l}\text { Europäische } \\
\text { Atomgemeinschaft }\end{array}$ \\
\hline ČSSR & $\begin{array}{l}\text { Československá } \\
\text { Socialistická Republika }\end{array}$ & EVG & $\begin{array}{l}\text { Europäische } \\
\text { Verteidigungsgemeinschaft }\end{array}$ \\
\hline CSU & Christlich-Soziale Union & EWG & $\begin{array}{l}\text { Europäische } \\
\text { Wirtschaftsgemeinschaft }\end{array}$ \\
\hline DB & Deutsche Bundesbahn & FAO & $\begin{array}{l}\text { Food and Agriculture } \\
\text { Organisation of the United }\end{array}$ \\
\hline DB & Drahtbericht & & Nations \\
\hline DDR & $\begin{array}{l}\text { Deutsche Demokratische } \\
\text { Republik }\end{array}$ & FAZ & $\begin{array}{l}\text { Frankfurter Allgemeine } \\
\text { Zeitung }\end{array}$ \\
\hline DE & Drahterlaß & FDP & $\begin{array}{l}\text { Freie Demokratische } \\
\text { Partei }\end{array}$ \\
\hline $\begin{array}{l}\text { Dept. } \\
\text { DFG }\end{array}$ & $\begin{array}{l}\text { Department } \\
\text { Deutsche Forschungs- }\end{array}$ & FLN & $\begin{array}{l}\text { Front de Libération } \\
\text { Nationale }\end{array}$ \\
\hline Dg & (Ministerial-)Dirigent & FNL & $\begin{array}{l}\text { Front National de } \\
\text { Libération }\end{array}$ \\
\hline DGB & $\begin{array}{l}\text { Deutscher } \\
\text { Gewerkschaftsbund }\end{array}$ & FRG & $\begin{array}{l}\text { Federal Republic of } \\
\text { Germany }\end{array}$ \\
\hline DIHT & $\begin{array}{l}\text { Deutscher Industrie- und } \\
\text { Handelstag }\end{array}$ & FS & Fernschreiben \\
\hline dpa & Deutsche Presseagentur & GATT & $\begin{array}{l}\text { General Agreement on } \\
\text { Tariffs and Trade }\end{array}$ \\
\hline DPC & $\begin{array}{l}\text { Defence Planning } \\
\text { Committee }\end{array}$ & GDR & $\begin{array}{l}\text { German Democratic } \\
\text { Republic }\end{array}$ \\
\hline DPWG & $\begin{array}{l}\text { Defence Planning Working } \\
\text { Group }\end{array}$ & $\begin{array}{l}\text { geh. } \\
\text { GG }\end{array}$ & $\begin{array}{l}\text { geheim } \\
\text { Grundgesetz }\end{array}$ \\
\hline DR & Deutsche Reichsbahn & GMT & Greenwich Mean Time \\
\hline EAG & $\begin{array}{l}\text { Europäische } \\
\text { Atomgemeinschaft }\end{array}$ & GNS & $\begin{array}{l}\text { Gemeinsame Nukleare } \\
\text { Streitmacht }\end{array}$ \\
\hline ECE & $\begin{array}{l}\text { Economic Commission for } \\
\text { Europe }\end{array}$ & h & hora/Stunde \\
\hline EEC & $\begin{array}{l}\text { European Economic } \\
\text { Community }\end{array}$ & $\begin{array}{l}\text { HQ } \\
\text { IAEA }\end{array}$ & $\begin{array}{l}\text { Headquarters } \\
\text { International Atomic }\end{array}$ \\
\hline EFTA & $\begin{array}{l}\text { European Free Trade } \\
\text { Association }\end{array}$ & IAEO & $\begin{array}{l}\text { Energy Agency } \\
\text { Internationale }\end{array}$ \\
\hline EG & $\begin{array}{l}\text { Europäische } \\
\text { Gemeinschaften }\end{array}$ & ICBM & energieorganisation \\
\hline EGKS & $\begin{array}{l}\text { Europäische Gemeinschaft } \\
\text { für Kohle und Stahl }\end{array}$ & i.G. & $\begin{array}{l}\text { Missile } \\
\text { im Generalstab }\end{array}$ \\
\hline
\end{tabular}


Abkürzungsverzeichnis

\begin{tabular}{|c|c|c|c|}
\hline IMF & $\begin{array}{l}\text { International Monetary } \\
\text { Fund }\end{array}$ & MRBM & $\begin{array}{l}\text { Medium Range Ballistic } \\
\text { Missile }\end{array}$ \\
\hline \multirow[t]{2}{*}{ IOC } & \multirow{2}{*}{$\begin{array}{l}\text { International Olympic } \\
\text { Committee }\end{array}$} & Mrd. & Milliarde/n \\
\hline & & MW & Megawatt \\
\hline IRBM & $\begin{array}{l}\text { Intermediate Range } \\
\text { Ballistic Missile }\end{array}$ & NADGE & $\begin{array}{l}\text { NATO Air Defense Ground } \\
\text { Environment System }\end{array}$ \\
\hline IPU & $\begin{array}{l}\text { Internationale } \\
\text { Parlamentarische Union }\end{array}$ & NASA & $\begin{array}{l}\text { National Aeronautics and } \\
\text { Space Administration }\end{array}$ \\
\hline ITU & \multirow[t]{2}{*}{$\begin{array}{l}\text { International } \\
\text { Telecommunications Union }\end{array}$} & NATO & $\begin{array}{l}\text { North Atlantic Treaty } \\
\text { Organisation }\end{array}$ \\
\hline i. V. & & NDR & Norddeutscher Rundfunk \\
\hline IWF & $\begin{array}{l}\text { Internationaler } \\
\text { Währungsfonds }\end{array}$ & $\mathrm{NfD}$ & $\begin{array}{l}\text { Nur für den } \\
\text { Dienstgebrauch }\end{array}$ \\
\hline IZH & Interzonenhandel & \multirow[t]{2}{*}{ NGO } & Non-Governmental- \\
\hline $\mathrm{KfW}$ & $\begin{array}{l}\text { Kreditanstalt für } \\
\text { Wiederaufbau }\end{array}$ & & Organisation \\
\hline KP & Kommunistische Partei & NP/NPT & $\begin{array}{l}\text { Non Proliferation/Non- } \\
\text { proliferation Treaty }\end{array}$ \\
\hline KPČ & $\begin{array}{l}\text { Kommunistische Partei der } \\
\text { Tschechoslowakei }\end{array}$ & NPD & $\begin{array}{l}\text { Nationaldemokratische } \\
\text { Partei Deutschlands }\end{array}$ \\
\hline KPCh & $\begin{array}{l}\text { Kommunistische Partei } \\
\text { Chinas }\end{array}$ & NPWG & $\begin{array}{l}\text { Nuclear Planning Working } \\
\text { Group }\end{array}$ \\
\hline KPD & $\begin{array}{l}\text { Kommunistische Partei } \\
\text { Deutschlands }\end{array}$ & $\begin{array}{l}\text { n. R. } \\
\text { NS }\end{array}$ & $\begin{array}{l}\text { nach Rückkehr } \\
\text { Nationalsozialismus }\end{array}$ \\
\hline KPdSU & $\begin{array}{l}\text { Kommunistische Partei der } \\
\text { Sowjetunion }\end{array}$ & NV/NVA & $\begin{array}{l}\text { Nichtverbreitung/ } \\
\text { Nichtverbreitungs- }\end{array}$ \\
\hline KPI & \multirow{2}{*}{$\begin{array}{l}\text { Kommunistische Partei } \\
\text { Italiens }\end{array}$} & \multirow[b]{2}{*}{ OAS } & \multirow[b]{2}{*}{$\begin{array}{l}\text { Organisation of American } \\
\text { States }\end{array}$} \\
\hline \multirow{2}{*}{ KPR } & & & \\
\hline & $\begin{array}{l}\text { Kommunistische Partei } \\
\text { Rumäniens }\end{array}$ & $\mathrm{OAU}$ & $\begin{array}{l}\text { Organisation for African } \\
\text { Unity }\end{array}$ \\
\hline LR I & $\begin{array}{l}\text { Legationsrat I. Klasse } \\
\text { Legationssekretär }\end{array}$ & OECD & $\begin{array}{l}\text { Organisation for Economic } \\
\text { Cooperation and } \\
\text { Development }\end{array}$ \\
\hline $\mathrm{MC}$ & Military Committee & OEEC & $\begin{array}{l}\text { Organisation for European } \\
\text { Economic Cooperation }\end{array}$ \\
\hline MD & Ministerialdirektor & ORR & Oberregierungsrat \\
\hline $\begin{array}{l}\text { MdB } \\
\text { Mdg }\end{array}$ & $\begin{array}{l}\text { Mitglied des Bundestages } \\
\text { Ministerialdirigent }\end{array}$ & O.T.A.N. & $\begin{array}{l}\text { Organisation du Traité de } \\
\text { l'Atlantique Nord }\end{array}$ \\
\hline MID & $\begin{array}{l}\text { Ministerstvo Inostrannych } \\
\text { Del }\end{array}$ & PAL & Phase Alternating Line \\
\hline Mio. & Million/en & PLO & $\begin{array}{l}\text { Palestinian Liberation } \\
\text { Organisation }\end{array}$ \\
\hline MLF & Multilateral Force & PSI & Partito Socialista Italiano \\
\hline
\end{tabular}




\begin{tabular}{|c|c|c|c|}
\hline PStS & $\begin{array}{l}\text { Parlamentarischer } \\
\text { Staatssekretär }\end{array}$ & UNEF & $\begin{array}{l}\text { United Nations Emergency } \\
\text { Force }\end{array}$ \\
\hline PVAP & $\begin{array}{l}\text { Polnische Vereinigte } \\
\text { Arbeiterpartei }\end{array}$ & UNESCO & $\begin{array}{l}\text { United Nations } \\
\text { Educational, Scientific and }\end{array}$ \\
\hline \multirow[t]{2}{*}{ RSFSR } & \multirow{2}{*}{$\begin{array}{l}\text { Russische Sozialistische } \\
\text { Föderative Sowjet- } \\
\text { republik }\end{array}$} & & Cultural Organisation \\
\hline & & UNFICYP & $\begin{array}{l}\text { United Nations Peace- } \\
\text { Keeping Force in Cyprus }\end{array}$ \\
\hline \multirow{3}{*}{$\begin{array}{l}\text { RR } \\
\text { RS } \\
\text { SACEUR }\end{array}$} & \multirow{3}{*}{$\begin{array}{l}\text { Regierungsrat } \\
\text { Rupies } \\
\text { Supreme Allied } \\
\text { Commander Europe }\end{array}$} & UNO & United Nations \\
\hline & & & \\
\hline & & UNRWA & $\begin{array}{l}\text { United Nations Relief and } \\
\text { Works Agency for Palestine } \\
\text { Refugees in the Near East }\end{array}$ \\
\hline SACLANT & $\begin{array}{l}\text { Supreme Allied } \\
\text { Commander Atlantic }\end{array}$ & UPI & United Press International \\
\hline \multirow{2}{*}{ SBZ } & \multirow{2}{*}{$\begin{array}{l}\text { Sowjetische } \\
\text { Besatzungszone }\end{array}$} & UPU & Universal Postal Union \\
\hline & & US & United States \\
\hline \multirow[t]{2}{*}{ SEATO } & \multirow{2}{*}{$\begin{array}{l}\text { South-East Asia Treaty } \\
\text { Organisation }\end{array}$} & USA & United States of America \\
\hline & & USSR & Union of Socialist Soviet \\
\hline \multirow[t]{2}{*}{ SECAM } & \multirow{2}{*}{$\begin{array}{l}\text { Système en couleur avec } \\
\text { mémoire }\end{array}$} & & Republics \\
\hline & & VAR & Vereinigte Arabische \\
\hline \multirow[t]{2}{*}{ SED } & \multirow{2}{*}{$\begin{array}{l}\text { Sozialistische Einheits- } \\
\text { partei Deutschlands }\end{array}$} & & Republik \\
\hline & & vertr. & vertraulich \\
\hline S.E. & Seine Exzellenz & $\mathrm{Vj}$. & Vierteljahr \\
\hline SHAPE & $\begin{array}{l}\text { Supreme Headquarters } \\
\text { Allied Powers Europe }\end{array}$ & VLR I & $\begin{array}{l}\text { Vortragender Legationsrat } \\
\text { I. Klasse }\end{array}$ \\
\hline SPD & $\begin{array}{l}\text { Sozialdemokratische Partei } \\
\text { Deutschlands }\end{array}$ & $\mathrm{VN}$ & Vereinte Nationen \\
\hline StS & \multirow[t]{2}{*}{ Staatssekretär } & VR & Volksrepublik \\
\hline SU & & VS & Verschlußsache \\
\hline \multirow{2}{*}{ TASS } & \multirow{2}{*}{$\begin{array}{l}\text { Telegrafnoe Agentstvo } \\
\text { Sovetskogo Sojuza }\end{array}$} & VS-v/vsv & VS-vertraulich \\
\hline & & WDR & Westdeutscher Rundfunk \\
\hline Tgb. & Tagebuch & WEU & Westeuropäische Union \\
\hline \multirow[t]{2}{*}{ TTD } & \multirow{2}{*}{$\begin{array}{l}\text { Temporary Travel } \\
\text { Document }\end{array}$} & WHO & World Health Organisation \\
\hline & & ZAB & Zentrale Austauschstelle \\
\hline \multirow[t]{2}{*}{ UdSSR } & \multirow{2}{*}{$\begin{array}{l}\text { Union der Sozialistischen } \\
\text { Sowjetrepubliken }\end{array}$} & & Bonn \\
\hline & & z.b.V. & zur besonderen \\
\hline UK & United Kingdom & & Verwendung \\
\hline UN & United Nations & ZDVP & $\begin{array}{l}\text { Zentrale Deutsche } \\
\text { Verbindungsstelle Portugal }\end{array}$ \\
\hline UNCTAD & $\begin{array}{l}\text { United Nations Conference } \\
\text { on Trade and Development }\end{array}$ & $\mathrm{ZK}$ & Zentralkomitee \\
\hline
\end{tabular}

